Florida International University FIU Digital Commons

7-29-1995

\title{
The role of stories in understanding the cultural context surrounding information systems practices
}

Line Dubé

Florida International University

DOI: $10.25148 /$ etd.FI15101233

Follow this and additional works at: https://digitalcommons.fiu.edu/etd

Part of the Business Commons

\section{Recommended Citation}

Dubé, Line, "The role of stories in understanding the cultural context surrounding information systems practices" (1995). FIU Electronic Theses and Dissertations. 3090.

https://digitalcommons.fiu.edu/etd/3090 


\section{FLORIDA INTERNATIONAL UNIVERSITY \\ Miami, Florida}

THE ROLE OF STORIES IN UNDERSTANDING THE CULTURAL CONTEXT SURROUNDING INFORMATION SYSTEMS PRACTICES

A dissertation submitted in partial satisfaction of the requirements for the degree of DOCTOR OF PHILOSOPHY

IN

BUSINESS ADMINISTRATION

by

Line Dubé 
To: Dean Harold Wyman

College of Business Administration

This dissertation, written by Line Dubé, and entitled THE ROLE OF STORIES IN UNDERSTANDING THE CULTURAL CONTEXT SURROUNDING INFORMATION SYSTEMS PRACTICES, having been approved in respect to style and intellectual content, is referred to you for judgement.

We have read this dissertation and recommend that it be approved.

Joyce J. Elam

Paul Hart

Rajiv Sabherwal

Daniel Robey, Major Professor

Date of defense: 07/29/1995

The dissertation of Line Dubé is approved.

Dean Harold Wyman

College of Business Administration

Dr. Richard L. Campbell

Dean of Graduate Studies

Florida International University, 1995 
A mes parents. 


\section{ACKNOWLEDGMENTS}

This is the final result of four years of hard work. It would not have been possible without the help of many people. First, I want to thank my advisor, Dr. Daniel Robey. More than an advisor, he has been a colleague, a real friend, and a mentor during the whole program and particularly during the difficult phase of the dissertation. I will always remember one of my first visits to his office. I timidly risked asking how busy he was. "Would you be willing to supervise my summer research project?" and he answered, "I thought you'd never ask."1 I still bless that day. That was the beginning of a beautiful relationship that has made going through the program, and more especially this dissertation, a pleasure, even in the most difficult moments of discouragement. Despite physical distance, we worked very closely, carrying on conceptual discussions and arguments via e-mail at least once a week (and sometimes much more!).

I also wish to thank the members of my committee, Dr. Joyce J. Elam, Dr. Rajiv Sabherwal and, from Florida Atlantic University, Dr. Paul Hart, for their timely comments. They brought me back to earth when I needed it. They also gracefully accepted a journey down a rather unconventional road. Finally they made my life much easier by being available for some rather unusual scheduling.

1. Dan does not remember the story the way $\mathbf{I}$ do! This is why stories are so interesting... 
I would also like to acknowledge the Decision Sciences and Information Systems department at Florida International University. Under Dan Robey and Joyce Elam's leadership and despite some divergent forces, the department was a free environment where research ideas, methods, and approaches could be openly discussed and applied. I know this is not the case in every MIS department. I received a non-restrictive and non-judgmental education and am able to appreciate different approaches and types of research. I came to appreciate this more and more as I met different people in the area. I feel privileged.

I also wish to thank my Ph.D. colleagues for creating an interesting learning environment. I will never forget our most interesting discussion on the picnic table under the trees amid the Florida sunshine. Even if the discussion sometimes strayed from MIS topics, discussions about life, research, and ethics were just as interesting and formative. I specifically want to thank Guy Paré. The dissertation is rather a lonely journey and he was able to understand my anxiety and provide comfort with only a few words. He was even more important to me in the first two years of the program. I will always remember our long hours of work and discussion as we tried to increase our understanding of a particular article, topic, or technique. I will always remember our light signals in the middle of the night from one apartment to the other and the long and challenging discussions in preparation for the comprehensive exams. The 
whole process would have been much more painful without Guy. My deepest thanks to him.

I would also like to thank the many people at the research site who were instrumental to the success of this dissertation. In addition to the respondents who took some time out from their busy schedules to discuss with me, I would express my appreciation to all of those who, in several ways, have contributed to make the data collection phase an enriching and enjoyable experience.

Un petit mot pour mes parents. Malgré le fait que j'ai un peu secoué leur idée de ce qu'une personne est supposée faire à la fin de la vingtaine, ils m’ont toujours chaleureusement supporté, psychologiquement (par leurs appels hebdomadaires et leur voyage annuel), physiquement (en m’aidant à déménager à Miami) et financièrement (par des prêts, quand les fins de mois s'avèraient difficiles). Très tôt, mes parents m'ont communiqué le goût d'apprendre, de lire, de questionner et d'être curieuse. Sans l'éducation qu'ils m'ont donné, rien de ceci $n^{\prime}$ aurait été possible. Je leur en serai éternellement reconnaissante.

Finally, studying abroad would not have been possible without the financial support of the Social Sciences and Humanities Research Council of Canada and a fee exemption from Florida International University. 


\title{
ABSTRACT OF THE DISSERTATION
}

\section{THE ROLE OF STORIES IN UNDERSTANDING THE CULTURAL CONTEXT SURROUNDING INFORMATION SYSTEMS PRACTICES}

by

\author{
Line Dubé \\ Florida International University, 1995 \\ Professor Daniel Robey, Major Professor
}

The culture of an organization constitutes the environment into which information systems (IS) practices take place. Despite the importance of culture in the organizational theory and management literature, this topic has received little attention in the IS area. The culture of an organization can be looked at from different angles. In addition to the usual view of culture, the integration view, two other perspectives have been identified in the literature: the differentiation and fragmentation perspectives. While the integration perspective focuses on the "assembling" role organizational culture is normally said to play, the differentiation perspective highlights important differences among groups of people in the organization and the fragmentation perspective includes the notion of ambiguity and uncertainty in the conceptualization of culture.

This study uses organizational stories as a way to investigate the culture of an organization and as a way to better understand IS practices. It uses 
simultaneously the three organizational culture perspectives in order to get a broad picture of the cultural context surrounding IS practices.

More specifically, the objective of this interpretive study is to investigate three 'research questions related to (1) the nature of the stories told and the themes that they carry, (2) the functions that these stories play in the organization, and (3) the relationships between themes and IS practices. Using an in-depth case study strategy, stories and their interpretations were collected from a softwaredevelopment company using primarily semi-structured interviews.

The results emphasize the bias resulting from the use of the integration perspective as the only way to look at the culture of an organization. This bias had a profound impact on the literature; it helped shape the identification of important organizational actors, the definition of stories, and the conceptualization of their functions. In this study, a broader conception of "significant stories" is given along with a broader range of functions that stories may fulfill. Finally, the results highlight the importance of cultural elements in understanding the general context surrounding IS practices and explore in more detail two very contemporary IS activities: implementing team reorganization (change) and managing outsourcing relationships. 


\section{TABLE OF CONTENTS}

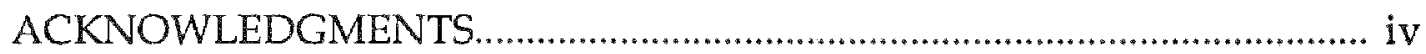

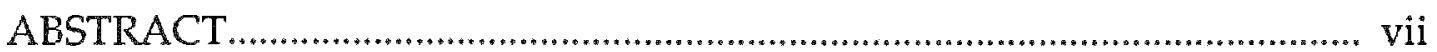

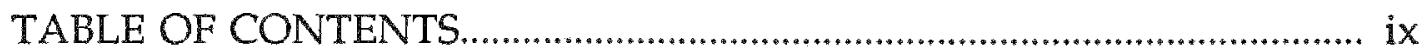

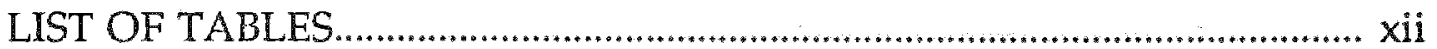

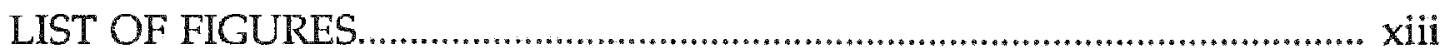

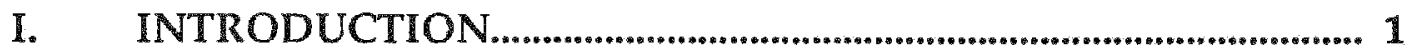

II. THEORETICAL FOUNDATIONS................................................... 14

2.1 Organizational Culture: Basic Concepts................................. 15

2.2 Organizational Culture: Three Perspectives............................ 19

2.2.1 The Integration Perspective........................................... 20

2.2.2 The Differentiation Perspective................................... 22

2.2.3 The Fragmentation Perspective..................................... 25

2.3 Organizational Symbols as an Expression of Culture............ 28

$2.4 \quad$ A Story: A Verbal Symbol......................................................... 35

2.4.1 Beyond Words: The Interpretation of Stories............... 41

2.5 Organizational Culture and Information Systems.................. 44

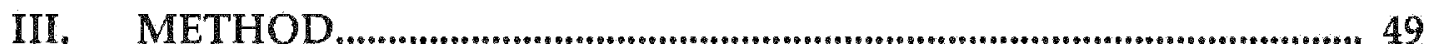

3.1 Research Design................................................................ 49

3.2 Research Site ..................................................................... 51

3.3 Selection of Respondents...................................................... 52

3.4 Data Collection................................................................... 52

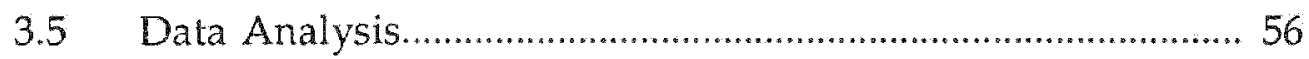


IV. RESULTS

4.1 Software Corporation: Some Background............................. 63

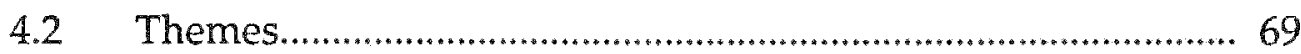

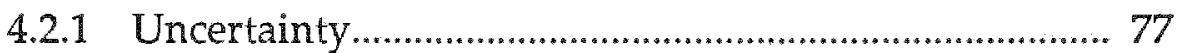

4.2.2 Humanist Image ........................................................... 81

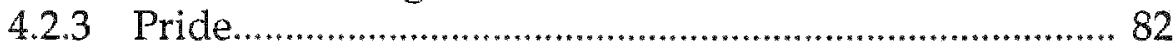

4.2.4 Survival Instinct............................................................. 83

4.2.5 Challenging Work ......................................................... 85

4.2.6 Difficulties in Working Together as a Cohesive Organization................................................................ 87

4.2.7 Culture Clash................................................................ 91

4.2.8 Constant Changes........................................................... 95

4.2.9 Resistance to Change..................................................... 98

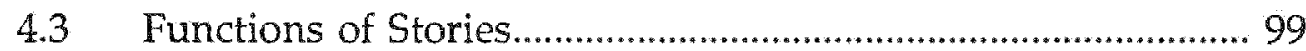

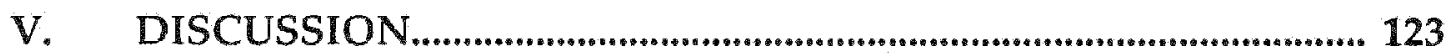

$5.1 \quad$ The Nature of Stories............................................................. 123

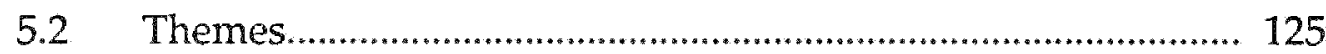

5.2.1 The Integration Perspective.......................................... 125

5.2.2 The Differentiation Perspective..................................... 133

5.2.3 The Fragmentation Perspective.................................... 140

5.3 Functions of Stories............................................................. 148

5.3.1 The Integration Perspective.......................................... 156

5.3.2 The Differentiation Perspective................................... 157

5.3.3 The Fragmentation Perspective.................................... 157

5.4 The Implications of Culture for IS Practices.......................... 160

5.4.1 System Development Team Organization.................... 161

5.4.1.1 The Integration Perspective......... 163

5.4.1.2 The Differentiation Perspective.. 164

5.4.1.3 The Fragmentation Perspective. 166 
VI. CONCLUSION

6.1 Summary of Results. 175

6.2 Implications for Practice.

6.3 Implications for Research.

6.4 Limitations and Future Research. 185

LIST OF REFERENCES.

I Interview Guide: 201

II Stories.. 204

III Data Analysis. 275 


\section{LIST OF TABLES}

1.1 Comparison of Assumptions - The Positivist Paradigm vs. the Interpretive Paradigm..........................................................................

2.1 Framework for Symbols Analysis (Dandridge et al., 1980).............. 32

4.1 Event Associated with Stories................................................................ 71

4.2 Relationship Between Grand Themes and Content Themes............ 74

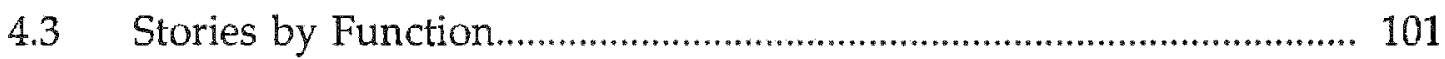

5.1 Occurrences of Functions by Theme................................................ 153

5.2 Occurrences of Functions by Perspective.......................................... 155

$5.3 \quad$ IS Issues by Perspective................................................................. 173 


\section{LIST OF FIGURES}

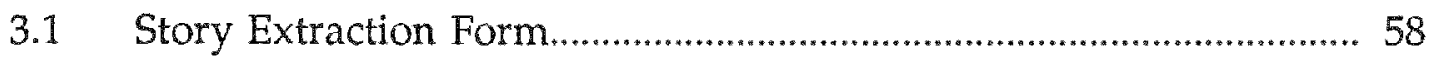

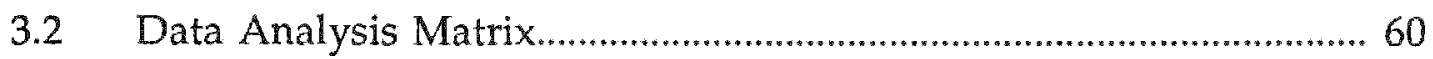

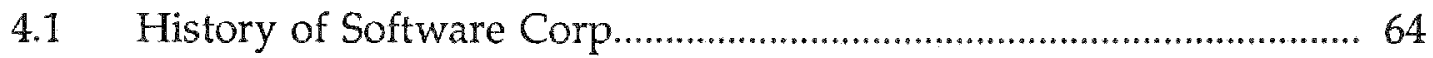

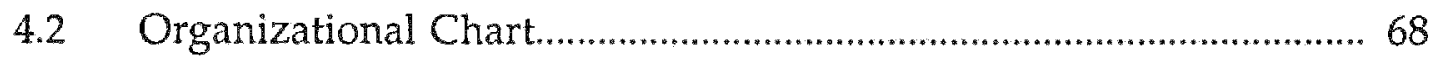

4.3 Themes and Stories............................................................................ 76

5.1 Themes and Stories - The Integration Perspective............................. 126

5.2 Themes and Stories - The Differentiation Perspective,.................... 134

5.3 Themes and Stories - The Fragmentation Perspective...................... 142 


\section{CHAPTER 1}

\section{INTRODUCTION}

While organizations evolve in a more and more turbulent business environment, the development and implementation of information systems (IS) often become a matter of survival (Huber, 1984; Porter \& Millar, 1985; Drucker, 1988; Scott Morton, 1991). These issues become even more crucial for organizations that owe their existence to the sales of those systems. Rapidly changing technology, ever-shorter product life cycles, and ever-increasing competition exert pressure for prices to go down and quality to go up.

Over the years, interested in the growing importance of computerization in the organization, researchers have tried many approaches in order to help understand and facilitate this process of IS development and implementation. For a long time, the only focus was on the technical aspects of these projects. The role of the users, for example, was solely conceived as a requirements provider.

More recently, the focus has changed. Researchers started to consider IS development and implementation as a technical process with behavioral consequences (Hirschheim, Klein, \& Newman, 1991). A recipe that would assure the success of a system was provided. Swanson (1988), for example, looked at IS implementation as a puzzle and identified nine pieces that play an important role 
in ensuing system success, namely: user involvement, management commitment, value basis (costs and benefits for the organization), mutual understanding (between users and IS people), design quality, performance level (in terms of reliability and responsiveness of the system), project management, resource adequacy (personnel and equipment), and situational stability (sensitivity of the project to possible changes). According to this author, the success of an implementation rests on establishing a fit among those nine important "pieces".

Unfortunately, experience has shown that no one recipe is successful in every case. More importantly, while the list of important factors is quite clear, the list of prescriptions about how to put them together is a lot less so (Sabherwal \& Robey, 1993). The literature is full of illustrations where information systems development and implementation did not achieve the intended benefits; in some cases, the benefits were achieved only after a difficult period of conflicts and negotiations (Markus, 1981; Robey \& Rodriguez-Diaz, 1989; Joshi, 1990), in other cases, organizations were confronted with costly system failures whereby benefits would never be attained and major investments were lost (see Lyytinen \& Hirschheim, 1987; Davis, Lee, Nickles, Chatterjee, Hartung, \& Wu, 1992).

Given that IS projects in the future are likely to be larger, involving greater complexity and more sophisticated technologies (Vitale, 1986), organizations need new ways to approach IS development that will result in increased flexibility, 
reduced delivery time, and increased expertise leverage. The rigid System Development Life Cycle (SDLC) (for example, in Lucas, 1985) in which a system is handed off from group to group does not seem to be a viable alternative any longer (Ahituv \& Neumann, 1984).

New solutions have therefore been proposed. Among them, two have seriously invaded IS departments. The first one consists in the reengineering of the IS function. Reengineering refers to the radical redesign of business processes in order to get radical improvements in performance (Hammer, 1990). In an IS context, it would mean to start with a clean slate (forget about how system development is carried out right now) and to redesign a new process mainly based on outcomes and empowered teams. Despite its success in some organizations (Hammer, 1990), the actual implementation of these concepts presents some major problems (see Robey, Wishart, \& Rodriguez-Diaz, 1995). Clean slate and radical changes as advocated by the concept of reengineering are not easily implemented. Issues such as readiness to change, savings estimation, and human issues still need to be examined.

The second proposed solution consists in outsourcing the IS activities. Outsourcing "reflects the use of external agents to perform one or more organizational activities" (Lacity \& Hirschheim, 1993, p.2). In an IS context, it may go from contracting the development of a new system to giving a vendor the 
responsibilities of the entire hardware and software support activities. While some organizations seem to have obtained great success from these contractual agreements (see Lacity \& Hirschheim, 1993), the long-term success of this alternative is still under study and remains to be seen.

In sum, despite much research, our understanding of the process of developing and implementing successful information systems in organizations is still piecemeal (Franz \& Robey, 1987; Kwon \& Zmud, 1987; Swanson, 1987). Different conceptual explanations can be offered as the causes of our actual state of knowledge. Historically, researchers have adopted a reductionist view of the organization and study only parts and pieces; two to five variables in a causal model was customary (Louis, 1983). The use of these oversimplified theories (Kling, 1987; Hirschheim \& Newman, 1991) and the proliferation of studies built on simple assumptions about causality (Markus \& Robey, 1988), about the social world in which computing is embedded (Kling, 1980; Mowshowitz, 1981; Hirschheim, 1986), and about the role of system design (Boland, 1979; Hirschheim \& Klein, 1989) did not provide a thorough understanding of organizational phenomena and more specifically of the process of change necessary for the successful development and implementation of an information system. The assumption of rationality that many information systems researchers had adopted early on (Keen, 1981; Robey \& Markus, 1984; Ebers, 1985) is an additional factor that affected our capacity to get a broader picture. 
A divergent trend has been to consider the development and implementation of an information system as a human activity that should more successfully be considered as a social process rather than a technical one (Boland, 1979; Markus, 1984; Hirschheim et al., 1991). "ISD [information system development] can then be seen as interlocked sequences of purposive performances by different actors to achieve meaningful responses from each other" (Hirschheim et al., 1991, p. 589). This social process involves multiple actors (user, analyst, manager, consultant $t_{f}$. ) trying to make sense of their world, their actions, and of the actions of others mainly through language (Boland, 1985; Hirschheim et al., 1991). The process is much more complex than what was first hypothesized and we are still not clear about all the sources of influence. The people involved in the process are under multiple sources of influence that will shape what they think, how they behave, and how they will interpret and make sense out of the new technology and its development process. This is why it is difficult to provide meaningful recommendations without considering the complexity in its entirety.

A cultural approach (Scholz, 1990; Walsham, 1993; Robey \& Azevedo, 1994) and the study of symbols in particular (Boland, 1979; Morgan, Frost, \& Pondy, 1983; Staw, 1985; Hirschheim \& Newman, 1991; Winter, 1993) have been suggested to understand the dynamics of information systems in organizations. The organizational culture perspective emphasizes some social characteristics 
(Morgan et al., 1983) and sees the organization as a "mini-society" (Ott, 1989). It forces researchers to go beyond organizational charts and formal procedures and to investigate a more fundamental set of social characteristics (norms, values, assumptions) that are at the core of organizational businesses, and that should not be considered as social noise or nuisance (Van Maanen, 1985). The study of symbols, more specifically, acknowledges the presence of symbolic activities in organizations and draws attention to the artifacts of the culture that are more easily observable (Morgan et al., 1983). The study of organizational culture and its symbolic representation offers a more holistic and less deterministic view of the organization (Louis, 1983) usually away from quantification, prediction, and structure and more toward qualitative, appreciative, and processual understanding (Knights \& Willmott, 1987). Its essence promotes looking at the introduction and development of IS as a social process and provides a better framework for getting a deeper understanding of these activities. A cultural analysis can help to understand the complex relationship between information systems and organizations because it emphasizes the socially constructed meanings of information technology and organizations and addresses the role of information systems in both the persistence and transformation of organizations (Robey \& Azevedo, 1994).

Despite the relative importance of organizational culture in the organizational literature (for example, Pettigrew, 1979; Smircich, 1983a; Schein, 
1985), the significant presence of symbolic activities in organizations (Morgan $e t$ al., 1983), and the key role of information technology in shaping contemporary organizations (Walsham, 1993; Robey \& Azevedo, 1994), the organizational culture metaphor and the related symbolic activities have received little attention in the information systems literature (Scholz, 1990; Walsham, 1991; 1993). An organizational culture perspective can therefore provide fresh images of organizations and new insights (Walsham, 1993) enabling a better understanding of the context surrounding IS activities.

In light of the above, this study will use symbols as representations of the culture of an organization and as a way to better understand phenomena related mainly to the development of information systems and the management of the IS function. Out of all possible symbolic activities, the focus will be on stories about information systems activities. A story is defined as being a "connected discourse" about a unified sequence of events that appear to be drawn from an oral history of the organization's past (Martin, 1982). Organizational stories have been found to be an important and pervasive component of organizational culture and social life (Martin, 1982; Martin, Feldman, Hatch, \& Sitkin, 1983; Feldman, 1990; Boje, 1991; Robey \& Sales, 1994), but have seldom been used to help understand information systems phenomena. 
On the organizational culture side, this study goes one step further. In addition to the usual view of culture, the "integration" view, it also uses two other perspectives: the differentiation and fragmentation perspectives (Martin, 1992). While the integration perspective focused on the "assembling" role organizational culture is normally said to play, the differentiation perspective highlights important differences among groups of people in the organization and the fragmentation perspective includes the notion of ambiguity and uncertainty in the conceptualization of culture. The use of the three perspectives in the same study helps get a broader picture which is impossible to obtain with the sole adoption of the traditional view.

Regarding its philosophical stance, this study adopts the interpretive one. Indeed, the assumptions behind the dominant positivist paradigm (see Table 1.1) do not very well suit the study of stories. It is impossible to look at stories as being objective and independent of their organizational context. Their sociallyconstructed nature resulting from a complex process of creation and interpretation defies many of its assumptions. 


\section{COMPARISON OF ASSUMPTIONS -}

\section{THE POSITIVIST PARADIGM VS. THE INTER PRETIVE PARADIGM ${ }^{1}$}

\begin{tabular}{|l|l|}
\hline \multicolumn{1}{|c|}{ THE POSIIVIST PARADICMN } & \multicolumn{1}{|c|}{ THE INTERPRETIVE PARADIGM } \\
\hline $\begin{array}{l}\text { Object of study is single, tangible, and } \\
\text { fragmentable }\end{array}$ & $\begin{array}{l}\text { Objects of study are multiple, constructed, } \\
\text { and need to be looked at holistically }\end{array}$ \\
\hline $\begin{array}{l}\text { The researcher is completely independent of } \\
\text { the object of study }\end{array}$ & $\begin{array}{l}\text { Researcher and objects of study interact } \\
\text { and influence each other }\end{array}$ \\
\hline $\begin{array}{l}\text { It is possible to set time and context-free } \\
\text { generalization }\end{array}$ & $\begin{array}{l}\text { Only time and context-bound working } \\
\text { hypotheses are possible }\end{array}$ \\
\hline Cause-to-effect relationships can be identified & $\begin{array}{l}\text { All objects are in a state of mutual } \\
\text { simultaneous shaping (impossible to } \\
\text { distinguish causes and effects) }\end{array}$ \\
\hline Inquiry is value-free & Inquiry is value-bound \\
\hline
\end{tabular}

Because the first objective of the study is to develop a better understanding of the role organizational culture plays in IS development and other IS-related activities, the assumptions of the interpretive stance better suit the objective of the study. Generalization is not the goal of the study, but exploration and understanding are. The nature of the stories themselves better fit the assumptions of the interpretive stance. Stories are elements of a complex social context and do not exist apart from the tellers. They need to be studied holistically (Georges, 1969) in their organizational context (Morgan \& Smircich, 1980; Smircich, 1983b; Bauman, 1986). Because of the complex interactions between messages, interpretations, actors, and organizational context, generalizations free of time and

1. Adapted from Lincoln \& Guba (1985; p.37) 
context are impossible. These complex interactions also include the actions of the researcher. The interpretive stance is therefore the most appropriate.

More specifically, this study wants to investigate the following three research questions:

(1) What is the message of stories about information systems?

The first research question pertains to the nature of the stories and the messages they carry. A story has a symbolic value because its meaning is greater than the words themselves, because between the lines a message is expressed (a point is made, an idea is expressed, or something is highlighted). From that story and its message can be extracted a theme expressing the most significant idea(s) carried by the story. A repeating theme reflects an important concept (an element of the culture) for the organization.

(2) What are the specific functions of stories about information systems within their social context?

Adopting a functionalist point of view, I accept the premise that a person deliberately uses a story in order to act on his or her environment. Telling a story 
is not an innocent act; it carries a purpose. In this line of thought, the second research question explores the functions of the stories investigated.

(3) How does the content of stories relate to practices in information systems?

Finally, the third research question aims at reconciling the content of stories (and more specifically the themes they carry) and IS activities. IS activities considered as social activities (where multiple groups of people are involved and interact) are carried out in a cultural context. As such, the cultural themes identified define the environment of those activities and can be fruitfully used to better understand how these activities are carried out and managed.

In this study, the IS phenomena of interest are broadly defined as all the IS practices and activities related to the development of information systems. This includes project organization and management, reengineering effort, relationship with outsourcing partner, and human resources management (allocation, training, and evaluation). The social context includes all the organizational actors involved in those activities.

An in-depth case study strategy was used to gather the stories. The results emphasize the bias resulting from the use of the integration perspective as the 
only lens through which to look at the culture of an organization. This bias had a profound impact on the literature; it helped shape the identification of important organizational actors, the definition of stories, and the conceptualization of their functions. In this study, a broader conception of "significant stories" is given along with a broader range of functions that stories may fulfill. Finally, the results highlight the importance of cultural elements in understanding two very contemporary IS activities: implementing team reorganization (change) and managing outsourcing relationships.

This dissertation is organized as follows. Chapter 2 presents the theoretical foundations of the study. It explains the basic concepts behind organizational culture and further defines it through the use of the three perspectives: integration, differentiation, and fragmentation. Symbols and stories along with their functions are then discussed. Chapter 3 details the method used. It elaborates on the design of the study, describes the research site, and explains the process of respondent selection and data collection. The last section of this chapter describes how the analysis of the data was performed.

The results are then presented. Chapter 4 first provides some corporate background necessary to understand the culture of the organization. It then presents the nine grand themes identified and gives examples of stories 
representing each of them. The last section of this chapter presents the functions identified and supports each of them with examples of stories.

Chapter 5 uses the functions and themes identified in Chapter 4 and discusses them in context with the three organizational culture perspectives. It then reconciles themes, functions, perspectives, and IS activities. Finally, the last chapter, Chapter 6 , concludes this document by summarizing the results of the study and discussing their implications for practice and research. The last section of the chapter discusses the limitations of the study and offers some avenues for future research. 


\section{CHAPTER 2}

\section{THEORETICAL FOUNDATIONS}

A cultural study of IS practices requires thorough grounding in the concept of organizational culture. Drawn from anthropology and sociology, the "culture" metaphor was imported into the organization theory literature in the late seventies. The first reference is usually attributed to Pettigrew in an article published in Administrative Science Quarterly in 1979. Major economic changes experienced by U.S. businesses along with the success of Japanese industry and management are the basis for the popularity of the organizational culture concept (Wilkins, 1983b; Turner, 1986; Trice \& Beyer, 1993). Western organizations became interested in evaluating the cultures of Japanese businesses to see how to improve their competitive strategies and management techniques (Erez \& Earley, 1993; Robey \& Sales, 1994). This inter-country cultural debate, the publication of best-seller books emphasizing this perspective (for example, Deal \& Kennedy, 1982; Peters \& Waterman, 1982), and its appeal to the practitioner's world as a possible solution to their current problems (to name a few, Gardner, 1985; O'Reilly, 1989) all contributed to the increasing popularity of the organizational culture concept.

This chapter first covers the basic concepts of organizational culture followed by a description of the three perspectives used in this study: integration, 
differentiation, and fragmentation. The following sections address the issue of using symbols to investigate the culture of an organization, and more specifically, organizational stories. Finally, the last section discusses the importance of culture in understanding information systems activities.

\subsection{Organizational Culture : Basic Concepts}

There are two main ways to conceptualize culture (Smircich, 1983a). It may be conceptualized as something an organization has, or as something an organization is. This study adopts the second conceptualization. Under this view, "culture is the product of negotiated and shared symbols and meanings; it emerges from social interaction" (Meek, 1988, p.463). At the core of the idea of culture is the expressive, subjective, interpretive, and nonrational qualities of the experience of an organization (Smircich, 1983a).

The concept of culture is closely related to the process of reality construction. Under this view, an organization becomes a socially-constructed reality (Berger \& Luckmann, 1967) where the heads and minds of its members are as important as the concrete and formal sets of rules and regulations (Morgan, 1986). Culture is the invisible force behind the visible characteristics of an organization (Kilmann, Saxton, \& Serpa, 1985). Evolving in a complex organizational setting necessarily involves the comprehension and interpretation of events (Erez \& Earley, 1993). Human beings are considered as social actors 
who interpret their environment and orient their actions in ways that are meaningful to them (Morgan \& Smircich, 1980). This enacting ${ }^{1}$ process allows organization members to see, understand, and develop their own interpretations of events, objects, or situations in distinctive ways, therefore creating and recreating the worlds in which they live (Morgan, 1986). In an organizational context, through social interactions, and particularly communication (Gray, Bougon, \& Donnellon, 1985), the enactment of meaning becomes a collective activity (Walsham, 1991) resulting in the creation, transmission, and maintenance of coincident interpretations of reality (Gray et al., 1985). These collective enactments of meaning, at least partially shared by a certain group in the organization, create the culture of an organization (Gregory, 1983; Young, 1989; Walsham, 1991).

Culture is both the product and the process; it helps shape human interaction and is, at the same time, being shaped by this interaction (Jelinek, Smircich, \& Hirsch, 1983). Culture promotes the existence of common modes of interpretation and shared understanding of experience that allow day to day activities to become routinized and taken for granted (Smircich, 1983a). Culture becomes the identity of a social group (Louis, 1983). It has therefore an important

1. Enactment is the process through which human beings shape and structure their realities (Weick, 1979). 
influence on the life of organization members, their perceptions, their desires, their goals, and their actions (Riley, 1983).

The power of a cultural analysis lies in the questioning of taken-for-granted assumptions and underlying values and in the acknowledgment of the importance of context and meaning (Smircich, 1983a). It emphasizes the investigation of motivation which lies behind human action in organizations (Mouritsen, 1989).

Organizational culture has three frequently studied components: forms, practices, and content themes (Martin, 1992). Cultural forms refer to those aspects of organizational life such as rituals, stories, jargon, and physical arrangements, that are used to express, affirm, and communicate with organization members in some tangible way (Trice \& Beyer, 1984; 1993). Practices, a long-time primary focus of organizational research, are separated in terms of formal and informal. Formal practices include organization structure, task and job descriptions, and rules and procedures, and informal practices include social norms, communication patterns, and unwritten expectations. The informal ones are closer to the object of cultural analyses. Finally, content themes are common threads of concerns underlying a subset of forms and practices (Martin, 1992). These themes can be external (for example, publicized corporate objective) or internal, either deliberately espoused (for example, valuing innovation and initiative) or deeply assumed (for example, importance of employees in the organization). "When 
cultural members interpret the meanings of these manifestations [forms], their perceptions, memories, beliefs, experiences, and values will vary, so interpretations will differ - even of the same phenomenon. The patterns or configurations of these interpretations, and the ways they are enacted, constitute culture" (Martin, 1992, p.3).

The conceptualization of culture used in this study differs from others also used in the literature. According to Schein (1985), for example, culture is defined in terms of artifacts, norms, and values that are based on taken-for-granted assumptions that are automatically true and non-negotiable. Considered as being mainly instigated by management, culture is seen as the necessary glue that holds an organization together, that unifies and encourages many different organization members to work towards the same goals. The objective of such studies is often to find out how culture may be manipulated in order for managers to influence and direct the destiny of their organizations. The conceptualization of culture used in this study is different or, should we say, more complete. It uses a different way to look at culture as proposed by Meyerson \& Martin (1987) and, in more detail, by Martin (1992). Importantly, these authors acknowledge that culture can be a unifying but also a divisive issue in the organization, and that every member has a role to play in shaping the cultural context of an organization. The next section discusses in detail the basis of their different perspectives as adopted in this study. 


\subsection{Organizational Culture: Three Perspectives}

While the basic characteristics discussed in the previous section remain accurate, three different perspectives on organizational culture have been identified and adopted in the literature. The three perspectives, integration, differentiation, and fragmentation (Martin, 1992) offer a different approach from which to conceptualize and investigate organizational culture. The perspectives are not considered as an accurate reflection of an objectively observed reality, but rather as an interpretive framework that is subjectively imposed on collecting and analyzing cultural data (Martin, 1992). These perspectives "need to be seen as subjective frames - like lenses, coloring what is seen, bringing some elements into focus, and blurring others" (Martin, 1992, p.170). Each perspective provides a different definition of organizational culture, emphasizes different elements, and conceptualizes differently potential cultural changes, but the way they deal with the presence (or absence) of ambiguity ${ }^{1}$ fundamentally differentiate each of them. Researchers usually choose the perspective they are the most familiar and/or comfortable with and this choice will influence how they see culture and how they conceive cultural changes (Meyerson \& Martin, 1987). For a long time, the perspective adopted suffered from "managementcentric" biases (Gregory, 1983). A multiperspective image of the culture of an organization will enrich

1. Ambiguity is defined as a lack of clarity, high complexity, and paradox that make multiple explanations plausible (Martin, 1992). 
understanding by emphasizing the cohesive, but also the divisive functions of culture in organizations (Gregory, 1983).

\subsubsection{The Integration Perspective}

The integration perspective defines culture as what is shared by and unique to an organization (Meyerson \& Martin, 1987). It describes the organization as having a set of content themes that are shared by all members of an organization and that are consistently represented in cultural manifestations (Martin, 1992). These themes represent an organization-wide consensus on values and basic assumptions. This is a picture of harmony where everything is clear; people at any hierarchical level are seen as agreeing about potentially divisive issues. "The organization is seen as made up of individuals, operating departments, and staff units which are relatively homogeneous regarding how they assess, pursue, and achieve their interests in relation to those [organizational] goals" (Lucas, 1987, p.145). Under this perspective, culture exists to remove anxiety and assure clarity and predictability. If something is ambiguous or uncertain, it means that the group does not have a culture facing these issues (Schein, 1991). The integration perspective acknowledges that organization-wide consensus is difficult; nevertheless, consensus is a worthwhile objective because it is assumed to lead to organizational effectiveness. 
The integration perspective emphasizes the role of leaders and top management as creators of culture. The idea is that leaders want to create a culture reflective of their own values. "... an assumption is made that corporate visions articulated by senior management not only exist but are appropriate to all subsystems of the organization" (Lucas, 1987, p.146). A unified culture is attractive because of the benefits it brings to individual employees and to the organizations where they work. These benefits are said to include cognitive clarification, commitment, and productivity (because people clearly know what is expected from them). This perspective is the most popular in the literature. Because of the promises it makes, this is the perspective the most popular to researchers writing for a managerial audience (Martin, 1992). This perspective has a clear managerial bias (Gregory, 1983; Riley, 1983; Turner, 1986); "its outcome is a curiously "flat" single faceted view of individual motivation and social relationships in general" (Young, 1989, p.189).

Under this perspective, culture is considered as a variable managers can manipulate. Changes are seen as organization-wide cultural transformations. Cultural changes are conceived in terms of establishing, maintaining, and returning to cultural unity; the usual unfreeze, change, and refreeze model (Lewin, 1947; Schein, 1969). Inconsistencies, ambiguity, and uncertainties are seen as dysfunctional and a deterioration before a new culture gets established. This is the only role ambiguity plays in this perspective. As a result, persistence, 
inertia and resistance are a natural part of this cultural perspective (Meyerson \& Martin, 1987) and are forces managers have to consider while planning any cultural changes.

\subsubsection{The Differentiation Perspective}

This perspective is mainly suspicious of claims of organization-wide consensus as made in the integration perspective. Under this perspective, interpretations of content themes, practices, and forms are often inconsistent and consensus exists primarily within subcultural boundaries. Clarity reigns inside the subcultures, while ambiguity is relegated to the periphery. Each subculture is an island of localized lucidity; culture is defined as what is unique or distinctive and shared in a particular group. "... organizational culture should be viewed as a system of integrated subcultures, not as a unified set of values to which all organization members ascribe" (Riley, 1983, p.414). This perspective encourages us to look behind the obvious unity and harmony that may mask a series of overlapping, nested organizational subcultures. This perspective focuses on inconsistencies, diversity, lack of consensus, contradictory meanings, and subcultural differences. It emphasizes disagreement rather than consensus (Meyerson \& Martin, 1987). Subcultures coexist sometimes in harmony, sometimes in conflict, and sometimes in indifference to each other. 
The differentiation perspective brings an additional level of richness to a cultural analysis. "In attending to the artifacts of culture, analysts have generally failed to expose relations of power and domination that underpin the construction and reproduction of what may appear to be a "shared system of norms and values" within work organizations" (Knights \& Willmott, 1987, p.42). On the other hand, some authors (Knights \& Willmott, 1987; Lucas, 1987) argue that "... the cultural phenomena... have been examined without adequate consideration of the material and political contexts within which these organizational artifacts are socially organized and reproduced" (Knights \& Willmott, 1987, p.43). This perspective adds to the issue of culture the idea of relationships between interests and groups within the organization, introduces the idea of constraints and divided interests, and acknowledges that events and social relationships can be vested with multiple meanings (Young, 1989). "Consequently, an organization's culture will be distinguished by various processes and administrative devices both constraining and facilitating the manifestation of sectional interests inside the organization" (Young, 1989, p.203).

The differentiation perspective is more congruent with the views of the people who do not have the power and status of top management; it explores the viewpoints of subcultures that see things differently. It acknowledges power relations, conflict of interest, and differences of opinion within a single organization. Some organizing strategies like functionalization, specialization, 
automation, professionalization, and standardization have led to the segmentation of the workforce promoting the development of subcultures within a single organization. Louis (1985) identified three types of subcultures: enhancing subcultures, countercultures, and orthogonal subcultures. An enhancing subculture is one where top management's views are reproduced in an exaggerated form; countercultures are pockets of resistance to the views espoused by top managers; orthogonal subcultures are purely orthogonal, that is neither positive nor negative in orientation toward management or each other. Subcultures can also be defined around demographic characteristics (race, age, ethnicity, gender), occupations or hierarchical factors (Trice, 1993). Individuals can therefore belong to more than one subculture at once (Martin, 1992).

The differentiation perspective has gained more and more importance in the literature. Most researchers will now recognize that subcultures are prevalent within work settings and vary to some extent from the dominant culture (Gregory, 1983; Louis, 1985; Schein, 1985; Cooke \& Rousseau, 1988; Ott, 1989; Trice, 1993). Under this perspective, environment is also an important component of the organization. Unlike the integration perspective, the differentiation perspective acknowledges the influence of larger forces such as environment and society on the culture of an organization. Culture is formed by multiple sources of influence from inside and outside the organization and the subcultures will reflect functional, national, hierarchical, ethnic, or project affiliations. "Subgroups 
with different occupational, divisional, ethnic, or other cultures approach organizational interactions with their own meanings and senses of priorities. Ethnocentrism, the tendency to take for granted one's own cultural view and to evaluate others' behavior in terms of it, increases the tendency for misunderstandings and conflicts to occur" (Gregory, 1983, p.359). Under this perspective, the boundaries of an organization are seen as permeable and arbitrary (Martin, 1992). If one wants to have a "correct" image of the organization, members of all possible subcultures should be included in the analysis; major locations of subcultures such as cliques and coalitions, technology and work flows, departments, top management, staff units, and countercultures resulting from mergers must all be closely considered (Trice, 1993).

Under the differentiation perspective, organization-wide cultural changes are impossible; only incremental and localized changes are possible (Martin, 1992). Changes must therefore occur at the subculture level, one subculture at a time.

\subsubsection{The Fragmentation Perspective}

The fragmentation perspective is a new way to look at the culture of an organization. Acknowledging ambiguity as an inevitable part of organizational life and decision-making (March \& Olsen, 1976), the fragmentation perspective considers it the essence of an organizational culture. Contrary to the integration 
perspective, this perspective does not emphasize general harmony, nor necessary conflict as in the differentiation perspective. Under this perspective, these conceptions are just imposing simplicity, order, and predictability on a sociallyconstructed reality characterized by complexity, multiplicity, and flux (Martin, 1992). Contrary to the differentiation perspective, under the fragmentation perspective, group identities do not form stable subcultures; consensus, dissensus, and confusion coexist, making it difficult to draw cultural and subcultural boundaries (Meyerson \& Martin, 1987). Members' views are dynamic; they change their views from moment to moment as the importance and salience of issues differ, as the tasks and the people involved change, and as new information becomes available (Martin, 1992). Different systems of meaning coexist leading to irreconcilable interpretations (contradictions) that are simultaneously entertained and accepted leading to no set of shared and integrated values (Martin, 1992). Expectations and evaluation criteria are not clear; no consensus exists on priorities (Meyerson \& Martin, 1987). There is therefore no organizationwide consensus possible as advocated by the integration perspective, nor clear subcultural groups as advocated by the differentiation perspective.

The best metaphor to illustrate the fragmentation perspective is a web (Martin \& Meyerson, 1988). In the web, organization members are nodes connected by shared concerns. When one issue becomes relevant, one pattern of connections becomes relevant (a unique array of agreements, disagreements, and 
domains of ignorance (ambiguity)). Whenever a new issue becomes important, new patterns of connection become significant. Under this perspective, therefore, culture is "a web of individuals, sporadically and loosely connected by their changing positions on a variety of issues" (Martin, 1992, p.153) and is always in a state of flux. Cultural change is therefore considered as continual (Meyerson \& Martin, 1987), changing in response to endogenous pressures (Green, 1988). This characteristic of the fragmentation perspective makes it very different from the two others. Under this perspective, culture is not completely shaped by any single group (for example, top management), but power and influence is more diffused in the environment and among organization members. Because of the inherent complexity, it is therefore more difficult to offer simple prescriptions under this perspective.

In addition, the fragmentation perspective encourages the deconstruction of organizational discourses (Martin, 1992). It fosters the discovery and analysis of unspoken organizational realities such as power and gender issues. It puts emphasis on what is not said as an important component of reality, as a source of meaning and understanding. The focus of this perspective should therefore be on investigating these silences and on discovering the multiple meanings (expressed and unspoken) present at any given time (Gray et al., 1985). 
Using the three perspectives to look at cultural phenomena implies investigating beyond appearances. The members of an organization will usually support one perspective in their discourse, forgetting about all the inconsistencies they meet in their everyday life. In this case, the two other perspectives should help identify and explain aspects that are ignored by the obvious one. The job of the researcher is to use the insights given by each perspective and look for alternative meanings and explanations. The idea is not to try to assimilate the three perspectives or find out which one is the best, but to use each of them in turn to better understand a cultural context, to see how each of them can help enrich and broaden a cultural analysis and lead to a more insightful and complete representation of the culture of an organization (Martin, 1992). The assimilation of the three perspectives would only undermine their oppositional stance (Martin, 1992).

\subsection{Organizational Symbols as an Expression of Culture}

This study is concerned with the study of organizational culture through its manifestations in symbols. "Symbols are objects, acts, relationships, or linguistic formations that stand ambiguously for a multiplicity of meanings, evoke emotions, and impel men to actions" (Cohen, 1974, p.23). Symbols can vary substantially in their degree of complexity and include patterns of action, language, discourse, laws, roles, rites, ritual, custom, ceremony, norms, folklore, 
stories, beliefs, myths, and logos. It is very fruitful to study these collective symbols to discover operative dynamics and meanings that would, otherwise, often remain inaccessible (Smith \& Simmons, 1983).

Symbols denote something much greater than themselves. "... symbols are created and recreated whenever human beings vest elements of their world with a pattern of meaning and significance which extends beyond its intrinsic content" (Morgan et al., 1983, p.5). Each symbolic construction embodies significant networks of meaning, through which patterns of social life are enacted, understood and sustained (Morgan et al., 1983; Morgan, 1986). In their classical definition, symbols reveal or exist as a sense-making mechanism reflecting the unconscious feelings, images, and values shared by the members of an organization (Dandridge, Mitroff, \& Joyce, 1980). They also act to reinforce basic assumptions and values (Louis, 1983). Symbolic activities can be consciously used to produce certain effects within the organization or may arise spontaneously (Morgan et al., 1983). While these symbolic devices embody and are used to convey the local culture, importantly, they are simultaneously the artifacts of that culture (Louis, 1983).

Symbols can vary in the extent to which they are shared (Morgan et al., 1983) and this can be very well understood using the three cultural perspectives. Under an integration perspective, symbols will be universally shared across 
organization members. They would more often convey top management messages. Under a differentiation perspective, symbols can express significant patterns of meaning for just a few people or a group, otherwise called a subculture. Symbols can also express a contradictory pattern of meanings to different people which would be consistent with a fragmentation perspective. One symbol can be intended to convey a certain message by management, but be interpreted differently by employees. This particular situation would depict the antagonistic position of subcultures as highlighted in the differentiation perspective, but also the ambiguity of organizational discourses as emphasized in the fragmentation perspective. It reemphasizes the fact that symbols are socially constructed. This last point must be kept in mind when performing symbols analysis. The individual interpretation of each symbol by each organization member is more important than the actual characteristic and/or description of a particular symbol.

Different perspectives can be adopted to perform an analysis of organizational symbols (Morgan et al., 1983). This study tends to use as a basis a functionalist approach that considers symbols as carriers of information and meaning and stresses the investigation of their functions. Emphasis is put on identifying and categorizing symbols, the functions they perform, the significance of symbolic activity as part of a wider cultural milieu, and the way in which it contributes to the functioning of a wider system. These general functions will 
have different emphasis as one goes from one perspective to the other. Under an integration perspective, symbols will tend to be used to reinforce management values and to disseminate them throughout the organization. Under the differentiation perspective, on the other hand, symbols would be used to accentuate differences between the different groups (subcultures) in the organization and preserve the power of the existing hierarchy. Finally, under a fragmentation perspective, the functions of symbols will be less clear as they will often convey a lack of order, an ambiguity and dynamism that will go against the preservation of one's particular point of view.

While these functions remain general, it is interesting to understand the more specific roles that symbols play in the shaping of any given organizational reality (Morgan \& Smircich, 1980): More than their surface-level meanings, the focus should be on understanding culture-specific meanings (Sackmann, 1991). To help in that direction, Dandridge and his colleagues (1980) developed a framework to analyze the types and functions of symbols in organizations (see Table 2.1). They identified three categories of symbols: verbal (such as myth, legend, stories, slogans, creeds, jokes, rumors, and name), actions (such as ritualistic special acts, parties, rites of passage, meals, breaks, and starting the day), and material (such as status symbols, company products, logos, awards, company badges, pins, and flags). Out of the existing literature, these authors also inventoried three main functions of symbols: descriptive, energy-controlling, 


\begin{tabular}{|c|c|c|c|c|c|}
\hline & & & \multicolumn{3}{|c|}{ TYPES OF SYMBOLS } \\
\hline & & & $\begin{array}{l}\text { Verbal } \\
\text { Myth, } \\
\text { legend, } \\
\text { stories, } \\
\text { slogans, jakes, } \\
\text { rumors, etc) }\end{array}$ & $\begin{array}{l}\text { Actions } \\
\text { (Ritualistic } \\
\text { special acts, } \\
\text { parties, rites } \\
\text { of passage, } \\
\text { meals, } \\
\text { breaks, etc.) }\end{array}$ & $\begin{array}{l}\text { Material } \\
\text { (Status, } \\
\text { symbols, } \\
\text { company } \\
\text { products, } \\
\text { Jogos, awards, } \\
\text { badges, pins, } \\
\text { lagss, etc) }\end{array}$ \\
\hline \multirow{6}{*}{$\begin{array}{l}\text { FUNCTIONS } \\
\text { OF } \\
\text { SYMBOLS }\end{array}$} & Descriptive & $\begin{array}{l}\text { Providing an } \\
\text { experienced } \\
\text { expression of the } \\
\text { organization }\end{array}$ & & & . \\
\hline & \multirow{3}{*}{$\begin{array}{l}\text { Energy } \\
\text { Controlling }\end{array}$} & $\begin{array}{l}\text { Increasing } \\
\text { tension; } \\
\text { inspiring; } \\
\text { attracting; } \\
\text { repelling } \\
\end{array}$ & & & \\
\hline & & $\begin{array}{l}\text { Facilitating re- } \\
\text { experience of } \\
\text { previous state }\end{array}$ & & & \\
\hline & & $\begin{array}{l}\text { Decreasing } \\
\text { tension; cathartic }\end{array}$ & & & \\
\hline & \multirow{2}{*}{$\begin{array}{c}\text { System } \\
\text { Maintenance }\end{array}$} & $\begin{array}{l}\text { Giving "reason"; } \\
\text { providing } \\
\text { coherence, order, } \\
\text { and stability; } \\
\text { differentiating; } \\
\text { integrating }\end{array}$ & & & \\
\hline & & $\begin{array}{l}\text { Providing or } \\
\text { guiding } \\
\text { acceptable } \\
\text { patterns for } \\
\text { change - } \\
\text { individual or } \\
\text { organizational }\end{array}$ & & & \\
\hline
\end{tabular}

Focus of the study 
and system maintenance. It is to be noted that one symbol can simultaneously play different roles and multiple symbols can fulfill the same role (Dandridge et al., 1980). Here is a description of the functions:

\section{(1) Descriptive function}

Purely descriptive symbols act "as a shorthand to convey the direct experience of a work situation and the associated feelings" (Dandridge et al., 1980, p.79). For instance, the stories communicate information that helps the listener grasp feelings and operative values present in the organization.

\section{(2) Energy controlling function}

An energy controlling symbol will have the effect of inspiring or discouraging individuals. Symbols, in this case, have an intent beyond a simple description. There are three ways in which symbols can function as energy control for organization members or outsiders (Dandridge, 1983). First, symbols under the form of stories, slogans, or material can be used to attract new recruits or repel undesired outsiders as symbols can influence people's feelings about the organization. Second, symbols can facilitate re-experiencing of a feeling; examples would be a plaque or a gold watch. Third, symbols serve an energy controlling function as they provide organization members with an acceptable outlet for feelings. Parties or athletic contests are good examples of this last category of symbols. 
Symbols can protect the system, stabilize it, or guide change in the structure (Dandridge, 1983). A symbol with a system maintenance function will help maintain the stability of the system through justification and reinforcement. Symbols (i.e., size of office, seating arrangement, dress code) can help make sense of relationships and help maintain them. Rites of passage, renewal, and integration (Trice \& Beyer, 1984), for example, serve this kind of function. Symbols can help the organization through transition by stabilizing commitment or organizational climate and carrying memories to support the system through difficult times (Dandridge, 1983).

Despite a few exceptions (e.g., Martin \& Powers, 1983a; 1983b), organizational symbols have predominantly been studied through qualitative and interpretive studies (e.g., Martin et al., 1983; Robey \& Markus, 1984; McConkie \& Boss, 1986; Young, 1989; Feldman, 1990; Boje, 1991; Hirschheim \& Newman, 1991). Because symbols are socially constructed, it is important that they be studied in their own context and researchers be in direct contact with the members of the organization (Morgan \& Smircich, 1980; Smircich, 1983b). Laboratory experiments as used by Martin and Powers (1983a; 1983b) were used in order to investigate the power of symbols and more precisely, the cognitive responses from subjects to different statements. These experiments had a very focused research question and were not, in any way, considering an organizational context. 


\subsection{A Story: A Verbal Symbol}

The focus of this study is on verbal symbols and more specifically on stories. Since the beginning of time, men and women have used stories to describe their environment and narrate the exploits of members of their species. "Oral performance, like all human activity, is situated, its form, meaning, and functions rooted in culturally defined scenes or events - bounded segments of the flow of behavior and experience that constitute meaningful contexts for action, interpretation, and evaluation" (Bauman, 1986, p.3). Stories are interesting and rich pieces to gain insights into the history and nature of man (Georges, 1969). Since the turn of the century, the study of stories has always been a multidisciplinary pursuit, mostly by folklorists and anthropologists. Anthropologists, for example, consider "oral literature... as expressions, reflections, or support mechanisms for cultures and social structures" (Bauman, 1986, p.2). The present study is in line with the anthropologist tradition where the main goals are to determine the functional relationships between story content and other aspects of a person's social structure or the behavioral implications of story content for members of a culture.

"Intensive studies of story texts from individual societies have revealed that stories can reflect cultural reality or distort it, that they can reinforce the social structure and contribute to social cohesion or weaken the social structure and threaten social cohesions, that they can function as conditioning mechanisms and instruments of social control or as escape mechanisms and instruments of social criticism" (Georges, 1969, p.315). 
The study of stories has produced many propositions about the effects of culture upon the individual and groups (Georges, 1969).

A new interest in storytelling exists now in anthropology where the conception of society has evolved from abstract, normative, and collective structures to an understanding of social and cultural life as forms of symbolic production (Bauman, 1986). People tell stories as a means of giving cognitive, moral, and emotional coherence to human experience and as a means of constructing and negotiating social identity (Myerhoff, 1978; Herzfeld 1985; Bauman, 1986).

Storytelling is also a pervasive phenomenon in organizational settings (Martin, 1982; Feldman, 1990; Schwartzman, 1993; Trice \& Beyer, 1993) where it seems to play similar roles (Wilkins, 1983a; 1984; Martin et al., 1983; Schwartzman, 1984; Boje, 1991). An organizational story is defined as being a "connected discourse" about a unified sequence of events that appear to be drawn from an oral history of the organization's past (Martin, 1982). The concept of stories also includes any explanation of past events that can be found to be shared (Feldman, 1990). Stories are concrete and full of unique and vivid details. They are usually brief, simple, and punchy (Trice \& Beyer, 1993). They contain details about specific people and actions, and often provide a description of the time period and the place (Wilkins, 1984). For this reason, they grab people's attention and 
stick in memories (Martin, 1982). Stories usually make reference to the organization's culture, an organizational policy or practice, and/or management philosophy (Martin, 1982). They feature organization members (Martin, 1992) (present, past, and particularly top management (Martin, 1982)) rather than clients (Martin \& Powers, 1983b) and are common knowledge among some group of people in the organization (Wilkins, 1984). While stories sometimes become a combination of reality and fiction (Trice \& Beyer, 1984), they are considered as factual by some groups of people (Wilkins, 1984). Stories often play the role of organizational memory (Boje, 1991) and are created and/or updated as significant events occur in the organization. Unlike saga, stories refer to one single episode. The same event, however, can lead to the creation of several stories possessing different motives (Boje, 1991).

Stories act as a window on the culture of an organization (Wilkins, 1983a). Storytelling is used as one of many effective forms of communication about origins and transformation of the organizational culture, beliefs about process, management philosophy, and some organizational policies (Martin, 1982). Stories are also widely used to illustrate the points organization members want to communicate (Martin, 1982; Wilkins, 1984). They also "frequently recount the games, strategies, intrigue, and power struggles that mark the inveterate politics of everyday organizational life" (Riley, 1983, p.414). They are often about "social contracts", have to do with how things are supposed to be done and how people 
are treated and rewarded or punished (Wilkins, 1984). The stories are narrated formally, by, for example, the production of books representing the story of the organization including anecdotes about founders and critical events (Dandridge et al., 1980), and informally, told during company-related conversations (Mitroff \& Kilmann, 1976; Martin, 1982).

Stories have important functions in the organization. Stories usually have morals that communicate the values of an organization (Martin, 1982; Martin et al., 1983) or contain scripts that act as "maps that help people know how things are done in a particular group" (Wilkins, 1984, p.43) and in a particular context. The stories and the values they convey are usually shaped by the key people in the organization (Louis, 1983); they are often derived from management actions occurring during a time of crisis or because they were out of the ordinary (Wilkins, 1984). By communicating cultural beliefs and values (Martin et al., 1983; Sathe, 1985) or providing examples of general themes or ideas (Wilkins, 1984), stories remain an important source of information about the company's culture for participants (Wilkins, 1984). Newcomers are eager to hear organizational stories that will help them in getting to know how to act and behave in a particular work setting (Wilkins, 1983a; 1984). Stories are told, as a socialization means, to explain to new employees "how things are done around here" (Martin, 1982; Mitroff \& Kilmann, 1976). Stories will help facilitate the process by which a newcomer comes to appreciate the values, abilities, expected behaviors, and 
social knowledge (Louis, 1980). More experienced employees, on the other hand, get from stories clues about how to behave in particular situations. Stories will also give indications about behavior and attitudes that are acceptable and about realistic expectations (Wilkins, 1984). Stories therefore serve as a precedent for individual assumption, decision, and action (Boje, 1991). Stories have the power to affect how people see their organizations and themselves (Feldman, 1990) and to impact organization members' attitudes (Martin, 1982). They would be especially powerful within modern large-scale organizations (Mitroff \& Kilmann, 1976).

In addition, stories seem to give the members of the organization a concrete and shared sense of what is important in the organization and a common vocabulary that helps them communicate with each other. Stories are interesting because they generate, as well as reflect, changes in organizations (Martin et al., 1983). They can be used to mediate conflicts and contradictions under changing circumstances (Feldman, 1990). Stories can also be used as a mechanism to cope with some organizational dualities:

"... the common organizational stories may be seen as both a description of the world as it exists (with its discomforting dualities) and, for most of the stories, a statement about how this organization alleviates or accentuates the tension created by the duality. Because these dualities... are not easily reconcilable, the common organizational stories may serve as a pressure valve, releasing tension that could not otherwise be dissipated, except by abolishing some of the basic attributes of most organizations, such as 
inequalities in power, the capacity to survive, and the desire to control outcomes" (Martin et al., 1983, p.449).

Stories can also reflect and express tensions that exist between the values promulgated in the organization and the values of individual employees (Martin et al., 1983). Overall, they "work to integrate... the complex and conflicting nature of organizational processes and actions" (Feldman, 1990, p.813). They often reflect the "hopes, dreams, fears, and uncertainties which employees and managers feel are important to try to "map"' (Wilkins, 1984, p.49). They help organization members cope with the uncertainty of their environment (Boje, 1991), and serve as a guide when exceptional situations are met. Stories create, maintain and legitimize past, present and future actions and consequences by their diverse descriptive, energy controlling and system maintenance functions as described in the previous section. Stories often offer a self-enhancing explanation of organizational successes and failures (Martin et al., 1983) as sought by people and organizations (Weick, 1979). They give meaning and structure and help make sense of critical life events (Dandridge et al., 1980; Riley, 1983; Schwartzman, 1993).

While some claims are being made about the possible management and manipulation of stories in organizations (Mitroff \& Kilmann, 1976; Pfeffer, 1981; Sathe, 1985; McConkie \& Boss, 1986; Morgan, 1986; Boje, 1991; Trice \& Beyer, 1993), the study of stories remains more a descriptive tool than a prescriptive one. 
"You do not control culture, at best you shape it" (Green, 1988, p.121). Because of our present state of knowledge, there is an important need to get a better understanding of cultures as they actually are before we can make any recommendation about what they should be (Gregory, 1983; Turner, 1986; Schwartzman, 1993). Research should therefore emphasize description and interpretation, rather than control and manipulation (Meek, 1988).

\subsubsection{Beyond Words: The Interpretation of Stories}

The interpretation of stories will be different depending on the framework and assumptions made by the researcher (Georges, 1969). The use of the three different perspectives will help the researcher to give a broader and more complete interpretation of the general messages carried by stories by bringing a different light to each of them. More importantly, the use of the three perspectives will allow the study of divergent and contradictory stories and help challenge the more obvious interpretations that easily come to mind when one is first told a story and therefore force further analysis. The value of this is in a deeper understanding of organizational phenomena. Further analysis should help in uncovering organizational phenomena (values, meanings, and priorities) that play an important role in the organization, but that are less openly addressed, discussed or acknowledged. 


\section{Integration}

Under an integration perspective, stories will be stressing harmony and cooperation. They articulate the philosophy of top management and the characteristics that make the organization unique (Martin \& Powers, 1983b). Therefore, they have a reinforcing role. They are also used as an instrument to legitimate power relations. Stories will be congruent with organizational themes espoused by top management and mainly used to disseminate these themes to the members in the organization. Stories often symbolize important values to which employees are committed (Wilkins, 1984) and will often serve the purpose of unifying organization members under the same umbrella.

\section{(2) Differentiation}

Under this particular perspective, stories will reflect conflicts and ambiguity between groups. Depending on the interests of the stakeholders, stories will have different and often conflicting interpretations. Under the differentiation perspective, stories will express and/or resolve contradictions between formal and informal norms, between organizational and subcultural beliefs, and between procedures of different involved groups. Stories can be used to depict organizational subunits as adversaries. A story can become a wholly negative focus and a defense mechanism for resisting change. On the other hand, stories can reflect some of the grounds and conditions under which two subcultures will agree to collaborate (Wilkins, 1984). Inside a particular 
subculture, stories will have a similar effect than under the integrationist view, but at a different level.

\section{(3) Fragmentation}

Under this perspective, stories will reflect confusion and show no consistent patterns of meanings, meanings being mainly contextual, depending upon the actual patterns of connection (issue, teller, audience, and physical conditions) (Martin, 1992). The perspective emphasizes the fact that the same words can mean very different things and have very different consequences depending on the context where they are told (Wilkins, 1983a). Stories will draw attention to contradictions mostly between individual and organizational and/or subcultural beliefs and values. They will also pinpoint issues that are confused, where no agreement seems to exist. Stories can also represent a solution to change an "an unintelligible complexity into a complexity that is more intelligible" (Lucas, 1987, p.152). The fragmentation perspective will also focus on the silence, on what is not said (Martin, 1992). The deconstruction of a story will allow us to read between the lines and find "traces of what has been suppressed by a dominant ideology" (Martin, 1992, p.148). 


\subsection{Organizational Culture and Information Systems}

Despite the importance of organizational culture in theories of organizations and organizational behavior as shown in issues such as the personorganization fit (Chatman, 1989; Caldwell \& O'Reilly, 1990), the financial performance (Denison, 1990), the success of an organization (O'Reilly, 1989; Francis \& Woodcock, 1990), and the choice and orientation of organizational strategies (Lorsch, 1985), little has been said and done to deepen our comprehension of the relationship between organizational culture and information systems. Scholz (1990, p.234), in his essay about the symbolic value of computerized information systems, summarized very well the actual situation:

"Even though there is a lot of literature on various topics in the field of organizational culture and, of course, an overwhelming amount of material on computers, our knowledge of the relationship between organizational culture and computers is still limited."

Some conceptual work has been done trying to investigate and explain this relationship (Morieux \& Sutherland, 1988; Scholz, 1990; Jones, 1991; Robey \& Azevedo, 1994), but very few empirical studies have been attempted. Some exceptions are the studies by Kendall, Buffington, and Kendall (1987) who studied the relationship between organizational subcultures and DSS user satisfaction, the one by Mirvis, Sales, and Hackett (1991) who investigated culture as a factor to be considered during the implementation process and, finally, the ones by Romm, Pliskin, Weber, and Lee (1991) and Pliskin, Romm, Lee, and Weber (1993) who 
used case studies to show the importance of considering the clash (or match) between the culture of an organization and the cultural assumptions embedded within an information system. It is also possible to find in the literature examples of studies where culture was used with other organizational context variables. While all these studies investigate some facets of organizational culture, none of them addresses IS practices such as the ones covered in the present study.

Overall, the work done trying to better understand the importance of culture as a contextual factor surrounding information systems phenomena is still at an embryonic stage. The studies have mostly adopted an integration or a differentiation perspective. The integration perspective has emphasized the fact that information systems are usually designed with the tendency to reflect organization-wide norms and values and to provide management with mechanisms to control and coordinate material and human resources (Walsham, 1993). Under this perspective, information systems capture and reinforce meanings (Orlikowski \& Robey, 1991; Orlikowski, 1992). They help create a common view of the world (Boland, 1979) and foster a common language (Walsham, 1991). Information systems would be seen as having a pacifying effect, softening the boundaries between departments (Galbraith, 1973); they would be designed solely to support official organizational goals, and would help to disseminate "management" values and norms to the entire organization (Borum, 1980). 
The differentiation perspective, on the other hand, would emphasize the divisive tendency of information systems, where the implementation of an information system would lead to power struggles and games (e.g., Grover, Lederer, \& Sabherwal, 1988), to very different subcultures working together (e.g., Newman \& Robey, 1992), to partitioning of efforts (e.g., Franz \& Robey, 1984), to cultural clashes (e.g., Pliskin et al., 1993), and to subcultural differences in the use of a system (e.g., Kendall et al., 1987). Under this perspective, information systems would mainly be the product of the most powerful actors and be used to perpetuate their positions in the organization (management vs. departments, department A vs. department B (e.g., Markus, 1981)), information systems professionals would be considered as a very different and particular subculture (e.g., Kling \& Iacono, 1989), and systems designers would be seen as designing systems in their own image (e.g., Mumford, 1981).

The present study expands on existing work by adding the fragmentation perspective as a fresh look at information system phenomena, but also by using, in the same organization, the three perspectives. This variant to existing studies helps uncover different issues that remain unknown when researchers choose an a priori lens. This use of different perspectives (rational vs. political, for example) has already been shown to be useful to further understand information systems phenomena (for example, Franz \& Robey, 1984). The fragmentation perspective helps connect information systems to the ambiguity that exists in organizations 
surrounding changes, but also responsibilities, organizational goals, needs, priorities, and informal power and control. The use of a fragmentation framework shows that the situation is not as neatly observed, judged, and established as assumed by the integration or differentiation perspective, but that members (at the organizational, subcultural, or individual levels) may agree on some issues and disagree on others. In a software development company, for example, outside events may affect the continuation of a particular development project. In another example, the assignment of a new urgent project could affect the way things are usually done in the organization, deeply disturbing the status quo, and leading to the formation of temporary alliances (existing even across usual subcultures) around this issue. The fragmentation perspective removes the obligation of having to adopt a "black and white" position and lets us acknowledge the importance of ambiguity in an information systems environment.

In summary, this chapter has reviewed the prior literature on organizational culture and stories. Despite the availability of this rich set of perspectives, research in IS has yet to establish strong connections between culture and IS practices. This study has been conceived to provide such an understanding. By focusing on the meaning and functions of stories about IS and by using the three organizational culture perspectives, we can increase our 
understanding and develop a new way to look at the social context surrounding IS activities. 


\section{CHAPTER 3}

\section{METHOD}

The choice of the methodological approach needs to be "contingent on the nature of the phenomena to be studied" (Morgan \& Smircich, 1980, p.499). This study explored empirically (1) the meaning of stories, (2) the specific functions (descriptive, energy controlling, system maintenance, etc.) of stories within their social context and (3) how their contents relate to practices in information systems using three different cultural perspectives. In this regard, the research strategy chosen needs to be congruent with the interpretive stance of a symbolism perspective.

\subsection{Research Design}

A qualitative analysis is the best strategy to tap the rich and full potential of stories in organizations (Morgan et al., 1983). "The complex, intangible, emotional dimensions of organizations probably cannot be processed through the fine filter of linear statistics" (Daft, 1980, p.632). The study of stories must be conducted holistically (Georges, 1969). The task at hand is to identify the stories in ways consistent with local understandings (Bauman, 1986). Because stories are socially constructed, it is important that they be studied in their own context and researchers be in direct contact with the members of the organization (Morgan \& 
Smircich, 1980; Smircich, 1983b). A qualitative approach brings a richness of information not easily obtained with other types of inquiry (Yin, 1989) and is well-suited to capture the complexity of organizational behavior (Hackman, 1985).

More specifically, a single case-study was used as a strategy to investigate the research questions. Cultural phenomena lend themselves to "thick descriptions" (Geertz, 1973) where depth over breadth is privileged, where tight focus is emphasized rather than representativeness (Myerhoff, 1978). "Some researchers give high priority to the principles of prediction, generalizability, causality, and control; while others are concerned by what appear to them to be more fundamental issues of meaning and the processes by which organizational life is possible" (Smircich, 1983a, p.354). The study of symbols is less concerned with prediction "than with understanding, with meaning, with interpretation" (Turner, 1990, p.88). In line with Czarniawska-Joerges (1992), it is better to think of this study as part of a cumulative science where the various elements contribute to a growing understanding of complex organizations. Generalizability to a population is not the goal of this study; the goal is a thorough understanding of the messages and functions of stories in a particular organizational context. Such a deep understanding can contribute to a general theoretical statement about the roles of stories in an information systems context. This is particularly true as the results of a study show that, in a management context, the general themes 
espoused and conveyed through stories are quite similar from one organization to another (Martin et al., 1983).

\subsection{Research Site}

Software Corporation ${ }^{1}$ is a software-development company developing and maintaining systems in the travel industry. Software Corp. has a short but eventful history. The company began as the MIS department of a large organization, became a separate subsidiary, was bought by a third company, suffered from the bankruptcy of its owner, asked for protection under Chapter 11, negotiated a major outsourcing of its operations, and is now going through a massive reengineering effort in order to assure its long-term survival. This study focuses on the stories told by the people in the division responsible for the development of Software Corp.'s software products. This division includes about 200 people and is divided into three departments; one focusing on PC products, one on mainframe products, and one on the administration of contracts with external parties.

1. All names have been changed in order to preserve anonymity. 


\subsection{Selection of Respondents}

It was important to discover and include all relevant groups in the organization, so we could assess the extent to which assumptions and orientations were shared (Wilkins, 1983a). Respondents were chosen using mainly two nonprobability sampling techniques (Bernard, 1988, p.95-98). Quota sampling was used to assure that all subpopulations of interest were represented in the final sampling (which is particularly important in the cases of the differentiation and fragmentation perspectives). For each working group, respondents were selected to represent different genders, races, positions, and levels of experience with the organization. The second technique used was snowball sampling where individuals were asked to participate and to suggest individuals who should be interviewed when considering a certain topic. This last type of sampling helped in identifying subcultures, informal groups, and social networks (Bernard, 1988).

\subsection{Data Collection}

A first important step in data collection was to become familiar with the language and the environment of this particular organization (Bernard, 1988). Cultural phenomena require one to get immersed as much as possible "in the flood of alien cultures in order to grasp the direction of the stream and to feel the temperature of the water" (Czarniawska-Joerges, 1992). In order to do so, general 
interviews were conducted with directors. A lot of free time was left between interviews which gave me the opportunity to spend a lot of time there, to be assigned to an office space, to wander around, to eat there, to read memos and bulletins, and get to know more about the company, their culture and their language which was full of abbreviations and very particular words. It was an ideal way to observe organization members in a variety of situations (staff meetings, planning sessions, interactions with co-workers, coffee breaks and casual conversations) and to better interpret and understand stories. It was also a good way to gather concrete cultural examples and to develop the trust needed to investigate more sensitive areas (Wilkins, 1983a).

The data was collected using the three basic strategies usually used in cultural anthropology: interviews, observation and document analysis (Bernard, 1988).

\section{Interviews}

Thirty-eight formal semi-structured interviews were conducted over a period of four months with members of the Technology division. These were used to identify IS practices, to gather stories, to understand the context of the stories and to confirm story interpretations. Individuals were encouraged to talk about a broad range of topics (what they were currently doing, what their early experience had been with the organization, their role in specific projects, etc.). In 
line with McCracken (1988), I ${ }^{1}$ tried to keep as "low" and unobtrusive a profile as possible and to phrase questions in a general and nondirective manner. Respondents were not asked specifically to "tell stories" about their experience, but, as noted by Schwartzman (1993), many chose this method to illustrate their points. Despite the fact that it is difficult to know a priori the right questions to ask in a particular setting (Schwartzman, 1993) and with a particular individual, an interview guide was developed and loosely used (see Appendix 1). All the interviews were tape-recorded and transcribed for analysis.

\section{Observation}

Direct observations were also made and recorded throughout the data collection phase. These observations were about organization members' habits, behaviors and physical environment such as meetings, day-to-day working environment, president's speech, etc. These observations were mainly used to get to know the organizational context. By being present in the organization for several weeks and by establishing rapport and trust, the problem of people reacting to the researcher's presence should be diminished (Bernard, 1988).

1. Because of the interpretive stance of this study and the acknowledged involvement of the researcher in the research process, the first person pronoun will be used throughout the text. 


\section{Document Analysis}

Many documents were gathered throughout the data collection phase.

Here is a list of these documents:

(1) Organizational chart

(2) Updated organizational chart

(3) List of employees by group

(4) Mission statement card

(5) Many editions of the employees' newsletter

(6) Corporate documents:

- Overview and directions

- Mission and objectives of the organization

- Evolution of Software Corp. and Competitive History

- Business Alliances

- Product overview

(7) Division reorganization memo

(8) Working procedures

(9) Job description

(10) Marketing videos (2)

As in the case of observations, documentation was used to better understand the organization and its culture. 
In addition, observations and documentation were also used to triangulate information. Triangulation, which involves the collection of data on particular issues or phenomena from distinct sources and using particular techniques, was used in order to assess culture and to establish trustworthiness (Lincoln \& Guba, 1985). For example, the survival instinct of the organization is well represented in the aggressive marketing videos the organization has produced. Another example is the way the work is organized (as represented in the organizational chart) and the communication problems and competition it promotes.

In addition to interviews, observations, and documentation, and in order to counteract the fact that the memory is a very poor recording device (Bernard, 1988), field notes were taken anytime something struck my interest during formal and informal interviews and tours. Impressions, perceptions and feelings about people, interviews and events were also gathered in a diary immediately after the event. These personal notes were used in remembering the details and setting of a particular interview.

\subsection{Data Analysis}

The data analysis method adopted in this study was derived from Martin (1992; p.38). My first task was to extract the stories from the transcribed interviews. My original intent was to follow the traditional definition of stories 
as usually used in the management literature (as it was elaborated in section 2.4). To fit that definition, a story would need to be about top management actions, be widely shared, and be used to reflect organization-wide values, norms and priorities. Considering the data I had, this definition seemed to be much too narrow. It was making an abstraction of all events that happened and that were told, for example, by lower level employees in the organization. The "widely shared" concept was also difficult to apply. After examination of the data, I found that, even if the stories were not exactly the same, in many of them, the message was. So, even if the story per se was not shared, the message that the story was telling was. To me, this was very interesting data and it was saying a lot about the culture of the organization. This is why I decided to broaden the definition and include all the stories.

The precise definition of a story used in this study could be stated this way: a "connected discourse" about a specific sequence of events that happened in or to the organization in the past (which can be recent or not). This includes events involving any organizational actors or people related to the organization in some way. While it could contain information that could help in the interpretation of other stories, this definition excludes any story that would involve a single organizational actor in activities outside of work (previous jobs, for example). The stories were extracted sequentially from the written transcripts. They contain specific descriptions of events and actors and may also contain some 
contextual information. The key word here is specific. On many occasions, organization members talked about things that happen in general in the organization, but were not talking about any particular case. These were not considered as stories.

Figure 3.1 shows the form which was used for this data reduction process. Appendix 2 contains the integral text of all stories used (all names and information permitting identification have been changed). Excerpts are used in Chapter 4. Those excerpts have been cleaned up of repetitions, hesitations, etc. to facilitate reading and comprehension. The reader can refer to the appendix for the original text.

FIGURE 3.1

STORY EXTRACTION FORM

Number:

Event:

Story: 
When the extraction was completed, the stories were then interpreted using the matrix in Figure 3.2. Appendix 3 contains the analysis. The objective of this phase was to identify the content themes, functions, and practices relevant to the inventoried stories. The matrix is composed of four elements: story number, content themes, functions, and practices.

\section{(1) Story number}

This column contains the number of the story. This number is sequential and was given as the stories were extracted from the full transcripts.

\section{(2) Content themes}

Content themes is concerned with the general message expressed in the story. As was discussed earlier, a person chooses to tell a story in order to express a particular idea, to make a point. This point or idea is the message of the story. The identification of the theme of each story was used to answer the first research question about the meaning of stories.

\section{(3) Functions}

Functions were identified based on Dandridge and colleagues' (1980) framework (see Table 2.1 and section 2.3) on the functions of stories. However, functions were not restricted to that framework. If no existing function seemed to be appropriate, a new one was added. These functions were then used to 


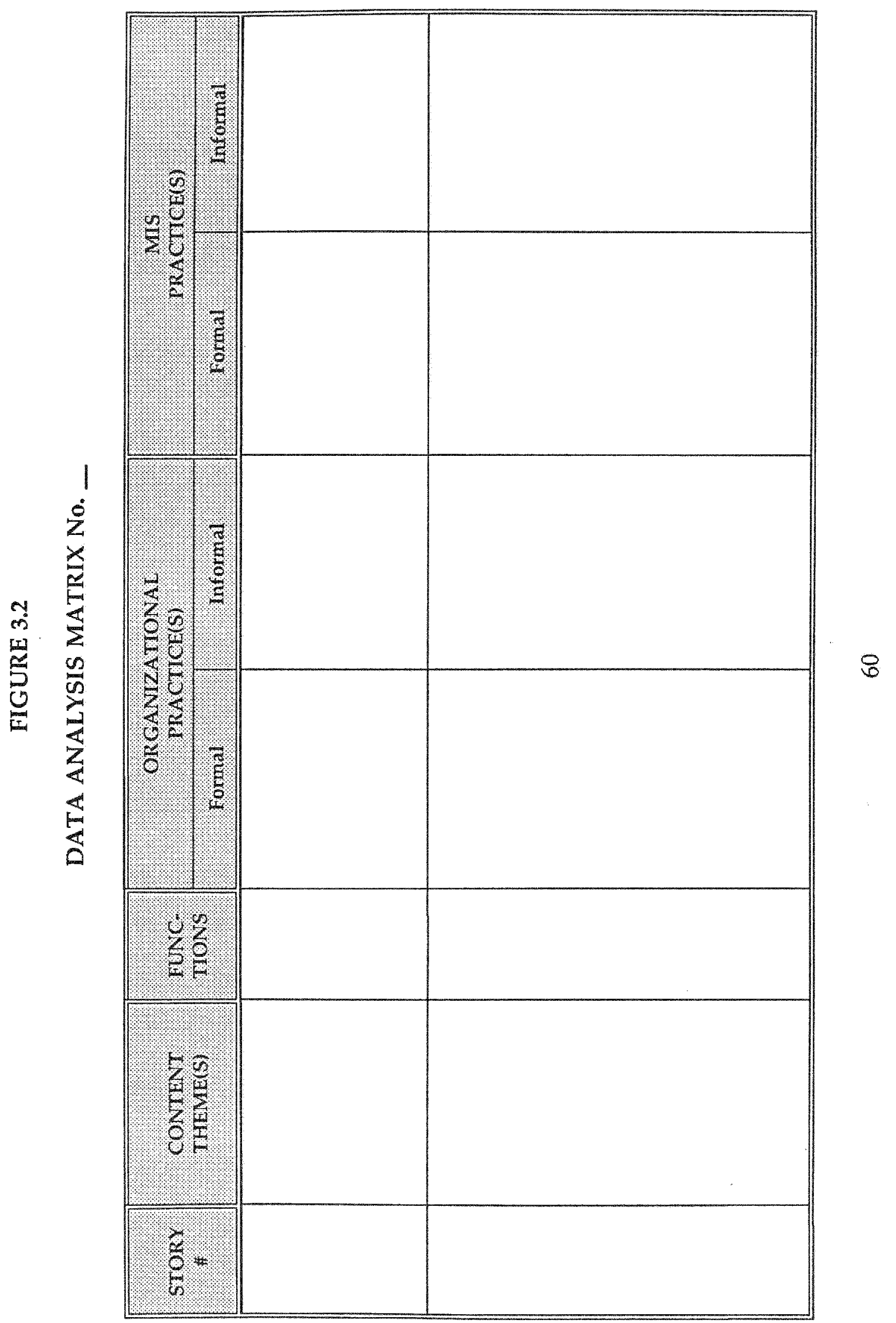


answer the second research question about the functions of stories in their social context.

\section{(4) Practices}

Practices represent the way the stories reflect on the daily activities of the organization. Practices are separated in terms of organizational and MIS and formal and informal. Organizational practices include those practices that can be more directly related to the organization as a whole, whereas MIS practices include those practices more directly related to MIS activities. Formal practices include organization structure, task and job descriptions, rules and procedures, and methodologies, while informal practices include social norms, communication patterns, unwritten expectations, etc. The sixth and seventh columns, "MIS practices", were partially used as a basis to answer the third research question about how stories relate to IS practices.

When these matrices were filled out, I ended up with 35 different content themes. These were too numerous to be useful; as a matter of fact, with so many of them, it was difficult to get a grasp of priorities and repetitions. The idea was to reduce the data to get a more manageable and meaningful number of themes. I therefore made a list of all the themes and looked for similarities. I ended up with nine themes which I called grand themes (no a priori number of themes was determined). The next and final step of data analysis was to use the functions 
and grand themes identified and interpret them using the three cultural perspectives provided by Martin (1992): integration, differentiation, and fragmentation. 


\section{CHAPTER 4}

\section{RESULTS}

This chapter is devoted to a general analysis of the stories gathered. I will first describe the organization and then proceed with the analysis of the stories, first by looking at the themes they convey and then, by investigating the functions they fulfill. The following chapter will then use this first analysis as a basis and use the three organizational culture perspectives, integration, differentiation, and fragmentation, to elaborate on the significance of stories for organizational and MIS practices.

\subsection{Software Corporation: Some Background ${ }^{1}$}

To better understand Software Corp.'s present situation, a little history is necessary (see Figure 4.1). As we will see later, history was shown to be an important factor in understanding the culture of Software Corp. With about 3,000 employees (in 1991), Software Corp. was originally the MIS department of a huge organization, Mother Inc., which evolved in the travel industry. Software Corp. had responsibility for the maintenance and development of all the computerized systems of the organization. Because Mother Inc. was spread out throughout the

1. All corporations' names have been modified. 


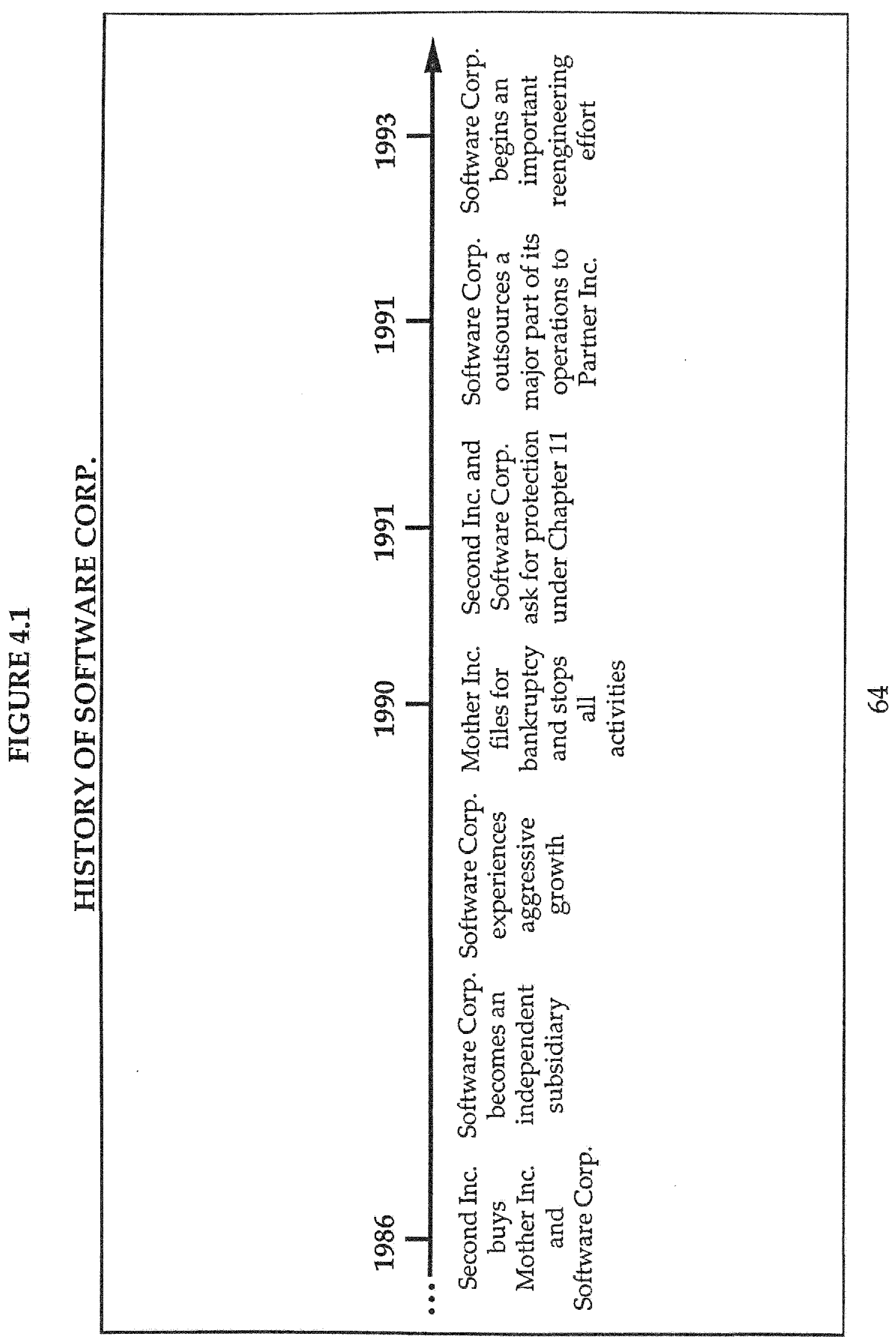


United States, telecommunications maintenance and management were also an important part of its activities.

At the beginning of the ' 80 s, in addition to its MIS services to Mother Inc, Software Corp. started the development and marketing of software products for the travel industry. While Software Corp. remained the fourth player in an important industry, it was able to get an interesting and growing market share. It concentrated its activities in the Southeast U.S. and targeted small businesses often neglected by bigger systems providers.

In 1986, Second Inc. bought Mother Inc. and then Software Corp. In early 1987, Second Inc. made Software Corp. an independent subsidiary and developed a sales force to increase the market share of Software Corp. From 1987 to 1990 , Software Corp. went through a period of aggressive growth. It signed some major strategic foreign alliances. Among these, a major European group made Software Corp, its main software provider and chose Software Corp.'s main product as its technological base. This alliance included a global marketing collaboration and future exchange of technology.

A big event was then going to change Software Corp.'s life forever. In 1990, due to many different factors, Mother Inc. filed for bankruptcy and ceased all activities. In addition to the emotional difficulties related to Mother Inc.'s 
disappearance, it is to be noted here that a major part of Software Corp. was still dependent on Mother Inc. and with its disappearance, a big part of Software Corp.'s business disappeared. This event along with a difficult economic situation forced Second Inc. and Software Corp. to ask for protection under Chapter 11 (bankruptcy).

Second Inc. was able to use Software Corp.'s profitability to get out of this dark hole. Major budget and pay cuts affected Software Corp.'s employees. This was a turning point for the organization. At this moment, the future of Software Corp. was very uncertain; it had no capital to rely on in order to survive and grow. To counteract these problems, in 1991, Software Corp. decided to outsource a major part of its operations to Partner Inc. in a ten-year contractual agreement. Along with 2,000 employees, all the development, telecommunications and mainframe operations were transferred to the outsourcing partner.

In 1993, Software Corp. and Second Inc. emerged from bankruptcy. As of 1994, Software Corp. has a little less than 1,000 employees and is taking care of the design of mainframe products, the design and development of PC products, and the sales and support of these systems to nearly 8,000 clients in 43 countries worldwide. The outsourcing has allowed them to focus their efforts on marketing and PC-based softwares (design and development) and to leave all the technical aspects (telecommunications, operations, and mainframe development) to Partner 
Inc. Software Corp. has no direct involvement in the development and maintenance of the computerized systems of Second Inc. which are taken care of by Partner Inc. In early 1993, in order to attain higher profits, Software Corp. launched a new reengineering project that had as a first objective to review the sales process. As of summer 1994, Software Corp.'s financial situation (which is very much linked to Second Inc.'s own financial situation) seemed better. For the first time in a long time, top management had encouraging predictions for the next financial quarters and the employees' salaries had been restored to their previous levels. New projects were being started and new people hired. The reengineering project was in full bloom and changes were implemented regularly.

The Technology division of Software Corp. was used for the study. The goal of the study is to look at IS activities and this group of people was the one most closely involved with the development of software products. In addition, they were directly affected by all the modern phenomena occurring in organizations today such as reorganization, outsourcing and reengineering in a development environment. This division includes about 200 people and is divided into three departments ${ }^{1}$ (see Figure 4.2): one focusing on PC products, one on mainframe products, and one on the administration of contracts with external parties (e.g. outsourcing partner). Inside the PC products department,

1. This was the organization of the division during the major part of the data collection. At the end of data collection, changes were implemented and the division was hardly recognizable (new departments were added). 


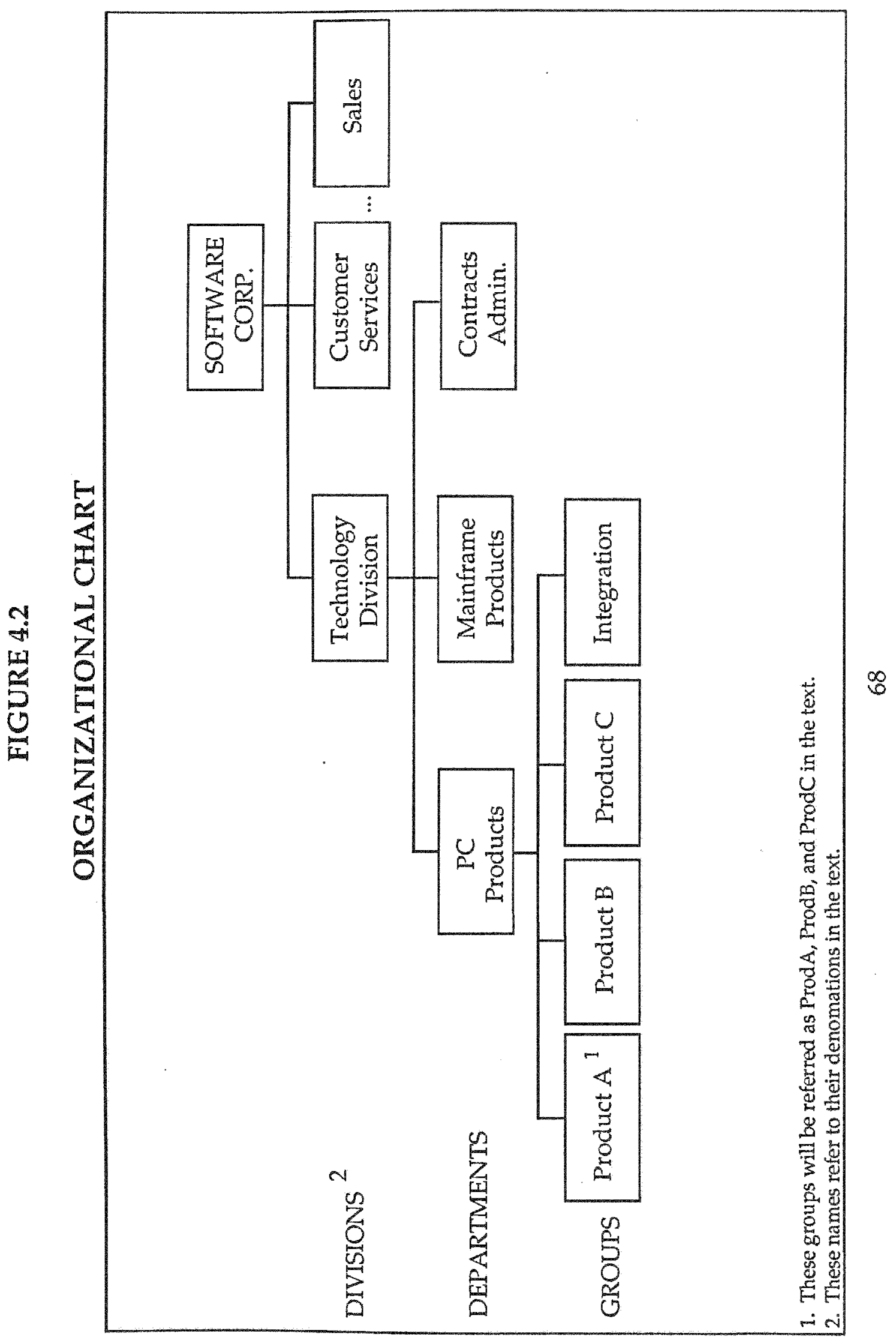


there are four groups mainly grouped by product type (despite its name, one of these groups develops on a mid-range platform). This group is the most important in terms of number and is growing very fast. The mainframe products department is a homogeneous group with responsibility for the design of their mainframe products; the development is done by Partner Inc. There is, therefore, a lot of interaction between the mainframe products department and Partner Inc. Finally, the contract administration department is a small group of five people. They take care of contractual agreements with third parties, including the clauses of the contract signed with Partner Inc.

In sum, Software Corp. has faced many of the challenges faced by U.S. corporations during the past ten years. It has experienced financial problems, and engaged in outsourcing and reengineering to increase its performance. It designs and develops computer-based information systems in a very competitive industry. This background provides the context for interpreting stories and understanding IS practices.

\subsection{Themes}

The strategy for the analysis of the data was to extract the stories and to relate them to themes and functions. Eighty-nine stories were compiled from the 
transcripts. (Appendix 2 contains the full text of each story ${ }^{12}$ ). In accordance with the definition elaborated in Chapter 3 , these stories all include specific historical events (more or less recent) told by organization members (whatever their level in the organization). Some contextual information may have been included in the stories in order to help the reader place the event in its context.

Each story made mention of one specific event that happened in the organization's past. These are listed in table 4.1. We can see in this table that some stories were about isolated events while others (such as the fare war or the transfer of employees to Partner Inc.) led to the telling of many stories. While the events may be different, we will see later that the messages are often the same.

The content themes of each story were then identified as listed in Appendix 3. As discussed in Chapter 3, the content themes refer to the messages expressed in stories. Thirty-five different content themes were identified as listed in the second column of the matrices in Appendix 3. This number is explained by the fact that, while 89 stories were extracted, some stories had the same content theme.

1. To preserve anonymity, the different titles of the respondents were grouped into three categories: managers, analysts, and programmers.

2. Names and other confidential details have been changed to prevent the identification of people. 


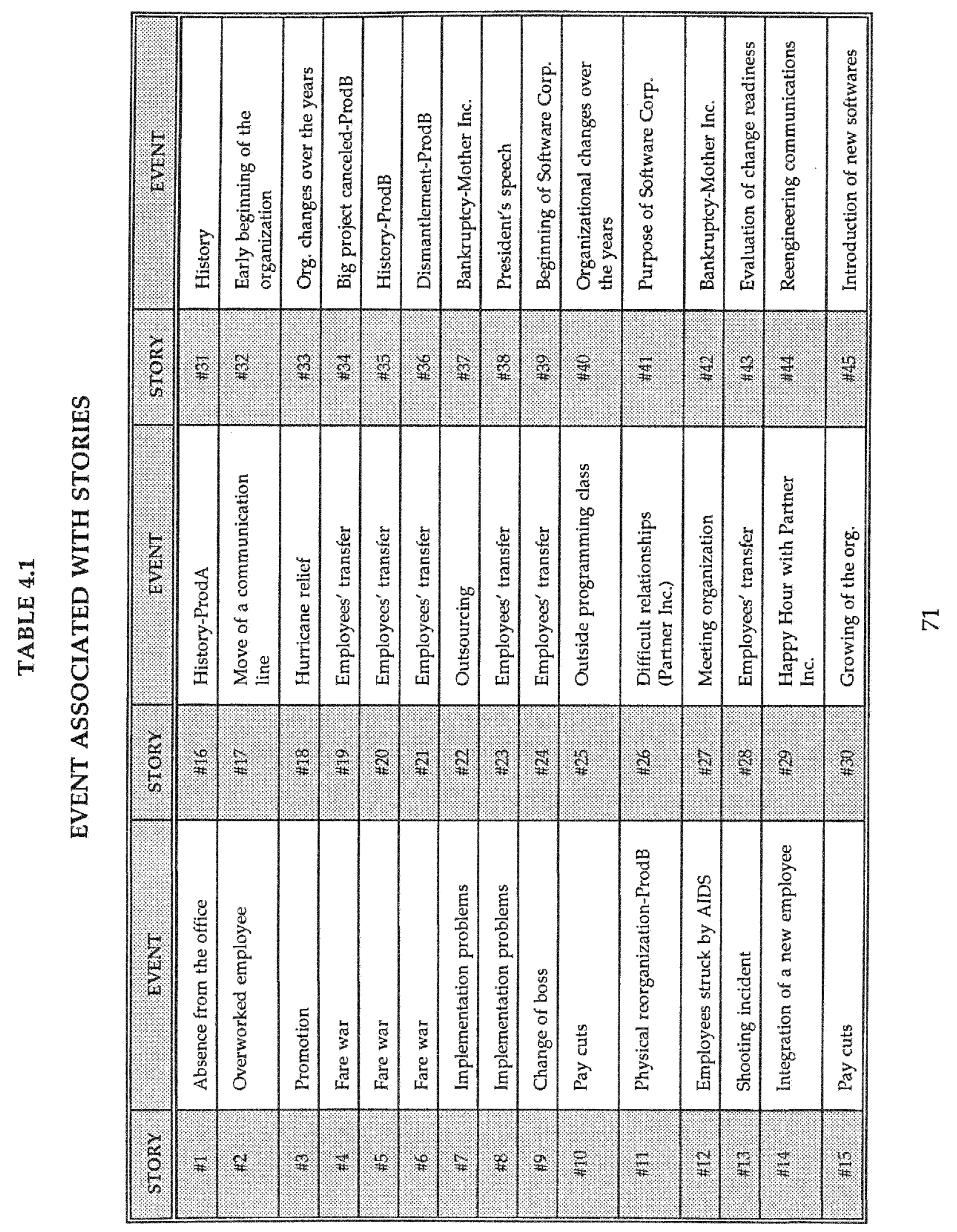




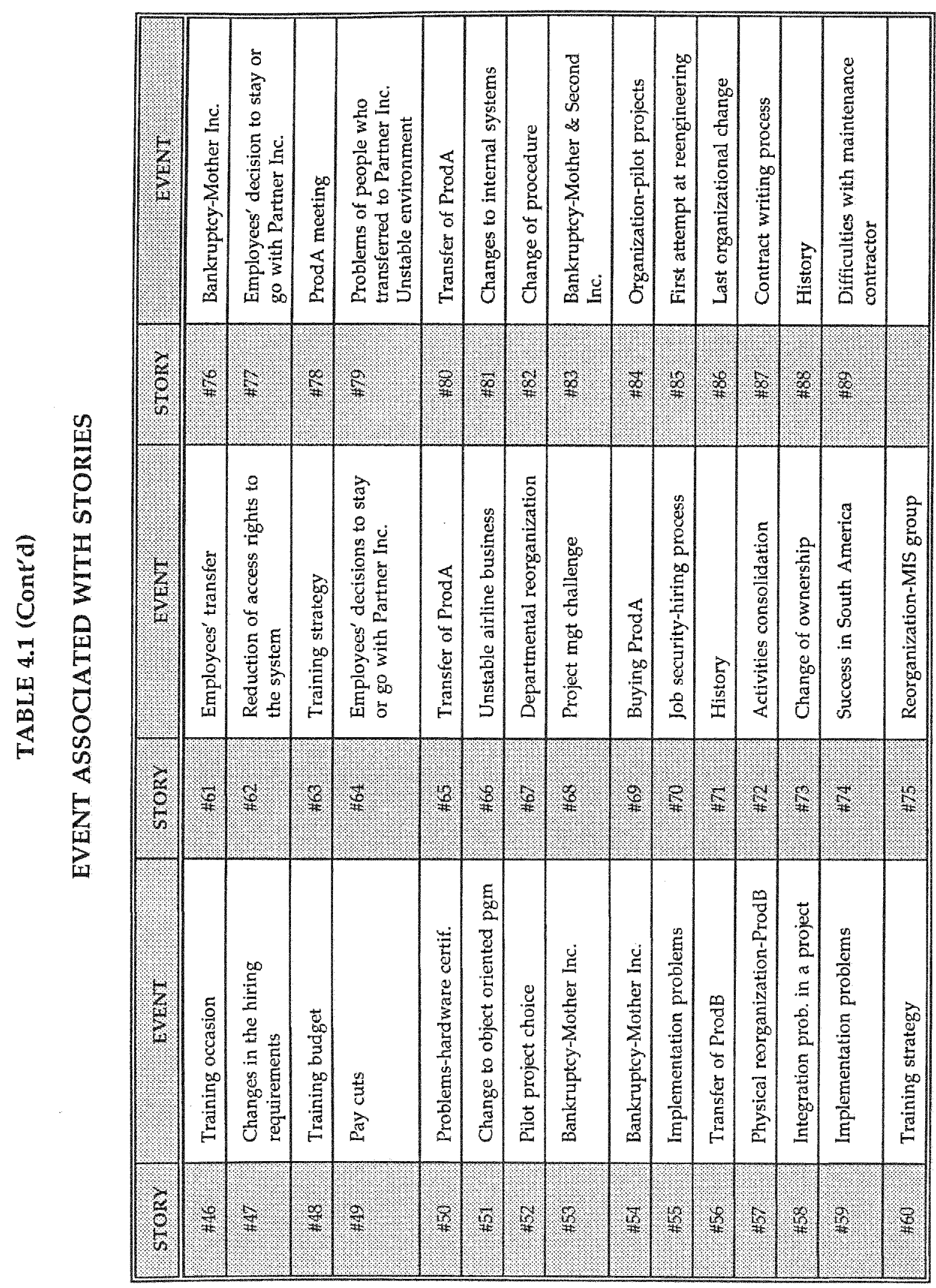


To get to a more manageable and meaningful number of themes, the 35 content themes were grouped based on similarities into nine grand themes. Table 4.2 shows this regrouping of themes.

At this point, six stories were removed from the theme analysis (story nos. $41,57,65,69,71$, and 89). These stories were somewhat isolated and less representative of shared cultural meanings.

Figure 4.3 represents an attempt at showing graphically the relationships between stories and grand themes. Because stories are not directly related to grand themes ${ }^{1}$, the purpose of this map is to present the results of the data aggregation in a concise format (Appendix 3 and Table 4.2). On this map, we can see how the 83 stories are related to the nine different grand themes. Some themes have many stories associated with them, while others only have a few. The themes supported by many stories represent cultural elements that were widely shared throughout the stories gathered. The figure also shows how some stories support more than one theme, although no story supports more than two themes. These common stories show relationships among themes. For example, the themes constant changes and resistance to change share four stories. This means that four stories were addressing those two issues at the same time.

1. Stories are related to content themes and content themes are grouped according to similarity into grand themes. 
TABLE 4.2

RELATIONSHIP BETWEEN GRAND THEMES AND CONTENT THEMES

\begin{tabular}{|c|c|}
\hline CMAND THEME & Contenthemes \\
\hline CONSTANT CHANGES & $\begin{array}{l}\text { - reengineering process (success and } \\
\text { difficulties) } \\
\text { - new working procedures } \\
\text { - resentment }\end{array}$ \\
\hline CHALLENGING WORK & $\begin{array}{l}\text { - } \text { exciting and varied work } \\
\text { - stress } \\
\text { - actualization } \\
\text { - lack of resources } \\
\text { - training issues }\end{array}$ \\
\hline CULTURAL DIFFERENCES & $\begin{array}{l}\text { - culture clash } \\
\text { - Partner Inc. does not keep its promises } \\
\text { - Partner Inc. as a member of cold } \\
\text { corporate America } \\
\text { - not understanding their business } \\
\text { environment } \\
\text { - formalization increase } \\
\text { - negotiations process } \\
\text { - recognize in one occasion as caring } \\
\text { human beings } \\
\text { - outsourcing impacts }\end{array}$ \\
\hline DIFFICULTIES IN WORKING TOGETHER & $\begin{array}{l}\text { - lack of communication } \\
\text { - improved communication } \\
\text { - priorities are different } \\
\text { - dependence/independence } \\
\text { - lack of understanding } \\
\text { - management differences }\end{array}$ \\
\hline
\end{tabular}


TABLE 4.2 (Cont'd)

RELATIONSHIP BETWEEN GRAND THEMES AND CONTENT THEMES

\begin{tabular}{|c|c|}
\hline $\mathrm{GMAND}$ THEME & conten hrentes \\
\hline HUMANIST IMAGE & $\begin{array}{l}\text { difficult split inside the divided } \\
\text { organization (created by the major } \\
\text { outsourcing and the transfer of } \\
\text { employees to Partner Inc.) }\end{array}$ \\
\hline PRIDE & $\begin{array}{l}\text { going far with little resources } \\
\text { - fond memories }\end{array}$ \\
\hline \multicolumn{2}{|l|}{ RESISTANCE TO CHANGE ${ }^{1}$} \\
\hline \multicolumn{2}{|l|}{ SURVIVAL INSTINCT ${ }^{1}$} \\
\hline UNCERTAINTY & $\begin{array}{l}\text { - changes of ownership } \\
\text { - uncertain future } \\
\text { - unstable business environment } \\
\text { - unexpected external demands } \\
\text { - unstable working environment } \\
\text { - "don't worry" attitude } \\
\text { - frustration } \\
\text { - problems with keeping the employees } \\
\text { informed }\end{array}$ \\
\hline
\end{tabular}

1. It can be noted that the two grand themes, resistance to change and survival instinct, have no related content themes. The reason is that those two grand themes were initially two content themes. Because these content themes were repeated through several stories (see Figure 4.3) and, at the same time, not easily related to any other content themes, they became grand themes. 


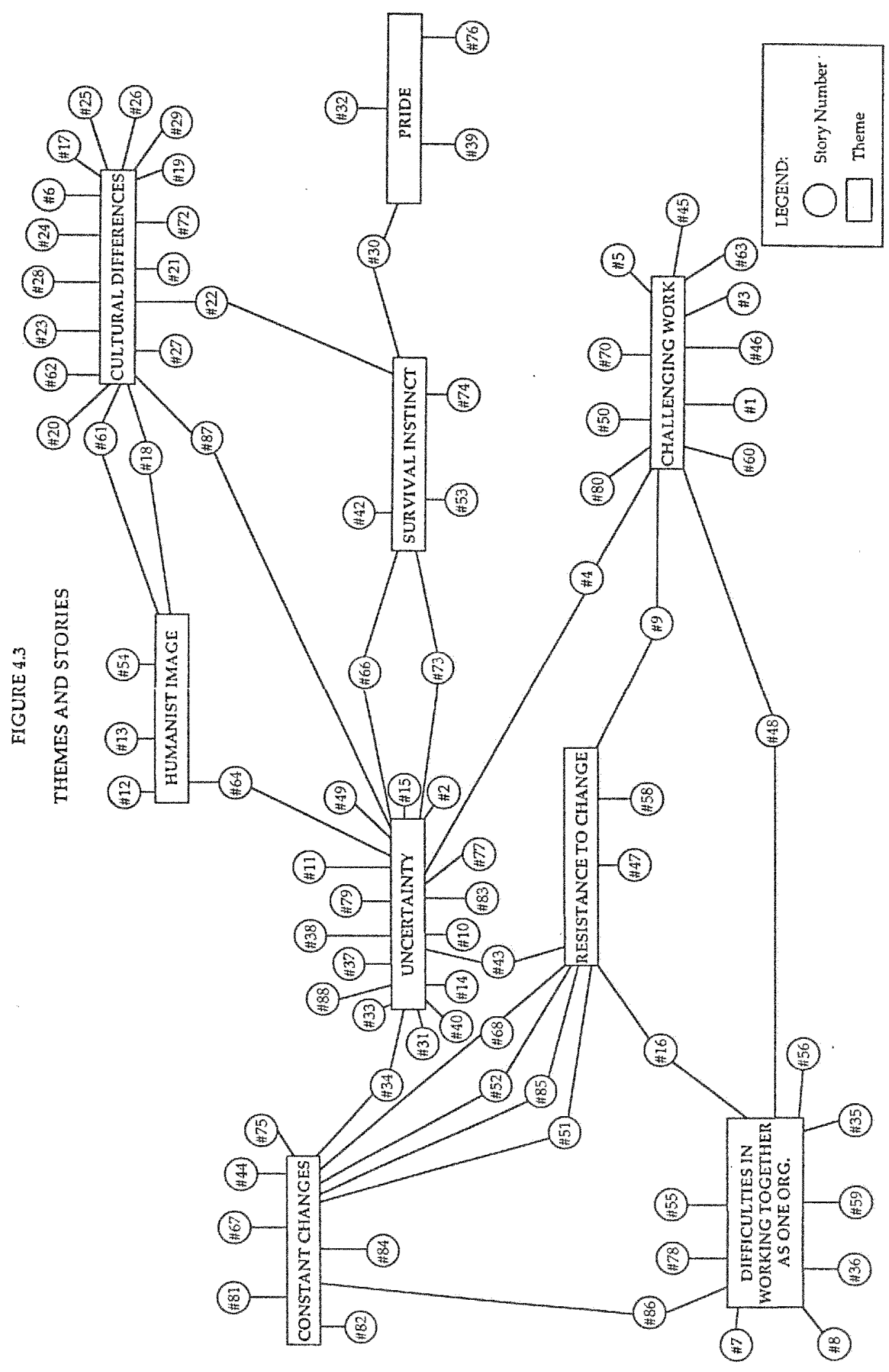

0 
The nine grand themes identified represent important concepts that are widely conveyed and carried out in the organization. The identification of these themes leads to a better understanding of the culture of Software Corp. as they express characteristics, values, priorities, norms, etc. These are the important themes that convey the essence of the organization. The nine themes are now discussed along with illustrative excerpts from the stories '.

\subsubsection{Uncertainty}

Uncertainty is an omnipresent theme at Software Corp. To better understand this uncertainty, we need to understand the historical context of the organization. Despite its short life, Software Corp. has lived through many major changes. Some important ones were the changes of ownership that Software Corp. faced over the years as reported in the following story:

Back in '91, we used to be a part of Mother Inc. The way it happened is when Second Inc. bought Mother Inc, they had [another company], Mother Inc., and they separated Software Corp,, and created a computer division. The computer operation was separated into its own entity. And then we decided to outsource. We gave our host computer mainframe operation to Partner Inc.; they're responsible for operating the big CPUs, the big computers; they're responsible for the telecommunications. (Manager \#31-1; Story \#40)

1. For the sake of readability, only excerpts of stories are reported hereafter. These have been cleaned up; hesitation, repetition, and missing words have been removed or added. The complete text of each story can be found in Appendix 2. 
The unstable business environment Software Corp. evolved in and the repeated bankruptcies of its "parent" companies along with its own protection request in 1991 have left a climate of uncertainty and precariousness surrounding the future of the organization. Employees feel like they do not really know what is going on "at the other level".

But looking at and still, right now, who knows what's going to happen with Software Corp.? And if Software Corp. and Partner Inc. and [a third company] come up with that deal, I have no idea. I just know that something is going on. I don't know what's -there is some deal. (Programmer \#37-2..6; Story \#79)

Even positive news coming from management is interpreted in a "suspicious" way as if the goal was to make the organization look good in order to get a better price on the market. Employees really dread hearing sudden bad news. This attitude can be understood when we realize that the employees heard about what was going on with their organization in the newspaper:

Mother Inc. had never been stable for the past 10, 20 years. But when I started in '87, pretty much all we would hear -- there's a reorganization, there's a layoff, there's all kind of troubles. So, in our mind, we know something is going to happen. Then Mother Inc. went to bankruptcy and there were strikes going on. All the mechanics or flight attendants; they went on strike. All kinds of stuff. So we know that we are in financial trouble, at that time. And, actually, the company didn't let us know, is not telling us -it's on the newspaper. And in the meantime, we know that people are bidding for Software Corp. (Programmer \#21-2; Story \#37)

But uncertainty has always been an integral part of working for Software Corp. The travel industry has always been an unstable business environment, but 
over the years, many employees seem to have developed a "thick skin", a "don't worry" attitude to protect themselves and be able to survive in this type of working environment:

When I started with Mother Inc, I started a month after these cutbacks, because Mother Inc. was teetering on the edge of bankruptcy. And it's been that way just about ever since. Because Mother Inc. went down and went bankrupt, and then Second Inc. just came out of bankruptcy last year, so throughout my career there has been constant rumors of disaster and things like that, and so I've pretty much just learned to ignore all that and get on with my job. [...] And so I don't worry about what goes on at the upper level. I mean, if my job gets to be unpleasant due to all that, then I'll find another job or something. I'm not going to worry about. I can't control it, anyhow, so... (Programmer \#11-4; Story \#83)

In addition to these sources of uncertainty, the organization's internal operations are very much affected by unexpected external demands over which they have no control. This certainly increases the level of stress and uncertainty inside the organization:

Because the way the industry operates is that you're operating at a given level, and all of a sudden that level doubles or triples, based on demand. You know, like an airline goes out and says, "You can fly Miami-London for $\$ 100^{\prime \prime}$-- and the system goes crazy. And the industry in general is not like that. Nobody is going to drink 10 times more Pepsi-Colas; well, in our system, that's the way it is. It's hard to understand it. What happens is the configuration, the installed hardware has to match the highest peak ever you can sustain. So, it's completely different than other industries. Last July was crazy. We almost tripled our normal volume on that week. It's hard to handle this now, then what do you do? How do you meet this demand? There is no way to predict them because it's the airlines that decide to start giving the tickets away. It becomes a fare war... (Manager \#31-12; Story \#6) 
Uncertainty is not only coming from outside sources, but also from inside, which creates a rather unstable working environment. In 1991, Software Corp. decided to outsource a major part of its operations to Partner Inc. This was just one more variable to deal with:

When the contract was signed, it was really Mother Inc. and Second Inc, and Software Corp. The business relationship with Partner Inc. went through many things, especially when Mother Inc. was here in bankruptcy; it changed a lot of stuff. A lot of our people, most of them, the better part of our people, went to Partner Inc., all the telecom people, all the people having to do with host computers. And there was a lot of not knowing in the transition period and so forth, who was going to go end up where. My group might well have ended up there, but it didn't, so... (Manager \#38-3; Story \#87)

At this point in time, some employees were given the choice to stay with the organization or to leave to become Partner Inc.'s employees (as part of the organizational outsourcing). This seems to have been a dramatic event in some people's lives. The overall uncertainty that was prevailing at that moment (story \#79) and general dissatisfaction with the organization seemed to be factors in people's decision to leave:

Our group was given a choice. A lot of Technology went with Partner Inc. Except the analysts, Mainframe Products, but everybody that had to do with programming was going to go with Partner Inc. But because we were not mainframe programmers, we were PC programmers, and Software Corp. wanted to keep our group of programmers, we were given the choice. And at that point, Software Corp. didn't have the best management, in my opinion. So, we had a lot of problems with the way Software Corp. was doing things, the way the departments internally were interacting, the way the products were coming about, so we decided to go with Partner Inc. (Programmer \#37-2...6; Story \#77) 
Mainly because of its young and rocky history, stories show how uncertainty is rather a normal condition at Software Corp. Facing an uncertain future and having difficulties reacting to outside demands, Software Corp. seems to have difficulty controlling its destiny. This has caused, what I call, Software Corp.'s "victim" syndrome. There is in the organization this overall feeling that somebody else is in charge (feeling of powerlessness) and/or that somebody else is guilty (lack of responsibility).

\subsubsection{Humanist Image}

Despite very difficult times (lay-offs, outsourcing, pay cuts, periods of high uncertainty), Software Corp. has managed to keep a humanist image in employees' minds. An example:

We had an unfortunate case here where one of our employees was being stalked by an old boyfriend and she was shot outside and another person was killed. Our President flew in from Houston to come to the one person's funeral and to visit the other person in the hospital. Now to me that means so much because they...it takes a lot for a President of the company in my mind to take the time to do that and to show that they care enough that you are important and they do a lot of that. The President is approachable here and that is not common in most companies. He will come down and say hello to me and ask me how I am doing or tell me that I did a good job on something. (Analyst \#5-10; Story \#13)

Other stories support this caring image.

Last year we went through quite a few employees dying of AIDS and it got rough for some of them financially. When we found out about it, the company would try to help whether it was a bake sale and give them some of the money or in some cases like in my old 
department what we would do is instead of having Christmas gifts is we would find someone who might need help so that instead of exchanging gift we would put $\$ 10.00$ and give them a gift certificate for Publix for food or whatever. So, they do things like that. [...] Companies do certain things and employees do other things. Employees will arrange the bake sale but the company could stop you from doing that because you are using company time and you could be affecting the company's productivity and most of the time they will look the other way. (Analyst \#5-9; Story \#12)

Finally, despite many difficulties, Software Corp. has managed to maintain a caring image in its employees' perceptions. Even despite many layoffs over the years (including the large outsourcing to Partner Inc.), it has succeeded in keeping

a "non-firing" employer image (Story \#54). I have heard Software Corp. employees talking about other employees as friends and members of their families, and about the company as a place where it is nice to go in the morning.

\subsubsection{Pride}

Many employees expressed great pride in working for Software Corp. and in its development over the years. The source of this pride seems to be the modest origins of the organization and the difficult conditions of the early beginning.

When Software Corp. started to build their first PC-based application, they, at least the first group that I ever knew, were in a building that was really - it was like downstairs in a basementlevel type of a thing with no windows, and they were stuck back there. (Manager \#30-10; Story \#39) 
This pride also seems to come from the feeling that, despite many difficulties, the organization has succeeded rather well. Software Corp. has developed and maintained a computerized system with few resources compared to its gigantic competitor (Story \#30). Many employees expressed their belief in the value of their system. This feeling of pride seems to be even stronger among the older employees who once worked for Mother Inc. Its disappearance had not been easy; a few of them expressed fond memories of their earlier days working for Mother Inc.:

Mother Inc. was a wonderful company to work for. It always was. We always had the newest toys in town, so it was easy to stay there. Newest computers and newest something. There was something interesting happening. Mother Inc. going away -- there was a lot grief involved, the people who'd worked there for a long time. You had everything you could -- no one will ever have that good of working conditions again. (Manager \#38-12; Story \#76)

At different levels, most employees seem very proud to be Software Corp. employees. While most are very objective about its weaknesses, most expressed an emotional link with the company.

\subsubsection{Survival Instinct}

All the uncertainty surrounding, first, the disappearance of Mother Inc, and second, the bankruptcy of Second Inc., along with the pride the employees had in the organization generated a very strong survival instinct among Software 
Corp.'s employees. It is obvious that this company would no longer exist were it not for this strong feeling. This need to survive and their success so far seems to be a source of pride:

What happens is that we did not know where we were going to be without Mother Inc. Who was going to provide the capital that we needed to grow? So, we had no capital. Mother Inc. was going under. All we had was liabilities. So, the only thing we had was the organization. (Manager \#31-5; Story \#73)

However, we were successful. We were very successful in the service that we provided to the travel agencies, and we don't have the market share that [our first competitor] has, but at least people thought that when Mother Inc. went under, that we'd disappear, and it hasn't been like that. (Manager \#31-5; Story \#42)

This need to survive was also at the heart of the decision to outsource an important part of their operations:

I think they probably needed it. This is my perception of it. Second Inc. is going bankrupt, and they take from Software Corp., because Software Corp. was making money during all this time, whereas Second Inc. was losing money like crazy. We even had wage cutbacks and everything else, even though this particular company was making money. So, at the time, I think, for us to survive, I think we had to sell part of ourselves to Partner Inc. This was necessary at the time. (Programmer \#11-6; Story \#22)

Despite or because of all that had happened, Software Corp. has managed to keep a fighting instinct. While everything was crumbling around them, they managed to stay alive. They have a rather aggressive strategy and have taken action. They have fixed corporate objectives that were clearly communicated to everybody, have reoriented their system strategy to a more lucrative one that 
expands on their previous system, have signed strategic alliances with outside partners, and have started a reengineering project to review their internal operations. The theme "survival instinct" reflects the belief that employees at Software Corp. definitely want to remain a force to contend with.

\subsubsection{Challenging Work}

Stories also contain information about the work itself. In general, everyone seems to agree that their work is quite challenging; very few people seemed to be bored. Challenge means exciting and varied work:

I've been lucky in being exposed to several previous systems and several environments since I've been working here. The first Product that we were working on was based on OS $/ 2$ platform. Then there was this group in Minnesota that developed a lot of applications and a very, fairly large system based on OS/2 and C. Software Corp. said, "Well, we're going to close that center." So, they asked me if I wanted to go to Minnesota and study the system so that I can bring it over here. I said, "Yes, I will go." It was a great experience, a lot of learning. And then we moved the system back down here, and so since then I've been part of this group. (Programmer \#37-2..6; Story \#80)

Challenge also means difficult (story \#50) and stressful work sometimes:

When we had the last big fare war last July, none of the computer companies anticipated the hits to the system that happened. We were working all sorts of hours because you would take the resources from one computer to take care of something else and that made something else not work. We put in what we called the war room. It was literally a war room. So, what you try to do is let me take something off-line that will give you some more resources. So, you sit here and have to decide what program to pull. Then you 
have to run around and...from your area I want to pull these three programs, is that going to cause you a problem? So, you negotiate that. [...] So, it becomes bedlam. We thrive on that though. We must thrive on the stress otherwise we wouldn't still be here. (Analyst \#5-7; Story \#4)

The fare wars that happened sporadically also took away computer resources from Software Corp.'s staff. As one respondent was mentioning, her due date was not changed despite the fact that computers were taken away for two or three days (story \#5). A lack of adequate equipment is a source of high frustration.

In an always evolving work environment, training is also at the heart of people's preoccupations. Some believe that they can actualize their knowledge and that the company is conscious of the training they need to receive to accomplish their work:

So, that's another very good thing about this particular group. I don't know if that applies for the whole organization, but they're interested in actualizing what you want to do, which, you know, it's very difficult to make that happen, because we have such a work load, but they do try to do that. And I also appreciate that. It's difficult, but it does happen. I'm learning, with their help, like, the last year I went to an electronic class in relation to power that supplies computers. That's a fantastic class. I know more about power problems with computers than probably most people in Florida do. So, it does happen. It's just difficult, but it does happen. (Programmer \#11-13; Story \#46)

Other employees, however, seem to be a little frustrated about the lack of training: 
What I would like is to get more training than we get. A while back they put Wordperfect on our PCs and they took away Display Write 4, but nobody bothered to train us on Wordperfect. So, here you are with this software that could probably do everything plus what Display Write 4 could do, but we don't know how to use it. I wish they wouldn't give me something that they are not going to teach me how to use. (Analyst \#8-6; Story \#45)

Because of its need to remain on the cutting edge of technological developments, Software Corp.'s employees constantly need to stay up-to-date. This is particularly true of the PC products department where everything is evolving so fast. Expectations of new employees are high. People are hired with a master's degree (if possible), receive minimal job introduction, and are expected to be smart and resourceful and learn on the spot. Any factor which eases the process such as training (one formal class per person per year) and resources acquisition (such as new and more powerful computers) becomes very important. External demands also put some pressure on internal activities and increase the challenge of some people's jobs. Finally, we will see in the next section that the difficulties groups have working together also increase the challenge of working at Software Corp.

\subsubsection{Difficulties in Working Together as a Cohesive Organization}

Another common message in many stories is the differences among organizational subunits (see organizational chart, Figure 4.2). If we look first at 
the departmental level, a lack of communication seems to be pervasive. This story told by an analyst is a good example of this widespread theme:

Well, just recently a project was loaded on-line and ProdA didn't know anything about it and it was corporate accounts...programs like that completely blew them out of the water. So, it can cause big problems. One time we had a little space...again it was ProdA. When they went to test it they didn't know...the document was different than what we were actually getting. So, when the service bureau coded...it got something back with an extra space in it and they couldn't end any records. A little space sounds little but if someone is editing this entry not to have a space and all of a sudden one is there it can cause big problems. It is hard sometimes because we don't really know what they check for. We are learning as we run into problems. (Analyst \#8-6/7; Story \#8)

Rather than an absence of good will, the problem seems to be the inadequate mechanisms of communication among the different groups:

Well, if they make changes to what they're putting in that interface record, if our program isn't changed, then, you know, nothing happens. It's quite embarrassing actually, so we had to get them to back off installing their changes until we could get our programming done. We didn't know. (Analyst \#32-11; Story \#59)

Despite many examples of these lacks of communication which cause embarrassing problems with clients, most employees feel that the situation is getting better. For example, the organization used to run and manage separate systems across the country. The physical distance increased communication problems. Over the past few years, top management has decided to centralize these systems and has moved them to the central office in Florida. This has improved communication among certain groups (see also story \#55). 
They didn't know what we did out in California. They had no idea of what were doing or what we were like. What they understood was some of their big clients calling up and yelling because all of a sudden they couldn't do their back office work. But that has gotten a lot better. (Analyst \#32-11; Story \#59)

Despite limiting the physical distance and making other improvements, the communication problems are not totally solved. "We are getting better that way but it takes some problems before everyone woke up and started to make it better" (Analyst \#8-6; Story \#7).

There seems to be little interaction between groups because of the nature of their work; they work on different platforms, products, systems and softwares, and have different priorities (Story \#59).

We don't even know who they are [other groups in the organization, in their own division]. We don't even know what their project looks like. We've been asking for two years, for a demo of what Product looks like, and most of us just don't ever see them. Like, there is no interaction between the groups. Zero. And that's a shame, because there's very interesting thing happening, but there is no interaction. And management has never made any attempt at all to really promote any kind of interaction. They've really missed a bet on that, I think. (Analyst \#32-11; Story \#55)

If differences and communication are difficult to manage among groups in the same division, inter-divisional communication also seems to be problematic. One often cited cause is the number of parties that must be involved (dependency) before a project can be completed. "We are not in control of our destiny; we have to interact with four thousand other departments" (Analyst \#32- 
3; Story \#56). While some groups (such as ProdB) are more technologically independent than others, they still have to interact with other divisions (such as documentation, customer services, etc.) to get a product out the door (Story \#36). The multitude of people involved makes it difficult to get adequate feedback and input at the right time. Because of its ultra specialization, the organizational structure is not conducive to close relationships. They hope that the new "team approach" to software development being implemented is a possible alternative to this lack of collaboration.

The differences in expertise in the various divisions also increases the difficulty of working together. The lack of understanding of organizational challenges by less "technically" oriented divisions was also pinpointed as an issue faced by the Technology division.

Other groups in the company haven't been as good about foreseeing what knowledge level was going to be required. So, there hasn't been money budgeted for all of the training that needs to occur in '94 and that's becoming a problem as well as upgrading the workstations that they use to have Windows. All of that is necessary and that's a huge financial expense that the company is going through now within the customer support group. And the lack of skills toward this project is immense. With the group that has to be involved with it. It is causing problems in that understanding what it is were building here, not truly understanding what this thing is that we're all working towards, which makes it difficult. (Analyst \#18-12; Story \#48)

Software Corp. suffers from poor communication and collaboration among groups. Many factors can be cited to explain this phenomenon: the nature of 
their work (different platforms and softwares), their knowledge level, their workload, and their ignorance of what other groups are doing (one person said that she did not have the time to read all the memos that were crossing her desk; inefficient communication mechanisms), In addition, limited resources have also increased the level of competition in the organization; this has a direct impact on one's willingness to communicate and collaborate with other groups. Even management differences from one group to the other (attendance, lunch time, etc.) are a source of friction among groups (story \#16). As one person was saying, "When you don't have money, stupid things become important like the size of your office, whether you have a window or not, whether you have a decent parking spot or not, what your title is and all of those things that shouldn't make a difference" (Analyst \#5-11; Story \#49).

\subsubsection{Culture Clash}

The outsourcing episode that happened in 1991 had a major impact on the organization. About 2,000 employees and an important part of Software Corp.'s operations were outsourced to Partner Inc. This event and its repercussions are still very alive in people's minds as witnessed by the stories told.

In addition to the high level of uncertainty surrounding the whole process, the split itself was a difficult event. For a period of time, the employees who 
transferred to Partner Inc. and the ones who stayed with Software Corp. all worked in the same building. Story $\# 61$ tells how friends who had been transferred to Partner Inc. were abruptly terminated, escorted to their cubicles, and followed to the door. These seemed to be particularly difficult times to live through,

Stories contain many facets of life with the outsourcing partner. An important one is surely the differences in culture between the two partners which they had to deal with on a daily basis. Stories were, for example, relating the difficulty some Software Corp. people had adapting to their new work environment (Story \#19). Belonging to a different organization has, of course, changed the relationships among working groups (the majority of the people they work with at Partner Inc. are former Software Corp.'s employees). These changes are attributed to the new management and Partner Inc.'s organizational philosophy (see also story \#22):

... before they were Software Corp. And before that we were all working together. When they went to Partner Inc, and we stay at Software Corp., the same people that used to deal with us created some... or the philosophy of the company over there or Software Corp., I don't know, but you can feel some friction between the same people we used to work together all the time. It used to be very collaborative and not anymore. Even though we get things solved, you can feel the friction. I believe it's Partner Inc. management. Now they're all quarreling themselves. They want everything in writing, they want this and this, they want... If you say something, they won't take your word, they want it in writing. That's the way it is now. I don't know why. It wasn't like that before. (Analyst \#19-3; Story \#26) 
Even though Partner Inc. ensured Software Corp.'s survival, it seems to play the role of the "bad" guy. Partner Inc. is a big organization and is often portrayed as a representative of "cold corporate America" (or "a bottom line company" (Analyst \#5)).

To tell you the truth, I wanted to go there. But I'm glad I didn't. Because of the philosophy they had, the management style, you know, the restrictions they impose on their people. I think it's like an old philosophy, they're very strict. I don't think they treat them like professionals. (Analyst \#19-3; Story \#28)

This previous story also refers to personal things (such as pictures) and a strict dress code which seem to be important rules at Partner Inc. Partner Inc. management made ex-Software Corp. employees take all their posters and pictures down and enforced a dress code that specified "on a man's shirt how far apart your stripes can be" (Programmer \#13-5; Story \#24). Software Corp. people don't miss an opportunity to express how silly and unimportant these things are. "I think that Partner Inc. puts the emphasis on the wrong thing" (Programmer \#13-6; Story \#25).

Stories also contain other illustrations of the "bad guy" image. One running theme is that Partner Inc. is a liar and has not kept its promises. When employees were transferred to Partner Inc, many promises were made. For example, benefits were promised that were not fully realized according to exPartner Inc. employees (Story \#23). 
Partner Inc.'s people are also criticized for their lack of understanding of Software Corp.'s business environment. This situation, according to Software Corp. employees, causes friction and more work for them. Because of the large involvement of Partner Inc. in Software Corp.'s activities, they are always directly or indirectly involved.

I was told that Partner Inc. told them (an hotel company) that they had to move a telephone line and they wanted to cut the line over during the middle of the afternoon, which shuts down my operations to that person. Well, that is not what I want. [It] is not smart from a customer service point of view. So, there are issues that they don't always think of the implications to us [before] they are doing something. There are degrees of inconvenience. This happens to be major. We are talking about big money. (Analyst \#55; Story \#17)

Everybody seems to agree that working with Partner Inc. has increased the formalization and meant delays in getting the work done ("red tape"). For example:

It's totally two different companies, so we really can't tell them what to do. So, everything else is just schedule. Right now, we're having a meeting, actually, next week. I've been told we needed a meeting to get some things organized, that if a person is down, especially a contractor, I can't wait all day for Partner Inc. to come by in the afternoon. The contractor is getting paid $\$ 50$ or $\$ 60$ an hour to sit there. That's not right. So, I'm getting a meeting put together for next week. But overall for the guys I've worked with at Partner Inc. have been fine. (Programmer \#20-9; Story \#27)

However, increased formalization has also brought some advantages. For example, in story \#20, a Software Corp. employee explains how having a written 
record on file of all conversations and work provides a better audit trail in case of problems.

These stories show us that a close outsourcing partnership entails a long period of adaptation and negotiation. While this partnership is three years old, important issues and cultural clashes are still very much present. As shown, each organization's ways of doing things, of prioritizing issues, of understanding each other's business may become important points of disagreement that need to be resolved. The outsourcing partner may become, as we have seen, an easy target for criticism. This important theme reflects how Software Corp. employees perceive Partner Inc.'s people and how this perception influences the daily interactions between the two.

\subsubsection{Constant Changes}

Another topic is at the heart of Software Corp.'s stories. Just out of bankruptcy and with 2,000 fewer employees, Software Corp. needed to re-think its internal operations. For more than two years now and following the American frenzy, Software Corp. is going through a reengineering process. The process does not seem to be easy. Many people seem to be not very interested, nor informed about what is going on, while others have been told that they were 
"saved" from the reengineering effort. For those who participated, the process seemed to be quite difficult:

Some things were done strangely. They identified all the work loads and so forth, and made a series of recommendations. The way they do the reengineering, usually, at least the way Partner Inc. did it [who was leading the project], it's very interesting, and you become ostracized if you point out any practical imperfections in these things. You're encouraged to participate, but only positively. (Manager \#38-7; Story \#85)

However, more positive sentiments were also expressed in some stories:

I did presentations on the billing system and how certain projects or processes could be modified to get a greater return and the amount expended on these projects was not going to be all that great for the return. The return was like one year, return on investment. And these particular projects were given a higher priority. So, I did see something come out of reengineering. (Analyst \#34-8; Story \#81)

Despite many procedures to try to keep the employees informed such as

a Hot Line, e-mail messages and memos, changes surprised a few employees.

Reengineering hasn't hit me personally yet, or directly. But one thing that -- it had to be attributed to reengineering -- is that I come in one day and I find out about this change in one group. It was known as Integration. I don't even know what it's known as anymore, but I come in one day and someone says, "Oh. This group is no longer under person $X$ and is now under person $Y$," and I do not really know who this person $Y$ is, someone on the third floor. And I said, "Well, when does it take effect," and they said, "Immediately." And I couldn't believe it. (Analyst \#33-6; Story \#67) 
What is most surprising is that this analyst did not know that this change had nothing to do with the recommendations of the reengineering committee. It was initiated by top management. This is further evidence that management is not sharing information and that the employees do not really know what is going on.

Throughout the years, Software Corp. has implemented new working procedures at different levels to improve productivity and product quality. Stories around those changes are common place. For example, story \#61 describes how the MIS group successfully implemented a new procedure to manage and follow user requests for changes on their internal system. Story \#84 also describes a change in working procedures. It tells how Software Corp. set up pilot projects to test a new team approach to software development in order to promote collaboration and, hopefully, reduce time.

Although employees in some organizations think it takes a miracle to implement changes, I did not feel this was the case at Software Corp. Software Corp. employees had experienced constant changes and did not know what would happen next. So many things happened in this organization over a short period of time and so much is happening right now, that employees seem to think that nothing is impossible. While changes encounter some natural 
resistance (as will be discussed in the next section), employees expect changes in the organization.

\subsubsection{Resistance to Change}

In many of the stories reported above, resistance to change is an everpresent theme. Because it is fundamental to the success of the reengineering process, it is talked about in several stories.

They did a change management study. We have contracted Company $X$ to help us in change management, because they've been through reengineering and they've got lots of experience, and the survey says that we've got both sides of the spectrum. A lot of people, they think, can manage change very good, and there's a lot of people that get schizo about change. But, we're somewhere in the middle. On an average, we're in the middle, like most companies who are going through a big change. (Manager \#25-11; Story \#43)

I think people would be willing to change as long as things don't get crazy with Second Inc. I mean, a couple of years ago, Second Inc. came out of bankruptcy, and people had their salaries frozen. Not frozen, they had to take a reduction, and there's no equity. Our president came last week, and things are looking very up and very positive, and we're going to get all the reinstatements of money you lost and for the increases. I think, if that stays up, then it's fine. Then people would be willing to change, but I think if that doesn't, if that's a really short-term thing and then all of a sudden the rug is pulled back under you, then I think it's going to be difficult to keep the change and be really positive. (Manager \#25-11; Story \#43)

According to this manager, uncertainty about the future of the organization is an important factor in the capacity of people to accept changes inside the organization. While the future seems brighter, past events are still remembered, 
and I have heard many people say cautiously, "we'll see". As was discussed earlier, many things have happened to this company over a short period of time. Living in an environment of constant change is not comfortable. To cope with this, employees were making a lot of rationalizations about what had happened, what is happening, and what will happen. This is particularly true regarding the future of the organization and the reengineering recommendations. I believe these rationalizations make this environment more bearable for people who look at changes with some degree of anxiety.

The nine themes identified - uncertainty, humanist image, pride, survival instinct, difficulties in working together as a cohesive organization, challenging work, culture clash, constant changes, resistance to change -- represent and describe important dimensions at the heart of the organization's actions, behaviors, and decisions. In Chapter 5, these themes will be used as the basis for an analysis using the three cultural perspectives -- integration, differentiation, and fragmentation. The next section inventories the functions assigned to stories and gives excerpts illustrating each of them.

\subsection{Functions of Stories.}

After the identification of the content themes of each story, functions were assigned using a functionalist approach. This approach ascribes a purpose to the 
act of performing a story. A story can play multiple roles and one role can be played by many stories. The following table (Table 4.3 ) lists the functions that were assigned, the total number of stories assigned to each function and, finally, the number of those stories.

The first three groups of functions, Descriptive, Energy Controlling and System Maintenance, were identified in the Dandridge et al. (1980) framework (Table 2.1). First, it is to be noted that Dandridge et al. (1980) did not provide very precise definitions of their functions. I therefore elaborated more precise definitions, which are given in the next section.

Second, Dandridge and colleagues' functions were not rich or complete enough to describe the variety of functions that my stories seemed to carry. Their functions are very much based on an integration perspective of culture and symbolism in the organization and do not include other aspects. In order to provide a more complete and precise picture, I needed to add additional functions. Following is a brief definition of each function along with excerpts from stories that illustrate each of them. 
TABLE 4.3

STORIES BY FUNCTION

\begin{tabular}{|c|c|c|c|c|}
\hline \multicolumn{3}{|r|}{ Frorion } & \% & stories Nimberts) \\
\hline \multicolumn{3}{|c|}{ (A) Descriptive } & 15 & $\begin{array}{l}4-31-32-33-39-40-41-53-69-71-72-77-81- \\
84-86\end{array}$ \\
\hline \multirow{2}{*}{\multicolumn{3}{|c|}{$\begin{array}{l}\text { (B) Energy Controlling: } \\
\text { (1) Increasing tension }\end{array}$}} & & \\
\hline & & & 11 & $14-15-23-26-29-34-44-45-49-57-62$ \\
\hline & (2) & Inspiring & 7 & $3-16-18-21-28-70-76$ \\
\hline & (3) & Attracting & 4 & $13-25-46-79$ \\
\hline & (4) & Repelling & 6 & $7-11-55-61-70-75$ \\
\hline & (5) & $\begin{array}{l}\text { Facilitating re-experience of } \\
\text { previous state }\end{array}$ & 0 & \\
\hline & (6) & Decreasing tension; cathartic & 1 & 30 \\
\hline \multirow[t]{6}{*}{ (C) } & \multicolumn{2}{|c|}{ System Maintenance: } & & \\
\hline & & $\begin{array}{l}\text { Giving "reason"; justifying; } \\
\text { explain actual state }\end{array}$ & 14 & $\begin{array}{l}17-22-24-26-28-35-36-54-68-75-79-82-87- \\
89\end{array}$ \\
\hline & (2) & $\begin{array}{l}\text { Providing coherence, order and } \\
\text { stability }\end{array}$ & 10 & $10-20-38-43-54-58-65-66-83-86$ \\
\hline & (3) & Differentiating & 12 & $17-22-24-25-26-28-29-35-59-61-78-79$ \\
\hline & (4) & Integrating & 4 & $12-18-27-36$ \\
\hline & (5) & $\begin{array}{l}\text { Providing or guiding acceptable } \\
\text { patterns for change }\end{array}$ & 1 & 70 \\
\hline (D) & \multicolumn{2}{|c|}{ Reflective } & 32 & $\begin{array}{l}1-9-11-12-13-14-19-20-21-23-27-30-34- \\
37-45-49-54-58-60-63-64-65-66-67-68-75- \\
76-79-82-85-87-88\end{array}$ \\
\hline (E) & \multicolumn{2}{|c|}{ Self-promotion } & 14 & $1-3-16-30-42-47-48-51-52-53-56-71-73-74$ \\
\hline (F) & \multicolumn{2}{|c|}{ Assigning blame } & 6 & $7-8-48-50-55-56$ \\
\hline (G) & \multicolumn{2}{|c|}{ Problem identification } & 17 & $\begin{array}{l}2-5-6-8-11-14-37-43-44-45-56-57-58-59 \\
62-67-85\end{array}$ \\
\hline (H) & \multicolumn{2}{|c|}{ Showing contentment } & 10 & $3-13-21-27-38-46-63-77-80-81$ \\
\hline
\end{tabular}

(a) These numbers are presented to give a general idea of what was found in the 89 stories. They do not represent any generalizable proportion or show any order of importance. 


\section{(A) Descriptive}

The purpose of a descriptive story is to recollect simple, neutral, rational past events. There is no attempt to provide anything but a description, i.e. to specify some "facts" 1 . Here are two examples of this type of story:

Software Corp., at the time, was a spin-off of what was then the Mother Inc. Computer Center. We had some three thousand employees at the time in the computer center and we also had what is called the Product Development Group. That was transitioned also with the computer center to become Software Corp. somewhere in 1986. This was then sold to Second Inc. and later sold to Second Inc.'s affiliate and then the rest is history. Then the transition to Partner Inc....this was in May of 1991 when there was this transition or outsourcing to Partner Inc. (Manager \#7-4; Story \#31)

Two gentlemen had a company called [Company $\mathrm{M}$ ] and it was a really good company. They did a lot of airline services, and Software Corp. bought them out. So, they said, "Hey, this is really good," and I guess they offered them an amount these guys couldn't refuse, so they said, "Sure,". Five years. Five years, it was up in Minnesota, but as a Software Corp. operation. (Analyst \#33-4; Story \#69)

\section{(B) Energy controlling}

The purpose of these stories is to influence someone's feelings or thoughts in a particular direction.

1. The word "facts" is in quotation marks here because, as briefly discussed before, the idea is not to verify the existence and details of events. I consider the stories as facts as long as the respondent considers them factual. 


\section{(B.1) Increasing tension}

This type of story consists of events related to a difficult situation. Talking about those events seems to increase the level of animosity towards the situation or the people related to the episode and, at the same time, to encourage the listener(s) to share the same point of view.

In the first story, the issue of animosity and frustration between old and new employees is apparent. The organization's difficult financial situation explains those feelings. The teller was very involved in the story; his tone and gestures were fiery and he was looking for approbation.

When I first came in, I sensed a lot of resentment from the people in my area, because some of the people that were working in my area came from Customer Service, so they have already been with Software Corp. for, like, about five years. And they saw myself coming in, an outsider. They assumed that I was probably getting paid more than they were -- because they made those comments every once in a while -- and the sense of trying to help me out if I had some sort of problems or whatever, I didn't find that that was there. I found that it was sort of like, "You're going to have to sink or swim on your own." (Analyst \#28-6; Story \#14)

In this second story, one can feel the teller's tension surrounding the transfer of employees when the outsourcing contract was signed. Despite the fact that this contract came into effect in 1991, the tension is still very present in the organization, probably because they have to deal with the outsourcing organization every day. The teller uses words and expressions such as "pissed", 
"break us in", "crap", "lied" and "bunch of weasels" to describe his feelings. He wants to convince me by giving many examples.

I was pretty pissed [when my job was transferred to Partner Inc.]. I think everybody was. We didn't volunteer for it. We had, you know, hired ourselves out to Software Corp., or to Mother Inc. or wherever we started, and suddenly, we were told you either lose your job or your sign on with Partner Inc. You had no choice. That was it. They gave us a lot of warning, like a year or something. They kept talking about. Partner Inc. was going to buy us out, so there were rumors for a long time. And then they slowly broke us in. They took us over to the golf place across the street? They had a big film and explained what Partner Inc. was and told us all the great benefits we were going to have and all that kind of stuff. So, they tried to break us in -- and they told us -- they gave us a bunch of promises and crap that didn't turn out. Most of them [people who were transferred and are still there] feel like they don't like, particularly like Partner Inc. either. I think most of them feel like - for instance, some of the benefits are not as good. They promised, like, the benefits were going to be so great and all that stuff. And actually, the benefits are not as good as Software Corp. benefits. So, they made these huge promises to us and basically, they lied. I think they're a bunch of weasels, if you ask me. (Programmer \#11-6; Story \#23)

\section{(B.2) Inspiring}

A story is inspiring if it specifies events that have led to positive outcomes and/or behaviors and if the teller openly encourages its repetition.

In this first story, the teller talks about the origin of new working procedures, how they were enthusiastically adopted in his department and how they stuck together to keep them alive. If he had his way, the whole organization would follow this philosophy. 
I think what helped us a lot was that our ProdA was started by a group of developers in Minnesota that used to work in this way that I'm explaining to you. And here I was in this other environment that was different, and when I was appointed to be chief architect, I had to work very closely with them. And I started seeing how well things worked there. And they didn't work quite as well here. So, I tried to change the environment. That was very hard. It was impossible. It didn't work. But at some point, they decided to close the Minnesota center, and they offered people to move to Florida, but none of them moved to Florida. So, they sent three people up to Minnesota to learn the system. We lived there for five months, working with them, and then we moved the system. And what happened was, we realized what a nice environment that was, how good it was that they all worked together and really how good they all were and how fast they could get things done. So, it was great. Because you learn. It's sort of great in theory or listen to somebody that's done it, but to live it, it's a completely different experience. So, when we came down to Florida, we decided, "Okay. This is how we're going to implement it." And we were three, and then now -- it's been growing the last year and a half. And then, we started hiring new people and trying to implement this environment, and it really worked well, even though at the beginning they tried to, sort of, change it. And so then we didn't - we stick together. We didn't allow it. And we kept on going, so it's been very rewarding. (Manager \#15-11; Story \#16)

Some other stories had the same functions. Story $\# 28$, for example, is about an employee who wanted to go to Partner Inc., but after a while, was happy with his decision to stay with Software Corp. "They don't treat them like professionals" (Analyst \#19-3; Story \#28). The whole issue is "an employee who made the right choice". Like many companies in the computer-related industry, Software Corp. has a relatively high turnover rate. It is important for them to keep people they have spent money and time to train. Communicating the idea that it is hard to find a better working environment is important and, I can presume, influences 
one's co-workers. As a matter of fact, the employees who left the organization at some point in time and came back were often brought up in conversations I had; so the message is loud and clear: "beware of greener grass".

\section{(B.3) Attracting}

A story is attracting if the teller wants to show or emphasize pleasant dimensions. It will tend to create positive feelings about the organization, the group or a person in particular.

This first story portrays top management as being human and approachable (Story \#13). This story has already been used to illustrate the humanist side of the organization (see section 4.2.2). The use of sentences such as "the president is approachable here and that is not common in most companies" and "he knows more than most" is to point up the advantages of the organization and to convince the listener of his point of view.

The following story also emphasizes an advantage of the organization over its outsourcing partner.

They are strict and everything. As a matter of fact, Robert and I went to a $\mathrm{C}$ programming class that was given by Partner Inc, and normally they give it to their own employees, but they allowed us to attend this class. And most classes that you go to out of town, you're allowed to dress casually. Well, I came into class, I guess the second day, wearing a nice pair of gold slacks and a silk blouse, and one of the Partner Inc. higher-ups went over to our instructor and said, "Who is that person? Send her home. Tell her to come 
back in a dress," because they don't allow women to wear slacks. So, if I had been an actual Partner Inc. person instead of a customer, they would have sent me all the way back home, no matter where that might have been, 3,000 miles or whatever to show back up in the proper attire. So, I think that Partner Inc. puts the emphasis on the wrong thing. (Programmer \#13-6; Story \#25)

The use of "and most classes that you go to out of town, you're allowed to dress casually" and "so, I think that Partner Inc. puts the emphasis on the wrong thing" shows the teller's disapproval of Partner Inc. and implies that Software Corp. knows better. Software Corp. has a rather relaxed dress code including a very popular "casual" dress day on Fridays.

\section{(B.4) Repelling}

This type of story relates an event that has negative outcomes with a view to discouraging its repetition. The next story recounts the changes a group lived through over the years. It tells how difficult this was for the employees and, at the same time, expresses the wish (and a message) that the reengineering project will not put the group in the same disturbing situation.

Reengineering might be hard on the people because of all these changes. As a matter of fact, some of my co-workers started out in one department, went to a second department, went to a third department, then went to [Robert]'s, and now it's Integration. So, they were bent out of shape, and understandably so, but this was not due to reengineering. This was before that. Just handed off to different managers. It was like nobody wanted these people, so they were getting handed off from manager to manager. (Analyst \#34-14; Story \#75) 
The following story exposes another difficult situation. It concerns the outsourcing of nearly 2,000 people to Partner Inc. and the layoffs that occurred in that company after the transfer. The Software Corp. employees knew everything that was happening to their former co-workers. It was a very difficult situation because uncertainty was important at this point in time and Software Corp. employees witnessed some of their friends being abruptly terminated. In addition to the terminations themselves, it is the way they were carried out that troubles the teller. There is a clear message in this story that things should not be handled this way.

It was hard for everybody, you know. So I'm very glad that I stayed. Like I said, it was extreme. I thought it was a shame that the company was divided like that. You have people that have been relocated to Carolina. You have people that were just let go under the reengineering blanket. Because as a matter of fact, there were a couple of people that I've been in touch with. One had 20 years with the company and one had 35 . One, they had let go, just last year. We were still housed in the same building. I mean the companies had split. You had your Partner Inc. people and you had your Software Corp. people, but at that time, there were layoffs. There were layoffs going on. So, it was very hard to see people that you have worked with for years being notified that your job has been terminated. They would just be escorted to their cubicle, and people would be waiting while they packed their things, and they were escorted out of the building. That's strict, that's [Mister X's] company. Very strict, very military style. So it was kind of hard to take. That was really difficult. (Analyst \#33-12; Story \#61) 


\section{(B.5) Facilitating re-experience of previous state}

A story fulfilling this function is told in order to re-experience the good or negative feelings related to certain past events. I was not able to clearly identify any stories that fulfilled this function.

\section{(B.6) Decreasing tension; cathartic}

This type of story helps people cope with a bad situation. Rationalizing the negative effects of a situation can make it easier to accept. In the following story, the teller explains the pride he has in the company despite the lack of resources and the difficult history of the organization.

When you think about where we started and when we started. We started in a little trailer with five people in the early 1980s and we are a force to contend with. We are only 950 employees and we are up against people like Company $X$ (their main competitor) and...to give you an example when I had my old job it was me. At lour main competitor] they had ten people doing what I did. Early $1980 \mathrm{~s}$ like 1981 or 1982 . So, as a company we have accomplished a lot with a lot smaller budget and a lot smaller work force than any of the other competitors. So, we have a lot to be proud of. I believe we also market more positively and honestly. I do believe that our system is better. (Analyst \#5-12; Story \#30)

\section{(C) System maintenance}

The purpose of these stories is to help maintain the stability of the organization over time by justifying the status quo or guiding acceptable changes. 


\section{(C.1) Giving "reason"; justifying; explaining actual state}

This type of story provides the reason(s) for the occurrence of a particular event or the justification for certain behaviors. The following story has this function. While many employees were automatically transferred to Partner Inc., others were given a choice. The following story justifies the choice to stay with Software Corp.

Initially, when the transfer first took place, we thought it would be a better thing to go with Partner Inc. I mean, at the time when PC products people weren't sure whether we were going to be staying with Software Corp. or going with Partner Inc., during that period of uncertainty, a lot of us though we'd be better off going with Partner Inc., because Software Corp. was in bankruptcy at the time and Partner Inc. was a very big company. And we heard they were being very generous in giving out salary increases and that type of thing, but as time went by, we realized that we were really better off with Software Corp. People felt both ways. I kind of thought it would be better to stay with Software Corp.. And one of the reasons for that is because Partner Inc. is a very strict company and a lot of changes were made once Partner Inc. took over next door. They started enforcing dress codes that we had not had before and I'm talking very strict dress codes that tell you on a man's shirt how far apart your stripes can be, that type of thing. Men are not allowed to have facial hair and things like that, where Software Corp. is much more relaxed about those things. And, to me, it was being silly about little things, like people had to take down posters and things that they had at their desks, because they don't allow any of that stuff. They don't allow you to have pictures of your kids and stuff like that, you know. It has to look very clean and antiseptic and military, since they were basically founded by a military leader. (Programmer \#13-5; Story \#24)

The second story explains the reasons behind the outsourcing decision and illustrates the relationship with this business partner. 
The outsourcing was necessary at the time. However, I think that since then, the service has gone down. The perception is, anyway, that the service provided by next door, that used to be Software Corp., is not as good as it used to be. And, you know, there's some friction, because it's a different philosophy of how to work and things like that. I think it ended up dividing the company, you know. People there used to be Software Corp. people, but now they have a totally different mentality because of the upper management. So, I don't think it's been good. It helped us survive. Other than that, I think it's been detrimental to the unity of the company because those people over there service travel agencies. And they run the telecommunications and things like that. (Programmer \#116; Story \#22)

\section{(C.2) Providing coherence, order and stability}

A story provides coherence, order and stability if it reflects the way the organization is now and minimizes the importance of problems or negative happenings (regulation mechanism). For example, the following story shows the difficult side of working with a new business partner, but the tone tends to minimize the importance of the difficulties and the story ends by exposing the advantage of the actual situation.

The programming staff used to be part of Software Corp. also and then the programming staff transitioned over to Partner Inc. In the beginning, I think, there was a little bit of skepticism and not wanting to do things a new way. There were a lot of new processes that we had to go through and it was sort of a learning curve in that way because they had a different way that they wanted things done. It was more regimented work, which is really good, but it took us a while. Instead of calling up and telling them to do this for me today we had to go through a lot of paperwork and stuff to get things done, but it really gives you a better audit trail if things went wrong. (Analyst \#8-2; Story \#20) 
In the following story, the teller emphasizes the non-firing reputation of the organization by explaining the reason behind the transfer of 2,000 employees. Explaining the past occurrence decreases its importance, but mainly justifies the organization's policy (status quo).

We have a six-month probation period, but it's highly unusual, highly unusual, for someone not to make it through that six-month period. We're not a company that fires people. We don't let people go. When we let go people to Partner Inc., we didn't let them out on the street. We didn't fire them. We relocated them to Partner Inc. Unfortunately, Partner Inc. then let go of a lot of them. That was because Mother Inc. went away. Our business went down by 25 percent overnight. Mother Inc. was responsible for 25 percent of our revenue. Software Corp. doesn't fire people, I'm not talking about losing 25 percent of your business -- and having to take immediate measures to cut costs. And theoretically -mathematically, okay, if 25 percent of your revenue goes away -then mathematically, 25 percent of your staff doesn't need to be there anymore. Whoever was supporting that 25 percent perhaps doesn't need to be there anymore. I'm not saying it was a good thing to do. I'm not saying that it was the right thing to do. I have seen it happen at many companies. It is generally done by the numbers. These people are going, these people are going, these people. These positions are going. It was not a happy time here. I had just started. (Analyst \#17-17; Story \#54)

\section{(C.3) Differentiating}

A differentiating story emphasizes the difference between two elements, for example, between two organizations or two groups. The following story highlights the differences between a manager and his employees and between the more and less experienced employees. In the following story, the teller knows, because of his senior position on the team, that he has to set the example and to quietly agree with changes proposed by the manager. 
My boss tells me, "You messed up there". Sometimes, in meetings, I behave like another one of the guys here and without considering my position, and sometimes he'll say, you know, "You have to set the example," and he treats us like kids, which is fine with me. And I guess the older has to set certain examples. That's the way I feel, like the older kid, and I have to set some example. Yesterday, in the meeting, he said he was proposing this distribution of work and having coordinators officially named. So he said "You are going to be coordinating this and you are going to be coordinating that, and anybody has an opinion, an objection or any ideas," and everybody stay quiet. "[Martin (fictious name)], you're not gonna say anything?" "I'm sorry to disappoint you," I said, "but not this time. I'm going to be quiet." Because, he had talked to me about this before, so I was expecting that, and I thought it was a great idea to do that. (Programmer \#37-11; Story \#78)

The second story is about differences between Software Corp. and outsiders. This story ${ }^{1}$ talks about the difficulty Software Corp. and Partner Inc. have working together.

More of the development or if I am acting as an escalation point because there is a problem and we determine it is something that possibly Partner Inc. did. To give you an example, one of our hotel companies was moving a telephone line. I was told that Partner Inc. told them that they had to move the line and they wanted to cut the line over during the middle of the afternoon, which shuts down my operations to that person. Well, that is not what I want. It turned out that it was the vendor, but in that case what I did was I went to Partner Inc. and said that they couldn't do this and it is unacceptable. It was that the hotelier owned the telephone line so they were calling the shots not Partner Inc. I am not sure that the hotel company is aware of what they are doing so that is what I will be doing after I am done here is just making sure they understand what they are doing and the problems that it is causing. So, we went and attacked them accusing them of messing us up and then they came back and said that they didn't. Our main complaint was

1. This story was briefly discussed under the culture clash theme in section 4.2.7. 
that nobody told us. We found out by chance when the system went down. So, there are other issues that they don't always think of the implications to us because they are doing something. They think that it is nothing but it could have vast implications for me to my end customer the travel agent because they can't get into the computer and that means dollars to us. There are degrees of inconvenience. This happens to be major. It handles eighteen of the major hotel chains like Marriott, Hyatt...huge companies. We are talking about big money. (Analyst \#5-5; Story \#17)

In this episode, despite the fact that the fault was not Partner Inc.'s, it was the first one accused. Trust seems to be a very sensitive issue between the two partners. The phrase "I am acting as an escalation point because there is a problem and we determine it is something that possibly Partner Inc. did" shows how they look at each other. This story also illustrates a feeling very much present in the organization: the "victim" syndrome. In their discourse, Software Corp. employees often feel out of control and under the power of outside influence (another group, another division, another company, etc.). This is often based, first, on their feeling that nobody else understands their business and, second, on the fact that they do not control their destiny (their priorities and their owner's priorities may differ). In this last story, Software Corp. is first portrayed as Partner Inc.'s victim and then, the client's victim.

\section{(C.4) Integrating}

On the other hand, an integrating story decreases the importance of differences between elements and/or emphasizes their similarities. The teller of the following story wants to present Software Corp. as a homogeneous group 
with a common goal and to show how Software Corp. and Partner Inc. were brought together as the result of a natural disaster.

When we had the hurricane the company footed the bill for buying some generators and they were lending them out. They sent repair teams and they sent search teams the first couple of days when we couldn't find people to go to people's homes to try to find their homes to see if they were alive. They set up 24 hour hot lines here...that brought Partner Inc. and Software Corp. very close because they would go out in tandem as relief teams and as the building inspector would come through and say that the house was condemned and they had to be out they would send a crew down to help you pack up what you could salvage and move you. The company allowed you to do it on company time. It wasn't like you had to do it on our off time. We opened up a day care center for the one week between when we were able to come back to work and before the schools opened. That is where I worked for a week. I didn't do my job. My job was to take care of employee's children. The hurricane brought a common denominator but it did that to South Florida to begin with. Some people that had very negative feelings toward Partner Inc. had some new respect for Partner Inc. because they saw them as more caring than we gave them credit for. That doesn't mean that we still don't knock heads but we saw them more than cold Corporate America. It took the hurricane for us to see that they can be as caring as we feel that we are, but we didn't ever give them credit that anybody else could be that way too. (Analyst \#5-8; Story \#18)

This second story shows the interdependency among different units. So, instead of depicting Software Corp. as a collection of separate groups, the story shows how they need each other to complete a project.

Very soon after ProdB was moved here, they split out the pieces of ProdB: the documentation went to the Software Corp. documentation area. Customer service, the trainers, operations and marketing, that was the other department. So, that was integrated into the rest of the company. The only thing that we have now is part of development, actually, the actual development of the product. So, when you ask if we are independent. We're not really 
independent, because, in order to get things out, we have to interface with everyone. (Programmer \#17-5; Story \#36)

\section{(C.5) Providing or guiding acceptable patterns for change}

This type of story explains how change has made a situation better. For example, in the following story, the analyst explains how the job security situation has changed for the better. He feels employees have responded to these new requirements.

Their job [at Mother Inc; because of unions] was for life, and that carried over into Software Corp. So, in that respect, I thought everybody was very secure in their jobs, because you were never going to get fired. It took an act of God to get fired from it. But when Mother Inc. went under, things seemed to change, and now they're not that flexible anymore. Now you do have to do your work, or I think they're gearing more towards that. And so they still have a lot of, quote-unquote, dead weight, because of time. Some people have over 25 years with the company. But I think now that they are looking for good people and they want good people to work and they're keeping an eye on it. Now you don't take it for granted that you'll have a job and you're going to be with this job forever. So, I think it's better. I think people don't take advantage of the company anymore, and that's good. (Analyst \#332; Story \#70)

\section{(D) Reflective}

A reflective story is basically a descriptive story into which the teller also interjects as emotions, opinions, thoughts, etc. In the following story, the teller narrates the episode when people were transferred to Partner Inc. and expresses his opinion about how it changed those people. 
Any change affects how things happen. Change affects people in a way they do certain things and also it is thought that change is sometimes transparent but that is not real. People transition from one company to another so there was a change because now they are Partner Inc. employees. So, in 1991, you have over two thousand people who became Partner Inc. employees. It meant that there is a different culture that they have to understand. They have different rules and regulations in Partner Inc. that no longer apply to Software Corp, and so forth. There was some change. You may do the same job on a day to day basis but eventually since there is a new management structure they look at things in a different light and they may treat the job or they may change people from doing things one way to another...contractually all they have to do is to provide the same level of service that they were providing for Software Corp. (Manager \#7-4; Story \#19)

In this second story, in addition to providing some historical details, the teller expresses his feelings about how to react to the uncertainty that has always existed at Software Corp.

Because the airline business is shaky. It always has been. I've been here 15 years, and the first six months that I started, they were threatening to lay off. Because the unions were always threatening to walk out. So, that was the first six months I worked here and I've been here for 15 years. So, we either kind of just take it, you know, with a grain of salt, or you just leave. But, that's the way I am. (Analyst \#33-6; Story \#66)

\section{(E) Self-promotion}

A self-promotion story's clear purpose is to place the teller (or any group to which he or she belongs) in a favorable light. In the following story, a manager explains how his group mastered a new development approach and how this was acknowledged in the organization. 
Like four or five months later, [the vice-president] had gone to a meeting in Europe, and he said, "Oh, it was with these people, and they're using Presentation Manager, which is the Windows, what it's doing, but they're not using object-oriented. They say that is for geniuses." And I said, "Oh, I agree." And he said, "How come you agree? We've never agreed on this before. You've always said all you have to be is good." And I said, "Yeah, but now I have a group that's doing it, and it'll be nice to be considered geniuses, even if you're not." And he just completely agreed. He was like, "Oh, you're doing it?" And I said, "Yeah. Yeah." And then we showed him. (Manager \#15-8/9; Story \#51)

The following story narrates the success of a group in spite of the uncertainty of the bankruptcies, the experienced people leaving the organization, and the group's move to Florida.

I had been in California for two weeks when Mother Inc. shut down. See, we were losing three-quarters of the staff, anyway, so we just didn't replace as many as we were going to. And actually, when Mother Inc. went bankrupt, when Mother Inc. and Software Corp. and Second Inc., when all the companies went bankrupt, I was in the cut-off group of the people that were held. I didn't get hired 'till January, because I got caught in the bankruptcy. Once we knew that ProdB was not being affected. Now, remember, we were just moving down here. They decided to move us in the middle of the biggest project that ProdB had ever undertaken until that point. And three-quarters of the staff who were working on the project were leaving, and so the rest of us were left really, really busy. Really busy. And so we had to get through the business at hand, I mean, immediately. And we were able to do that. Once we knew we were not going to be affected, we were able to do that. And we delivered on time. (Analyst \#17-17; Story \#53)

\section{(F) Assigning blame}

A story that has an "assigning blame" function portrays a negative situation

(or behavior) and clearly specifies who is to blame. The following story is an 
example of the communication problems among groups in the organization. Reflecting the "victim" syndrome that exists in the organization, this story pinpoints another department or group as the one responsible for the problematic situation.

Before...business-wise it would cause problems. I see it getting better. I know an application that I had some time back...before we got ready to load they went "...we didn't know you were doing that..." Well, if they would have come to the meeting they would have known that. It is getting better. If they have a question they will come over and ask about it rather than guessing and then guessing the wrong way. (Analyst \#8-6; Story \#7)

The following story narrates the problem of communication and integration among the departments in the organization. It blames the other department for not telling them about a possible impact on their system.

It's a lot better actually now that we're here. When we were in California, they almost put us out of business a couple of times, because they didn't know anything about what we did out there. They would make changes on the host side and we wouldn't know about it. (Analyst \#32-11; Story \#55)

\section{(G) Problem identification}

This kind of story identifies a problematic situation or behavior. As in the previous section and under the "difficulty to work together" theme (section 4.2.6), we have discussed several stories about the problems groups had working together. Story $\# 8$, for example, told how changes made in one system affected the proper functioning of another system. It pinpointed communication problems among groups and departments. 
The following story identifies two problems: unhappiness about the move and the size of the cubicles, and management's lack of awareness as witnessed in the phrase "management sometimes just doesn't understand that". This statement seems to underscore a deeper problem that is the barrier between employees and management, the lack of connection and understanding between the two levels.

Today's hot button is that we were just told we're moving and will be cramped in a cube one-half the size of the cube we've got now. We are being moved out where marketing is back here. They're mad at us -- they're being moved out to the 3rd floor. We're getting moved all the way over there, so the distributed systems can take over our area, and then we're adding a whole bunch of people for these new projects, so that more people are going to have to get moved out of there to move over here. And if they don't redo these cubes and make them as small as the new cubes, then there will be open warfare. Management sometimes just doesn't understand that. On the other hand, we're all getting new equipment, and that pleases most people. (Analyst \#32-5; Story \#57)

\section{(H) Showing contentment}

A story fulfills this function if the teller expresses contentment towards a situation or a behavior. In the following story, the teller expresses his satisfaction with the company adopting a clear direction.

I think so [that the speech of the president had some sort of impact]. Where before, the direction of the company kind of was "we don't know, we'll wait and see". Now, wait and see is over. I feel we could see a definite direction in where the company wants to go. They plan. Where before it was bankruptcy and with everything else that was going on, the airline business was taking... a big nose dive at that point in time also. It's good to see some definite plans going into effect. (Analyst \#24-8; Story \#38) 
Finally, this last story talks about the positive change that occurred following the transfer of programmers to Partner Inc. It reveals the teller's satisfaction with those changes.

Sometimes you think it was better, because now we're their customer, whereas before there was an old mentality when Mother Inc. was around that we did it the Mother Inc.'s way. Programming was put on this pedestal and they pretty much didn't change. Nothing was ever written down, so you didn't know why anything was ever done. And to get something changed or fixed took an act of God. So, when Partner Inc. split them off and we became their customer, it was almost a 180-degree turn there. Before, they'd try to help you out, too, but there was a lot of old mentality there that, you know, "I'm not going to change it. A lot of them would go to lunch at 11:00 and you wouldn't see them until 3:00 in the afternoon. You could look out there and find them (by the window). Right at the golf course. That's where they were. So, that, in itself, that was good. There were certain groups that were like that, yes. (Analyst \#10-4; Story \#21)

Stories fulfill numerous functions - descriptive, increasing tension, inspiring, attracting, repelling, decreasing tension, giving reason, providing coherence, differentiating, integrating, providing acceptable patterns for change, reflective, self-promotion, assigning blame, problem identification, self-promotion, and showing contentment. Dandridge et al.'s initial set of functions was expanded in order to get a more defined and complete picture of the functions of organizational stories. Understanding functions gives us support for understanding culture and IS practices. These connections are discussed in Chapter 5. 
This concludes the results section. After an historical and contextual description of the research site, we saw the themes as they represent the messages expressed in the stories. I then presented the different functions that these stories seem to play in the organization's oral discourse. The next chapter discusses the themes and the functions using the three cultural perspectives: integration, differentiation, and fragmentation. 


\section{CHAPTER 5}

\section{DISCUSSION}

The main purpose of this chapter is to take the elements presented in the previous chapter - the stories, the themes and the functions - and examine them in the light of the three organizational culture perspectives: integration, differentiation, and fragmentation. It is important to remember that the objective is not to find the "best" perspective, but to use each of them to get as complete a picture as possible of Software Corp.'s organizational culture. I will then conclude by discussing two IS activities (development team organization and outsourcing) and, following the same procedure, will see how the three perspectives can help us better understand their organizational context.

\subsection{The Nature of Stories}

The use of the three cultural perspectives (integration, differentiation, and fragmentation) allows us to look at the culture of Software Corp. from different angles. For a long time, the integration perspective adopted by a majority of researchers influenced the research done in this area. Under this perspective, the stories worthy of analysis were considered to be mainly about top management and its actions (Martin et al., 1983). However, my data has shown that the nature of stories can be different. It can be about the history of the organization (for 
example, story \#31), about the impacts of other organizations on them (for example, story \#4), about top management (for example, story \#13), about a more of less large group of people in the organization (for example, story \#8), or about some organizational occurrence that happened to the teller (for example, story \#25). Whatever their nature, stories are told for a reason. This is why the messages they carry are important. Deciding that only the stories including facts about top management are worth analyzing is subscribing blindly to the integration perspective.

In addition, under the integration perspective, stories are mainly assumed to be an instrument of control in the hands of top management (Wilkins, 1983a, 1984). By "using" and "manipulating" stories, they can model the culture according to their desire. By adding the differentiation and fragmentation perspectives, we get a different picture of the culture of an organization, i.e. that stories can be used by people at every level in the organization in order to express a particular message. The canvas of organizational life is created by the grand, but also smaller events and by all members of the organization, whatever their level. People outside the organization (parent companies, competitors and partners) may also have an influence on the culture of an organization. The use of the three perspectives allows us to take all these organizational actors into consideration. 


\subsection{Themes}

In the previous chapter, I identified nine general themes that represented important dimensions of Software Corp.'s organizational culture. As discussed in Chapter 2, the organizational culture perspective chosen imposes a frame of mind or lens through which to look at the culture of an organization. Under the different organizational culture perspectives, themes are not created equal; some will be highlighted and others overlooked. So, each perspective will give some themes more or less importance, and this is why using of all them should help us get a more complete picture and a better understanding of Software Corp.'s organizational culture.

\subsubsection{The Integration Perspective}

The integration perspective defines culture as what is shared throughout and unique to an organization (Meyerson \& Martin, 1987). Under this perspective, only the themes that have been found to be widely shared throughout the organization will be considered as important; the others would be considered as "noise" and not representative of the organization's reality. The only uncertainty acknowledged under this perspective would be a temporary one resulting from a change affecting the whole organization. Figure 5.1 shows the themes associated with this perspective along with the related stories. 

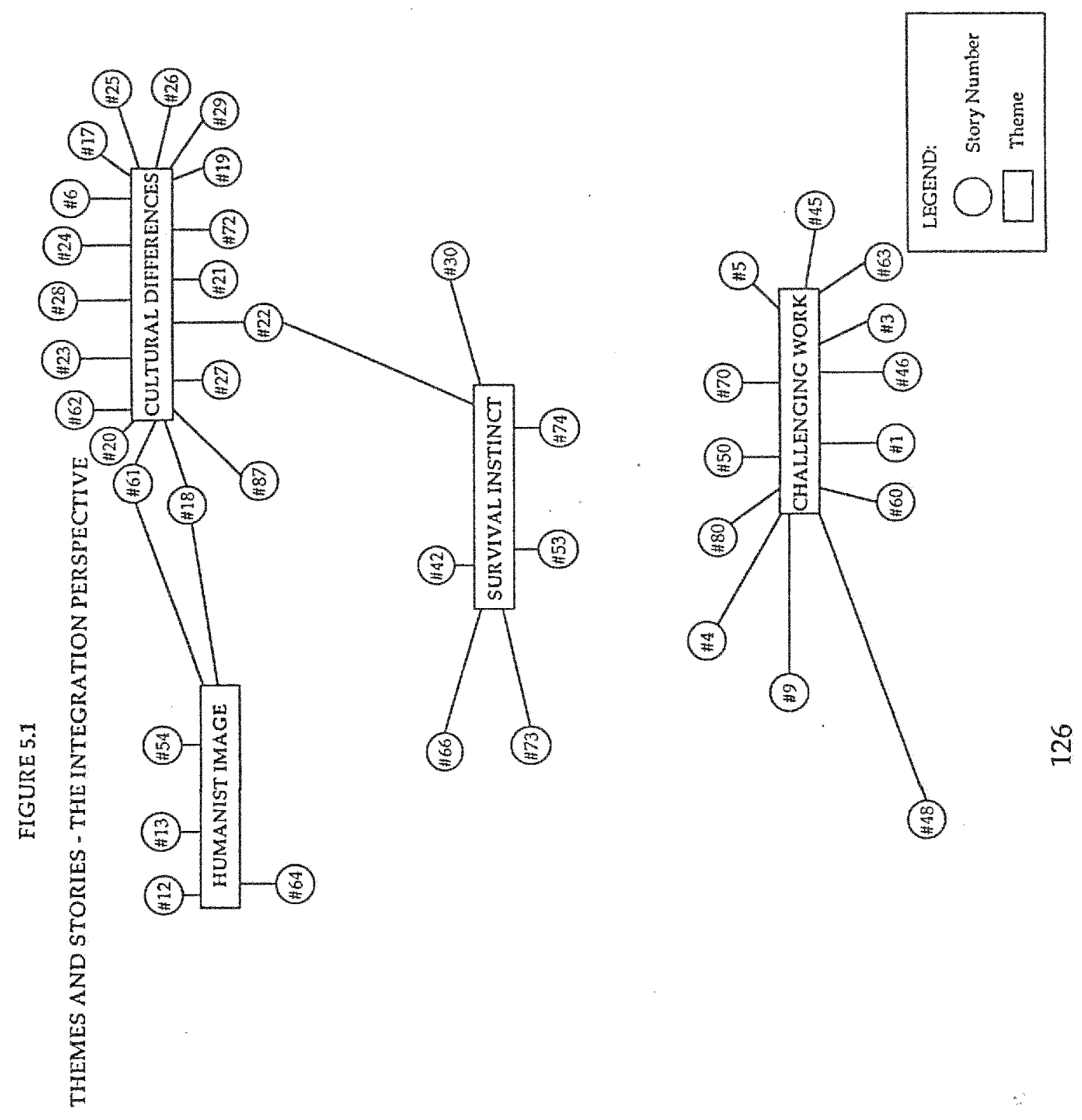
One organization-wide theme identified is the humanist image of the organization. Despite many chaotic situations over the years, Software Corp. has preserved a human side or at least has succeeded in giving its employees a humanist image (perception). In general, employees seem to feel like the organization, and more especially top management, really care about their wellbeing (for example, story \#13). They seem to consider Software Corp. a good place to work. The importance of this theme was also evident in top management discourse. This theme is the basis for the solidarity the employees have exhibited in the face of adversity (for example, natural disaster (story \#18) or disease (story \#12)). I think it also explains in part the strength of the organization despite a very difficult past.

This humanist side constantly comes up in any discussion about their relationship with Partner Inc. During the interviews, cultural differences between the two partners were quickly identified. In Software Corp. employees' discourse, Partner Inc. is always a "representative of cold corporate America" while Software Corp. is portrayed as a professionally-managed or sensitively-managed organization. Partner Inc. has a very "military" culture where, for example, a strict dress code is enforced and personal effects (such as pictures) are forbidden. As one respondent said: "I think that Partner Inc. puts the emphasis on the wrong thing" (story \#25), clearly implying that Software Corp. knows what is important and what is not and does not waste time on frivolous matters. There is also a 
feeling among employees that Software Corp. treats them professionally while Partner Inc. management does not (story \#28).

While these big cultural differences have led to friction between the two parties (for example, stories \#25), I think they had a very positive effect on Software Corp. Employees were able to appreciate what they had in their work and cultural environment. For those employees who made the difficult choice of staying with Software Corp. instead of transferring to Partner Inc (for example, story \#77), Partner Inc.'s horror stories reinforced their choice, showing them that it would have been difficult to work in such an environment. For those employees who did not have the option of transferring, Partner Inc. is portrayed daily as a place where one would not want to work. They were better off staying with the "humanist" Software Corp.

Other repercussions of this partnership have been widely discussed in the different stories. Cultural differences have complicated the lives of the two partners in some positive and negative ways. Before the outsourcing, Software Corp.'s culture was one where technical people (and more specifically programmers) were at the top of the power hierarchy. They pretty much did what they wanted (story \#21), and everybody else was at their mercy. When this group of people was transferred to Partner Inc., Software Corp. formally became a client of Partner Inc. and by the same token, of these technical people. The 
nature of the relationship had changed. The "power" relationship was no longer appropriate nor possible; contractually, the programmers needed to provide a service to the analysts. Some Software Corp. employees welcomed this change with enthusiasm.

This new relationship also had its down side. Because Software Corp. employees tended to be suspicious, Partner Inc. was treated accordingly. Because of their different roles and objectives and some major cultural differences, friction and tension often existed when they tried to establish priorities and solve problems. In the past, when faced with a problem, they could run to someone's office and ask for a quick favor. This was now impossible. Everything had to be scheduled, organized and in writing because of the contractual nature of their relationship and the "military" culture of Partner Inc. "If you say something, they won't take your word; they want everything in writing" (story \#26). This has greatly decreased the flexibility of their procedures and dramatically increased the amount of "red tape". As a matter of fact, this was the most widely mentioned problem: very low responsiveness. Ad hoc requests are not dealt with very efficiently. On the other hand, the new formal procedures have increased the amount of control one has on a project, and leave an audit trail of promises and due dates which are very comfortable for some Software Corp. employees (story \#20). Finally, after the transfer, Partner Inc. fired many people and some Software Corp. employees expressed anger and dissatisfaction (for example, story \#24). 
However, one could wonder if Partner Inc. did not only perform Software Corp.'s dirty work.

In sum, many stories exposed the acute cultural differences between the two organizations. The relationship with Partner Inc. gave Software Corp. employees a convenient group to which they could compare themselves to. The clear contrast between the two organizations helped them establish their own identity.

Another interesting organization-wide theme is how challenging the work is. As was mentioned in Chapter 4, challenging means exciting and varied, but also difficult and stressful. Unlike in many organizations, Software Corp.'s employees do not seem at all bored. Most seems to enjoy their work very much; they talk about it enthusiastically and show a high degree of interest and motivation ${ }^{1}$. This seems to be the result of their aggressive product improvement and marketing techniques which require them to stay up-to-date of all technological development. This gives employees the opportunity to learn the latest new "toys", and to "actualize" 2 themselves (for example, story \#80). In

1. It was impossible to get an official turnover rate. However, some people described it as "normal considering the industry". What was more surprising is that there is a popular notion in the organization to the effect that "most who left, came back".

2. Surprisingly, this is a word that many used during the interviews. 
people's conversations, this factor was cited as an important element in the capacity of the organization to retain its people despite an uncertain future. The employees seem to believe that these opportunities increase their value in the job market. This helps them deal with their difficult work (their training is their safety net).

The survival instinct is another important theme. Software Corp. is an aggressive company. Because it is a small player in a competitive industry and because of its turbulent financial situation, Software Corp. is and has been significantly affected by events very much outside of its control. Despite or probably because of those events, there is a strong will to survive and grow. This is very much present in everybody's conversations. This translates into energy, openness to new ideas (creativity and action) and readiness to change (despite some normal resistance), etc. They have, for example, realigned their marketing strategy; they are moving their platform from a mainframe one to a distributed one; they are developing alliances with international partners and are investing in the development of an international internal accounting management software. Software Corp. is therefore a very dynamic player. While this orientation has probably come from the top, the message has been heard loud and clear and seems to have been adopted (and repeated) by most people in the organization. 
The negative side of this strong survival instinct is the victim attitude. One needs to aggressively fight to survive because one has enemies. The nature of their industry and the type of services they provide leave a lot of power with their clients and the population they serve. I think this victim attitude can be explained by Software Corp.'s history, the non-forgiving industry they are evolving in and the fact that they are small (relatively) and have to compete with very big and powerful companies. In many conversations, in order to justify actions or events, there is a tendency to assign guilt and to express a total lack of control in the face of these outside "enemies" or "opponents". So, there seems to be a continuous war between them and the "enemies". This attitude inevitably leads to a lack of self-questioning and objectivity regarding one's own weaknesses. It may also help build a united front, in much the same way that Software Corp.'s relationship with Partner Inc. helped to expose contrasts and define its own identity.

Taken together, these themes portray Software Corp.'s culture as united against external obstacles and opponents (partners and competitors). The stories told by organizational members serve to define common values and priorities and to unite members around them. The implications are that a shared culture helps Software Corp. establish its working environment, define relationships, and assign priorities. When the organizational culture is shared and clearly defined and understood, every organizational member at every level can make decisions and 
act in agreement with everybody else (especially top management). It helps guide the members of the organization to work toward a common goal.

\subsubsection{The Differentiation Perspective}

While the integration perspective acknowledges only organization-wide themes, the differentiation perspective questions this organization-wide consensus and highlights differences that exist among groups (formal and informal) in the organization. Under this perspective, therefore, themes will express groups' differences on priorities, values, norms, management styles, etc. Figure 5.2 shows the themes associated with this perspective along with the related stories.

Pride is one of the differentiating themes at Software Corp. It differentiates two informal groups in the organization: the people who were employees at the time when Software Corp. was part of Mother Inc, and the new employees. The members of the former group have a much stronger link with the organization. These "old timers" talk about the company with much pride and fondness (for example, story \#76). They express their surprise that the organization is still alive today despite everything it has been through (for example, story \#42). These employees feel very proud of where the organization is today considering the resources it has compared to their major competitors; they have the clear feeling that a lot has been done with very little resources (for example, story \#30). These 


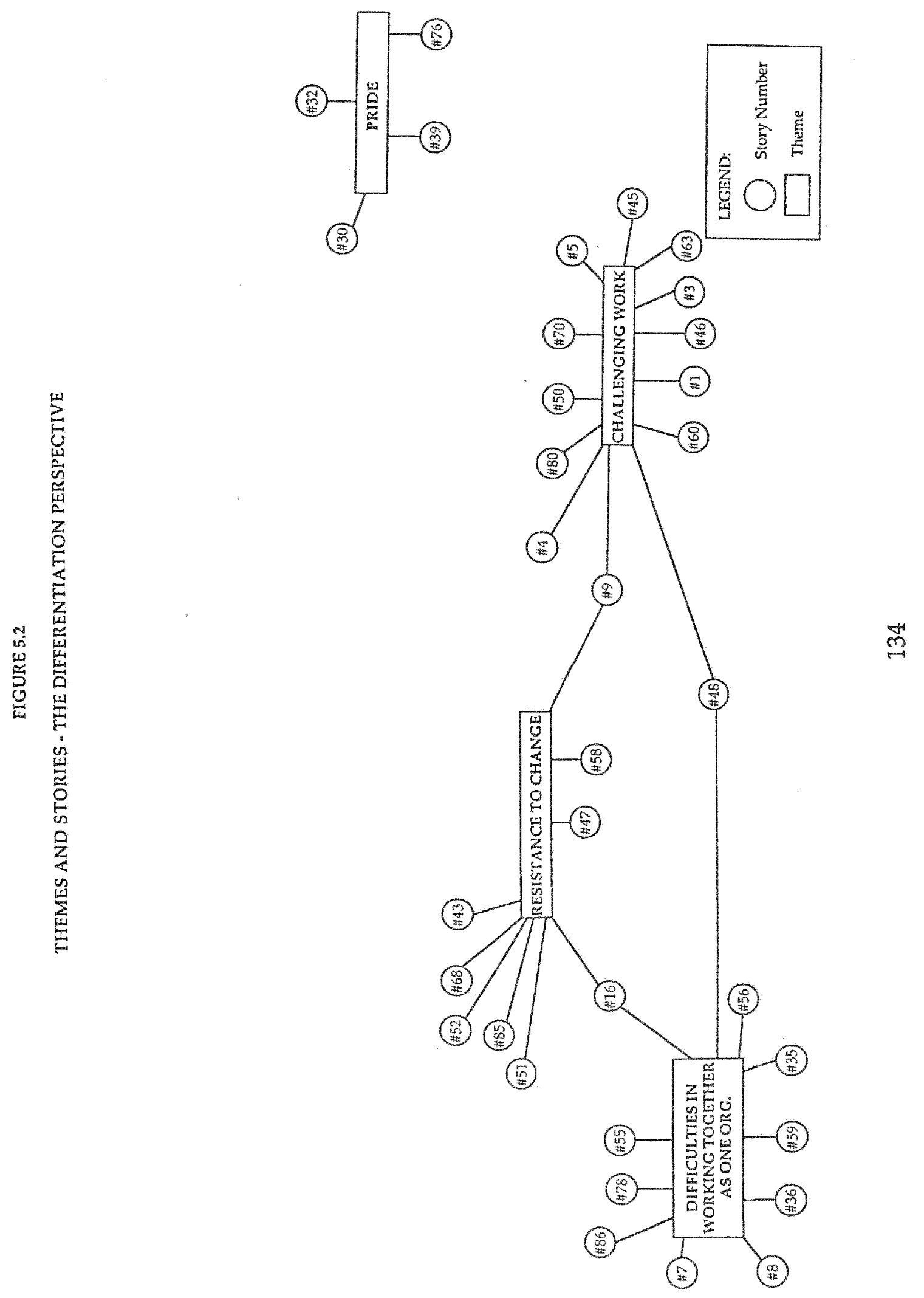


employees seem to be very attached to the organization and its future. The new employees, on the other hand, do not know much about the history of the organization (only the broad strokes) and do not talk very much about their attachment to the organization. They show a much more individualistic attitude, concentrating mainly on the opportunities the organization provides them to learn, self-improve and stay up-to-date in this fast-evolving technology industry.

As a consequence, the management of these two groups of people needs to be very different. They are motivated and driven by different values and priorities. It is possible to hypothesize that the first group ("old timers") will be more willing to "sacrifice" personal needs for the well-being of the organization while the second one will behave more selfishly. As a matter of fact, the second group talked much more, for example, about the pay cuts and the impact it had on the employees (for example, story \#49). Overall, they talked more about what the organization could do for them than what they could do for the organization. Software Corp. will therefore need to give this second group of employees what they want in order to retain them. It will have to provide them with challenging and varied work, extensive off- and on-the-job training, new projects, etc. As long as these conditions are met, these people will be satisfied and will stay with the organization. The first group, on the other hand, seems happy with the present situation and easier to satisfy. 
The difference between these two groups can also be explained by the events happening in the organization over the last few years, the fact that about 2,000 people were transferred to Partner Inc. (a piece of culture went with them), the fact that many outside companies have joined Software Corp. over the years (bringing their own culture) and the fact that massive hiring has been going on in the last year or so in the PC products department. It seems obvious that Software Corp. failed to integrate everyone, at least to get them working towards a common goal; it would have been difficult at the time considering the organization's precarious situation.

Another differentiating issue is the fact that groups have tremendous difficulty working together. This adds to the challenge of working at Software Corp. Despite an obvious level of cohesion inside groups, Software Corp. experiences enormous problems getting these distinct formal groups (ProdA, ProdB, ProdC, Integration, and Mainframe products) to present a unified front and work together. A look at the division's organizational structure and historical development can help explain the situation (see Figure 4.2). In the Technology division, groups are mainly organized by product type (ProdA, ProdB, ProdC, and Mainframe Products) with the exception of the Integration group which system tests the products for final approval. These groups also interact with other groups in other divisions (training, documentation, sales, marketing, customer support, etc.). This is a textbook case of specialization. Because of 
different origins and massive hiring over a short period of time, each group has developed its own little culture.

Despite the fact that the main tasks of each group are independent, they are also dependent on each other (a change in the database, for example, may affect how another software will treat the information). Changes made by one group can affect another group's work; one group's procedures and new methods could be communicated and shared with the others (leverage). Ideally, for these groups to be productive and efficient, information needs to flow freely among them. This is unfortunately not the case. Friction and competition is the state of affairs at Software Corp. Many times, one group's work has caused great problems to another one because the latter did not know about the changes made and how they could affect them (for example, story \#8). These troubles have been important enough to create difficulties with clients (for example, story \#59). It is painful, but acceptable, that products do not work well together when they come from different vendors, but it is completely unacceptable when they come from the same company.

Groups are also managed differently. This situation creates friction and jealousy among groups. This is not conducive to cooperation (interview \#19). In addition, many group members express a desire to stand apart from the rest of 
the organization. Their group is the best because they function differently or perform better than the other groups (for example, story \#16).

Despite some noted improvements in communication among groups (for example, story \#55), the situation is still far from being perfect. To try to improve the situation, the division has launched a new approach to product development based on a project team concept, the project team including members from all the groups involved. The new approach is still in a testing phase and is facing some problems. The "glass walls" (as they have been called) are very, very thick. Despite the departments' participation on the development team, their competitive culture is so strong that members view their role on the team as one of defending and protecting their group's interests. It is difficult to promote team building and solve the initial problems in such an atmosphere.

Another more usual division in organizations is the one between management and employees. Employees complain that they do not really know what is going on which is the source of a lot of uncertainty in the organization. For example, they learned about Mother Inc.'s bankruptcy in the newspaper (story \#37). Because of this lack of top-down communication, rumors are stressful and seem to play an important role in getting to know what the future holds (for example, story \#79). Despite regular meetings with top management, some 
wonder about the truthfulness of these speeches and whether the goal is not really to reassure them but to "sell" the company.

Because of all that has happened and is happening in the organization, a certain degree of resistance to change is evident in people's conversations. As explained by a manager (story \#43), a consultants' study has revealed that Software Corp.'s score was average regarding the capacity of its employees to deal with and react positively to change. The results reveal that the organization is evenly split with half the people reacting positively and the other half afraid of change. This situation has important implications for an organization that wants to be aggressive and flexible enough to adapt to an ever-changing market. It requires careful planning of the implementation of the recommendations of the reengineering project. The committee in charge set up a hot line to provide information about the project. Information also flows by electronic mail. Managers attended a special reengineering information and training session on the process and its objectives; they were then given responsibility for sharing that information with their group. The reengineering project itself has left some people in a greater state of anxiety. Others seem to have adopted the attitude that they are already doing their best, so they will not be directly affected. As a matter of fact, many people in the organization feel this way. This is probably why they are so surprised when a big change is implemented. 
All the themes under the differentiation perspective pinpoint the differences among groups of people. Stories mainly relate those differences and the difficulties of successfully dealing with them. This view of culture has challenging implications for the management of the organization. The differentiation perspective highlights the fact that there are very heterogeneous groups in the organization. The interactions among groups are a little uncertain and may easily lead to friction. Because these culturally different groups exist in the organization, (1) one cannot generalize behaviors and attitudes to the whole organization, (2) each group will react differently to top management actions, (3) each group will react differently to changes depending on how they affect or challenge their own culture, and (4) special mechanisms will have to be put in place in order for those groups to harmoniously work together. Finally, I think that groups need to be involved in the management of their internal differences. They need to be aware of their different personalities, acknowledge them, treat different cultures (other groups) with respect and finally, find innovative ways to work together.

\subsubsection{The Fragmentation Perspective}

The major difference among the three perspectives is in the role of ambiguity in the organization. The integration perspective does not acknowledge the existence of ambiguity as part of the culture of an organization. The 
differentiation perspective, on the other hand, recognizes the existence of ambiguity among formal and informal groups, but not inside those groups. Finally, in the fragmentation perspective, ambiguity is an inevitable part of organizational life and this acknowledgment is particularly useful to look at the culture of Software Corp. Figure 5.3 shows the themes associated with this perspective along with the related stories.

To better understand the importance of ambiguity in looking at organizational culture, we have to look at the process of change under the integration perspective. Schein (who adopts an integration perspective) says that the culture changes according to an "unfreeze-change-refreeze" process and that any ambiguity, uncertainty or state of flux or chaos is only temporary; in fact, it exists momentarily because the process is in the "change" phase and the culture is not settled yet. However, when we look at Software Corp., uncertainty seems to be a constant state. Organization members face uncertainty about the future of the organization (for example, story \#79), its overall direction (story \#38), its unstable industry (for example, story \#66), from the parties they work with (for example, story \#4), the constant changes affecting the structure of the organization (for example, story \#67), in dealing with an outsourcing partner who is taking charge of an important part of their operations (for example, story $\# 87$ ), from many heterogeneous groups who have different cultures (for example, story \#16), from the decisions of the reengineering groups (for example, story \#81), from the 

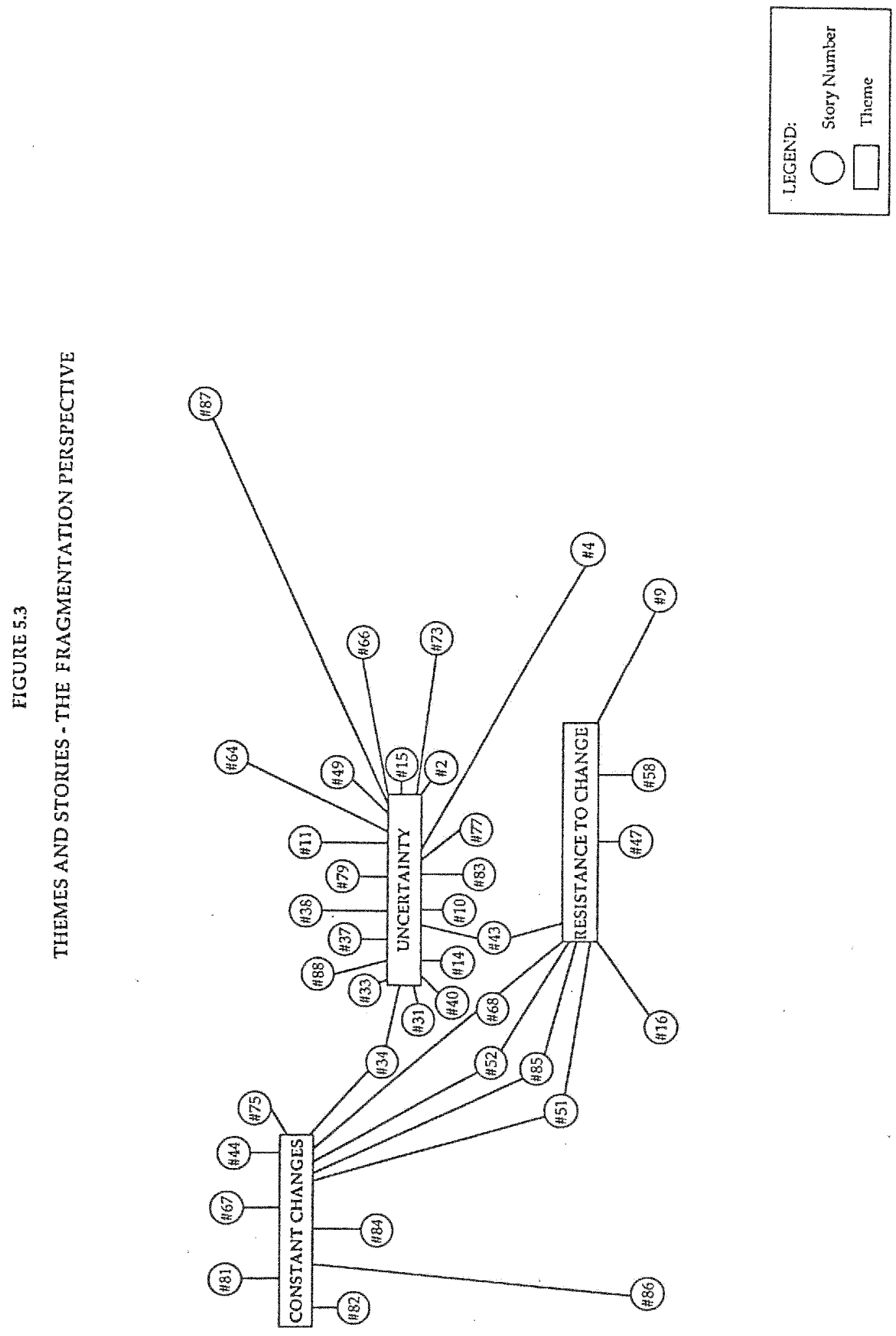
testing of a new working procedure ("pilot project") (for example, story \#84), etc. Software Corp. has been in this state all its life.

These sources of uncertainty significantly influence every pocket of culture in the organization. Priorities are constantly rearranged in this unstable environment (outside deals and Second Inc.'s financial situation); groups are transferred from division to division affecting the formal and informal structure of the organization; many new people are hired who challenge the values held by the organization; new groups are integrated who bring their own set of norms and values which needs to be taken into account when dealing with them, etc. Changes and uncertainty are omnipresent at Software Corp. Will the dust ever settle or is it the culture of the organization to be in a constant state of flux?

People in other organizations feel that nothing ever changes, that the organizational structure and culture are very heavy barriers, but this does not seem to be the case at Software Corp. On the contrary, people feel that things are changing all the time or could change at any moment (even the existence of the organization itself). For example, there was a big structural change in the organization right at the end of the data collection; the employees were amazed (story \#67). It affected formal groups in the organization. 
Because of these constant changes and the financial situation of the organization, employees experience a high degree of uncertainty. While the flexibility that comes with uncertainty and rapid change is a nice advantage because it helps the organization respond to problems and a changing environment, uncertainty and constant changes have a major impact on the employees themselves. As was briefly mentioned before, Software Corp. employees look out for their own interests (even more so among new employees who have no big attachment to the organization). They seem to feel that they need to keep up-to-date on technological developments in order to increase their personal value on the job market in case they have to find a new job tomorrow. This can lead to decisions that are better for some individuals than for the good of the organization.

On the other hand, this constant uncertainty tends to keep people on their toes. I think that nobody is resting on their past achievements at Software Corp. People need to prove themselves everyday. While it can be very beneficial for the organization, it also leads to competitiveness and individualistic behavior. There is, in the organization, an important race for resources and power. As the organization gets flatter, i.e. as levels are eliminated, people need other outlets to "actualize" themselves. Expertise and being in control of the "hottest" project, to name a few, become important sources of power. This can be good for productivity, but it is not conducive to working together. For example, it could 
hinder management's efforts to implement changes in the way products are developed.

The issue of resistance to change can be easily explained under the fragmentation perspective. At Software Corp., uncertainty is quite prevalent so we must assume that many people have learned to live with it (story \#83). The culture of this organization is in a constant state of flux but this situation is rarely acknowledged in the literature.

In addition to uncertainty, the fragmentation perspective highlights cultural contradictions in the organization. By performing an across-theme analysis, questions are raised about how those themes can harmoniously coexist in the same environment. For example, the company's humanist image is an important theme in the organization. However, this contradicts a lot of the things that have happened over the years and are still happening in the organization such as the transfer to Partner Inc, and then the firings of many employees, the pay cuts, the lack of top-down communication, etc. One would think, for example, that the lack of communication leaves people in the dark and that organization members would be resentful. However, this is not the case at Software Corp. The strength of the other themes may have stopped this from happening. The pride they have in their company (for some) and the opportunities it offers them (for others) allow them to overlook those "small" details. Organization members also use stories to 
deal directly with these contradictions. For example, in story \#54, an analyst rationalizes the firing of the Software Corp. employees who transferred to Partner Inc. by saying that they had been fired by Partner Inc. Therefore, it was not Software Corp.'s responsibility. This was his way of explaining the contradiction between the non-firing policy of Software Corp. and the "indirect" firing of these employees.

Another explanation for the existence of this contradiction is the history of the organization. Software Corp.'s employees have experienced much more dramatic situations in the past and are now confident that top management will not let them down. As one respondent was saying "you cannot spend your life worrying about that". It makes this lack of information a less significant problem.

The survival instinct and the difficulties in working together themes are also contradictory. In order to be strong and survive, one would think that Software Corp.'s employees would present a united front and easily work together to achieve organizational goals. As was seen before, this is not the case at Software Corp. Groups manifest very individualistic behaviors and, at one point, even resisted attempts to make them collaborate. The overall uncertainty prevailing in the organization can explain the existence of these two contradictory characteristics. Employees know that, in case of problems, only the strongest and most indispensable employees will remain. This creates a competitive situation 
inside the organization. Despite the need to be aggressive and survive, the organizational atmosphere is not conducive to increased collaboration within the organization. Contradictory themes can therefore coexist harmoniously.

The themes under the fragmentation perspective all highlight the level of uncertainty in the organization. Stories tell of events leading to high levels of uncertainty in the organization and how these events influence organizational life. Uncertainty is created by individuals inside the organization, but also increased by all those internal and external factors exercising influence on the priorities, values and norms which prevail in the organization. Stories may function as coping mechanisms to help deal with uncertainty and contradictions.

Looking at culture from the fragmentation perspective has several implications. Every organizational member plays a role in the culture of the organization. No single group (such as top management) has more control over the culture than another group. Everybody participates in what the organization has become. Groups (formal, informal and temporary) develop their own working environment which will evolve throughout the life of the group in response to the individuals themselves and outside factors and events. Because of this heterogeneous group of people and the constant changes in rules, priorities, values and norms, nothing will ever be settled. Each situation needs 
to be dealt with without presuming of any cultural context. This is why ambiguity is a factor that needs to be dealt with continuously.

Taken together, the three perspectives have allowed me to look at the organization and the different themes from many angles. The integration perspective would have only allowed the identification of some "assembling" themes. In that case, I would have been more likely to identify only coherent or consistent themes. The use of the differentiation and fragmentation perspectives has allowed me to identify a broader spectrum of themes. As we have seen, some are in contradiction with each other and are, at the same time, harmoniously sustained in the organization. We have seen that stories can be used to explain those contradictions.

\subsection{Functions of Stories}

The Dandridge et al. framework (1980) was used as a basis to assign functions to stories. In the preceding chapter, we looked at the different functions and their definitions and uses. In this section, in order to get a better picture of how the functions, themes and perspectives are related, I created the two tables that follow. The first one, Table 5.1, shows the occurrences of functions by theme. During the data analysis, functions were assigned to stories, (matrices in Appendix 3) then themes were assigned to stories. Next, I compiled the number 
of times a function was used for each theme. I then analyzed the functions that were used in 5 or more stories. We can see that most themes have one or several functions that stand out. This cut-off point was selected in order to identify those functions that really stand out for each theme.

The first two themes, challenging work and constant changes, are mainly related to stories having a reflective function (D). It means that many stories about constant changes were meant to describe changes happening or that had happened in the organization while the others about challenging work were used to describe their job situation. This means that the teller usually expressed emotions and/or opinions about an event that he or she was narrating. This indicates that people are involved in their work and what is happening in their organization.

The theme cultural differences seems to be related to stories that have a justifying function (C1), a differentiating function (C3) and a reflective one (D). Cultural differences as a theme describes the relationship between Software Corp. and their outsourcing partner, Partner Inc. The function of many stories under that theme was to explain the relationship between the two partners and to justify why things were the way they were. And stories were used to describe the relationship, as well as clearly distinguish between the two partners (cold 
corporate America vs. humane organization, ridiculous dress code vs. putting emphasis on important things, etc.).

The next theme, difficulties in working together, is related to stories whose function is to assign blame (F). This is not surprising. We saw how the different groups had problems working together and how they sought to blame the problem on someone. I called this the "victim" syndrome.

Self-promotion (E) is the function most often associated with the survival instinct theme. This was to be expected. In this case, the self-promotion mechanism works to promote the organization over outside parties (partners and competitors). Their survival instinct exposes the positive aspects of their organization and is a built-in marketing mechanism.

The last theme with functions that stand out is uncertainty. In the table, four different functions attract our attention: descriptive (A), providing coherence (C2), reflective (D), and problem identification $(G)$. Let's look at each of them independently. The first function, descriptive, involves a description of situations creating uncertainty in the organization; this is the same for the third function, reflective, where, in addition to a basic description, the teller was providing a personal analysis (position, opinion, and emotion) of the event. People told stories describing the uncertainty in the organization and expressed their feelings. 
about it. The second function, providing coherence, is normal in this case. We know that people need to have a minimum level of stability or predictability in order to function in an organization. Telling stories may be a coping mechanism, i.e. a way to explain a situation of high uncertainty and find ways to rationalize it in a way which is acceptable and allows one to continue and function. Finally, the last function, problem identification, pinpoints situations which create uncertainty in the organization. When events that lead to uncertainty are seen as problems, people may be more likely to resolve the difficult situation.

Several themes - humanist image, pride, and resistance to change - had no functions with five or more stories attributed. However, two themes (humanist image and resistance to change) did have 4 stories attributed to the reflective function. In the two cases, several stories were describing situations where people were getting personally involved in the discussion. If we look at the nature of the themes, this seems very typical. Humanist image and resistance to change are themes that lend themselves to description. In addition, they touch people directly and it was to be expected that they would become emotionally involved in their stories.

In summary, Table 5.1 allows us to perform two principal tasks. First, it helps validate the assignation of functions to stories. It was possible, for all the themes, to see a logical connection between a particular theme and the main 
functions assigned to the stories related to that theme. Because both themes and functions were assigned independently, the logical connections between the two increase our confidence in the findings. Second, the analysis performed in Table 5.1 shows what types of functions stories perform under a particular theme. The value of this analysis lies in the fact that it is important to better understand how stories support the themes that are present in the organization. The functions characterize the messages that are transmitted. For example, take the theme difficulties in working together. The principal function, assigning blame, lets us find out more about what is going on among the groups in the organization. The study of functions permits a more global understanding of the messages in stories. The functions help further define a particular theme. The stories by their function sustain the existence of the themes, give them a particular direction, and allow their continuous diffusion within the organization. 


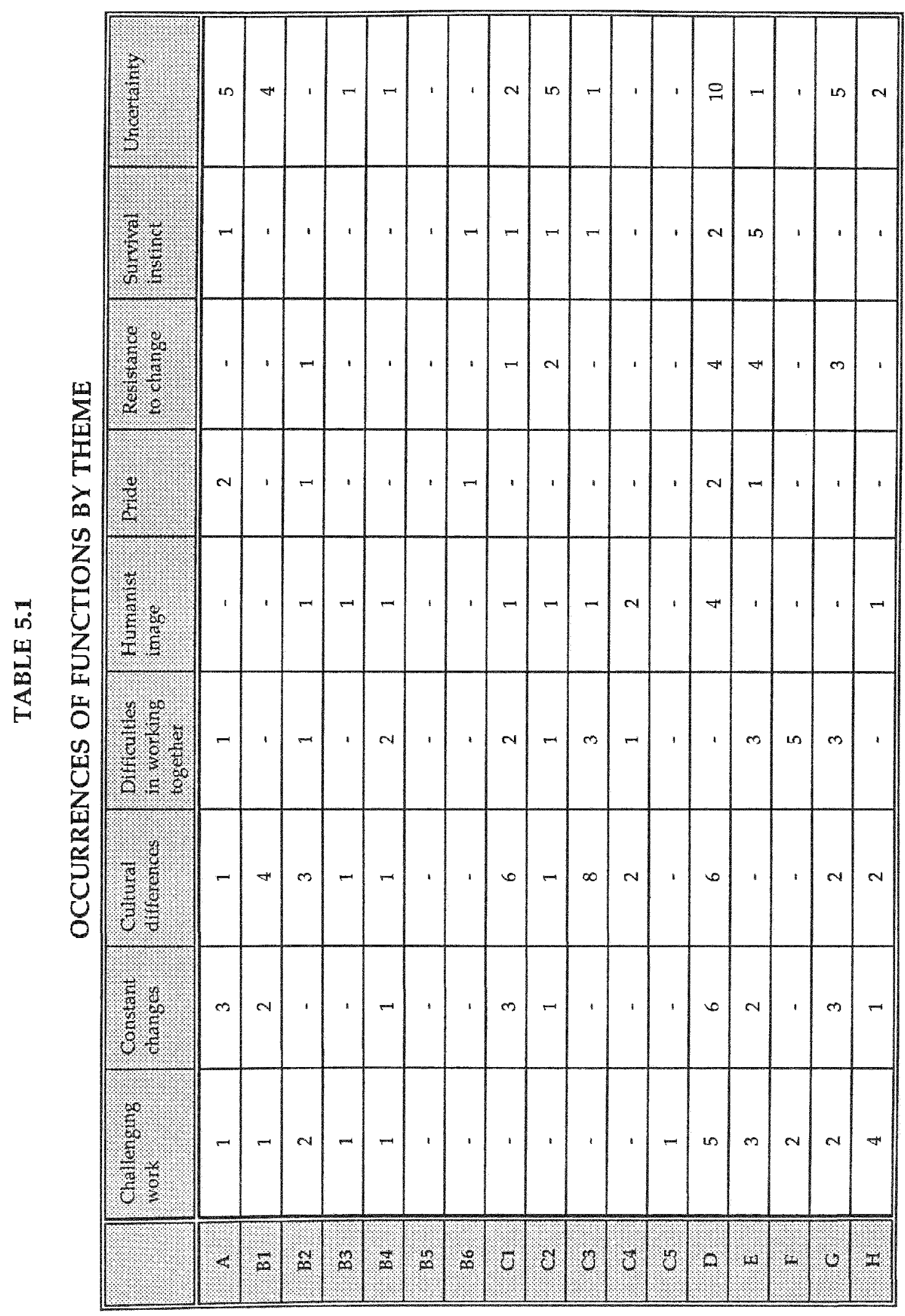

量 
The second table, Table 5.2, shows the use of functions by perspective. This table is an aggregation of the previous one. It was built by using the themes best related to each perspective (Figures 5.1, 5.2, and 5.3) and by calculating the total number of times a function was used for each perspective ${ }^{1}$. If a theme was represented in two perspectives, the functions of stories related to that theme were included in both perspectives. Using the same criterion, we will look at the functions that appear most often under each perspective. This table leads to interesting observations.

1. It is to be noted here that adding columns from the previous table (Table 5.1) will not give the following table (Table 5.2). This is because a story used for two themes in the same perspective was not counted twice. 
TABLE 5.2

OCCURRENCES OF FUNCTIONS BY PERSPECTIVE

\begin{tabular}{|c|c|c|c|c|}
\hline & $\mathrm{HNCHON}$ & $1 N T 20 \mathrm{KATHON}$ & DHFERENTH THON & FLACMENTATION \\
\hline \% & Descrotrus & 3 & 4 & 8 \\
\hline 81 & Throrsion & 5 & 1 & 5 \\
\hline $\mathrm{Bz}$ & ninspinn & 5 & 4 & 1 \\
\hline 133 & (11,acting & 3 & 1 & 1 \\
\hline 84 & Repellms & 2 & 3 & 2 \\
\hline 35 & Froclitating & - & - & $=$ \\
\hline B6 & becreasing & 1 & 1 & - \\
\hline C) & 14tinting & 7 & 3 & 5 \\
\hline ?2. & roviring & 3 & 3 & 7 \\
\hline s. & Diferentatros & 8 & 3 & 1 \\
\hline 4 & Niregraing & 3 & 1 & - \\
\hline c5 & 840118 changs & 1 & 1 & - \\
\hline $\mathrm{D}$ & Reflettro & 17 & 10 & 17 \\
\hline $\mathrm{E}$ & Self promotion & 8 & 9 & 5 \\
\hline f & flanerignting & 2 & 6 & - \\
\hline 6. & Problent & 4 & 8 & 9 \\
\hline $\mathrm{H}$ & shoving & 7 & 4 & 3 \\
\hline
\end{tabular}




\subsubsection{The Integration Perspective}

The focus of the integration view of culture is to assemble the whole organization under a common umbrella. If we look at Table 5.2, we see that the main functions attributed to stories are increasing tension (5), inspiring (5), justifying (7), differentiating (8), reflective (17), self-promotion (8), and showing contentment (7). Under that perspective, a function such as reflective is to be expected; it is rather neutral and used to describe an occurrence with some personal commentary. Showing contentment is also a typical function under an integration perspective. The members of the organization express contentment with a situation; it shows they want approval and to fit in with the organization as a whole ("don't rock the boat"). As briefly discussed before, the functions increasing tension, justifying, differentiating, and self-promotion are closely associated with their outside relationships. Identifying irritating situations, wanting to be different from others, justifying differences and situations, and selfpromotion all have an integration effect on the organization. It builds an "us" identity which is completely in line with an integration perspective. The last used function increasing tension was used in most cases to characterize the environment and the sometimes difficult relationship with their outside partners and more especially with their outsourcing partner. 


\subsubsection{The Differentiation Perspective}

Under the differentiation perspective, the functions of stories should be to identify differences between formal and informal groups. When we examine the table, we see that the functions most widely used under that perspective are reflective (10), self-promotion (9), assigning blame (6), and problem identification (8). Besides reflective, which is quite a neutral function, the three others are very typical under the differentiation perspective. They are all functions that divide or differentiate groups inside the organization. If we look at self-promotion or assigning blame, the idea is to distinguish groups in the first case (one better than the other) and to find a guilty party in the second case (not us, them). The third function, problem identification, also serves the function of dividing the organization because other groups are usually the source of the problem.

\subsubsection{The Fragmentation Perspective}

The fragmentation perspective leaves room for ambiguity and contradictions. If we look at Table 5.2, we find that the most common functions are descriptive (8), increasing tension (5), justifying (5), providing coherence (7), reflective (17), self-promotion (5), and problem identification (9). It is hard to miss the 17 stories having a reflective function (to which we can add the eight having a descriptive function). Under the fragmentation perspective, the function 
of stories seems primarily to be to describe the environment (sources of uncertainty and changes) and to explain how it affects people (its impacts on the organization). The problem identification function also has a very high score. Stories were used to report problematic situations which create or increase the uncertainty existing in the organization. The function increasing tension expresses the difficulties people have in dealing with ambiguous events or events leading to more uncertainty; the stories having justifying or providing coherence functions can be assumed to help people deal with those events. Stories seem therefore to be used as a sense-making mechanism. Finally, the self-promotion function was mainly used to describe events leading to uncertainty where one group was better than another at dealing with the situation.

Looking at functions of stories through the three organizational culture perspectives allows a better understanding of the general functions of symbols in organizations. Indeed, the use of the three perspectives provides a conceptual framework that demystifies the integration role as the only one stories are supposed to play. It also helps us understand the relationship between stories and their functions and the culture of an organization. With this in mind, it is now possible to look at other types of symbols and acknowledge a broader spectrum of functions. 
In conclusion, Dandridge et al.'s framework has two main weaknesses. First, because it was developed for all types of symbols, some of the functions seemed to be less appropriate for explaining the particular case of a verbal symbol such as a story (e.g. B5: facilitating the re-experience of a previous state). The framework's second weakness is its inability to describe all the functions of stories under the three perspectives of organizational culture. The function analysis done by perspective (Table 5.2) showed that Dandridge and his colleagues developed their framework based on an integration view of organizational culture. Their framework does not include functions of symbols that do not relate directly to that perspective. Most functions included in the framework are related to the "assembling" or "integrating" role that culture fulfills. As was mentioned before, through that perspective, stories are primarily an instrument to be used by management to control the organization. However, in my data, there were stories that clearly had functions other than integration. If we look at Table 5.2, in the case of the integration perspective, only 48 per cent of the assigned functions pertain to the new functions that were added to the initial framework, 60 per cent in the case of the differentiation perspective and 53 per cent in the case of the fragmentation perspective. These new functions can therefore be more easily associated with a differentiation or fragmentation view of culture and these numbers tend to show the bias of the Dandridge et al. framework. I think that my work includes many more facets and provides a 
more complete picture of the functions of stories than was first explored in the initial framework.

\subsection{The Implications of Culture for IS Practices}

Software Corp.'s problems and environment are not unique. Software Corp. is facing IS issues rather typical for an organization of its size evolving in the competitive world of the 1990s. Let's take two important issues that are important for Software Corp. and also prevalent in other organizations: system development team organization and outsourcing. The quality of software development and the development of IS human resources, which are at the heart of system development team organization, were both in the top 10 IS management issues for the 1990s (Niederman, Brancheau, \& Wetherbe, 1991). Outsourcing is a rapidly growing trend in the IS arena; it was estimated to be about a $\$ 50$ billion-market in the U.S. in 1995 (Teresko, 1990). All in all, these issues are strategic for the organization. The important point here is that IS practices are cultural practices because they are carried out in a cultural context and can be better understood from each cultural perspective. 


\subsubsection{System Development Team Organization}

Like many organizations, Software Corp. is facing product development problems. Cost overruns and delays are common place. Yet, software development is critical to its survival. Lengthy system development decreases Software Corp.'s flexibility i.e. its ability to respond rapidly to a changing market in a very competitive environment.

IS professionals and researchers have been very good at discussing how to successfully introduce new working procedures and/or computerized systems to users. However, they have produced little research on how IS professionals react when their work is fundamentally changed. While some studies have looked at the introduction of CASE tools (for example, Orlikowski, 1988 and Norman \& Nunamaker, 1989), very few have examined what happens when an IS professional's workplace undergoes changes. For a long time, the usual sequential system development life cycle (SDLC) was the most effective way to develop software. As Software Corp. was once an MIS department, its whole organizational structure is based on the SDLC. So, softwares in development are handed off from department to department until completion. There is little sense of ownership developed over the product's life; it is a bit like a hot potato that everybody throws at each other (more so in the testing phase). When problems are discovered, the product goes back to its starting point and the whole process 
repeats itself. This leads to a lengthy development process. No work is done in parallel because each department has to get to know the product first before they can be productive.

One way to solve the problem was to create a large development team composed of all the people involved in the project. This new way to organize development teams did not work either. Unproductive meetings with too many people would bore and frustrate everybody. Precious time would be lost on details only of interest to one or two people.

To try to improve Software Corp.'s productivity and solve some organizational problems, two important committees were set up. The first one's objective was to look at organizational communication and make recommendations on how it could be improved. Later on, following the American wave, a reengineering committee was set up to look at organizational procedures. While this committee would eventually look at the whole organization, its first focus was on the Sales department. The Technology division felt it could not wait for the recommendations of the reengineering committee, and with its approval, conceived a new way to develop systems. The results of a few pilot tests were fed back to the reengineering committee who will include them in a global organization strategy. 
The new team approach to software development consists of having two separate teams: a core team and an extended team. The core team includes the project leader and a representative from each department working on the product (typically five or six people). The extended team includes the people from those departments whose expertise and work are required. Meetings are held by the core team and each member is responsible for bringing the information back to his or her group. This organization mode has several advantages. It eliminates the large, unproductive meeting and, more importantly, it allows each group to work in parallel and decreases the set up time in each group when work needs to be done in a sequential manner. The three cultural perspectives can help us analyze the situation that existed when this new approach was implemented.

\subsubsection{The Integration Perspective}

First, let's look at the objective of the new implementation approach. In addition to reducing development time, one of the objectives of the new project was to facilitate collaboration among groups. As was discussed before, it remains an important issue for this organization. The new approach is an effort to integrate groups under one project leader and direct their work toward a common goal. Working together more closely may help build common visions, priorities and values. It may also help build a feeling of ownership among the different groups toward the product being developed. At present, products are "owned" 
by the development team (analysts and programmers) and the other groups feel more or less involved. A stronger feeling of ownership could lead to better collaboration, more involvement, and increased interest among the involved members.

\subsubsection{The Differentiation Perspective}

The differentiation perspective is helpful in understanding the results of the implementation of the new approach. First of all, management was aware that they could not change the entire organization in one shot. So they decided to try some "pilot" projects that would be used to test the new procedure and make changes if necessary. They carefully chose projects that could be handled that way. Their first pilot project, the last phase of a small project, was successfully completed. They then identified two other important projects ( $A$ and $B$ ) that were just starting. When project A started, management met with major resistance.

One of the ideas behind the new approach was to develop a pool of project leaders who would be in charge of all projects in the organization. In the past, the line manager of the development group was ultimately in charge of each project. When they tried to assign the new approach to a certain development group (who was chosen to be in charge of the analysis and programming), some resistance was encountered. Many excuses were given; tight schedule, group 
knowledge and experience, etc., but it was easy to see that the real reason was a power-related one. According to its members, this group already had an effective way of managing and organizing themselves. They were really saying is that they do not want or need the "pilot" approach. The manager would have had to relinquish his power to an outside project leader. Because of the opposition, project A was never organized as a "pilot" project.

On the other hand, project B was assigned a project leader and successfully organized under the "pilot" umbrella. Despite the initial success, some difficulties were encountered over the course of the project. The new approach raised questions that have not yet been answered. What is the new role of the line managers? of the extended team? Who is responsible in case of failure? How do you create a common sense of ownership among very heterogeneous group members? The oppositional culture of the organization makes it particularly difficult to adopt this new approach. To be successful, more than a change in procedure is needed; a profound change in culture is necessary. A differentiation perspective focuses on these historically deep divisions among departments and makes us aware of the tremendous difficulty of implementing a new structure that requires interdepartmental teamwork. 


\subsubsection{The Fragmentation Perspective}

Any major change increases the level of uncertainty in the organization and brings confusion. Different stories gave us examples of the uncertainty surrounding a change in organizational procedure. For example, in one case, the respondent did not know that he was part of a pilot team. It was for me a surprising fact as I had seen his name on the project list and knew those lists to be up-to-date.

Contradictions also arise and put more pressure on the successful implementation of change. Members have to deal with the paradox of selfinterest and the need to collaborate closely on those teams. Ideally, the organization would like to tend toward a matrix organization for system development. This involves putting teams together for a certain time and then dismantling them at the end of a project. Members would then go back to their own functional units. In such a context, contradictions may appear between the project team culture and the culture of the members' functional units. For example, team members would have to deal with the usual competition among groups (as members of their functional unit) and the contradictory need to collaborate with their project team. A contradiction also exists in the case where the development group refused to manage project $A$ (as discussed in the previous section) as a pilot project. It was against the development group's culture to be 
managed by an outside project leader. The decision to refuse the new working approach was a way to put an end to that contradiction. In one way or another, contradictions will have to be dealt with by team members and development groups.

The new organization form will group together heterogeneous people who are not used to working together. In such a context, priorities, values and norms will have to be constantly negotiated. Roles will need to be constantly redefined as more and more teams are put together. Line managers, for example, will have to relinquish some power and play, if any, a role of consultant to the different teams.

The previous analysis supports the important role that culture plays in implementing changes in an organization. While the integration and differentiation (to a certain degree) perspectives assume that the culture can be cleverly manipulated in order to facilitate changes, the fragmentation perspective highlights the dynamic and, more importantly, uncontrollable dimensions of culture. Culture can only be observed and acknowledged. Under the fragmentation perspective, the culture of an organization is continuously under the pressure of different forces (such as team composition, organization priorities, external forces (from competitors or partners)) and will therefore be influenced by any changes occurring in the organization. This is why it is possible to say 
that, under this perspective, change influences the culture and the culture influences the changes (their rejection or acceptance or the result of some negotiation process). Managers need to be aware of this dynamic characteristic of culture; it may explain the failure of some attempts to consciously change the culture of an organization.

\subsubsection{Outsourcing}

A rapidly growing trend in the IS field, outsourcing has attracted a lot of attention in the literature (for example, Huff, 1991; Loh \& Venkatraman, 1992a; 1992b; Lacity \& Hirschheim, 1993). Organizations decide to outsource for a variety of reasons: to reduce and control costs, to have access to greater skills and knowledge, or to concentrate on their core business (Huff, 1991). Software Corp. outsourced a large part of its operations ${ }^{1}$ in a final attempt to save the organization. Outsourcing brings its own set of advantages and challenges. It brings together two organizations that have different histories, cultures and ways of conducting business. "While legal contracts are still used, the spirit of outsourcing is one of partnerships, strategic alliances and long term relationships between the vendor and client firms. While facilities management is like a dating service, outsourcing is more like marriage" (Huff, 1991, p.62). The three

1. In this particular case, all the mainframe programming, the telecommunications activities, the computer support and operations, the client installation and technical support were outsourced. 
perspectives can help us better understand the importance of culture in this relationship.

\subsubsection{The Integration Perspective}

The role of culture under an integration perspective is to build a set of values, norms and priorities that are shared throughout the organization. We have seen that the survival instinct was an important theme for Software Corp. and the outsourcing deal was a way to respond to this desire to stay in business. Outsourcing was also a way to streamline the organization (through a tighter focus on design and marketing) and, under the integration perspective, to make it more culturally manageable and controllable. Outsourcing also provided the organization with a common group to oppose, which helped to develop a sense of internal unity. Finally, one of the objectives of the outsourcing deal was to free Software Corp. of some operations details and allow it to focus on customer needs. This also give a direction to the entire organization. In fact, for a long time, employees complained about the lack of direction or vision coming from top management. With decreased responsibilities, top management was able to pay attention to this issue. 
If we look at the partnership as a whole, the differentiation perspective highlights the differences between the two groups. According to the stories told by Software Corp. respondents, the culture clash between the two organizations is at the heart of many difficulties. Despite the fact that Software Corp. is serviced by its former employees, current employees seem to agree that Partner Inc.'s management deteriorated the working relationship between them. As briefly discussed before, the organizational cultures of the two partners are quite different. Partner Inc.'s organizational culture is still influenced by its military founder. It is a very large, formal and bureaucratic organization. It has a lot of rules to work by. Because the partnership is contract-bound, everything needs to be in writing, authorized, prioritized and controlled. This seems to be a little difficult for some Software Corp. employees. Many of them find these rules are obstacles to quick problem resolution. Software Corp.'s culture is more laid back. Because the organization is much smaller, it is more personalized and can respond more rapidly to problems and customer needs. Because Partner Inc. takes care of some strategic pieces, Software Corp. employees sometimes question Partner Inc.'s good will and how they set priorities. Despite the fact that they have been together almost three years, Partner Inc. does not understand their business and the implications of their decisions. Over time, these episodes create friction and complicate the relationship between the two partners. 
Finally, the fragmentation perspective highlights the uncertainty created by this outsourcing deal. Software Corp. now has an additional party to contend with. Because it has relinquished a strategic part of its activities, Software Corp. has to have full confidence that things will be handled professionally by Partner Inc. The work situation between the two can always be changed if the account manager is replaced or if new Partner Inc. employees are assigned to Software Corp.'s projects. Any changes require negotiation which brings uncertainty. As a matter of fact, Software Corp. has a team of people taking care of misunderstandings, performance levels, and contract interpretations with Partner Inc. In addition, because Software Corp. feels like Partner Inc does not understand its business, it is always on its toes to make sure decisions are not be made without prior analysis.

Possible contradictions can also be highlighted in this partnership. At the beginning of the relationship, transferred employees had to reconcile the philosophy of their new organization (Partner Inc.) with their usual way of doing business. Software Corp.'s employees also had to deal with a different set of rules at Partner Inc. (such as the dress code for the training session). Living by those rules contradicts the culture of their organization but facilitates their interaction with Partner Inc. 
The culture of an organization influences relationships inside and outside the organization. The previous analysis has shown how organizational culture influenced the relationship of an organization with its outsourcing partner. Because an outsourcing contract is almost a "marriage" as Huff said (1991), the integration perspective would recommend getting to know a potential parther before venturing to a long-term outsourcing relationship. The differentiation perspective, on the other hand, would suggest defining and getting acquainted with the particular group the organization will have to work with. Under this perspective, the general culture of the organization will not necessarily be a reflection of the culture of a particular working group. Finally, the fragmentation perspective would highlight the fragility of the culture of that particular group. Any changes could tremendously shift its culture.

The table that follows (Table 5.3) summarizes the two IS activities - team organization and outsourcing - by perspective. It provides some insights highlighted by the use of the three perspectives. 


\section{IS ISSUES BY PERSPECTIVE}

\begin{tabular}{|c|c|c|c|}
\hline & NNTCGNATOU & OIHIUR NTM TION & 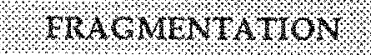 \\
\hline Trantaration & $\begin{array}{l}\text { The change is an } \\
\text { attempt at integrating } \\
\text { under a common goal } \\
\text { some divergent forces } \\
\text { in the organization } \\
\text { (making groups having } \\
\text { different priorities and } \\
\text { ways of doing things } \\
\text { work and collaborate } \\
\text { together). }\end{array}$ & $\begin{array}{l}\text { New team organization } \\
\text { challenges the actual } \\
\text { culture among groups } \\
\text { based, in this case, on } \\
\text { power and competition } \\
\text { rather than } \\
\text { collaboration. } \\
\text { For this reason, it is } \\
\text { easy to predict } \\
\text { implementation } \\
\text { difficulties. }\end{array}$ & $\begin{array}{l}\text { Changes increase } \\
\text { uncertainty. } \\
\text { New people having to } \\
\text { work together will have } \\
\text { to constantly negotiate } \\
\text { priorities, ways to do } \\
\text { and go about things, } \\
\text { values and norms. } \\
\text { Members will need to } \\
\text { deal with contradictions } \\
\text { arising from differences } \\
\text { between their project } \\
\text { team's culture and their } \\
\text { functional unit's one. }\end{array}$ \\
\hline OHrourcurs & $\begin{array}{l}\text { An outsourcing deal } \\
\text { may help the } \\
\text { organization to put } \\
\text { together all its } \\
\text { strengths and use them } \\
\text { to focus and achieve a } \\
\text { common goal. } \\
\text { Having a clear group } \\
\text { to oppose to may also } \\
\text { help create a sense of } \\
\text { unity inside the } \\
\text { organization. }\end{array}$ & $\begin{array}{l}\text { Outsourcing deals bring } \\
\text { together two groups } \\
\text { having different visions, } \\
\text { priorities, values and } \\
\text { norms. This explains } \\
\text { some difficulties in the } \\
\text { relationship. } \\
\text { This perspective also } \\
\text { highlights the need to } \\
\text { get to know an eventual } \\
\text { partner before signing a } \\
\text { long-term contract. }\end{array}$ & $\begin{array}{l}\text { The implications of } \\
\text { vendors in daily } \\
\text { activities contribute to } \\
\text { adding a new player in } \\
\text { the dynamic forces } \\
\text { constituting the culture } \\
\text { of the organization. } \\
\text { As it would happen for } \\
\text { new people working } \\
\text { together inside the } \\
\text { organization, an } \\
\text { outsourcing will bring an } \\
\text { additional dimension to } \\
\text { team working and } \\
\text { priorities, ways to do } \\
\text { and go about things, } \\
\text { values and norms will } \\
\text { have to be negotiated. } \\
\text { These negotiated values, } \\
\text { norms, procedures may } \\
\text { end up being in } \\
\text { contradiction with } \\
\text { Software Corp.'s ones. }\end{array}$ \\
\hline
\end{tabular}

The culture defines the organization and the different groups working together and interacting. It influences how organizational life is, how members respond to changes and how relationships are carried out inside and outside the 
organization. The objective of this chapter was to show how the three cultural perspectives could be simultaneously used to get a richer understanding and interpretation of organizational activities and more specifically IS activities. After a discussion of the nature of the stories found in the interviews, I looked at themes, functions and IS activities through the three perspectives. 


\section{CHAPTER 6}

\section{CONCLUSION}

Using three organizational culture perspectives, this study applied a qualitative method to elicit and interpret organizational stories about the IS activities of a single organization. This chapter will summarize the results of the study by briefly answering the three research questions. The next section will then discuss the implications of the results for practice and research. Finally, the limitations of the study and some possible future research avenues will be highlighted.

\subsection{Summary of Results}

Because of the lack of research in this area, this study's general objective, was to investigate of the role of organizational culture in IS activities. Importantly, the study did not want to be restricted by the usual perspective used to define organizational culture. Three perspectives, integration, differentiation, and fragmentation, were therefore used simultaneously to conduct a more thorough and insightful investigation. The objective was not to find the best perspective, but to use them simultaneously and see how they could enrich our comprehension of organizational phenomena. 
Because no such work had been performed in the IS field before, the first goal was to investigate the types of IS stories told in an organization and see what kinds of messages they were conveying. The first discovery was about the nature of the stories. Surprisingly, the spectrum was larger than what is usually acknowledged in the management literature. The literature usually emphasizes "widely shared" stories about management actions. The results of this study show that stories are told by people at all levels. It also shows that stories are about anybody who is related to the organization in some way; it can be the employees, an outsourcing partner, or the clients. More important is that whatever their origin or topic or whether they were widely shared or not, all stories carried a message that was important for the teller and that revealed an interesting facet of the organization. Even if the source of some stories was not the same, the message often was. This data was too interesting to be discarded.

Another part of this research question was about the messages carried by stories. The messages really seem to be a good indicator of the culture of the organization. Because it was possible to group most of the content themes under the nine grand themes, we can say that most stories, to various degrees, relate to some fundamental issues and values for the organization. Some grand themes - humanist image, pride, survival instinct - refer directly to organizational 
values, others - uncertainty, constant changes, and challenging work - refer to the organizational environment, while finally, others - cultural differences with outsourcing partner, difficulties in working together, resistance to change represent important internal issues (or problematic situations) for the organization.

A second research question pertained to the functions of stories. More than the "integrative" or "controlling" roles that are usually assigned to stories in the literature (as included in Dandridge and colleagues' framework (1980)), I found that stories could fulfill a larger spectrum of functions. It is possible for stories to be used, for example, to identify problems, to assign blame, and for selfpromotion. They can also be used to play a "divisive" role or to rationalize organizational actions and explain contradictions.

Finally, the goal of the third research question was to investigate how the content of stories relates to practices in information systems. It was shown throughout Chapter 5 that many of the themes identified could be closely related and could explain some organizational context surrounding IS activities. For example, some themes such as resistance to change and difficulties in working together illustrate very well the difficulties management had in trying to implement a new team approach to system development. The theme cultural differences (mainly on values and priorities) also illustrates some of the friction 
and tense relationships that occurred between the organization and its outsourcing partner. To complete the investigation of this question, it was shown how the three organizational culture perspectives could help in the analysis of IS activities such as outsourcing and system development team reorganization (change). We will now see how those results can be of use to practitioners and researchers.

\subsection{Implications for Practice}

Stories are a powerful means of communication and a very efficient way to gather information about the culture of an organization. They help focus on key events that have helped define and shape what an organization has become over the years and remain an important source of information for anyone inside or outside an organization. We need to be attentive to the recurring messages. They reflect the organizational reality because they contain expressions of what is important at all levels of an organization.

The application of the three organizational culture perspectives, integration, differentiation, and fragmentation, to look at a single organization raises questions about the easy solutions often promised by the integration perspective and the people who use it (consultants, for example). Claims made about the somewhat easy manipulation of culture by managers are debatable. A larger 
conceptualization based on the use of the three perspectives may help explain the difficulties or lack of results of those miracle recipes. The three organizational culture perspectives show that the culture of an organization is a complex organizational process; its control can hardly be considered to be exclusively in the hands of top management. The three perspectives offer a complete framework for performing organizational analyses.

The organization studied had its own characteristics and culture, but faced many contemporary issues that also touch other organizations. We saw that all the relationships carried out inside or outside the organization reflected the important cultural themes identified in this organization. Despite the lack of prediction and prescription, applying the three perspectives to look at a particular organizational context may help raise important questions that could help in the management of IS activities. Whether we believe that culture is at the organization level (such as in the integration perspective), at the group level (such as in the differentiation perspective) or constantly negotiated by interacting people (such as under the fragmentation perspective), culture creates the environment or the context where IS activities take place and emphasizes the importance of that context in understanding the social relationships that are carried on. This is rather important given that IS development, for example, is considered more and more as a social activity (Boland, 1985; Hirschheim et al., 1991). Looking at culture with more than an "integration" point of view helps identify divergent 
forces in the organization which can lead, as we have seen, to tense relationships, difficulties in working groups, or resistance to change. Changes in an organization have to take the existing culture into consideration. This is why the identification of organizational themes is so important. It must be taken into consideration that even if, in general, the culture is in a certain way (at the management level), for example, it cannot be presumed that it is the same everywhere in the organization and that decisions can easily be made considering the culture prevailing in one particular group (it also has to be assumed that, even inside a group, sensitive issues can shift the actual culture and rules may change). Even if an organization seems to agree on an issue (a change, for example), the differentiation perspective may highlight pockets of resistance, the actors involved, and the reasons for this situation. A look at the personality of each and every formal and informal group in the organization may be the key to organizational understanding.

In the very competitive market in which organizations evolve today, sources of uncertainty are omnipresent. Organizations need to identify those sources, learn to deal with them, and acknowledge the impacts they can have on the culture of the organization. These impacts can take several forms. As was seen in the organization studied, these sources may help shape the values in the organization. For example, I found that the uncertainty surrounding the future of the organization was a force that helped explain the difficulties groups had 
working together. More importantly, it is important to acknowledge that sources of uncertainty add new actors (for example, another company, client or working group) changing the way people interact and the environment in which they evolve. When new people are closely involved in an activity, a subtle process of negotiation is initiated which will define the culture of that group. Any change (conflicting or new issues, change to the composition of the group, outside events, etc.) can affect its fragile equilibrium. This may explain why, after a period of peaceful work, a group gets into a state of chaos.

In summary, the organizational culture perspectives provide us with tools to analyze the context of IS activities while stories help uncover important organizational messages. The perspectives allow us to put IS activities in a larger, more global organizational context that includes every organizational actor in their daily interactions.

\subsection{Implications for Research}

This study has shown the richness provided by the application of the three organizational culture perspectives to a single organization. The use of the integration perspective would have excluded the study of the differences among groups. One interesting observation here is that Software Corp. appears to have stayed away from the whole strong culture concept. It did not try (or failed, 
according to the integration view) to give people a sense of unity, which is so often recommended by consultants looking at culture from an integration perspective (for example, Peters \& Waterman, 1982). Under this paradigm, managers are supposed to act on culture, to make it strong and stable. This is hardly the case here on an organization-wide basis, but is more likely to happen at the group level (for example, ProdA group). The differentiation perspective highlighted the organization's lack of cohesion and allowed me to look at those differences more closely.

In addition, the sole use of the integration perspective would not have acknowledged the role uncertainty can play, which was a major factor at Software Corp. The importance of the effect of uncertainty on any organization lies in its sources and its impacts. In addition to the on-going negotiations of culture (priorities, issues, norms, and values) among individuals or working groups that are acknowledged under the fragmentation perspective, additional players reflecting different sources of uncertainty (new groups, financial situation, clients ${ }^{\prime}$ demands) can unexpectedly and tremendously change the rules of the game.

The fragmentation perspective on organizational culture also explains very well the contradictions that may exist in the organization at any one point. For example, despite a strong will to survive, groups in the organization do not collaborate or work together very efficiently. Under an integration perspective, 
one would have focused on the more "widespread" theme and discounted the others or considered them as noise. Under the fragmentation perspective, it is possible to acknowledge the simultaneous presence of contradictory themes and even investigate and understand why they exist; in this case, the history of the organization was an important factor in this coexistence. The fragmentation perspective also allows us to look at stories as a mechanism for coping with and making sense of organizational uncertainty.

After an investigation of the functions of stories, it was also possible to identify the bias in Dandridge and colleagues' (1980) framework. This framework included only the "integrative" roles of symbols and stories. Additional functions, more closely related to the differentiation perspective, such as showing problems, assigning blame or self-promotion, were identified in some stories. These functions were added to the list of functions that can be fulfilled by stories in an organizational context. These functions exemplify the "divisive" roles that stories can play in an organization.

Overall, the use of the three perspectives has revealed the bias present in the management literature on the concept of organizational culture. The definition of a story and the investigation of its functions in the organization have been completely developed using an "integration" perspective. The actions of lower level employees are mostly ignored and the act of telling a story is only 
seen as a device to unite people in the same direction. The results of this study showed something different: it can be highly appropriate to broaden the definition of stories to include more than the "widely shared" and "top management" stories. Other organization members also have interesting things to say that need to be considered. I would suggest to organizational culture researchers that they question the appropriateness of the perspective they use, consider the richness of possible alternatives, and carefully argue their positions and biases.

More specifically, this study has shown how a broadening of the organizational culture concept can help us understand the organizational environment surrounding IS activities. While the different organizational culture perspectives have been shown to be useful in analyzing activities such as reorganization and outsourcing, they may very well be extended to other IS activities. For example, the differentiation perspective can provide a framework for analyzing the reactions of different groups to the implementation of a particular system. The fragmentation perspective may help in understanding the initial set up process (and difficulties) when a new group from diverse departments is assembled to design a system. This perspective would help highlight and focus on the negotiation process that needs to take place in order for these people to develop their own culture and ways of working. 
In summary, this study provides some empirical foundations to support the look at organizational culture as an important variable of the context in which IS activities are carried out. It also argues for a broader conceptualization of the concept of organizational culture to allow for a newer look at phenomena and the investigation of questions that have been so far dismissed as noise.

\subsection{Limitations and Future Research}

The method for data collection was particularly difficult to choose. In such a study, getting the stories is a delicate operation. Unknown tape-recording would be the best, but is unfortunately illegal! Any means, whether direct observation or tape-recording, is an intrusive mechanism and, to some extent, affects the behavior of organization members. A possible but difficult alternative would be the involvement of the researcher as a participant-observer over a long period of time. The researcher who is also an organization member would have complete and unobtrusive access to organizational stories. Unfortunately, this is not really a feasible option.

Considering the time constraints I had and the weaknesses of the alternatives, I decided that I would extract the stories from the interviews. I tried to minimize the limitations of that approach in two ways. First, I did not probe the respondent for stories. I let the conversation flow freely and used stories that 
were told naturally by respondents. I therefore feel that the stories reflect their organizational reality and are not subject to demand characteristics (see Rosenthal \& Rosnow, 1991). I also used cross-validation to assure the validity of the stories I gathered. In addition to the stories, I had a lot of formal and informal conversations with organization members. Even if the same stories were not repeated word for word, the same messages and themes recurred. The nine themes identified represent important dimensions of the organization studied.

Taking the method into consideration and allowing for the possibility of investigating the functions of stories, I assumed that the stories would have been told in a similar fashion to other organizational members. Two things allowed me to think this. First, as discussed previously, cross-validation allowed me to see that the messages carried in the stories were widespread throughout the organization. It can therefore be hypothesized that the same stories are told with or without my presence. Second, people seemed very involved in the stories they told me. For example, many of the stories were assigned a "reflective" function (where, in addition to a basic description, people were expressing a position, an opinion or an emotion); they relate important dimensions of people's lives. This leads me to believe that they would be repeated in the organization.

By focusing on stories, this study does not want to denigrate the role of other symbolic activities or cultural manifestations in the organization. However, 
the use of only one type of symbol helped me focus and made sure I did not get lost in an ocean of data. By allowing a broader range of stories than is usually acknowledged in the management literature, I think I had enough relevant data to get a rather complete picture of the culture of Software Corp.

Alternatively, other choices could have been made and a wider variety of symbols studied. However, the IS activities looked at and the range of symbols would have to be carefully defined in order to keep the project manageable. The idea would be to make it more focused. For example, a wider range of symbols could be used for a very specific activity, such as outsourcing, for example.

This study was intended, and I hope succeeded, in providing some insights into organizational culture as a variable of the context surrounding IS activities. One further interesting study would be to replicate this study in other organizations. I think that the best approach would be to use the same data collection strategy (stories and themes extraction) and very specific IS activities, and study that relationship in many different organizations. The results could be very enlightening.

In conclusion, I hope that research of organizational culture and its influence on the organizational context surrounding IS activities will continue. This type of research offers its own challenges, but, piece by piece, could really 
enhance practitioners' and researchers' comprehension of the complex organizational environment surrounding IS activities. 


\section{REFERENCES}

Ahituv, N., \& Neumann, S. (1984). A flexible approach to information system development. MIS Quarterly $\underline{8}(2), 69-78$.

Bauman, R. (1986). Story, Performance, and Event: Contextual Studies of Oral Narrative. New York: Cambridge University Press.

Berger, P., \& Luckmann, T. (1967). The Social Construction of Reality. New York: Doubleday.

Bernard, H. R. (1988). Research Methods in Cultural Anthropology. Newbury Park, CA: Sage.

Boje, D. M. (1991). The storytelling organization: A study of story performance in an office-supply firm. Administrative Science Quarterly, 36, 106-126.

Boland, R. J. (1979). Control, causality and information system requirements. Accounting, Organizations and Society 4 (4), 259-272.

Boland, R. J. (1985). Phenomenology: A preferred approach to research on information systems. In E. Mumford, R. Hirschheim, G. Fitzgerald, \& A. T. Wood-Harper, Research Methods in Information Systems, (pp. 193-201). North-Holland: Elsevier.

Borum, F. (1980). Systems design and scientific management. Acta Sociologica, 23 287-295.

Caldwell, D. F., \& O'Reilly, C. A., III (1990). Measuring person-job fit with a profile-comparison process. Journal of Applied Psychology 75(6), 648-657.

Chatman, J. A. (1989). Improving interactional organizational research: A model of person-organization fit. Academy of Management Review, 14(3), 333-349.

Cohen, A. (1974). Two Dimensional Man: An essay on the Anthropology of Power and Symbolism in Complex Society. London: Routledge and Kegan Paul.

Cooke, R. A., \& Rousseau, D. M. (1988). Behavioral norms and expectations: A quantitative approach to the assessment of organizational culture. Group \& Organization Studies, 13(3), 245-273. 
Czarniawska-Joerges, B. (1992). Exploring Complex Organizations: A Cultural Perspective. Newbury Park, CA: Sage.

Daft, R. L. (1980). The evolution of organization analysis in ASQ, 1959-1979. Administrative Science Quarterly, 25(4), 623-636.

Dandridge, T. C. (1983). Symbols' function and use. In L. R. Pondy, P. J. Frost, G. Morgan, \& T. C. Dandridge (Eds.), Organizational Symbolism (pp.69-79). Greenwich, CT: JAI Press.

Dandridge, T. C., Mitroff, I., \& Joyce, W. F. (1980). Organizational symbolism: A topic to expand organizational analysis. Academy of Management Review, $\underline{5}(1), 77-82$.

Davis, G. B., Lee, A. S., Nickles, K. R., Chatterjee, S., Hartung, R., and Wu, Y. (1992). Diagnosis of an information system failure; A framework and interpretive process. Information \& Management 23, 293-318.

Deal, T. E., \& Kennedy, A. A. (1982). Corporate cultures: The rites and tituals of corporate life. Reading, MA: Addison-Wesley.

Denison, D. R. (1990). Corporate culture and organizational effectiveness. New York: John Wiley.

Drucker, P. F. (1988, January/February). The coming of the new organization. Harvard Business Review, 45-53.

Ebers, M. (1985). Understanding organizations: The poetic mode. Iournal of Management, 11(2), 51-62.

Erez, M, \& Earley, P. C. (1993). Culture, Self-Identity, and Work. New York: Oxford University Press.

Feldman, S. P. (1990). Stories as cultural creativity: On the relation between symbolism and politics in organizational change. Human Relations, 43(9), 809-828.

Francis, D., \& Woodcock, M. (1990). Unblocking organizational values. San Diego: University Associates.

Franz, C. R., \& Robey, D. (1984). An investigation of user-led system design: Rational and political perspectives. Communications of the ACM, 27(12), 1202-1209. 
Franz, C. R., \& Robey, D. (1987). Strategies for research on information systems in organizations: A critical analysis of research purpose and time frame. In R. J. Boland, Jr. \& R. A. Hirschheim (Eds.), Critical Issues in Information Systems Research (pp.205-225). New York: John Wiley.

Galbraith, J. R. (1973). Designing Complex Organizations. Reading, MA: AddisonWesley.

Gardner, M. P. (1985, January/February). Creating a corporate culture for the eighties. Business Horizons, pp. 59-63.

Geertz, C. (1973). The Interpretation of Cultures: Selected Essays. New York: Basic Books.

Georges, R. A. (1969). Toward an understanding of storytelling events. Journal of American Folklore, $\underline{82}$, 313-328.

Gray, B., Bougon, M. G., \& Donnellon, A. (1985). Organizations as constructions and destructions of meaning. Iournal of Management, 11(2), 83-98.

Green, S. (1988). Strategy, organizational culture and symbolism. Longe Range Planning, 21(4), 121-129.

Gregory, K. L. (1983). Native-view paradigms: Multiple cultures and culture conflicts in organizations. Administrative Science Quarterly 28, 359-376.

Grover, V., Lederer, A. L., \& Sabherwal, R. (1988). Recognizing the politics of MIS. Information \& Management 14, 145-156.

Hackman, J. R. (1985). Doing research that makes a difference. In E. E. Lawler III, A. M. Mohrman, Jr., S. A. Mohrman, G. E. Ledford, Jr., T. G. Cummings and Associates, Doing Research That Is Useful for Theory and Practice, (pp.126-149). San Francisco: Jossey-Bass.

Hammer, M. (1990, July/August). Reengineering work: Don't automate, obliterate. Harvard Business Review, 104-112.

Herzfeld, M. (1985). The Poetics of Manhood: Contest and Identity in a Cretan Mountain Village. Princeton: Princeton University Press.

Hirschheim, R. A. (1986). The effect of a priori views on the social implications of computing: The case of office automation. Computing Surveys, 18(2), 165-195. 
Hirschheim, R., \& Klein, H. K. (1989). Four paradigms of information systems development. Communications of the ACM, 32(10), 1199-1216.

Hirschheim, R., Klein, H. K., \& Newman, M. (1991). Information systems development as social action: Theoretical perspective and practice. OMEGA International Journal of Management Science, 19(6), 587-608.

Hirschheim, R., \& Newman, M. (1991). Symbolism and information system development: Myth, metaphor and magic. Information Systems Research, 2(1), 29-62.

Huber, G. P. (1984). The nature and design of post-industrial organizations. Management Science 30(8), 928-951.

Huff, S. (1991, Spring). Outsourcing of information services. Business Quarterly 55 (4), $62-65$.

Jelinek, M., Smircich, L., \& Hirsch, P. (1983). Introduction: A code of many colors. Administrative Science Quarterly 28, 331-338.

Jones, M. R. (1991). The impact of organizations on computers. SIGCHI Bulletin, 23(1), 66-67.

Joshi, K. (1990), Reorganization of the work system for successful information systems implementation. Information \& Management, 19, 271-284.

Keen, P. G. W. (1981). Information systems and organizational change. Communications of the ACM $24(1), 24-33$.

Kendall, K. E., Buffington, J. R., \& Kendall, J. E. (1987). The relationship of organizational subcultures to DSS user satisfaction. Human Systems Management, Z, 31-39.

Kilmann, R. H., Saxton, M. J., \& Serpa, R. (1985). Introduction: Five key issues in understanding and changing culture. In R. H. Killmann, M. J. Saxton, \& R. Serpa (Eds.), Gaining control of the corporate culture, (pp. 1-16). San Franscisco: Jossey-Bass.

Kling, R. (1980). Social analyses of computing: Theoretical perspectives in recent empirical research. Computing Surveys, 12(1), 61-110.

Kling, R. (1987). Defining the boundaries of computing across complex organizations. In R. J. Boland, Jr. \& R. A. Hirschheim (Eds.), Critical Issues in Information Systems Research (pp.307-362). New York: John Wiley. 
Kling, R. and Iacono, S. (1989). "The Institutional Character of Computerized Information Systems." Office: Technology and People, 5(1), 7-28.

Knights, D., \& Willmott, H. C. (1987). Organizational culture as management strategy: A critique and illustration from the financial services industry. International Studies of Management \& Organizations, 17(3), 40-63.

Kwon, T. H., \& Zmud, R. W. (1987). Unifying the fragmented models of information systems implementation. In R. J. Boland, Jr. \& R. A. Hirschheim (Eds.), Critical Issues in Information Systems Research, (pp.227251). New York: John Wiley.

Lacity, M. C., \& Hirschheim, R. (1993). Information Systems Outsourcing: Myths, Metaphors and Realities. New York: John Wiley.

Lewin, K. (1947). Frontiers in group dynamics. Human Relations, (1), 5-41.

Lincoln, Y. S., \& Guba, E. G. (1985). Naturalistic Inquiry. Newbyry Park: Sage.

Loh, L., \& Vankatraman, N. (1992a). Diffusion of information technology outsourcing: Influence sources and the Kodak effect. Information Systems Research, $\underline{3}(4), 334-358$.

Loh, L., \& Vankatraman, N. (1992b). Determinants of information technology outsourcing: A cross-sectional analysis. Lournal of Managemenet Information Systems, 8, 7-24.

Lorsch, J. W. (1985). Strategic myopia: Culture as an invisible barrier to change. In R. H. Killmann, M. J. Saxton, \& R. Serpa (Eds.), Gaining control of the corporate culture, (pp. 84-102). San Franscisco: Jossey-Bass.

Louis, M. R. (1980). Surprise and sense making: What newcomers experience in entering unfamiliar organizational settings. Administrative Science Quarterly, 25, 226-251.

Louis, M. R. (1983). Organizations as culture-bearing milieux. In L. R. Pondy, P. J. Frost, G. Morgan, \& T. C. Dandridge (Eds.), Organizational Symbolism, (pp.39-54), Greenwich, CT: JAI Press.

Louis, M. R. (1985). An investigator's guide to workplace culture. In P. Frost, L. Moore, M. Louis, C. Lundberg, \& J. Martin (Eds.), Organizational Culture, (pp. 73-94). Beverly Hills, CA: Sage. 
Lucas, H. C., Jr. (1985). The analysis, design, and implementation of information systems (3rd edition). New York: McGraw-Hill.

Lucas, R. (1987). Political-cultural analysis of organizations. Academy of Management Review 12(1), 144-156.

Lyytinen, K., \& Hirschheim, R. (1987). Information systems failures - a survey and classification of the empirical literature. Oxford Surveys in Information Technology 4, 257-309.

March, J. G., \& Olsen, J. P. (1976). Ambiguity and Choice in Organizations. Bergen: Universitetsforlaget.

Markus, M. L. (1981). Implementation politics: Top management support and user involvement. Systems, Objectives, Solutions, 1, 203-215.

Markus, M. L. (1984). Systems in Organizations: Bugs + Features. Boston: Pitman.

Markus, M. L., \& Robey, D. (1988). Information technology and organizational change: Causal structure in theory and research. Management Science, 34(5), 583-598.

Martin, J. (1982). Stories and scripts in organizational settings. In A. H. Hastorf, \& A. M. Isen (Eds.), Cognitive Social Psychology (pp.255-305). New York: Elsevier.

Martin, J. (1992). Cultures in Organizations; Three Perspectives. New Yord: Oxford University Press.

Martin, J., Feldman, M. S., Hatch, M. J., \& Sitkin, S. B. (1983). The uniqueness paradox in organizational stories. Administrative Science Quarterly, 28, 438-453.

Martin, J., \& Meyerson, D. (1988). Organizational cultures and the denial, channeling and acknowledgment of ambiguity. In L. R. Pondy, R. J. Boland, Jr., \& H. Thomas (Eds.), Managing Ambiguity and Change (pp.93125). New York: John Wiley.

Martin, J., \& Powers, M. E. (1983a). Truth or corporate propaganda: The value of a good war story. In L. R. Pondy, P. J. Frost, G. Morgan, \& T. C. Dandridge (Eds.), Organizational Symbolism, (pp.93-107). Greenwich, CT: JAI Press. 
Martin, J., \& Powers, M. E. (1983b). Organizational stories: More vivid and persuasive than quantitative data. In B. M. Staw (Ed.), Psychological Foundations of Organizational Behavior (2nd ed.), (pp.161-168). Glenview, IL: Scott, Foresman and Company.

McConkie, M. L., \& Boss, R. W. (1986). Organizational stories: One means of moving the informal organization during change efforts. Public Administration Quarterly 10(2), 189-205.

McCracken, G. (1988). The Long Interview. Newbury Park, CA: Sage.

Meek, V. L. (1988). Organizational culture: Origins and Weaknesses. Organization Studies, 9(4), 453-473.

Meyerson, D., \& Martin, J. (1987). Cultural change: An integration of three different views. Iournal of Management Studies, 24(6), 623-647.

Mirvis, P. H., Sales, A. L., \& Hackett, E. J. (1991). The implementation and adoption of new technology in organizations: The impact on work, people, and culture. Human Resource Management, 30(1), 113-139.

Mitroff, I. I., \& Kilmann, R. H. (1976). On organization stories: An approach to the design and analysis of organizations through myths and stories. In R. H. Kilmann, L. R. Pondy, \& D. P. Slevin (Eds.), The Management of Organization Design: Strategies and Implementation (Volume 1) (pp.189207). New York: North-Holland.

Morgan, G. (1986). Images of Organization. CA, Beverly Hills: Sage.

Morgan, G., Frost, P. J., \& Pondy, L. R. (1983). Organizational symbolism. In L. R. Pondy, P. J. Frost, G. Morgan, \& T. C. Dandridge (Eds.), Organizational Symbolism, (pp.3-35). Greenwich, CT: JAI Press.

Morgan, G., \& Smircich, L. (1980). The case of qualitative research. Academy of Management Review, 5(4), 491-500.

Morieux, Y. V. H., \& Sutherland, E. (1988). The interaction between the use of information technology and organizational culture. Behaviour and Information Technology Z(2), 205-213.

Mouritsen, J. (1989). Accounting, culture and accounting-culture. Scandinavian Journal of Management, 5 (1), 21-47. 
Mowshowitz, A. (1981). On approaches to the study of social issues in computing. Communications of the ACM 24(3), 146-155.

Mumford, E. (1981). Values, Technology and Work. Boston: Martinus Nijhoff Publishers.

Myerhoff, B. (1978). Number Our Days. New York: E. P. Dutton.

Niederman, F., Brancheau, J. C., \& Wetherbe, J. C. (1991). Information systems management issues for the 1990s. MIS Quarterly 15(4), 474-495.

Newman, M., \& Robey, D. (1992). A social process model of user-analyst relationships. MIS Quarterly 16(2), 249-265.

Norman, R. J., \& Nunamaker, J. F., Jr. (1989). CASE productivity: Perceptions of software engineering professionals. Communications of the ACM 32(9), 1102-1108.

O'Reilley, C. (1989, Summer). Corporations, culture, and commitment: Motivation and social control in organizations. California Management Review, 9-25.

Orlikowski, W. (1988). CASE tools and the IS workplace: Some findings from empirical research. Proceedings of the 1988 ACM SIGCPR Conference of the Management of Systems Personnel, College Park, Maryland, 88-97.

Orlikowski, W. J. (1992). The duality of technology: Rethinking the concept of technology in organizations. Organization Science, 3(3), 398-427.

Orlikowski, W. J., \& Robey, D. (1991). Information technology and the structuring of organizations. Information Systems Research 2(2), 143-169.

Ott, J. S. (1989). The organizational culture perspective. Pacific Grove, CA: Brooks/Cole.

Peters, T .J., \& Waterman, R. H. (1982). In search of excellence, New York: Harper \& Row.

Pettigrew, A. M. (1979). On studying organizational cultures. Administrative Science Quarterly, 24, 570-581.

Pfeffer, J. (1981). Management as symbolic action: The creation and maintenance of organizational paradigms. In L. L. Cummings, \& B. M. Staw, Research in Organizational Behavior (volume 3), (pp.1-52). Greenwich, CT: JAI Press. 
Pliskin, N., Romm, T., Lee, A. S., \& Weber, Y. (1993). Presumed versus actual organizational culture: Managerial implications for implementation of information systems. The Computer Iournal, 36(2), 143-152.

Porter, M. E., \& Millar, V. E. (1985, July/August). How information gives you competitive advantage. Harvard Business Review, 149-160.

Riley, P. (1983). A structurationist account of political culture. Administrative Science Quarterly, 28, 414-437.

Robey, D. (1981). Computer information systems and organizational structure. Communications of the ACM 24(10), 679-687.

Robey, D., \& Azevedo, A. (1994). "Cultural analysis of the organizational consequences of information technology," Accounting, Management, and Information Technology, 4, 23-37.

Robey, D., \& Markus, M. L. (1984). Rituals in information system design. MIS Quarterly $\underline{8}(1), 5-15$.

Robey, D., \& Rodriguez-Diaz, A. (1989). The organizational and cultural context of systems implementation: Case experience from Latin America. Information \& Management 17 229-239.

Robey, D., \& Sales, C. (1994). Designing Organizations (4th ed.). Homewood, IL: Irwin.

Robey, D., Wishart, N. A, \& Rodriguez-Diaz, A. G. (1995). Merging the metaphors for organizational improvement: Business process reengineering as a component of organizational learning. Accounting, Management, \& Information Technology 5(1), 23-39.

Romm, T., Pliskin, N., Weber, Y., \& Lee, A. S. (1991). Identifying organizational culture clash in MIS implementation: When is it worth the effort ? Information \& Management, 21, 99-109.

Rosenthal, R., \& Rosnow, R. L. (1991). Essentials of Behavioral Research: Methods and Data Analysis. New York: McGraw Hill.

Sabherwal, R., \& Robey, D. (1993). An empirical taxonomy of implementation processes based on sequences of events in information system development. Organization Science, 4(4), 548-576. 
Sackmann, S. A. (1991). Uncovering culture in organizations. Journal of Applied Behavioral Science, 27(3), 295-317.

Sathe, V. (1985). Culture and Related Corporate Realities. Homewood, L: Irwin.

Schein, E. H. (1969). Process Consultation: Its Role in Organizational Development. Reading, MA: Addison-Wesley.

Schein, E. H. (1985). Organizational culture and leadership. San Francisco: JosseyBass.

Schein, E. H. (1991). What is culture? In P. J. Frost, L. F. Moore, M. R. Louis, C. C. Lundberg, \& J. Martin (Eds.), Reframing Organizational Culture, (pp. 243-253). Newbury Park, CA: Sage.

Scholz, C. (1990). The symbolic value of computerized information systems. In P. Gagliardi (Ed.), Symbols and artifacts: Views of the corporate landscape, (pp. 233-254). Berlin: de Gruyter.

Schwartzman, H. B. (1984). Stories at Work: Play in an organizational context. In E. D. Bruner (Ed.), Text, Play, and Story: The Construction and Reconstruction of Self and Society, (pp. 80-93). Washington, DC: American Ethnological Society.

Schwartzman, H. B. (1993). Ethnography in Organizations. Newbury Park, CA: Sage.

Scott Morton, M. S. (1991). Introduction. In M. S. Scott Morton (Ed.), The Corporation of the 1990s, (pp.3-23). New York: Oxford University Press.

Smircich, L. (1983a). Concepts of culture and organizational analysis. Administrative Science Quarterly 28, 339-358.

Smircich, L. (1983b). Studying organizations as cultures. In G. Morgan (Ed.), Beyond Method, (pp.160-172). Beverly Hills, CA: Sage.

Smith, K. K., \& Simmons, V. M. (1983). A rumpelstiltskin organization: Metaphors on metaphors in field research. Administrative Science Quarterly 28, 377392.

Staw, B. (1985). Spinning on symbolism: A brief note on the future of symbolism in organizational research. Journal of Management 11(2), 117-118. 
Swanson, E. B. (1987). Information systems in organization theory: A review. In R. J. Boland, Jr. \& R. A. Hirsch heim (Eds.), Critical Issues in Information Systems Research (pp.181-204). New York: John Wiley.

Swanson, E. B. (1988). Information System Implementation. Homewood, IL: Irwin.

Teresko, J. (1990, July 16). Make or buy? Now it's a data processing question too. Industry Week 54-55.

Trice, H. M. (1993). Occupational Subcultures in the Workplace. Ithaca, NY: ILR Press, Cornell University.

Trice, H. M., \& Beyer, J. M. (1984). Studying organizational cultures through rites and ceremonials. Academy of Management Review, 9(4), 653-669.

Trice, H. M., \& Beyer, J. M. (1993). The Cultures of Work Organizations. Englewood Cliffs, NJ: Prentice Hall.

Turner, B. A. (1986). Sociological aspects of organizational symbolism. Organization Studies, Z(2), 101-115.

Turner, B. (1990). The rise of organizational symbolism. In J. Hassard \& D. Pym, The Theory and Philosophy of Organizations: Critical Issues and New Perspectives, (pp.83-96). New York: Routledge.

Van Maanen, J. (1985). Spinning on symbolism: Disquisition. Iournal of Management 11(2), 119-120.

Vitale, M. R. (1986). The growing risks of information systems success. MIS Quarterly, 10(4), 327-334.

Walsham, G. (1991). Organizational metaphors and information systems research. European Journal of Information Systems, 1(2), 83-94.

Walsham, G. (1993). Interpreting Information Systems in Organizations. New York: John Wiley.

Weick, K. E. (1979). The Social Psychology of Organizing (2nd ed.). Reading, MA: Addison-Wesley.

Wilkins, A. L. (1983a). Organizational stories as symbols which control the organization. In L. R. Pondy, P. J. Frost, G. Morgan, \& T. C. Dandridge (Eds.), Organizational Symbolism, (pp.81-92). Greenwich, CT: JAI Press. 
Wilkins, A. L. (1983b). The culture audit: A tool for understanding organizations. Organizational Dynamics, 12(3), 24-38.

Wilkins, A. L. (1984). The creation of company cultures: The role of stories and human resource systems. Human Resource Management, 23(1), 41-60.

Winter, S. J. (1993). The symbolic potential of computer technology: Differences among white-collar workers. Proceedings of the Fourteenth Annual International Conference on Information Systems, Orlando, Florida.

Yin, R. K. (1989). Case study research: Design and Methods (revised edition). Newbury, CA: Sage.

Young, E. (1989). On the naming of the rose: Interests and multiple meanings as elements of organizational culture. Organization Studies, 10(2), 187-206. 
APPENDIX 1

INTERVIEW GUIDE 


\section{INTERVIEW GUIDE}

\section{INTRODUCTION}

Objective of the study.

Free participation in the study.

Confidentiality of the data.

\section{GETTING TO KNOW THEM}

What is your position?

What are your main responsibilities?

How long have you been with Software Corp.? What is your background?

What major projects are you involved in right now?

Do you think that Software Corp. is different from other organizations? How would you say it is different?

What methodology do you use in your work? Is it imposed?

What are the big issues going on in the organization right now?

\section{OUTSOURCING}

What was the need for outsourcing?

How are the relationships with Partner Inc?

What was the impact of this decision on Software Corp. people? on Partner Inc. people?

How is it different now compared to what it was before? 


\section{REENGINEERING PROJECT}

What was the need for such a project?

Have you been involved in any way in this project?

What do you expect out of this project?

What is the reaction of people to this project?

Do you know anything about the three pilot teams they have implemented?

\section{TRYING TO ELICIT STORIES}

Do you have any example of that?

What particular events make you think that?

Can you think of any well-known event which illustrates your feelings?

\section{MISCELLANEOUS}

How would you describe Software Corp. to a potential applicant?

What are the strengths and weaknesses of Software Corp.?

How is Software Corp. different from where you were working before? or any expectations of a work environment?

What surprised you when you first start working with Software Corp?

How do people mainly communicate (face to face, e-mail, voice mail, memo)? What is your best source of information?

How are the relationships between supervisor and employees? 


\begin{tabular}{|l||}
\hline Number: 1 \\
\hline Event: Absence from the office \\
\hline Story: (Analyst \#17-15) \\
"Sometimes I don't want it [any feedback]. Right now, I'm so overwhelmed, I don't \\
want the feedback. Don't tell me how I'm doing. I know I'm not doing well. I'm \\
feeling a little overwhelmed this week. Do I get enough feedback. I really don't \\
know how to answer that, because unless it's positive feedback, I don't want to \\
know. Don't give me any more problems. Yeah, I guess he's -' I guess he's - I can \\
tell how I'm doing by whether things are getting resolved. I judge my performance \\
by - for example, I went away for a week to a conference. I was away for a whole \\
week, and when I came back, there were no hot issues that required my attention, \\
that were waiting for my attention. Whatever came up, someone handled. I \\
consider that my success. That's what I consider a good job, for me."
\end{tabular}

\begin{tabular}{|l||}
\hline Number: 2 \\
\hline Event: $\quad$ Overworked employee \\
\hline Story: (Programmer $20-6)$ \\
"Actually, at first, I felt like they were taking advantage of me, really, because I was \\
here -- when I first started, I used to work odd hours. I used to work maybe 13 \\
hours a day, and working six days a week. Yeah, it was for a long time. Maybe a \\
lot of people do that now. I don't know, but coming from a new company, you \\
know, I was really working. I couldn't go to school, because I worked too much. \\
But maybe it was the time or the period. They didn't believe we needed another \\
person. I don't know. I finally gave up, and I just went to my manager and said, \\
"Listen, we need help. I can't be doing this, you know. I'm going to go nuts here." \\
But just in time, we started getting more help." \\
\end{tabular}




\begin{tabular}{|l||}
\hline Number: 3 \\
\hline Event: Promotion \\
\hline Story: (Programmer $\$ 20-6)$ \\
"I] At the promotion, they gave you a piece of paper, and it gave you the \\
evaluation. They tell you what your supervisor wrote about you or so forth. But I \\
came to them, and I said -- I told them that, you know, - my last raise, or my last \\
promotion was to xxxxxxxxx. I went to them before I was even getting that. I told \\
them, "I'm doing a lot more than I should be. I consider myself, you know, part of \\
this company. I'm knowledgeable. I'm doing xxxxxxxxx. I'm doing all kinds of \\
different things, and I'm not getting paid for it or the recognition of it." And then \\
my boss had to say, "Oh, well, I'm working on your promotion," or whatever, but, \\
you know. He said that, but I don't know if it's true or not true, but I got my \\
promotion."
\end{tabular}




\begin{tabular}{|c|c|}
\hline Number & 4 \\
\hline Event: & Fare war \\
\hline \multicolumn{2}{|c|}{ Story: (Analyst \#5-7) } \\
\hline & $\begin{array}{l}\text { "Things change so quickly and you have to respond. You really can't do much } \\
\text { planning because you have to respond. If xxxxx files a fare tomorrow and everyone } \\
\text { else matches it that can throw our system into turmoil. You have to respond. When } \\
\text { we had the last big fare war last July none of the computer companies anticipated } \\
\text { the hits to the system that happened. We were working all sorts of hours because } \\
\text { you would take the resources from one computer to take care of something else and } \\
\text { that made something else not work. So, it was just bedlam. We didn't know which } \\
\text { way was up...people were here monitoring the system...we put in what we called the } \\
\text { war room. We had a room that heads of departments would go to and that was the } \\
\text { name it was given...hourly and half hourly as the system was...we were pulling } \\
\text { programs and pulling enhancements. It was literally a war room. [ ] Because the } \\
\text { travel agencies want that information we have to be able to supply it. So, what they } \\
\text { are doing is they are all sitting there hitting their keyboard and hitting our } \\
\text { mainframe to get that information. Normally, it may take you three seconds to get } \\
\text { that information that...say a thousand people are hitting it. Well, you have two } \\
\text { thousand people trying to get the same information and your time goes up to six } \\
\text { seconds or you have so many that hit the system it just explodes and it freezes up. } \\
\text { Then you add to that our computer may be linked to xxxxx's computer. So, now not } \\
\text { only do you have the people who have the xxxxx computer accessing xxxxxx but, } \\
\text { you have the people on xxxx trying to get into xxxx. Then you have the xxxxxx } \\
\text { people trying to get into xxxx and it just mushrooms. So, what you try to do is let } \\
\text { me take something off-line that will give you some more resources. So, you sit here } \\
\text { and have to decide what program to pull. Then you have to run around and...from } \\
\text { your area I want to pull these three programs, is that going to cause you a problem? } \\
\text { So, you negotiate that. Then you have to get it out to the customers and the people } \\
\text { who are supporting on the telephone to let them know that we have pulled a specific } \\
\text { program and that is why they can't get anything. So, it becomes bedlam. We thrive } \\
\text { on that though. We must thrive on the stress otherwise we wouldn't still be here." }\end{array}$ \\
\hline
\end{tabular}




\begin{tabular}{l}
\hline Number: 5 \\
\hline Event: Fare war. \\
\hline Story: (Analyst $\# 10-8$ ) \\
"Well, what it [the fare war] will affect is: They'll take all - the processors that we \\
use to run - we aren't in the actual online system that the travel agents are on. They \\
have got - I don't know how many they have now. I want to say it's eight big, \\
huge, processors. They probably have a lot more by now. But they'll usually use \\
one of the processors, the big, huge one, and run all of, you know, these PC's in our \\
building, the ones up at Programming, where we do in VM, and if it's a fare war \\
situation, they'll take the test system down, because it's on another processor, use \\
that processor for online, because there's all the activity and - which slows -- or it \\
could slow us down, or they may even take our processor for VM, so we can't do \\
anything. There - there is an impact. [The July fare war]; that was a big one. Yeah. \\
Yeah. That was a killer. Yeah, we were down for like -- here, we couldn't do \\
anything, pretty much, for like two or three days, because they were keeping - they \\
were using all the processors that do the auxiliary type things and using those for \\
online as well because of the number of people hitting on the system and the types \\
of entries they were doing caused a lot of access to the processors, so they were..."
\end{tabular}




\begin{tabular}{l} 
Number: 6 \\
\hline Event: Fare war \\
\hline Story: (Manager $\$ 31-12$ ) \\
"Because the way the industry operates is that you're operating at a given level, and \\
all of a sudden that level doubles or triples, based on demand. You know, like an \\
airline goes out and says, "You can fly Miami-London for $\$ 100$ - - and the system \\
goes crazy. And the industry is not like that. Nobody's going to drink 10 times \\
more Pepsi-Colas, you know, so, well, in our system, that's the way it is. It's hard to \\
understand it. We have to -- and what happens is the configuration, the installed \\
hardware has to match the highest peak ever you can sustain. So, it's completely \\
different than other industries. I ] It [last July] was crazy. We sort of -- we almost \\
tripled our normal volume on that week. Your resources, it's hard to handle this \\
now, you know, then what do you do? How do you meet this demand? [There is no \\
way to predict them] because it's the airlines decide to start giving the tickets away. \\
It becomes - yeah, it becomes a fare war, and then what happens is, they - they \\
never -- airlines never sell the entire airplane. If an airplane has 200 seats - So, \\
now, you've heard about it and seen in the newspaper, and now you're looking in \\
the system, you know, more. If the seat is available, well, easy, you're happy to go \\
home. If it's not available, then you look for another one and another one and \\
another one. So, it creates a heavy demand on the system, and you have to realize \\
that the travel agency, the only link to their business is that workstation that they \\
have. Because if they call the airlines, the airline's not going to answer, because \\
they're busy, too. So, the only link they have to do business is having a system \\
operate."
\end{tabular}




\begin{tabular}{|l||}
\hline Number: 7 \\
\hline Event: $\quad$ Implementation problems. \\
\hline Story: (Analyst \#8-6) \\
"Before...business-wise it would cause problems. I see it getting better. I know an \\
application that I had some time back...before we got ready to load they went "...we \\
didn't know you were doing that..." Well, if they would have come to the meeting \\
they would have known that. It is getting better. If they have a question they will \\
come over and ask about it rather than guessing and then guessing the wrong way. \\
So, we are getting better that way but it takes some problems before everyone woke \\
up and stared to make it better."
\end{tabular}

\begin{tabular}{|l||}
\hline Number: 8 \\
\hline Event: Implementation problems. \\
\hline Story: (Analyst $\#$ 8-6/7) \\
"Well, just recently a project was loaded on-line and the ProdA group didn't know \\
anything about it and it was...corporate accounts...programs like that completely blew \\
them out of the water. So, it can cause big problems. One time we had a little \\
space...again it was ProdA. When they went to test it they didn't know...the \\
document was different than what we were actually getting. So, when ProdA \\
coded...it got something back with an extra space in it and they couldn't end any \\
records. A little space sounds little but if someone is editing this entry not to have a \\
space and all of a sudden one is there it can cause big problems. It is hard \\
sometimes because we don't really know what they check for. We are learning as \\
we run into problems."
\end{tabular}




\begin{tabular}{l}
\hline Number: 9 \\
\hline Event: Change of boss. \\
\hline Story: (Analyst $10-6$ ) \\
"Well, we had a - matter of fact, our other supervisor - I think she's on your chart \\
there, Julie (fictious name). She's off working on lanother project right now. We \\
just recently got Suzanne (fictious name), I think, November or December. Julie was \\
absolutely wonderful. Couldn't have asked for a better boss. Suzanne's new. She \\
doesn't really know a lot -- she came from a different area, so she doesn't really \\
know a lot of this particular area that she's in charge of, so it's sort of a learning \\
situation for her. So, it's -- and to come from such an excellent boss, like Julie was, \\
to Suzanne who is still learning the area, it's kind of hard that way, but Suzanne will \\
never be Julie. The other - the other -- I've never worked with - never worked for \\
or with xxxxx, xxxx or any of the others, because when I came here it was - well, \\
we - we had another manager, who's out on sick leave right now. I worked with \\
her, and then when she went out, I went to work for Julie, so I haven't worked with \\
the others."
\end{tabular}

\begin{tabular}{|l|}
\hline Number: 10 \\
\hline Event: $\quad$ Pay cuts - Difficult financial situation. \\
\hline Story: (Analyst $\# 16-10$ ) \\
"When I was here before, you know. I mean, that time when there was a lot of \\
negative things going on, you know, I talked to him then [the director of the \\
department]. You know, he had a - the other time, when he had a one-to-one with \\
everybody in the group. [..] So, you know, you [...] vented your frustrations with \\
him. You know. [...] Put everything on the table."
\end{tabular}




\begin{tabular}{|l||}
\hline Number: $\quad 11$ \\
\hline Event: \\
\hline Story: (Analyst $\# 28-4$ ) \\
"Something very minor. I mean, it's not - it's not a big thing. This morning we had \\
a meeting. We found out we were moving from one area of the building to another \\
area of the building. And, so, I mean, because I was involved with the move at [this \\
other company], see, I kind of - you know, you always tend to - I mean, I was \\
involved, and I'm not saying I want to be involved with that here, but I was \\
involved with the planning and where - you know, where certain - and then we \\
would back to our different areas and says, "Okay, Where would you like to be, \\
where would you...," and then, you know, reasonable accommodations, we would try \\
to do that. Where, here, it was like, we came into this meeting, and it was like, "Oh, \\
we're moving," and it was like, "Oh, really?" I mean, you - that type of thing. So, it \\
was - it's just -- I think it's just me, adjusting to what I was there and what I am \\
here kind of a thing."
\end{tabular}




\begin{tabular}{|c|c|}
\hline Number & 12 \\
\hline Event: & Employees struck par AIDS. \\
\hline \multicolumn{2}{|c|}{ Story: (Analyst $\# 5-9$ ) } \\
\hline & $\begin{array}{l}\text { "Last year we went through quite a few employees dying of AIDS and it got rough } \\
\text { for some of them financially. When we found out about it they would try to help } \\
\text { whether it was a bake sale and give them some of the money or in some cases like in } \\
\text { my old department what we would do is instead of having Christmas gifts is we } \\
\text { would...people are always ashamed to ask for help but we would find someone who } \\
\text { might need help so that instead of exchanging gift we would put } \$ 10.00 \text { and give } \\
\text { them a gift certificate for Publix for food or whatever. So, they do things like that. If } \\
\text { you need...like somebody here was sick and we always constantly support the blood } \\
\text { drive and you can as a company designate certain blood to a certain person because } \\
\text { blood is so expensive. Well, we had a blood drive here and all of that blood that } \\
\text { was collected went into credit for this woman. [...] When there was the earthquake } \\
\text { in L.A. or something like that they will put out a notice and have a collection area } \\
\text { and people bring things in and they will ship it out. It is just people that care. We } \\
\text { may be at each there's throat and we may think that people hate us but, then } \\
\text { something happens and these people just band together and forget the fact that...they } \\
\text { just know that you are someone who needs help and they try to help you. It is not } \\
\text { everybody...I am not saying that we are perfect and everybody participates in that } \\
\text { but you have a big group that will...it varies with who it is and what it is and that } \\
\text { type of thing. Basically, the company will try. Some things are more successful than } \\
\text { others. [... It is by employee contribution not the company itself. It is like me giving } \\
\text { them } \$ 5.00 \text { a month towards this woman's medical. Maybe someone else can only } \\
\text { give them } \$ 2.00 \text {. It is employees...companies do certain things and employees do } \\
\text { other things. Employees will arrange the bake sale but...the company could stop you } \\
\text { from doing that because you are using company time and you could be affecting } \\
\text { company productivity and most of the time they will look the other way..." }\end{array}$ \\
\hline
\end{tabular}




\begin{tabular}{|l||}
\hline Number: 13 \\
\hline Event: $\quad$ Shooting incident at Software Corp. \\
\hline Story: (Analyst \#5-10) \\
"We had an unfortunate case here where one of our employees was being stalked by \\
an old boyfriend and she was shot outside and another person was killed. Our \\
President flew in from [another statel to come to the one person's funeral and to visit \\
the other person in the hospital. Now to me that means so much because they...it \\
takes a lot for a President of the company in my mind to take the time to do that \\
and to show that they care enough that you are important and they do a lot of that. \\
The President is approachable here and that is not common in most companies. He \\
will come down and say hello to me and ask me how I am doing or tell me that I \\
did a good job on something. Not everyone but a good portion...he knows more \\
than most. I don't think he knows everybody but it also depends on how he comes \\
in contact with them. He doesn't know everyone in my department but he knows \\
some of us because of what we have done."
\end{tabular}




\begin{tabular}{|c|c|}
\hline Number & 14 \\
\hline Event: & Integration of New Employees. \\
\hline 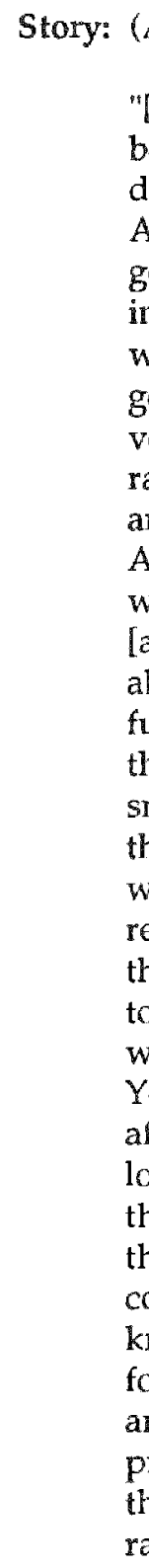 & 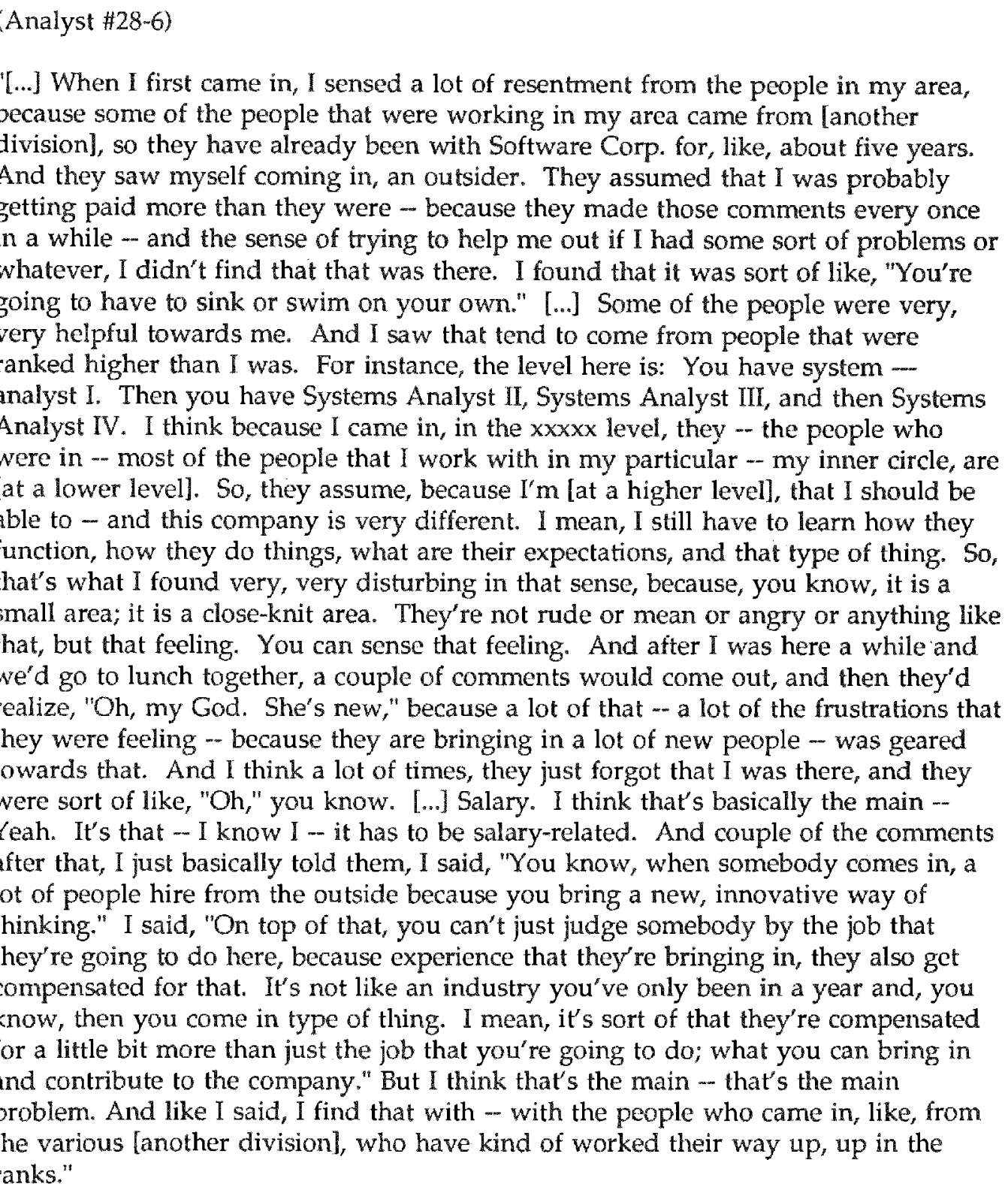 \\
\hline
\end{tabular}




\begin{tabular}{|l||}
\hline Number: 15 \\
\hline Event: $\quad$ Pay cuts - Difficult Financial Situation. \\
\hline Story: (Manager \#25-14) \\
$\begin{array}{l}\text { "I've never taken a pay cut ever in my career before I came here, but I did. Now, } \\
\text { obviously, they've -- they"ve made some adjustments." }\end{array}$ \\
\hline
\end{tabular}

\begin{tabular}{|c|c|}
\hline Number & 16 \\
\hline Event: & History - ProdA \& work organization. \\
\hline \multicolumn{2}{|c|}{ Story: (Manager \#15-11) } \\
\hline & $\begin{array}{l}\text { "[...] I think what helped us a lot was that our ProdA was started by a group of } \\
\text { developers in Minnesota that used to work in this way that I'm explaining to you. } \\
\text { And here I was in this other environment that was different, and when I was } \\
\text { appointed to be chief architect, I had to work very closely with them. And I started } \\
\text { seeing how well things worked there. And they didn't work quite as well here. So, } \\
\text { I tried to change the environment. That was very hard. It was impossible. It didn't } \\
\text { work. But at some point, they decided to close the Minnesota center, and they } \\
\text { offered people to move to Florida, but none of them moved to Florida. They liked } \\
\text { Minnesota. Their families were there, you know. So, they sent three people up to } \\
\text { Minnesota to learn the system. We lived there for five months [...] during which the } \\
\text { hurricane came through Florida, by the way. [...] It was crazy. And we lived there } \\
\text { for five months, working with them, and then we moved the system. And what } \\
\text { happened was, we realized what a nice environment that was, how good it was that } \\
\text { they all worked together and really how good they all were, you know, and how fast } \\
\text { they could get things done. So, it was - it was great. Because you -- I mean, to be } \\
\text { in the environment, you learn. You could - sort of great theory or listen to } \\
\text { somebody that's done it, but to live it, it's a completely different experience. So, } \\
\text { when we came down to Florida, we decided, "Okay. This is how we're going to } \\
\text { implement it." And we were three, and then now - it's been growing the last year } \\
\text { and a half. It went from -- there were five. It was three that spent five months } \\
\text { there. Two that went for a month each. And then, when we came back, there was } \\
\text { those five, and we started hiring new people and trying to implement this } \\
\text { environment, and it really worked well, even though at the beginning they tried to, } \\
\text { sort of, you know, change it. And so then we didn't -- we stick together. We didn't } \\
\text { allow it. And we kept on going, so it's been very rewarding." }\end{array}$ \\
\hline
\end{tabular}




\begin{tabular}{|c|c|}
\hline Number: & 17 \\
\hline Event: & Move of a communication line. \\
\hline 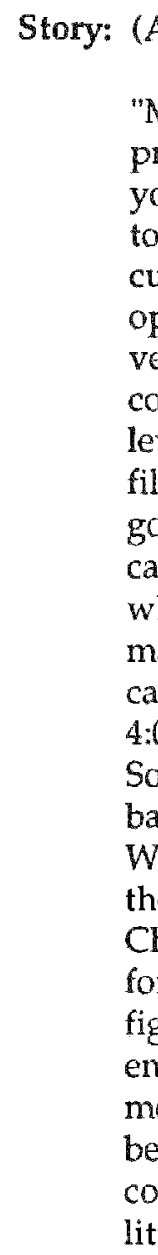 & 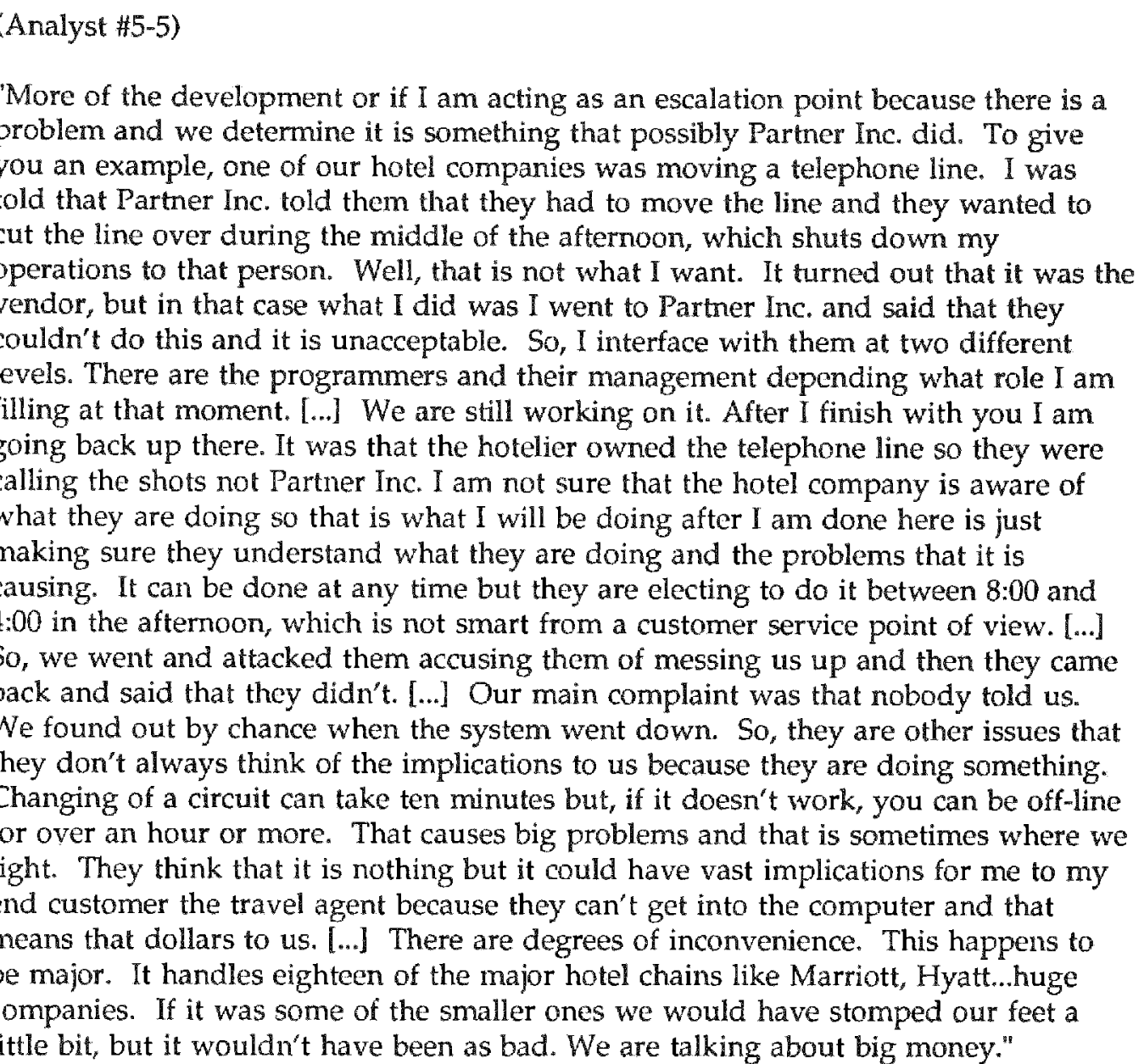 \\
\hline
\end{tabular}




\begin{tabular}{|c|c|}
\hline Number: & 18 \\
\hline Event: & Hurricane relief. \\
\hline $\begin{array}{l}\text { Story: } \\
\text { "I } \\
\text { le } \\
\text { of } \\
\text { h } \\
\text { re } \\
\text { ho } \\
\text { yc } \\
\text { th } \\
\text { yo } \\
\text { be } \\
\text { Th } \\
\text { en } \\
\text { fo } \\
\text { of } \\
\text { to } \\
\text { ga } \\
\text { th } \\
\text { bu } \\
\text { ne } \\
\text { th } \\
w \\
\text { to } \\
\text { w }\end{array}$ & $\begin{array}{l}\text { (Analyst \#5-8) } \\
\text { 'I think basically it is a good company. How many other companies would take up } \\
\text { collection for you because you can't handle your medical bills? When we had the } \\
\text { hurricane the company footed the bill for buying some generators and they were } \\
\text { lending them out. They sent repair teams and they sent search teams the first couple } \\
\text { of days when we couldn't find people to go to people's homes to try to find their } \\
\text { homes to see if they were alive. They set up } 24 \text { hour hot lines here...that brought } \\
\text { Partner Inc. and Software Corp. very close because they would go out in tandem as } \\
\text { elief teams and as the building inspector would come through and say that the } \\
\text { house was condemned and they had to be out they would send a crew down to help } \\
\text { you pack up what you could salvage and move you. They also gave...it wasn't like } \\
\text { he company...the company allowed you to do it on company time. It wasn't like } \\
\text { you had to do it on our off time. We opened up a day care center for the one week } \\
\text { yetween when we were able to come back to work and before the schools opened. } \\
\text { That is where I worked for a week. I didn't do my job. My job was to take care of } \\
\text { mployee's children. [Regarding the Partner Inc. team], it was mixed. We have } \\
\text { ormer Software Corp. employees [and old] Partner Inc.'s ones. [...] There was a mix } \\
\text { of people who had not worked here and people who did and everyone just pulled } \\
\text { ogether. We had water and they needed some water for some of their people so we } \\
\text { yave it to them. One of their crews out and found out it was one of our people and } \\
\text { hey took care of them. So, it was...the hurricane brought a common denominator } \\
\text { put it did that to South Florida to begin with. [...] Some people that had very } \\
\text { hegative feelings toward Partner Inc. had some new respect for Partner Inc. because } \\
\text { hey saw them as more caring than we gave them credit for. That doesn't mean that } \\
\text { we still don't knock heads but we saw them more than cold Corporate America. It } \\
\text { ook the hurricane for us to see that they can be as caring as we feel that we are, but } \\
\text { we didn't ever give them credit that anybody else could be that way too." }\end{array}$ \\
\hline
\end{tabular}




\begin{tabular}{|l||}
\hline Number: 19 \\
\hline Event: $\quad$ Employees' transfert to Partner Inc. \\
\hline Story: (Manager \#7-4) \\
"Any change then affects how things happen. Change affects people in a way they \\
do certain things and also it is thought that change is sometimes transparent but that \\
is not real. People transition from one company to another so there was a change \\
because now they are Partner Inc. employees. So, in 1991 you have over two- \\
thousand people who became Partner Inc. employees. It meant that there is a \\
different culture that they have to understand. They have different rules and \\
regulations in Partner Inc. that no longer apply to Software Corp. and so forth. \\
There was some change. You may do the same job on a day to day basis but \\
eventually since there is a new management structure they look at things in a \\
different light and they may treat the job or they may change people from doing \\
things one way to another...contractually all they have to do is to provide the same \\
level of service that they were providing for Software Corp."
\end{tabular}

\begin{tabular}{|l||}
\hline Number: 20 \\
\hline Event: $\quad$ Employees' transfert to Partner Inc. \\
\hline Story: (Analyst \#8-2) \\
"The programming staff used to be part of Software Corp. also and then the \\
programming staff transitioned over to Partner Inc. In the beginning, I think, there \\
was a little bit of skepticism and not wanting to do things a new way. There were a \\
lot of new processes that we had to go through and it was sort of a learning curve in \\
that way because they had a different way that they wanted things done. It was \\
more regimented work, which is really good, but it took us a while. Instead of \\
calling up and telling them to do this for me today we had to go through a lot of \\
paperwork and stuff to get things done, but it really gives you a better audit trail if \\
things went wrong."
\end{tabular}




\begin{tabular}{|l||}
\hline Number: 21 \\
\hline Event: Employees' transfer to Partner Inc. \\
\hline Story: (Analyst \#10-4) \\
"[...] It's actually -- sometimes you think it was better, because now we're their \\
customer, whereas before there was an old mentality when Mother Inc. was around \\
that we did it Mother Inc.'s way. Programming was put on this pedestal and they \\
pretty much didn't change. And you had one program - nothing was ever written \\
down, so you didn't know why anything was ever done. And to get something \\
changed or fixed took an act of God. So, when Partner Inc. split them off and they -- \\
we became their customer, it's almost -- that was almost a 180-degree turn there. \\
They were -- and then you had a lot of guys that were -- before, they'd try to help \\
you out, too, but there was a lot of old mentality there that, you know, 'I'm not \\
going to change it. [...] A lot of them would go to lunch at 11:00 and you wouldn't \\
see them until 3:00 in the afternoon. You could look out there and find them (by the \\
window)... right at the golf course. That's where they were. Yeah. So, that, in \\
itself, that was good. There were certain groups that were like that, yes."
\end{tabular}




\begin{tabular}{|c|c|}
\hline Number & 22 \\
\hline Event: & Outsourcing to Partner Inc. \\
\hline $\begin{array}{c}\text { Story: (1 } \\
\text { th } \\
\mathrm{g} \\
\mathrm{p} \\
\mathrm{ta} \\
\mathrm{a} \\
\mathrm{k} \\
\mathrm{m} \\
\mathrm{o} \\
\mathrm{si} \\
\mathrm{p} \\
\mathrm{u} \\
\mathrm{o} \\
\mathrm{k} \\
\mathrm{th} \\
\mathrm{th} \\
\mathrm{d} \\
\mathrm{sc} \\
\mathrm{th} \\
\mathrm{co} \\
\mathrm{h} \\
\mathrm{sc} \\
\mathrm{yc} \\
\mathrm{k}\end{array}$ & $\begin{array}{l}\text { (Programmer \#11-6) } \\
\text { "I think - well, at the time, they probably needed it, because Second Inc. -- this is -- } \\
\text { this is the lower management - this is my view. I don't know really know what's } \\
\text { going on, because, like I said, I don't pay attention to all of this stuff. This is my } \\
\text { perception of it, was - is that Second Inc. is going bankrupt, and they take -- they } \\
\text { take money from Software Corp, because Software Corp. was making money during } \\
\text { all this time, whereas Second Inc. was losing money like crazy. We even had, you } \\
\text { know, wage cutbacks and everything else, even though this particular company was } \\
\text { making money. So, at the time, I think, for us to survive, I think we had to sell part } \\
\text { of ourselves to Partner Inc. This was necessary at the time. However, I think that } \\
\text { since then, the service has gone down. The perception is, anyway, that the service } \\
\text { provided by the - next door, that used to be Software Corp., is not as good as it } \\
\text { used to be. And, you know, there's some friction, because it's a different philosophy } \\
\text { of how to work and things like that. I think it ended up dividing the company, you } \\
\text { know. People -- the people over there used to be Software Corp. people, but now } \\
\text { they have a totally different mentality because of the upper management. So, I don't } \\
\text { think it's been good. I mean, it helped us survive. Other than that, I think it's been } \\
\text { detrimental to the unity of the company, you know, because those people over there } \\
\text { service travel agencies. Right? And they run the telecommunications and things like } \\
\text { that. It's much better when it's all one company, I think, because there's more } \\
\text { cohesion, working together, you know. And we had the telecommunications center } \\
\text { here. Now they've got it in Carolina, and they're just more inaccessible. If you need } \\
\text { something done, you know, it's just that much more difficult. And it used to be that } \\
\text { you could go over and have lunch with those people and you'd know them, you } \\
\text { know, or whatever. You'd know some of them, anyway. Now it's like you don't } \\
\text { even know who they are; they don't know who you are. There's less of a interest, } \\
\text { you know. So, I think it's been detrimental in the long run. I think a lot of people } \\
\text { feel that way, too. }\end{array}$ \\
\hline
\end{tabular}




\begin{tabular}{|c|c|}
\hline Number & 23 \\
\hline Event: & Employees" transfer to Partner Inc. \\
\hline Story: ( & 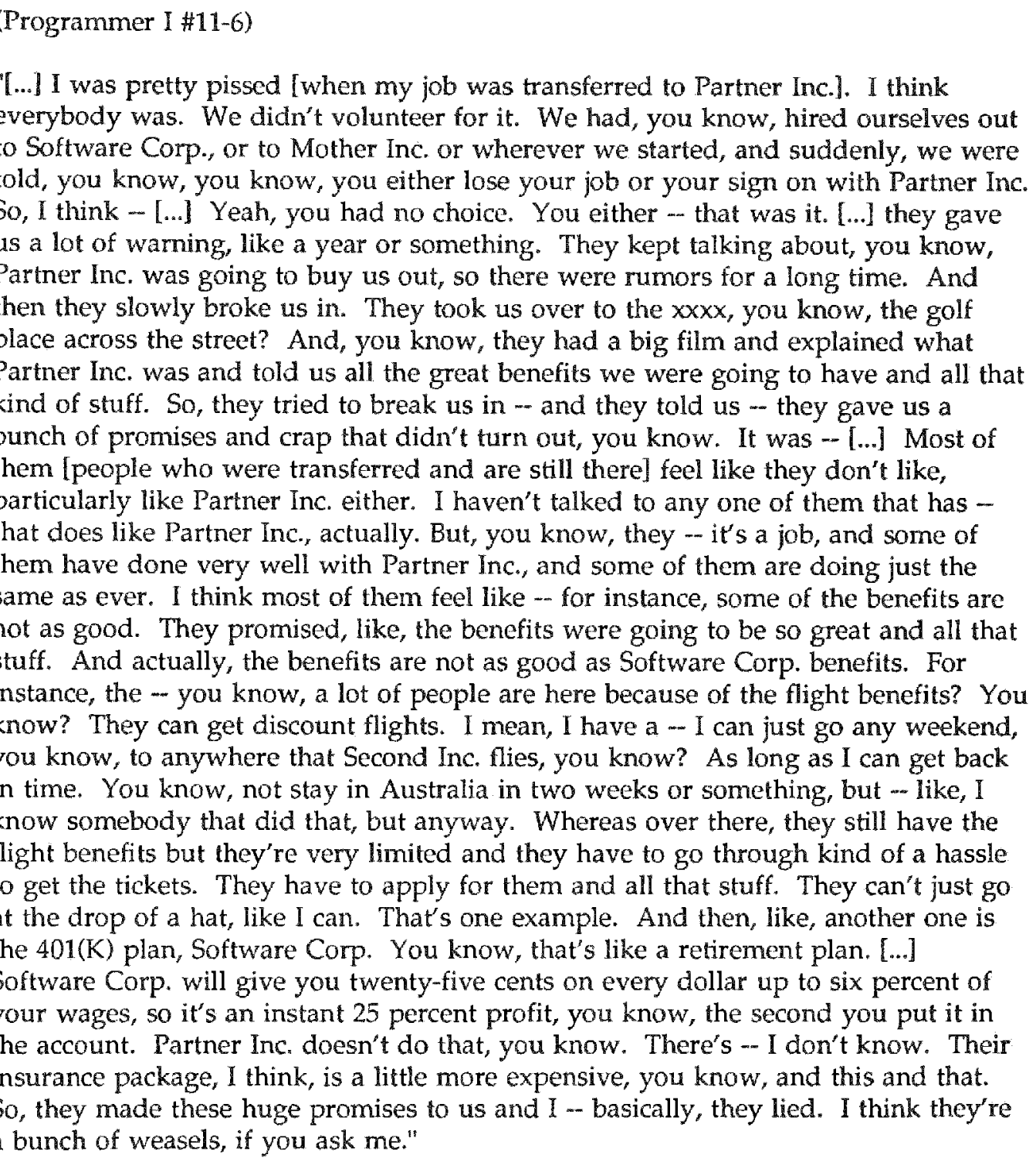 \\
\hline
\end{tabular}




\begin{tabular}{|l}
\hline Number: 24 \\
\hline Event: $\quad$ Employees' transfer to Partner Inc. \\
\hline Story: (Programmer \#13-5) \\
"Well, initially, when the transfer first took place, we thought it would be a better \\
thing to go with Partner Inc. I mean, at the time when la certain group of people] \\
weren't sure of which way they were going to be going, whether we were going to \\
be staying with Software Corp. or going with Partner Inc., during that period of \\
uncertainty, a lot of us though we'd be better off going with Partner Inc., because \\
Software Corp. was in bankruptcy at the time and Partner Inc. was a very big \\
company. And we heard they were being very generous in giving out salary \\
increases and that type of thing, but as time went by, we realized that -- that, hey, I \\
think we were really better off with Software Corp. People felt both ways. You had \\
some people that felt it would be better to stay with Software Corp. You had some \\
people that felt that Partner Inc. was better, but... [...] I kind of thought it would be \\
better to stay with Software Corp. And one of the reasons for that is because Partner \\
Inc. is a very strict company and a lot of changes were made once -- once Partner \\
Inc. took over next door. They started enforcing dress codes that we had not had \\
before -- and I'm talking very strict dress codes that tell you on a man's shirt how far \\
apart your stripes can be, that type of thing. It's like, you know, men are not \\
allowed to have facial hair and things like that, where Software Corp. is much more \\
relaxed about those things. And, to me, it was being silly about little things, like \\
people had to take down posters and things that they had at their desks, because \\
they don't allow any of that stuff. They don't allow you to have pictures of your \\
kids and stuff like that, you know. It has to look very clean and antiseptic and \\
military, since they were basically founded by a military leader." \\
\end{tabular}

\begin{tabular}{|l||}
\hline Number: 25 \\
\hline Event: Outside programming class. \\
\hline Story: (Programmer \#13-6) \\
"[...] they are [strict] and everything. As a matter of fact, xxxxxx and I went to a \\
programming class that was given by Partner Inc., and normally they give it to their \\
own employees, but they allowed us to attend this class. And most classes that you \\
go to out of town, you're allowed to dress casually. Well, I came into class, I guess \\
the second day, wearing a nice pair of gold slacks and a silk blouse, and one of the \\
Partner Inc. higher-ups went over to our instructor and said, "Who is that person? \\
Send her home. Tell her to come back in a dress," because they don't allow women \\
to wear slacks. So, if I had been an actual Partner Inc. person instead of a customer, \\
they would have sent me all the way back home, no matter where that might have \\
been, 3,000 miles or whatever to show back up in the proper attire. So, I think that \\
Partner Inc. puts the emphasis on the wrong thing."
\end{tabular}




\begin{tabular}{|l||}
\hline Number: 26 \\
\hline Event: Difficult relationships with Partner Inc. \\
\hline Story" (Analyst \#19-3) \\
"Hum, unfortunately, it used to be... before, you know, I don't know if you, if you \\
know the history about... they were Software Corp. And before that I was, we were \\
all working together. When they went to Partner Inc., and we stay at Software \\
Corp., the same people that use to deal with us created some, I don't know, \\
[facade?], or the philosophy of the company over there, or Software Corp., I don't \\
know, but you can feel some......] frictions between the same people we used to \\
work together all the time. It used to be very collaborative and not anymore, I mean, \\
even though we get, we get things solved, but you can feel the friction. [...] I believe \\
it's a...Partner Inc. management, I think. This... Now they're all, you know, \\
quarreling themselves, you know, you have to... they want everything into writing, \\
they want this and this, they want... you understand what I mean? If you say \\
something, they won't take your word, they want it in writing. It's... that's the way \\
it is now. I don't know why. It used to be... wasn't like that before."
\end{tabular}

\begin{tabular}{|l}
\hline Number: 27 \\
\hline Event: Meeting organization. \\
\hline Story: (Programmer $\# 20-9$ ) \\
"Sometimes no, because of the politics issue, meaning they work for Partner Inc., we \\
are Software Corp. It's totally two different company, so we really can't tell them \\
what to do. So, everything else is just schedule. Right now - we're having a \\
meeting, actually, next week. I've been told we needed a meeting to get some things \\
organized, that if a person is down, especially a contractor, I can't wait all day for \\
Partner Inc. to come by in the afternoon. The contractor is getting paid $\$ 50$ or $\$ 60$ an \\
hour to sit there, you know. That's not right. So, I'm getting a meeting put together \\
for next week. But overall for the guys I've worked with at Partner Inc. have been \\
fine."
\end{tabular}




\begin{tabular}{|l|l|}
\hline Number: 28 \\
\hline Event: $\quad$ Employees' transfer to Partner Inc.. \\
\hline Story: (Analyst \#19-3) \\
"To tell you the truth, I wanted to go there. [...] But I'm glad I didn't. [...] [I wanted \\
to gol because of a... of the financial situation that I saw Software Corp. in and \\
Mother Inc. and Second Inc. and I thought that I had a better opportunity at Partner \\
Inc. Big company, you can do... I don't know, financial security, but a, years later, \\
not 1 year later, between 6 month to 1 year, I realized I'm glad that I wasn't there. \\
Because, because of the philosophy they had, the management style, you know, the \\
restrictions they impose on their people, and their... I think it's like an old \\
philosophy, they're very strict, you know, they treat them... I don't think, I don't \\
think they... professional, like they don't treat them like professionals. "
\end{tabular}

\begin{tabular}{|l||}
\hline Number: 29 \\
\hline Event: $\quad$ Happy Hour episode. \\
\hline Story: (Programmer \#20-9) \\
"It might [make a difference if they are former Software Corp. employes], yeah, \\
because there was always a conflict with Partner Inc, and Partmer Inc. always \\
thought they were better than Software Corp., that kind of attitude, at least that I \\
saw. My own opinion. Because I've gone out to Happy Hour and we had Software \\
Corp. employees here and Partner Inc. employees here, and -- oh, after a few drinks \\
we all were together, but, you know, without those drinks, they say, "Oh, that's \\
them," you know. They would say "Partner Inc. is No. 1. Old Software Corp." And \\
then the DJ would announce different companies that were there. But, overall, I only \\
deal with a couple of Partner Inc. employees."
\end{tabular}




\begin{tabular}{|l|l|}
\hline Number: $\quad 30$ \\
\hline Event: The growing of the organization. \\
\hline Story: (Analyst \#5-12) \\
"When you think about where we started and when we started. We started in a little \\
trailer with five people in the early 1980 and we are a force to content with. We are \\
only 950 employees and we are up against people like [their competititorl and...to \\
give you an example when I had my old job it was me. At [their competititor] they \\
had ten people doing what I did. [..] Early 1980s like 1981 or 1982. So, as a \\
company we have accomplished a lot with a lot smaller budget and a lot smaller \\
work force than any of the other competitors. So, we have a lot to be proud of. I \\
believe we also market more positively and honestly. I do believe that our system is \\
better. Sometimes we are left to the market and that is because when we build it we \\
don't just build vanilla we build vanilla, chocolate and strawberry. So, you come \\
with the idea that you want "A" and we say that "A" is really nice but "B" and "C" \\
make it even better and that is not always recognized by the whole world. They \\
don't always understand that we may not have this but what we have built is better \\
than what someone else has."
\end{tabular}

\begin{tabular}{|l||}
\hline Number: 31 \\
\hline Event: $\quad$ History of Software Corp. \\
\hline Story: (Manager $\# 7-4$ ) \\
"Software Corp., at the time, was a spin-off of what was then the Mother Inc. \\
Computer Center. The department at the time was...we had some three thousand \\
employees at the time... [...] The computer center and also what is called the Product \\
Development Group. That was transitioned also with the computer center to become \\
Software Corp. somewhere in 1986. This was then sold to Second Inc. and later sold \\
to a Second Inc. affiliate and then the rest is history. Then the transition to Partner \\
Inc...this was in May of 1991 when there was this transition or outsourcing to Partner \\
Inc."
\end{tabular}




\begin{tabular}{|c|c|}
\hline Number & 32 \\
\hline Event: & The early beginning of Software Corp. \\
\hline \multicolumn{2}{|c|}{ Story: (Manager \#7-4) } \\
\hline $\begin{array}{l}\text { "T } \\
\text { w } \\
\text { fo } \\
\text { th } \\
\text { p }\end{array}$ & $\begin{array}{l}\text { Well, that was many years ago. That was still under Mother Inc. We were still on } \\
\text { Mother Inc. at that point...the trailer was where the computer center was and what } \\
\text { vas called Software Corp. } \times \times \times \times X \text {, which was the group that was formed to interface } \\
\text { vith the travel agencies. At the time Mother Inc. and the computer center was } \\
\text { ormed to service the airline. The Software Corp. Direct Access was formed to serve } \\
\text { he travel agents because that portion which was called } X \times \times \times \times \times \times \times X \text { was... I... I a } \\
\text { part of the programming team which was serving the airline." }\end{array}$ \\
\hline
\end{tabular}

\begin{tabular}{|l||}
\hline Number: 33 \\
\hline Event: Organizational changes over the year at Software Corp. \\
\hline Story: (Programmer \#11-2) \\
"It's a long story. I started with Mother Inc. in 1986. And I don't know if you know \\
the evolution of this whole thing, but -- so, I've been - I used to work in [some \\
building]. My background is telecommunications. I worked in the \\
telecommunications center over there, who is now in Carolina. They moved. Okay. \\
But -- so, I've worked over there. I worked in xxxxx first, became the lead, then \\
moved over to telecommunications in the chronics group, which was another, you \\
know, the final escalation group over there for telecommunications, and then finally \\
came over here. So, I've been through, you know, Mother Inc, Another Department \\
of Mother Inc., Software Corp., you know, which has changed hands at Second Inc. \\
in the meantime."
\end{tabular}




\begin{tabular}{|l||}
\hline Number: 34 \\
\hline Event: Big project cancelled in MAX. \\
\hline Story: (Analyst \#16-2) \\
"No [I've not always been in this working group]. Initially, I - initially, I started off \\
as -- there was a project here that got canceled. Basically, I was hired for that \\
project, and then after about a year that project was canceled, so then we were \\
integrated into the MAX group, the people who were in the other group. It was \\
under the MAX group, but it was a totally separate product that they were \\
developing for the cruise lines, but... [...] atter about a year, it got canceled. [...] I \\
don't know what the bottom line was, but it was, like, a joint application with the \\
cruise line, and from what I know -- and I'm not privy -- you know, this is just --.. \\
rumors - yeah. It was that, you know, there was no contract signed, you know, it \\
was always -- there was a letter of intent, but there was nothing signed, and then, \\
you know, the project was dragging, and then the cruise line just pulled out and \\
the... [...] they just decided to cancel the project."
\end{tabular}

\begin{tabular}{|l||}
\hline Number: $\quad 35$ \\
\hline Event: $\quad$ History of MAX. \\
\hline Story: (Analyst \#16-6) \\
"And, you know, as you know - I don't know if you know this, but the MAX group \\
actually moved into, you know - it was -- it was an independent kind of -- they \\
were out - out in California, and then about three years ago, they were -- they \\
moved to Florida. [...] So, initially MAX was a completely separate unit from \\
Software Corp. You know, it was under the umbrella of Software Corp., but it was \\
out -- out in California, and, you know, I believe they had their own directors and \\
Human Resources and the whole thing. So, you know, in that sense, it's -- I think \\
it's retained a little big of its independent kind of group image."
\end{tabular}




\begin{tabular}{|l|}
\hline Number: \\
\hline Event: \\
\hline Story: (Analyst \#17-5) dismantlement of MAX. \\
"[...] when the -- when MAX was moved here, very soon after it was moved here, \\
they split out the piece of MAX that I mentioned, the documentation - went to the \\
Software Corp. documentation area. Customer service, the trainers, operations and \\
marketing. That was the other department. So, that was integrated into the rest of \\
the company. The only thing that we have now is part of development, actually, the \\
actual development of the product. So, when you say, "Are you independent" -- [...] \\
we're not really independent, because --in order to get things out, we -- I mean, we -- \\
have to interface with everyone, correct."
\end{tabular}

\begin{tabular}{|l||}
\hline Number: 37 \\
\hline Event: Bankruptcy of Mother Inc. \\
\hline Story: (Programmer $\$ 21-2)$ \\
"Well, Mother Inc. had never been stable for the past 10,20 years. Okay? But I \\
started with, '87, pretty much every - all the word, we would hear -- hear \\
something, there's a reorganization, there's a layoff, there's all kind of troubles. So, \\
in our mind, that we know something going to happen. Okay? Then Mother Inc. \\
went to bankruptcy and there - there was strikes going on. I mean, all the xxxxxx \\
or xxxxxxxxxx, they went on strike. All kind of stuff. So we know that we are in \\
financial trouble, we were in, at that time. And, actually, we didn't - the company \\
didn't let us know that we are -- I mean, we are not - the company, I mean, is not \\
telling us -- I mean, it's on the newspaper. And in the meantime, we know that \\
people are bidding for Software Corp."
\end{tabular}




\begin{tabular}{|l||}
\hline Number: 38 \\
\hline Event: $\quad$ President's speech. \\
\hline Story: (Analyst \#24-8) \\
"I think so [that the speech of the president had some sort of impact. From the \\
stand as I was speaking earlier directions. Where before, couples of years ago, the \\
direction of the company kind of was "we don't know, we'll wait and see". Now, \\
wait and see is over. I feel we could see a definite direction in where the company \\
wants to go. They're geting... they plan. Where before it was bankruptcy and with \\
everything else that was going on, the airline business was taking... a big nose dive \\
at that point in time also. It's good to see some definite plans going into effect."
\end{tabular}

\begin{tabular}{|l||}
\hline Number: 39 \\
\hline Event: $\quad$ The beginning of Software Corp. \\
\hline Story: (Manager $\# 30-10)$ \\
"[...] I've worked for Software Corp., but I've worked for the computer services part \\
of Mother Inc. I do know that when Software Corp. started to build their first PC- \\
based application, they were in a building that was - at least the first group that I \\
ever knew - a building that was really -- it wasn't a trailer, but it was close. It was \\
like downstairs in, you know, in a basement-level type of a thing with no windows, \\
and they were stuck back there."
\end{tabular}




\begin{tabular}{|l|}
\hline Number: 40 \\
\hline Event: Organizational changes over the years. \\
\hline Story: (Manager \#31-1) \\
"Back in '91, okay, we used to have -- we used to be a part of Mother Inc. [...] The \\
way it happened is when Second Inc. bought Mother Inc., they had [another \\
company], Mother Inc., and they separated Software Corp., and they created a -- a \\
computer [division], which was Software Corp. The computer operation was \\
separated into its own entity. [...] And then we decided to outsource, okay? And we \\
gave our host computer mainframe operation to Partner Inc., so they' re responsible \\
for operating the big CPUs, the big computers, they're responsible for the \\
telecommunications."
\end{tabular}

\begin{tabular}{|l||}
\hline Number: 41 \\
\hline Event: $\quad$ Purpose of Software Corp. \\
\hline Story: (Manager \#31-4) \\
"[...] Software Corp. has always operated sort of independent. We were -- in the \\
regular, it was sort of independent from Mother Inc. [...] Because Mother Inc., we \\
had two -.- okay - we had an administration system and we had a reservation \\
system. So, we had an internal system, okay, that took care of the airplane and the \\
airline operations and payroll and parts inventory. We had a system concentrated on \\
the business of Mother Inc. Okay? Then we had another system that dealt with the \\
outside world, the reservations, the link to other airlines, and then the travel \\
agencies."
\end{tabular}




\begin{tabular}{|l|}
\hline Number: 42 \\
\hline Event: $\quad$ Bankruptcy of Mother Inc. \\
\hline Story: (Manager \#31-5) \\
"However, we were successful. We were very successful in the service that we \\
provided to the travel agencies, and we don't have the market share that [our main \\
competitor] has, but at least people thought that when Mother Inc., you know, went \\
under, that -- that we'd disappear, and it hasn't been like that."
\end{tabular}

\begin{tabular}{|c|c|}
\hline Number & 43 \\
\hline Event: & Evaluation of organizational change readiness. \\
\hline \multicolumn{2}{|c|}{ Story: (Manager $\sharp 25-11$ ) } \\
\hline & $\begin{array}{l}\text { "They did a change management study, you know. We have contracted Company X } \\
\text { to help us in change management, because they've been through reengineering and } \\
\text { they've got lots of experience, and the survey says that we've got both sides of the } \\
\text { spectrum. A lot of people, they think, can manage change very good, and there's a } \\
\text { lot of people that get schizo about change. But, we're somewhere in the middle. On } \\
\text { an average, we're in the middle, like most companies who are going through a big } \\
\text { change. I think people would be willing to change as long as things don't get crazy } \\
\text { with Second Inc. [..] Well, I mean - I don't know if you know, but a couple of } \\
\text { years ago, Second Inc. -- just came out of bankruptcy, and, you know, people had -- } \\
\text { freezing their salares, you know, you had to think about -- not freezing. They had } \\
\text { to take a reduction, and there's no equity. I think everything will be great, if, you } \\
\text { know -- things now, we just had a -- our president came last week, and things are } \\
\text { very -- looking very up and very positive, and we're going to get all the } \\
\text { reinstatements of money you lost and for the increases. I think, if that stays up, then } \\
\text { it's fine. Then people would be willing to change, but I think if it - if that doesn't -- } \\
\text { if that's a really short-term thing and then all of a sudden the rug is pulled back } \\
\text { under you, then I think it's going to be difficult to keep the change and be really } \\
\text { positive. Because, you know, bottom line is people are worried about jobs and } \\
\text { paying their bills and their career, and when you have to deal with those things that } \\
\text { pre abnormal, I think change is -- and I think even though you might embrace it, you } \\
\text { know, but I think deep down you're thinking, "Well, am I going to have a job } \\
\text { tomorrow, and I'm going to look out for me," versus, "Am I going to try to make the } \\
\text { company better?" So, I'm hoping things will, you know, will -- will - where Second } \\
\text { Inc. will stay good or get better, which that's the projection, and I think, yes, people } \\
\text { will be very, very open. And I think if something negative happened and they start } \\
\text { laying off people and cutting back and, you know, you see a spiraling down, I think } \\
\text { then people will just start worrying about basic necessities." }\end{array}$ \\
\hline
\end{tabular}




\begin{tabular}{|l||}
\hline Number: 44 \\
\hline Event: $\quad$ Reengineering communications. \\
\hline Story: (Analyst \#28-9) \\
"[...] I - I try to call the Hot Line every once in a while to see, but because I came -- \\
I have no idea what the reengineering project is about. I don't know what the \\
objective of the engineering project is. When I first came in, I didn't have any \\
orientation for that. So with the Hot Line, I kind of try to, you know, to put the \\
pieces together, or I try to keep updated on it so I can really understand what it is \\
that they're trying to do. I mean, just by saying "reengineering," you basically have \\
some sort of knowledge about what it is that they're trying to do, but we didn't have \\
any orientation on that, so I don't know anything about it. [...] Basically, you get a \\
message in the E-mail, in the electronic mail in the system, that kind of tries to keep \\
telling you, to remind you to call the reengineering Hot Line, and they give us, like, \\
little stickers to put on the phones, to tell, "Call the reengineering Hot Line." Any -- \\
in my area, I don't think - I mean, like, I'm sure a couple of people call to find out \\
what's going on, but they don't -- you don't talk -- I mean, it's not talked about. Not \\
because of anything, but I guess it's not brought up in conversations that I have with \\
the other people or anything,"
\end{tabular}

\begin{tabular}{|l||}
\hline Number: 45 \\
\hline Event: Introduction of new softwares. \\
\hline Story: (Analyst \#8-6) \\
"What I would like is to get more training than we get. A while back they put \\
Wordperfect on our PCS and they took away Display Write 4, but nobody bothered \\
to train us on Wordperfect. So, here you are with this software that could probably \\
do everything plus what Display Write 4 could do, but we don't know how to use it. \\
They can give you a little template to put on your PC but it would have been nice to \\
have some more training. Some people have gone to training since then but I still \\
haven't gone. They have put CEO [an e-mail system] in our system, which is an \\
electronic way of communicating, but nobody ever gave us a manual or training on \\
how to do it. I wish they wouldn't give me something that they are not going to \\
teach me how to use."
\end{tabular}




\begin{tabular}{|l|}
\hline Number: 46 \\
\hline Event: $\quad$ Training occasion. \\
\hline Story: (Programmer \#11-13) \\
"So, that's another very good thing about this particular group. I don't know if that \\
applies for the whole organization, but they're interested in actualizing what you \\
want to do, which, you know, it's very difficult to make that happen, because we \\
have such a work load, but they do try to do that. And that's --I also appreciate \\
that. You know. [...] It's difficult, but it does happen. It does happen. I mean, I'm \\
learning, with their help, like, the last year I went to a, you know, an electronic class \\
in relation to power that supplies computers. That's a fantastic class. I learned -- I \\
know more about, you know, power problems with computers than probably most \\
people in Florida do. I'm serious, you know? So, it's like I really actualized myself \\
on that one. And it was a fantastic class, and -- and, you know, then I had some \\
practice. I have -- I can -- but I can apply this with travel agencies. I can apply it \\
here, and so forth. So, it does happen. You know. It's just difficult, but it does \\
happen."
\end{tabular}

\begin{tabular}{|l||}
\hline Number: 47 \\
\hline Event: Changes in the hiring requirements. \\
\hline Story: (Analyst \#15-5) \\
"But this is a situation, the people that are in charge used to be from that \\
environment. So, in a way, they don't understand. It took -- one of the things that I \\
worked real hard was in getting them to a point -- where they would hire people \\
that had a degree in computer science, where I -- What I would say, "This is really \\
important. This really makes a difference. This is somebody that's already made a \\
big effort to learn a lot of the background they need to be able to be proficient in this \\
environment. Why would you want to train somebody that doesn't know anything \\
in this environment? In the mainframe, maybe you just learned Cobol and you \\
could do it, but in here, if you don't understand interprocess communication and \\
multi-task and operating system, you're lost." And it takes a lot of training to get to \\
the point where you can understand that. So, it was a long process to show them, \\
"Look, these people will be much more efficient and much more productive, because \\
they have the background." These other types of persons who needs Inc. today to \\
give all their time to work cannot dedicate the time to learn. Therefore, they never \\
catch up. It's a big difference. And it took - it took years for them to change their - \\
- the way they hired people, to say, "Okay. We're gonna require a degree in \\
computer science."
\end{tabular}




\begin{tabular}{l} 
Number: 48 \\
\hline Event: Training budget. \\
\hline Story: (Analyst $18-12$ ) \\
"Well, Technology had budgeted for a lot of training, knowing that this project was \\
going to hit us in'94 and they were very good about sending out all of the \\
developers to go get adequate training for programming and designing and \\
understanding the environment and for support, and things like that. Now, \\
Technology has done that. Other groups in the company haven't been, I don't think, \\
as good about foreseeing what knowledge level was going to be required. So, there \\
hasn't been money budgeted for all of the training that needs to occur in 94 and \\
that's becoming a problem as well as upgrading the workstations that they use to \\
have Windows and to be, you know... all of that is necessary and that's a huge \\
financial expense that the company is going through now within the customer \\
support group. It's getting their hardware up to speed, getting their software up to \\
speed, and then getting their people trained. And that's the lack of skills toward this \\
project is immense. With the group that has to be involved with it. It is causing \\
problems in that understanding what it is we're building here, you know, not truly \\
understanding what this thing is that we're all working towards, which makes it \\
difficult. We're trying to bring that to resolution and again, Ithe manager] has been \\
escalating some of those issues up to higher managenent so that they can, you \\
know, start looking into their budgets to find out how they are going to resolve that \\
and get the people their adequate training. It's not just going to happen by osmosis. \\
No. It's too different. So, training, internal training, has been a big issue with this \\
project."
\end{tabular}




\begin{tabular}{l}
\hline Number: 49 \\
\hline Event: Pay cuts - No increase - Difficult financial situation. \\
\hline Story: (Analyst \#5-11) \\
"When you don't have money stupid things become important like the size of your \\
office, whether you have a window or not, whether you have a decent parking spot \\
or not, what your title is and all of those things that shouldn't, make a difference. It \\
is just happening to a friend of mine. They moved her work space to another space \\
that is smaller and it is driving her nuts and it is going to affect her productivity \\
because that was important to her and that is what they are missing. People are \\
getting stressed because we are working too hard. We need to kick back and not just \\
keep looking at the bottom line and say that I need to get this out because I expect \\
this kind of revenue. If they keep working the people they way they are they might \\
as well turn this into a hospital because we are all going to be sick. There are certain \\
people that you always go to when you need something done and it doesn't matter \\
what kind of workload they are carrying they can always carry more and they will \\
always go that extra ten miles to get something done and those people are getting \\
burned down and they are getting to point where they are saying "..why should I \\
work beyond my eight hours because they don't appreciate it." You are not going to \\
see it now but, we will see it in about three to four months, the affects of what is \\
happening today and I don't know if they paying attention. Those are the negatives. \\
They are loosing touch."
\end{tabular}




\begin{tabular}{|l||}
\hline Number: 50 \\
\hline Event: Problems with hardware certification. \\
\hline Story: (Programmer H11-1) \\
"Some problems - some products -.- projects will have too many problems or they \\
won't fit into our system the way that we're looking at. For instance, one product \\
was a printer that we were looking at as being not only an ATV ticket printer for, \\
you know, airline tickets and stuff like that, but also to be a DOS printer, you know, \\
that you could just plug in and use your word processor with, and unfortunately the \\
company that was providing that, they said you could do all of these things, but \\
when they gave us the product it wasn't ready for it. So, when we found that out \\
after testing it for a couple of weeks, we had to give it back to them and say, "Great. \\
Give it back to us when you're ready." You know, that type of thing. So, yeah, \\
some products have bugs and some of them don't fit in with what we're looking for, \\
with our goals, I guess, company goals type of thing."
\end{tabular}




\begin{tabular}{|c|c|}
\hline Number & 51 \\
\hline Event: & Change to object-oriented programming. \\
\hline $\begin{array}{c}\text { Story: ( } \\
\mathrm{w} \\
\mathrm{th} \\
\mathrm{d} \\
\mathrm{c} \\
\mathrm{k} \\
\mathrm{c} \\
\mathrm{a} \\
\mathrm{g} \\
\mathrm{s} \\
\mathrm{u} \\
\mathrm{s} \\
\mathrm{a} \\
\mathrm{e} \\
\mathrm{w} \\
\mathrm{k} \\
\mathrm{p} \\
\mathrm{I} \\
\mathrm{h} \\
\mathrm{k} \\
\mathrm{a} \\
\mathrm{li} \\
\mathrm{a} \\
\mathrm{E} \\
\mathrm{M} \\
\mathrm{o}\end{array}$ & 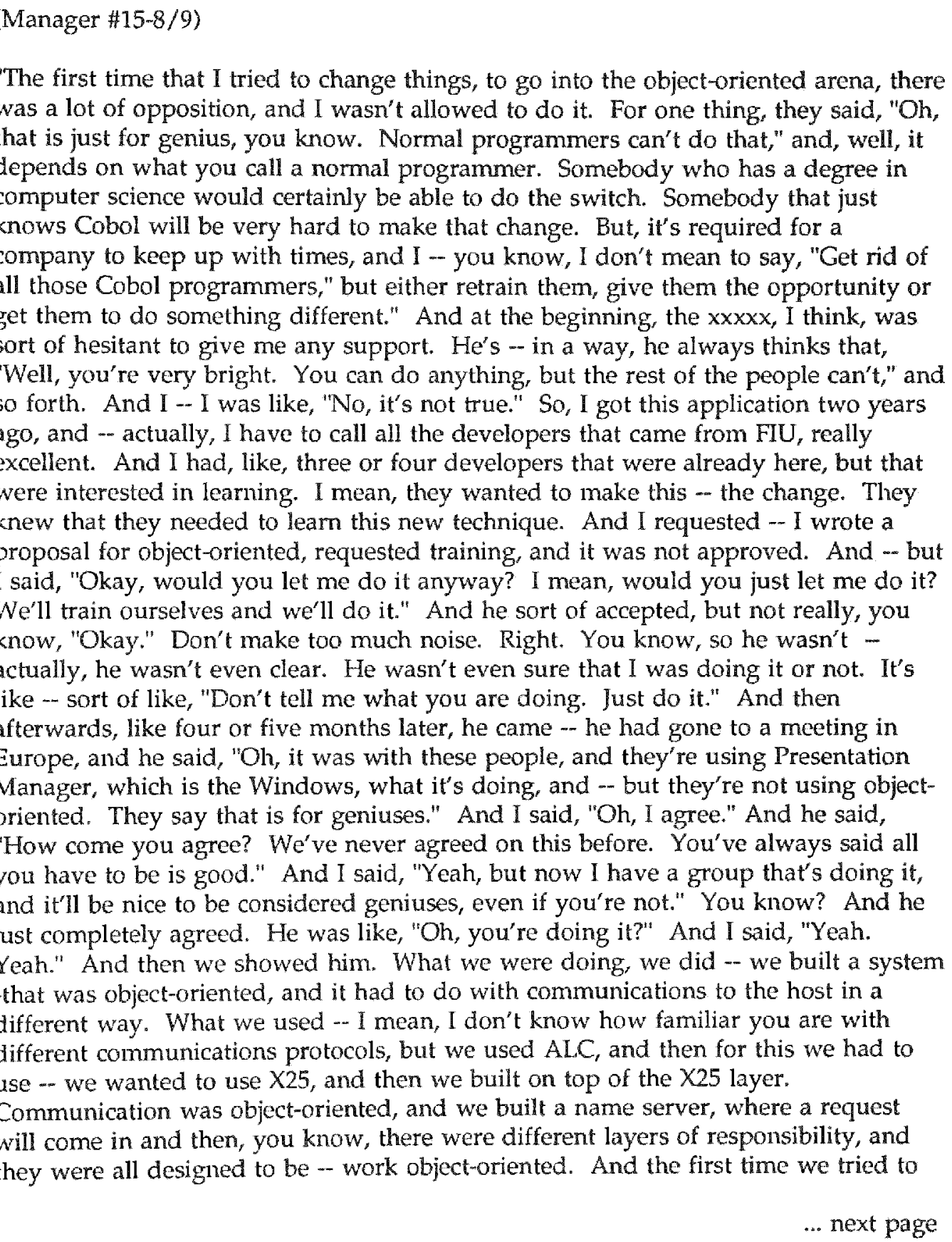 \\
\hline
\end{tabular}




\begin{tabular}{|l||}
\hline Number; 51 (Cont'd) \\
\hline Event: Change to object-oriented programming. \\
\hline Story: (Manager $15-8 / 9)$ \\
integrate the system together, it worked. And that was really impressive. The first \\
ones that were surprised were us. You know? It's like, "Wow. It works." You \\
know, "Hey, guys. How can you, you know, you have to have some confidence, but \\
when did you, before, integrated a system and it worked?" You know. I mean, \\
never. And it's just because object-oriented allows you to encapsulate the \\
information, and then all you need to do is have an API. So, once you make it work, \\
make the object work, then when you call different objects from different places, they \\
work. That's what's amazing. So, to me, it was like a big success that we had, and \\
so we got confidence. You know, we got his confidence, and then he gave us this \\
responsibility of a new project and said we had to do it in three months. And I said, \\
"Okay. We'll do it," and we did it in three months, and it worked. You know, \\
everybody went -- we designed it, and everybody went up with their own piece, but \\
it came back together integrated, and it worked. And that was really good."
\end{tabular}




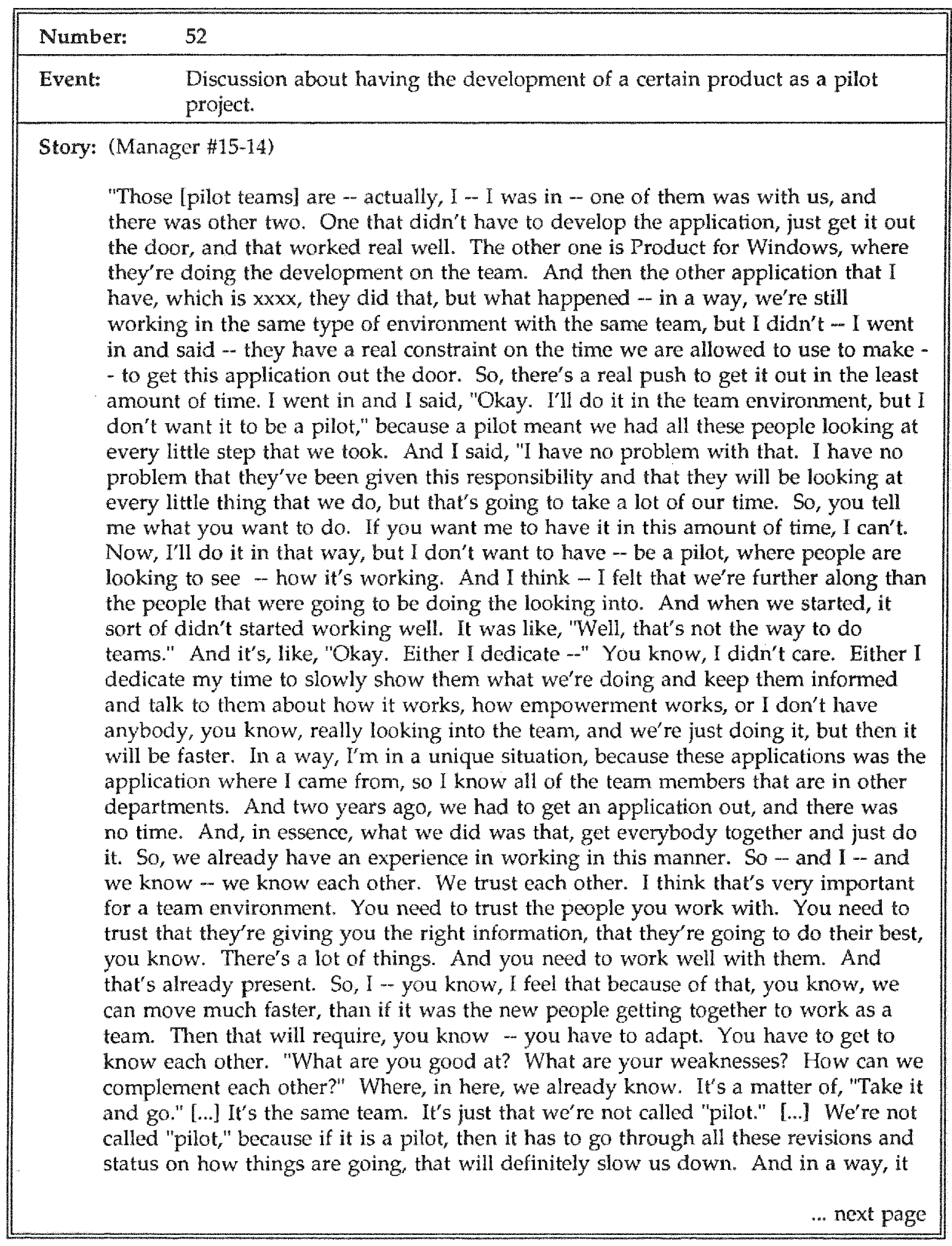




\begin{tabular}{|c|c|}
\hline Number & $52\left(\right.$ Cont'd $\left.^{\prime}\right)$ \\
\hline Event: & $\begin{array}{l}\text { Discussion about having the development of a certain product as a pilot } \\
\text { project. }\end{array}$ \\
\hline $\begin{array}{c}\text { Story: ( } \\
\text { c } \\
\text { st } \\
\mathrm{m} \\
\mathrm{s} \\
\mathrm{p} \\
\mathrm{m} \\
\mathrm{th} \\
\mathrm{It} \\
\mathrm{re} \\
\mathrm{it} \\
\mathrm{w} \\
\mathrm{to} \\
\mathrm{h} \\
\mathrm{ig} \\
\mathrm{st} \\
\mathrm{kr} \\
\mathrm{it} \\
\mathrm{as} \\
\mathrm{kr} \\
\mathrm{pr} \\
\mathrm{to} \\
\mathrm{ho} \\
\mathrm{st} \\
\mathrm{w} \\
\mathrm{gr} \\
\mathrm{te}\end{array}$ & 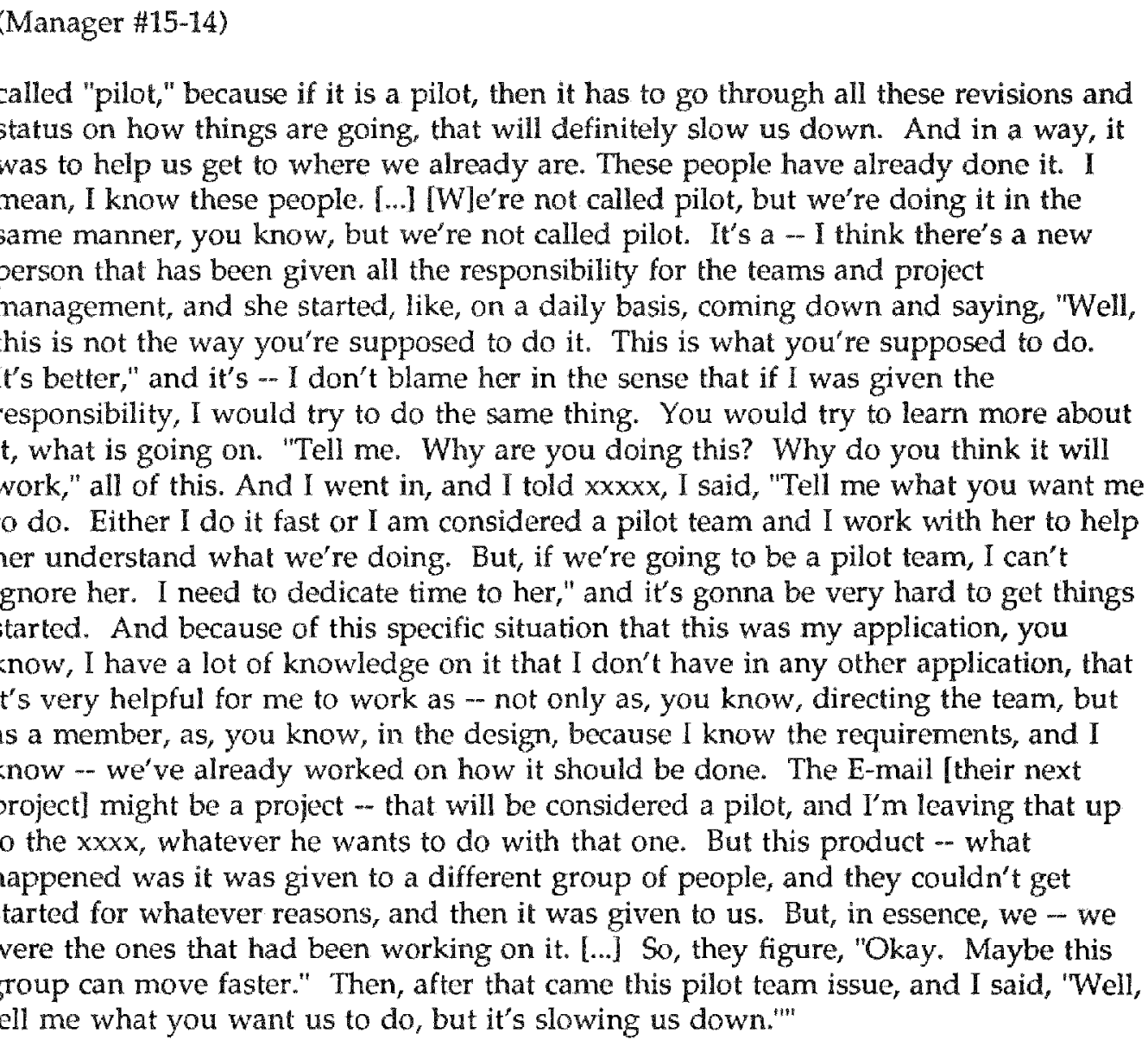 \\
\hline
\end{tabular}




\begin{tabular}{|c|c|}
\hline Number & 53 \\
\hline Event: & Bankruptcy of Mother Inc. \\
\hline Story: ( & 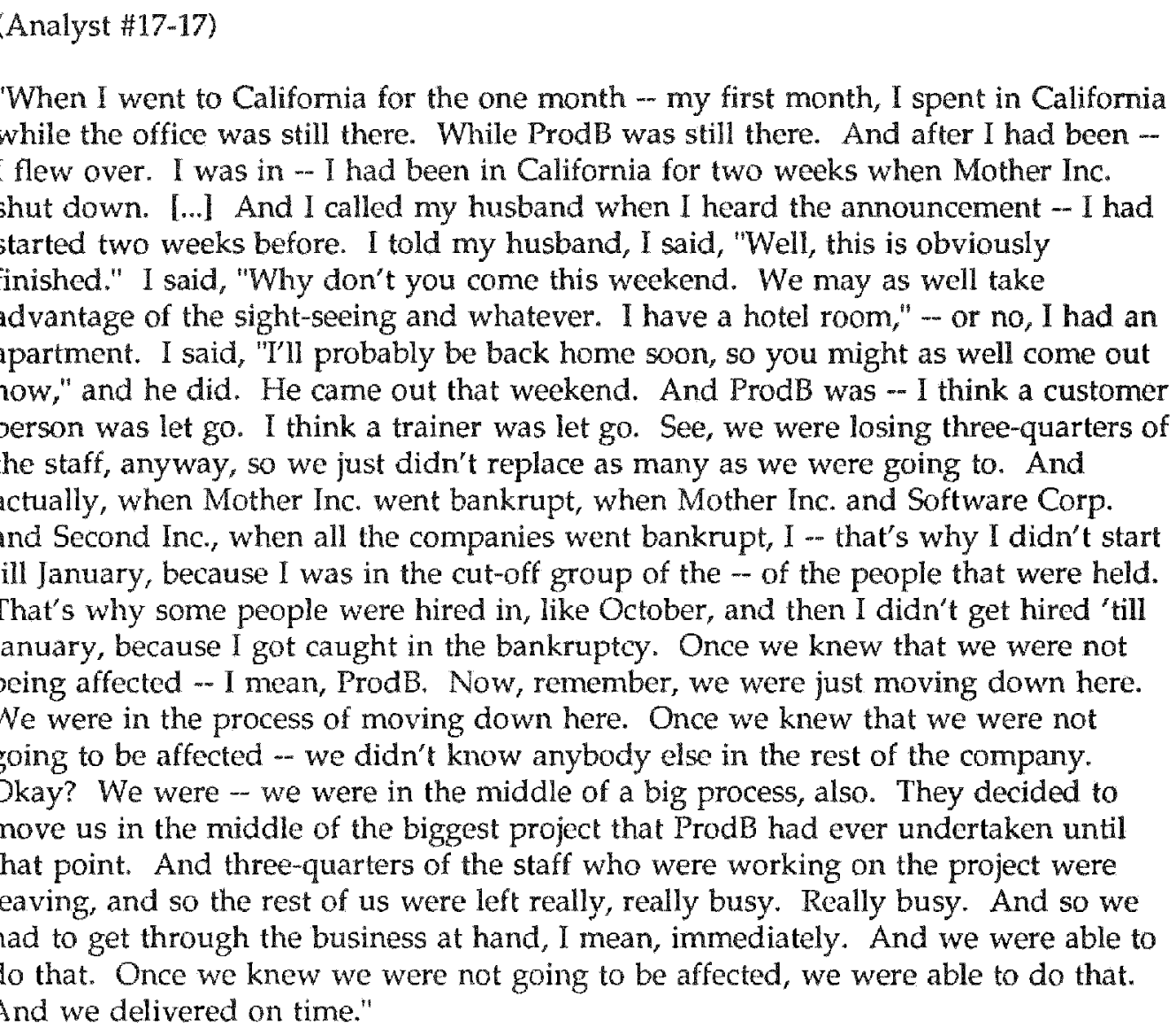 \\
\hline
\end{tabular}




\begin{tabular}{|l||}
\hline Number: 54 \\
\hline Event: Bankruptcy of Mother Inc. \\
\hline Story: (Analyst $17-17$ ) \\
"We have a six-month probation period, but it's highly unusual, highly unusual, for \\
someone not to make it through that six-month period. We're not a company that \\
fires people. We don't let people go. [When we let go people to Partner Inc.], [w] \\
didn't let them out on the street. We didn't fire them. We relocated them to Partner \\
Inc. Unfortunately, Partner Inc. then let go of a lot of them. When I say --m that was \\
a layoff. That was because Mother Inc. went away. Our business went down by 25 \\
percent overnight. Mother Inc. was responsible for 25 percent of our revenue, so \\
when I say Mother Inc. - Software Corp. doesn't fire people, I'm not talking about \\
losing 25 percent of your business -- and having to take immediate measures to cut \\
costs. And theoretically - mathematically, okay, if 25 percent of your revenue goes \\
away - then mathematically, 25 percent of your staff doesn't need to be there \\
anymore. Whoever was supporting that 25 percent perhaps doesn't need to be there \\
anymore. I'm not saying it was a good thing to do. I'm not saying that it was the \\
right thing to do. I have seen it happen at many companies. It is generally done by \\
the numbers. These people are going, these people are going, these people. These \\
positions are going. Okay? It was not a happy time here. I had just started."
\end{tabular}




\begin{tabular}{|l}
\hline Number: 55 \\
\hline Event: Implementation problems. \\
\hline Story: (Analyst \#32-11) \\
"We don't even know who they are lother groups in the organization, in their own \\
division]? We don't even know what their project looks like. We've been asking for \\
two years, for a demo of what Product looks like, and most of us - most people just \\
don't ever see them. Like, there is no interaction between the groups. Zero. And \\
that's a shame, because there's very interesting thing happening, but there is no \\
interaction. And management - management has never made any attempt at all to - \\
to really promote any kind of interaction. I -- I - they've really missed a bet on \\
that, I think. [... It's a lot better actually now that we're here. When we were in \\
California, they almost put us out of business a couple of times, because they didn't \\
know anything about what we did out there. They would make changes on the host \\
side and we wouldn't know about it. So it's better now that we're here. That was \\
one of the real benefits about coming here, is at least we know what these people are \\
doing. We have much more interaction with them now. And this has been a slowly \\
developing kind of relationship. It's taken us a long time for even people - I got to \\
know some of the people because I was doing a project that required, you know, \\
getting input from the host side and so I got to know a number of people, even \\
though I still actually don't know a lot of them. We - we do different kinds of \\
things."
\end{tabular}




\begin{tabular}{|c|c|}
\hline Number: & 56 \\
\hline Event: & Transfer of ProdB to Florida. \\
\hline $\begin{array}{c}\text { Story: (A } \\
\text { "I } \\
\text { di } \\
\text { co } \\
\text { an } \\
\text { ar } \\
\text { de } \\
\text { far } \\
\text { pr } \\
\text { yo } \\
\text { me } \\
\text { or } \\
\text { ca } \\
\text { No } \\
\text { su } \\
\text { do } \\
\text { us } \\
\text { wo } \\
\text { en } \\
\text { do } \\
\text { de } \\
\text { an } \\
\text { ge } \\
\text { inf } \\
\text { yo } \\
\text { So } \\
\text { So }\end{array}$ & $\begin{array}{l}\text { Analyst \#32-3) } \\
\text { I was transferred here; I came out in the first wave, so January of } 91 \text {. [It was } \\
\text { ifferent belcause ProdB, in California, we were on our own. Much much a sense of } \\
\text { ommunity, that so dissipated around here, we don't even have lunch together } \\
\text { nymore. That's unfortunate. We were a self-contained unit; we are not here. We } \\
\text { re not in control of our destiny; we got to interact with four thousands other } \\
\text { lepartments, [that's] like.. Actually, we weren't a smaller group at all; as a matter of } \\
\text { act, I think we're about like now, we' je just starting to [ramp upl for a whole big } \\
\text { roject, but it's about the same size, number of people, but the real difference is that, } \\
\text { ou know, in California, we were a self-contained unit; we had our own general } \\
\text { nanager, our own Help or Customer Service group, the trainers were part of the } \\
\text { rganization, operations, development, you know, sales. We were, yeah... When we } \\
\text { ame here, they quickly pealed off everything; everybody went their own way. } \\
\text { Jow, other groups in Software Corp., I know that we work more closely with our } \\
\text { upport group than anyone else, [that's real obvious what I wanted to do], but we } \\
\text { on't know any other way to do it, actually, given the product. It's inconceivable to } \\
\text { s, [just program and run away]. Programmers could not run away because they } \\
\text { vere just next door. So, we can conceive how we could work in that kind of } \\
\text { nvironment. I don't think you can do mid-range system development that way. I } \\
\text { on't think you can do it that way. There is too much give and take between the } \\
\text { esign, execution stages, if you want. I don't want to call it programming and } \\
\text { nalysts, but basically, design and execution, they really fit together very well. We } \\
\text { et a lot of feedback and input from our Customer service group. We get a lot of } \\
\text { aput from our trainers. Well, if people are out there trying to train people to use } \\
\text { our software and then they come back and tell us what is good, what is not good. } \\
\text { o, but in California, there were only us, we're all directly control, as here we're not. } \\
\text { o, it's quite a difference, quite a different thing." }\end{array}$ \\
\hline
\end{tabular}




\begin{tabular}{|l||}
\hline Number: 57 \\
\hline Event: Physical reorganization - ProdB \\
\hline Story: (Analyst \#32-5) \\
"Today's hot button is that we were just told we're moving and will be cramped in a \\
cube one-half the size of the cube we've got now. [] We are being moved out where \\
the marketing leaves back here. They're mad at us because they had to give up \\
theirs - they're being moved out to the 3rd floor. We're getting moved all the way \\
in... over there, so the PC products group can take over our area, and then we're \\
adding a whole bunch of people for these new projects, so that more people are \\
going to have to get moved out of there to move over here. And if they don't redo \\
these cubes and make them as small as the new cubes, then there will be open \\
warfare. I mean, people don't -- management sometimes just doesn't understand \\
that. [ ] On the other hand, we're all getting new equipment, and that pleases most \\
people."
\end{tabular}

\begin{tabular}{||l||}
\hline Number: 58 \\
\hline Event: Integration problems in a project. \\
\hline Story: (Analyst \#35-14) \\
"I've never experienced that, with the exception of the group that I'm working with \\
right now, with [the managerl and his group. I -- and I met with him last week, and \\
I told him that - I said - you know, I've been with him now for six months or more \\
on this project, and I said -- and I said, "I still feel like an outsider and I've never \\
been really pulled in." And part of it is the way he manages, very closed, and he's -- \\
he's a great - from what I've been told, is great about having teams and \\
empowering teams and working the teams, and I'm still out here. I've never been \\
brought into the team. And I told him that last week, and he said, "We'll change it," \\
and I'll start going to some development meetings with him and the programmers, \\
which I think will help. And I think that's just partly because it's new for him, too, \\
but other than that, there's pretty well -- if you communicate your needs, you know, \\
if you let other people know what you would like, everyone is open."
\end{tabular}




\begin{tabular}{|c|c|}
\hline Number: & 59 \\
\hline Event: & Implementation problems - Management sets priority. \\
\hline $\begin{array}{l}\text { Story: (A } \\
\text { "I } \\
\text { ca } \\
\text { ad } \\
\text { pr } \\
\text { ha } \\
\text { in } \\
\text { sy } \\
\text { di } \\
\text { w } \\
\text { be } \\
\text { a } \\
\text { pr } \\
\text { try } \\
\text { be } \\
\text { us } \\
\text { lo } \\
-- \\
\text { be } \\
\text { W } \\
\text { W } \\
\text { Bu } \\
\text { in } \\
\text { ha } \\
\text { op } \\
\text { "h } \\
\text { we } \\
\text { re } \\
\text { ca } \\
\text { th } \\
\text { wo } \\
\text { en }\end{array}$ & 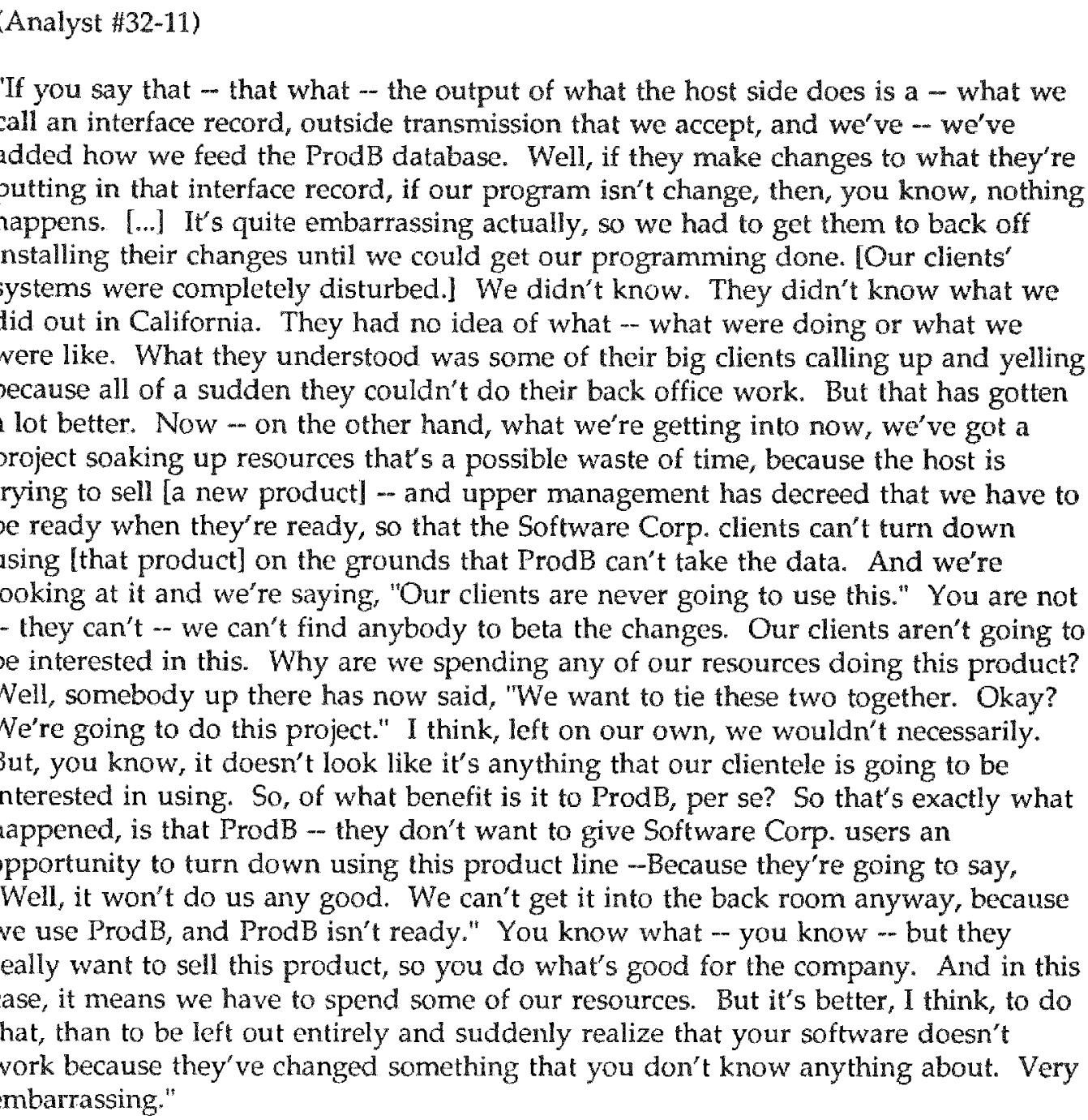 \\
\hline
\end{tabular}




\begin{tabular}{|l|}
\hline Number: $\quad 60$ \\
\hline Event: $\quad$ Training strategy. \\
\hline Story: (Analyst \#33-16) \\
"[...] Because if anything happens when - I was programming in Assembler, and \\
then when I was put into [a certain Product groupl, okay, then it was time to learn \\
C. You know. So I took a college course. I mean, they sent me off to some \\
seminars and - it's really you learn as you get - And so that the way things are \\
gonna go for C+t."
\end{tabular}




\begin{tabular}{|c|c|}
\hline Number & 61 \\
\hline Event: & Employees' transfer to Partner Inc. \\
\hline \multicolumn{2}{|c|}{ Story: (Analyst \#33-12) } \\
\hline $\begin{array}{l}\text { "I } \\
\text { sa } \\
\text { th } \\
\mathrm{C} \\
\mathrm{m} \\
\mathrm{B} \\
\mathrm{w} \\
\mathrm{ju} \\
\mathrm{bu} \\
\mathrm{yc} \\
\text { th } \\
\mathrm{yc} \\
-\mathrm{ar} \\
\mathrm{th} \\
\mathrm{co} \\
\text { to } \\
\text { th } \\
\text { sa } \\
\mathrm{m} \\
\mathrm{bo} \\
\mathrm{co} \\
\mathrm{be} \\
\mathrm{ki} \\
\text { let } \\
\text { "I } \\
\text { be }\end{array}$ & 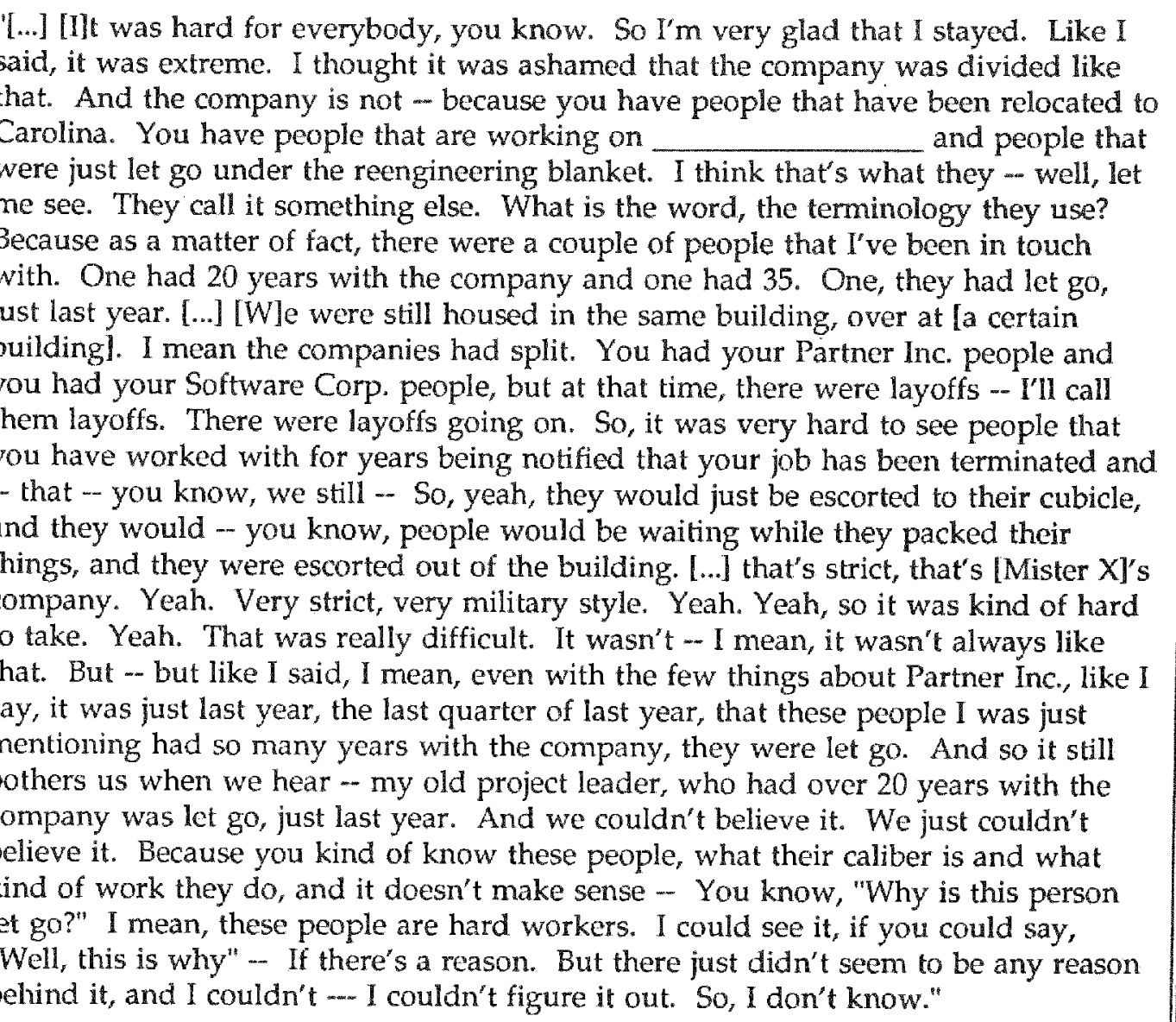 \\
\hline
\end{tabular}




\begin{tabular}{|ll|}
\hline Number: & 62 \\
\hline Event: & Reduction of access rights to the system. \\
\hline
\end{tabular}

Story: (Analyst $\$ 33-14$ )

"That's all it is. I can - I can - there's one person, I mean, you know, that comes over here and has been working with our department from - from Partner Inc. And, you know, some relationships haven't changed a bit. And it's funny, because they still will call up, like $X \times X \times$, you know, is a very __ man, and these people over here will call him for advice still, because there's problems going on, and you know -- so - so it's -- it's not like it used to be. I'm going to give you an example. Okay? I came from operations over in the mainframe. So, I pretty much am aware of - you know, all the functionalities, the whole bit. And we used to be able to, let's say, look at certain definitions of, let's say, travel agents out in the field, like how their printers are set up or their terminals are set up, because there's all definitions that exist, and if one is not set up correctly, it could cause some problems. Okay? Whenever we would get a call from the field, let's say, you have to determine if you have a hardware problem or a set-up problem, or is it an actual software problem. So, we used to be able to - our first step was, well, let's - let's - you'll have to department. Get all of that out of the way, you know. The ticket printer printing boarding passes. Okay. So, I would go there for different - if there's a problem with the set-up. Let's check the definition. You know, things like that. We had access to all of that. We no longer have access to any of that. That was taken away from us, because it was to Partner Inc. Now, we still have a lot of problems, you know, or problems can occur within our own system, and because if they change the way that our equipment is set up, it could cause them not to work correctly. And that has happened. Okay? And I have made a formal request through my vice president, saying, "I need that capability back. I will not change anything, but I need at least the capability to look, so that when a problem comes up, you know," because half the time I call those people over there, and say, "I'm having this problem," they don't know what I'm talking about. So, then my vice president then has to send a formal request through somebody else over at Partner Inc., right? And then this gentleman calls me into his office and says, "Okay. Why do you want this, because I don't understand." And then he assigns some of his people to have a meeting with me and with $x \times x \times x$, and saying, "You have to explain to us why you want this," and, you know, I sent out, you know, PDO's to everybody and copied everybody in the world, and it was really funny because we had another problem, and I put on the bottom of this one, I mailed it to everybody, I said, "Had I had the capability to look at these definitions" -- because it was just a definition, you know, but it really messed up our processing format, but, "If I had had the capability to look at these definitions, this could have been avoided." And I sent it out. And I'm still waiting for responses. So, that's why. Yeah. It's definitely very different. You know. We had a lot taken away. [...] You have to go through the proper channels. Because Partner Inc. is very security conscious." 


\begin{tabular}{|l||}
\hline Number: 63 \\
\hline Event: Training strategy. \\
Story: (Analyst \#33-15) \\
"Two weeks ago, three people went for training at the seminar or conference, \\
whatever you want to call it, for - I think it was at New Orleans. So, three people \\
went to that. Last week, two people went for more, like, advanced \\
you know, computer language. They went to training. And these are - it's not that \\
these are the people that have been here. Like, one of the people that just went to \\
the training last week was xxxxxxx, \\
in the group, he and xxxxxxxxxxxx. [...] So, xxxxx just - so, yeah, [our manager]'s \\
very -- and I guess it does, it depends, I guess, on your manager, but he is very \\
education [...] Training, you know. He sees - he wants to get everybody involved. \\
He's got - there's this person, xxxxxxxxx, who's in -- he wants [this person] - he's \\
scheduling him for, like, programming, language training."
\end{tabular}




\begin{tabular}{|c|c|}
\hline Number & 64 \\
\hline Event: & $\begin{array}{l}\text { Employees make their mind about staying with Software Corp. or } \\
\text { transferring to Partner Inc. }\end{array}$ \\
\hline \multicolumn{2}{|c|}{ Story: (Analyst \#33-10) } \\
\hline & 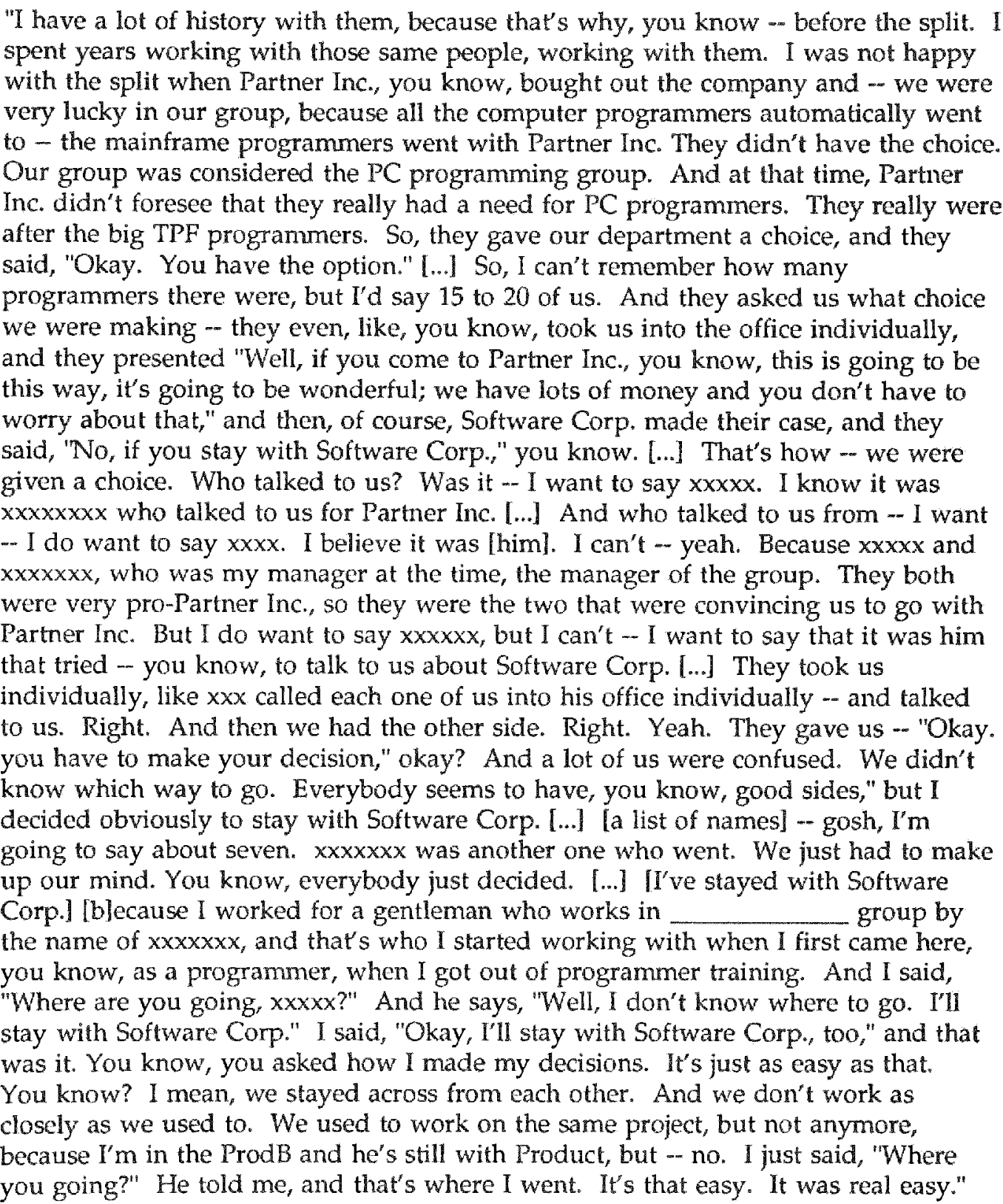 \\
\hline
\end{tabular}




\begin{tabular}{|l||}
\hline Number: 65 \\
\hline Event: Moving ProdA to Florida. \\
\hline Story: (Analyst \#33-5) \\
"[I've been in this group] [s]ince last year, in July. They approached two developers, \\
myself and xxxxxx. We both worked for Product, and they said, "We need two \\
developers to go up to Minnesota, because we are relocating that operation to \\
Florida." And the developers there did not want to leave Minnesota. They were all \\
home-grown. And there were job offers that were coming in for all of them. They \\
didn't have to worry about employment. So, they sent xxxxxx and I up there for \\
approximately four months to learn the operation and to move it down. Oh, well, in \\
this case, no, I felt like I did not have a choice, because I said I did not want to go. I \\
talked to my manager, xxxx. And I really liked the project that I had -- I was \\
currently working on. And I talked to xxxxx, you know, our director. And I said, "I \\
really don't want to go," and I'm sure - there were other people in the group that \\
probably would have volunteered, but I was not one of them. But, no, I didn't have \\
a choice. And everybody kept saying, "Well, it's such a great opportunity." So, I \\
went, you know. It was kind of put to a point, like, "You are going," so there's no -- \\
there's no ifs, no ands or no buts about it. [I resented it] [i]n the beginning. But \\
once I got up there, everything went well. And we were really fortunate, because \\
even though these people were being terminated from their jobs, they were very, \\
very good as far as teaching us the system." \\
a
\end{tabular}

\begin{tabular}{|l|}
\hline Number: 66 \\
\hline Event: Unstable airline business \\
Story: (Analyst $\# 33-6$ ) \\
"[...] [Reengineering] [w] hich a lot of companies are doing. So, that seems to take a \\
priority. The restructuring that goes with it, because that's also going on. And \\
another factor is the competitive business that we're in, the airline industry, because \\
it's very unstable, you know. Working for an airline, it's difficult, and I think that's \\
why they're trying to permit the company more of an xxx system instead of a xxxx \\
system. I just - you know, that's what they're going towards, and I think if's good \\
for the company's survival. Because, the airline business is shaky. It always has \\
been. I've been here 15 years, and the first six months that I started, they - they \\
were threatening to lay off. Because the union - the unions were always threatening \\
to walk out. So, you know, that was the first six months I worked here, and I've \\
been here for 15 years. So, we either kind of just take it, you know, with a grain of \\
salt, or you just leave. But, that's the way I am."
\end{tabular}




\begin{tabular}{|l||}
\hline Number: 67 \\
\hline Event: $\quad$ Departmental reorganization. \\
\hline Story: (Analyst \#33-6) \\
"It hasn't hit me personally yet, or directly. No. I imagine it will, as it gets to \\
coming closer to our area. I think they're going by phases. I think they've alleady \\
done Customer Service, or they're in the process, and then I think that they'll \\
address our area. But one thing that - it had to be attributed to reengineering, is \\
that I come in one day and I find out - I'm hearing - about this change in one \\
group. It was known as Integration. I don't even know what it's known as \\
anymore, but I come in one day I...] to speak, and someone says, "Oh. This group is \\
no longer under person X and is now under person Y," and I do not really know \\
who person Y is, someone on the third floor. And I said, "Well, when does it take \\
effect," and they said, "Immediately." And I couldn't believe it. So, that part of it \\
has hit me, now it's closer to, you know, to home, because that group was someone \\
that was working under, you know, my vice president, and now it's under \\
somebody completely different. But it hasn't -- as far as I'm concerned, it hasn't hit \\
me, this department, yet. Not yet."
\end{tabular}




\begin{tabular}{l} 
Number: 68 \\
\hline Event: Product management challenge. \\
\hline Story: (Analyst \#35-3/4) \\
"I was one -- a project I was appointed to was being set up as a pilot team to test this \\
new way of doing business. And then it was -- went through some transition with \\
both the Technology group and, also, the Marketing group, who defines what a \\
product is supposed to be, and it went under a whole new group of developers and, \\
ultimately, the development leader decided that she would prefer not to have - be \\
managed as a pilot. So, it - it was taken off the pilot concept. I... I still -- I'm still \\
the project manager for that one, but it's being managed - it's bcing managed kind \\
of like the old - it's in the middle of both. It's a strange - it's a strange monkey. \\
Because, I'm kind of - I'm finding with the project with that the core team concept \\
under what the pilot teams were supposed to be being set up, tends to be more \\
successful. It's a lot more productive, the use of people's time, and you get a lot \\
more done and - I don't know. I had a big team meeting last week, and there were, \\
like, 28 people in the room, and it was -- it's just not effective. The core team \\
concept does - is a much better way to go. So, I'm managing it kind of in between \\
the old way and the new way. Because it's a new development leader that I'm \\
working with, and so it's a kind of a strange creature. She was the one that \\
requested it not be run as a pilot. Because, with a pilot, everybody was looking in at \\
what was going on and you had to give regular status updates and people were \\
snooping around, and she just decided, "I don't want to be..." from what I was told, \\
that she would prefer not to be - have to deal with that added pressure and \\
snooping, because she - we're under a very - aggressive schedule to try to get it out \\
as quickly as possible. And so she didn't want to have all those extraneous \\
reporting stuff because of the pilot. So, that's the reason. But - that's the reason."
\end{tabular}




\begin{tabular}{|l|}
\hline Number: 69 \\
\hline Event: $\quad$ Software Corp. buys ProdA. \\
\hline Story: (Analyst \#33-4) \\
"Two gentleman had a company called xxoxxx, and it was a really good company. \\
You know, they did a lot of airline services, and Software Corp. bought them out. \\
[...] So, they said, "Hey, this is really good," you know, and I guess they offered them \\
an amount these guys couldn't refuse, so they said, "Sure,". [... Five years, yeah. \\
Five years, it was up in Minnesota, but as a Software Corp. operation, it was."
\end{tabular}

\begin{tabular}{|c|c|}
\hline Number: & 70 \\
\hline Event: & Job security at Software Corp. - Hiring process. \\
\hline 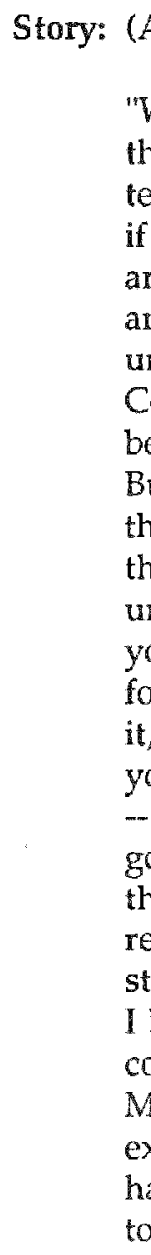 & $\begin{array}{l}\text { Analyst \#33-2) } \\
\text { When Mother Inc. was still around, the company seemed very relaxed in a lot of } \\
\text { heir policies. Well, I noticed that it - it seemed very difficult to -- how to say -- } \\
\text { erminate someone's employment. And like, even if they were not doing their job or } \\
\text { f they were not up to par with their responsibilities, because Mother Inc. was } \\
\text { round and you had unions, it just seemed to carry over into Software Corp., so - } \\
\text { nd you could never -- at that time, you could never really get rid of, let's say, a } \\
\text { inion member, you know. Their job was for life, and that carried over into Software } \\
\text { Corp. So, in that respect, I thought, yeah, everybody was very secure in their jobs, } \\
\text { pecause you were never going to get fired. It took an act of God to get fired from it. } \\
\text { 3ut when Mother Inc. went under, things seemed to change, and now they don't -- } \\
\text { hey're not that flexible anymore. Now they - you do have to do your work, or I } \\
\text { hink they're gearing more towards that. And so they still have a lot of, quote- } \\
\text { anquote, dead weight, because of - of, you know, the time. Some people have, like, } \\
\text { ou know, over } 25 \text { years with the company. But I think now that they are looking } \\
\text { or good people and they want good people to work and they're keeping an eye on } \\
\text { t, so... Now you're not -mou don't take it for granted that you'll have a job and } \\
\text { rou're going to be with this job forever, you know. So, I think it's better. I think it's } \\
\text { - people, yeah, they don't take advantage of the company anymore, and -- and that's } \\
\text { good. And I notice that the people that they hire, especially recently, you know, } \\
\text { hey're going for Master's degrees, you know, they're going for people that have } \\
\text { ecommendations, you know, good recommendations, good references, so - when I } \\
\text { tarted, I did not have a degree. And I did not even go to school for programming. } \\
\text { had no computer science background whatsoever. So, I was trained with the } \\
\text { onpany, but they don't do that anymore. Now they want people with at least a } \\
\text { Master's degree. That's what they're looking for. And there might be some } \\
\text { xceptions, but I know in our department, I think the majority of these people do } \\
\text { lave Master's degrees. Especially the new hired, especially, so... They're looking for } \\
\text { op-notch people." }\end{array}$ \\
\hline
\end{tabular}




\begin{tabular}{|c|c|}
\hline Number: & 71 \\
\hline Event: & History of Software Corp. \\
\hline \multicolumn{2}{|c|}{ Story: (Manager \#31-5) } \\
\hline & 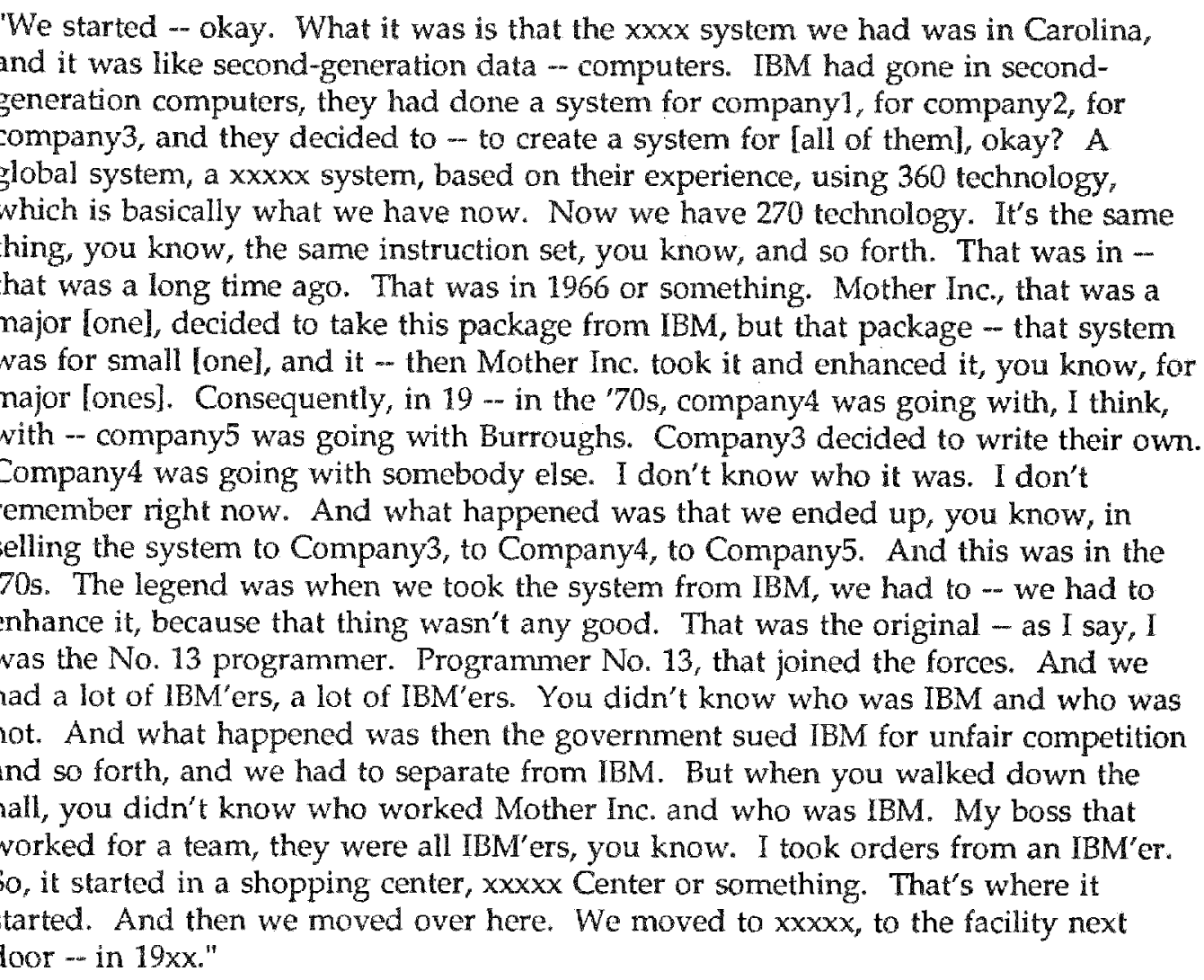 \\
\hline
\end{tabular}

\begin{tabular}{|l||}
\hline Number: $\quad 72$ \\
\hline Event: $\quad$ Consolidation of Software Corp.'s activities by Partner Inc. \\
\hline Story: (Manager $\# 31-5)$ \\
"And now, Partner Inc. took the system lease to Carolina. [It] [w]las right there, next \\
door, yes. [...] And then, just recently, in October of last year, they took the system \\
to Carolina. Partner Inc. has a contract with Second Inc, also. They operate the \\
computer facilities for them. When we became Software Corp., then we had people \\
in California and a data center in California, basically for Second Inc. We had \\
administration systems in Texas, and we had the Software Corp., you know, in \\
Florida. So, what Partner Inc. did, they consolidated it all into -- into a facility in \\
Carolina."
\end{tabular}




\begin{tabular}{|c|c|}
\hline Number & 73 \\
\hline Event: & Software Corp. changes owner. \\
\hline Story: (1 & 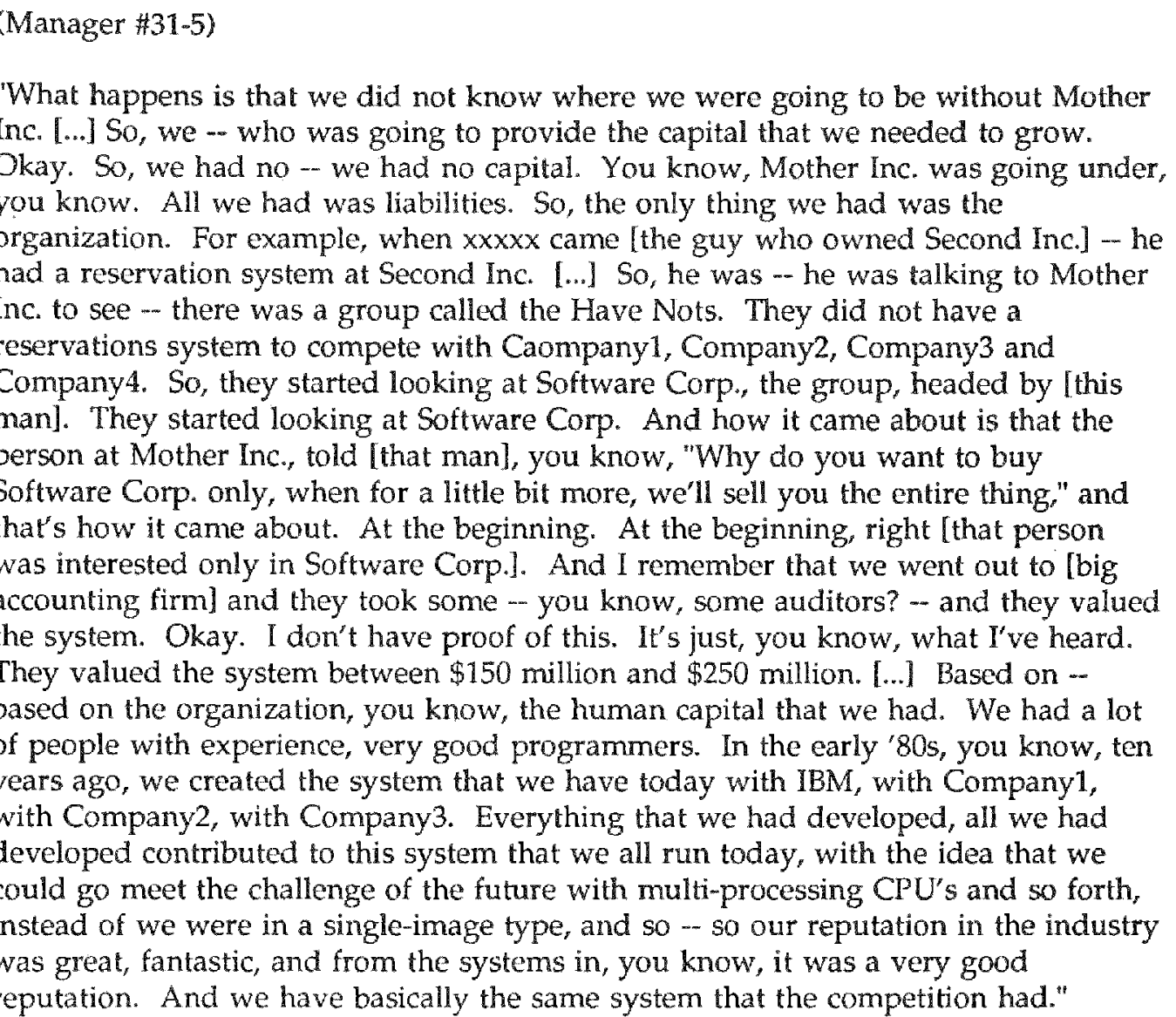 \\
\hline
\end{tabular}




\begin{tabular}{|l}
\hline Number: 74 \\
\hline Event: Success of Software Corp. in South America. \\
\hline Story" (Manager \#31-5) \\
"We have - we have a -- we started - let's talk the international arena. We start \\
with Mother Inc. had the routes to Central and South America. So, we started, you \\
know, providing services to travel agencies in Central and South America. Then all \\
of a sudden, you know, Mother Inc. sells the routes to [another company]. Well, \\
what's going to happen to your travel agents? They're not going to - they erase an \\
influence, you know. [...] There's a relation between an airline and a [system]. They \\
may not be legal, but that's the way you do business. So - so - especially in the \\
United States, it's not legal, but outside of the United States, it's not controlled by the \\
Department of Transportation or anything. But what that means is if you are in \\
Mexico and you want - and you want to be with - with my CRS, you know, the \\
people from the airlines may want to give you a better commission or discounted \\
tickets or something. That happens all the time. So, when we left -- when we left \\
South America and Central America, these people were lost. Well, we told them that \\
they could go to [their competitorl, and a lot of them stayed with us, it's \\
unbelievable, without having the airline subsidy, if you want to call it. You know, \\
it's a little bit like a subsidy. So, they kept us because we had the service, the \\
telecommunications service, you know, the maintenance, the - it had been, you \\
know, when they flowed -- when the information flows to the United States, the \\
processing of that data, you know, it's a good system."
\end{tabular}




\begin{tabular}{|l||}
\hline Number: 75 \\
\hline Event: Reorganization of the MIS group. \\
\hline Story: (Analyst \#34-14) \\
"[...] I don't - it might be hard on the people because of all these changes, you know. \\
As a matter of fact, some of my co-workers started out in one department, went to a \\
second department, went to a third department, then went to xxxo, and now it's \\
[under Integration]. You know. So, they were bent out of shape, and \\
understandably so, but this was not due to reengineering. This was before that. Just \\
handed off to different managers. It was like nobody wanted these people, so they \\
were getting handed off to -- from manager to manager. So, I would - in that \\
respect, I would definitely feel out of place, but I don't think reengineering's doing \\
that. I mean, we've only had one change, and we've been working on reengineering \\
for probably a year, year and a half, if that. Maybe less. I don't know. My sense of \\
timing has gotten so bad."
\end{tabular}




\begin{tabular}{|c|c|}
\hline Number & 76 \\
\hline Event: & Bankruptcy of Mother Inc. - Independency of Software Corp. \\
\hline $\begin{array}{l}\text { "I } \\
\text { st } \\
\text { in } \\
\text { an } \\
\text { al } \\
\text { to } \\
\text { to } \\
\text { in } \\
\text { in } \\
c c \\
\text { h } \\
\text { ex } \\
\text { In } \\
\text { a } \\
\text { d } \\
\text { to } \\
\text { w } \\
\text { w } \\
\text { so } \\
\text { th } \\
\text { th } \\
\text { th } \\
\text { w }\end{array}$ & $\begin{array}{l}\text { Manager \#38-12) } \\
\text { 'I miss [programming] terribly. But there's some reasons why I needed to do this. It } \\
\text { wasn't a career thing; it was more a loyalty thing - I always found -- and I've } \\
\text { superyised a lot of program-, a lot of really good programmers -- that they're very } \\
\text { easy people to keep happy. Technical people. You just give them something } \\
\text { interesting to work on, and they're happy. They don't even care whether it produces } \\
\text { any particular results, long as it's interesting. They like to produce results -- but I've } \\
\text { always had very good working conditions. Mother Inc. was a wonderful company } \\
\text { to work for. It always was. We always had the newest toys in town, so it was easy } \\
\text { o stay there. Newest computers and newest something. There was something } \\
\text { nteresting happening. [... Mother Inc. going away - although it was a lot grief } \\
\text { nvolved, the people who'd worked there for a long time -- the best jobs in this } \\
\text { country were for airlines in the early "70s, late '60s, and those were the best jobs. We } \\
\text { had -- I mean, they were good jobs. You had everything you could - no one will } \\
\text { ever have that good of working conditions again. But the transition from Mother } \\
\text { nc. to Software Corp., of course, occurred before Mother Inc. went down, so we had } \\
\text { couple of years, three or four years of sort of weaning away from the total } \\
\text { lependency on Mother Inc.'s business. And a lot of other things that happened too, } \\
\text { o sort of mask that, or for the -- the really, you know -- and it was awful. I was still } \\
\text { working at the base when Mother Inc. stopped flying, and it was terrible, but it } \\
\text { wasn't - you know, it's easy for me to say. I didn't lose my job. But you had been } \\
\text { sort of weaned away from that complete dependency on Mother Inc., because we } \\
\text { Iready had the travel agency business and they'd already been set up, all the } \\
\text { computer stuff had been, and Mother Inc. was a customer more than anything else at } \\
\text { hat point. [...] It was a very emotional thing. Well, I mean, you had a lot of friends } \\
\text { hat did work for Mother Inc., that were suddenly out of jobs. There's people } \\
\text { around here now - one of the consultants up here now working on the system, I had } \\
\text { worked with for years in the xxxxxx Department there. I mean, he - it's not a fun } \\
\text { hing to see happen." }\end{array}$ \\
\hline
\end{tabular}




\begin{tabular}{|c|c|}
\hline Number & 77 \\
\hline Event: & Employees' decision regarding Partner Inc. \\
\hline $\begin{array}{c}\text { Story: } \\
\\
\mathrm{h} \\
\mathrm{T} \\
\mathrm{T} \\
\mathrm{P} \\
\mathrm{p} \\
\mathrm{p} \\
\mathrm{h} \\
\mathrm{p} \\
\mathrm{ir} \\
\mathrm{tc} \\
\mathrm{I} \\
\mathrm{x} \\
\mathrm{k} \\
\mathrm{C} \\
\mathrm{p} \\
\mathrm{x} \\
\mathrm{u} \\
\mathrm{w} \\
\mathrm{x} \\
\mathrm{a} \\
\mathrm{w} \\
\mathrm{I} \\
\mathrm{I} \\
\mathrm{I} \\
\mathrm{a} \\
\mathrm{T} \\
\mathrm{k} \\
\mathrm{w} \\
\mathrm{C} \\
\mathrm{to} \\
\mathrm{w} \\
\mathrm{w}\end{array}$ & 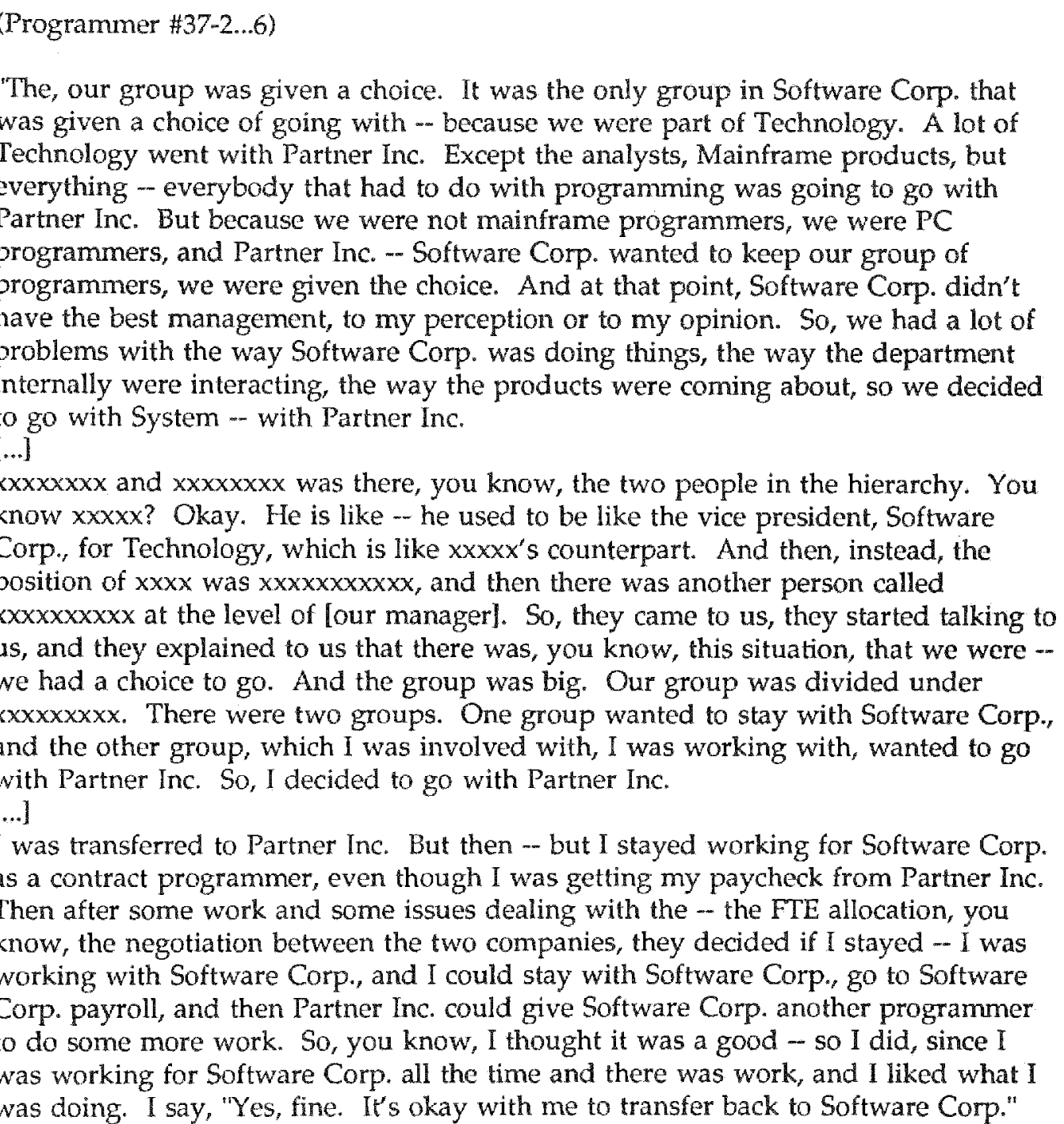 \\
\hline
\end{tabular}




\begin{tabular}{|c|c|}
\hline Number & 78 \\
\hline Event: & ProdA meeting. \\
\hline \multicolumn{2}{|c|}{ Story: (Programmer \#37-11) } \\
\hline $\begin{array}{l}\text { "I } \\
\mathrm{m} \\
\mathrm{cc} \\
\mathrm{e} \\
\mathrm{o} \\
\text { to } \\
\mathrm{be} \\
\mathrm{w} \\
\mathrm{m} \\
\mathrm{co} \\
\text { te } \\
\mathrm{bo} \\
\text { w } \\
\text { ar } \\
\mathrm{w} \\
\text { yo } \\
\text { ye } \\
\text { it }\end{array}$ & $\begin{array}{l}\text { [My boss] tells me, "You messed up there," or, you know -- yeah, she sometimes, in } \\
\text { neetings, I don't say -- I behave like another one of the guys here and without } \\
\text { considering my position, and sometimes she'll say, you know, "You have to set the } \\
\text { example," and she treats us like kids, which is fine with me. And I guess, like, the } \\
\text { lder has to set certain examples. That's the way I feel, like the older kid, and I have } \\
\text { o set some - [...] And she also shares with me the idea that she has with the group } \\
\text { efore she presents them to the outside group and she wants to know if I - where I } \\
\text { vould stand there. She always expect me to say something. Yesterday, in the } \\
\text { meeting, she said she was proposing this distribution of work and having } \\
\text { oordinators officially named. Before, we didn't have official coordinators in the } \\
\text { eams, but we knew, everybody knew, who was the coordinator of the activity. But } \\
\text { gecause the outside of the company doesn't understand that part of, that side of the } \\
\text { vork, and they were saying that we were not cooperating with the outside company } \\
\text { nd this and that, she say, "Okay. So, we're gonna do this so that everybody knows } \\
\text { who to talk to." So she said, you know, "You are going to be coordinating this and } \\
\text { rou are going to be coordinating that, and anybody has an opinion, an objection or } \\
\text { ny ideas," and everybody stay quiet. "xxxxx, you're not gonna say anything?" "I'm } \\
\text { orry to disappoint you,"I said, "but not this time. I'm going to be quiet." Because, } \\
\text { eah, she had talked to me about this before, so I was expecting that, and I thought } \\
\text { was a great idea -- good idea to do that." }\end{array}$ \\
\hline
\end{tabular}




\begin{tabular}{|c|c|}
\hline Number: & 79 \\
\hline Event: & $\begin{array}{l}\text { Problems of people who transferred to Partner Inc. - Unstable environment at } \\
\text { Software Corp. }\end{array}$ \\
\hline 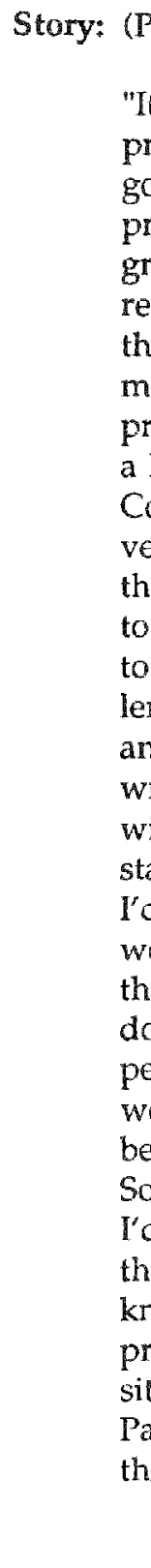 & 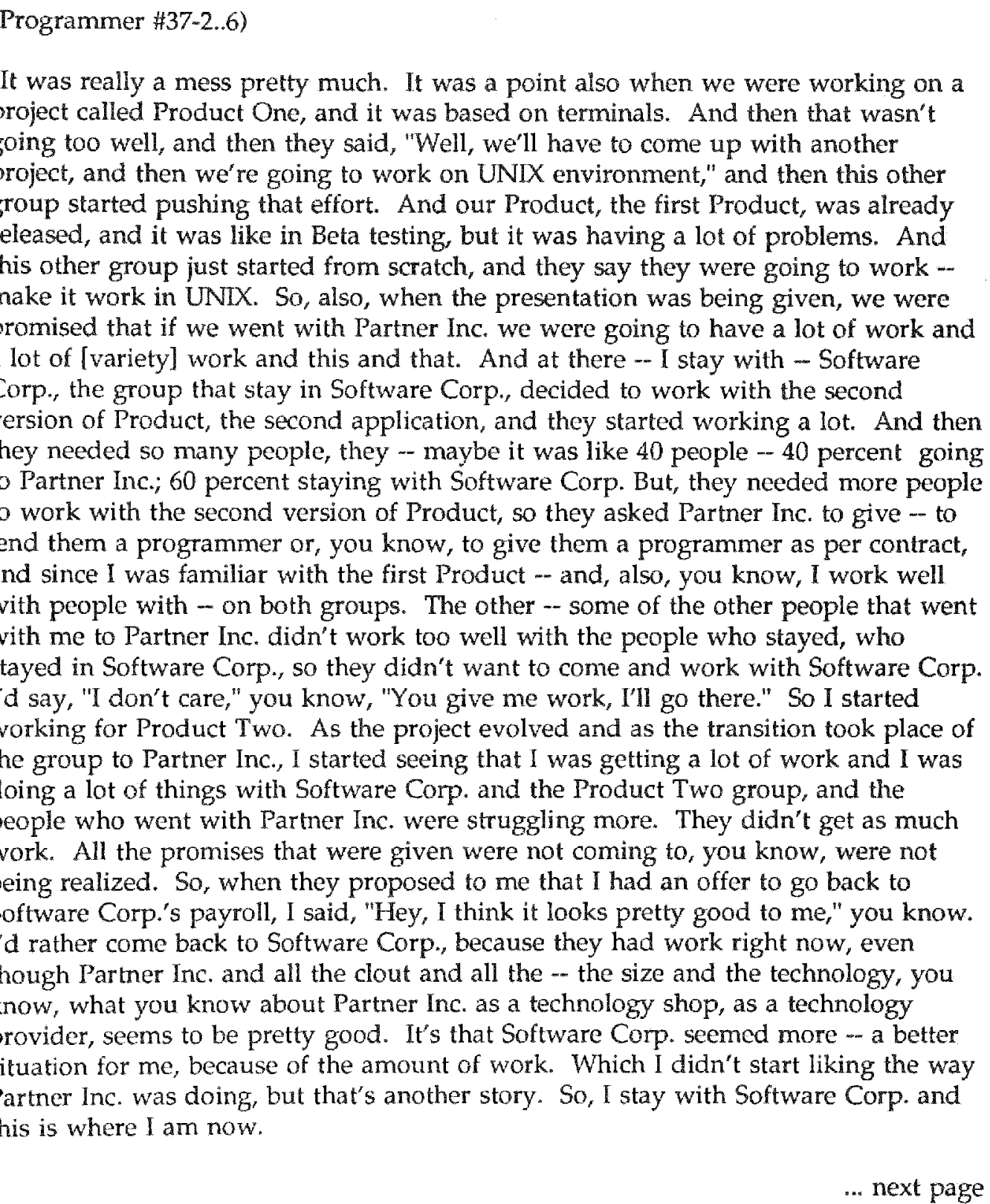 \\
\hline
\end{tabular}




\begin{tabular}{|l|}
\hline Number: 79 (Cont'd) \\
Sroblems of people who transferred to Partner Inc. - Unstable environment at \\
Software Corp. \\
\hline Story: (Programmer $\# 37-2.6$ ) \\
[...] \\
Well, now, the beginning, they really didn't have much to do [at Partner Inc.]. They \\
were doing, like, database work for internal maintenance or internal programs, \\
utilities, but nothing like coming up with an application to sell or an application to \\
mass-produce to, you know, our clients, our customers. Now it's getting better. \\
They have come up with, like, two or three projects. One is for Second Inc. for -- I \\
think it's xxxxx maintenance and routing. They get a lot of data, weather data, and \\
they map it on the screen and they route the planes according to the weather data, \\
and it seems like a pretty big, exciting application. And a couple of other projects \\
that I've heard, that seems to be, you know, picking up. So, these are good. [...] [I]t \\
took a while. And then a lot of - oh, there must be layoff or, you know, a couple of \\
very stressful situations. [...] Now it's beginning to get better, you know. I still have \\
friends over there, and when I talk to them it seems like there's more work coming \\
their way, but it's been a struggle all along. But looking at - and still, right now, \\
who knows what's going to happen with Software Corp.? And if Software Corp. \\
and Partner Inc. and [a third company] come up with that deal, I have no idea. I \\
just know that something is going on. I don't know what's -- There is some deal. \\
Like upper management says here, there's always a deal going, you know, in being \\
talked about, and right now it's like the talk is more extensive as far as a deal \\
between Partner Inc, and la third company] and Software Corp. I don't know what \\
the details are. I just know the three parties are involved in putting together some \\
kind of agreement."
\end{tabular}




\begin{tabular}{l}
\hline Number: 80 \\
\hline Event: $\quad$ Move of ProdA to Florida \\
\hline Story: (Programmer $\# 37-2.6$ ) \\
"I was working on Product, and I've had the luck - I've been lucky in being exposed \\
to several previous systems and several environments since I've been working here. \\
The first Product that we were working on was based on OS/2, on OS/2 platform. \\
Then there was this group in Minnesota that developed a lot of application and a \\
very, fairly large system based on OS/2 and C. They did the programming in C, \\
and in 1990 -- 1990 ? In '92, I think when the pay cuts, the pay cuts that we had and \\
a lot of shakeups that we had in Software Corp., they decided - the director of that \\
group resigned and they were -- Software Corp. got scared that they were going to \\
lose the people in that group, and they didn't want to be left out with a system, a \\
big system that nobody could support and nobody could run, and it was making \\
money at that time. So, they kind of panicked and they said, "Well, we're going to \\
close that center," without really consulting the people that were there and making \\
sure that, you know, there were going to be enough people to run the system and \\
they could maintain the system in Minnesota and do a good transition, you know, \\
better arrangement, I guess. So, they asked me if I wanted to go to Minnesota and \\
study the system so that I can bring it over here, because they were going to close \\
that center in Minnesota. So, you know, that's how I got involved. I said, "Yes, I will \\
go." "You get to go." And I went there and I spent four months there, studying the \\
system. I went with another person, XXXXXXXXXXX. It was a great experience, \\
a lot of learning. And, you know, then we moved the system back down here, and so \\
since then I've been part of this group."
\end{tabular}




\begin{tabular}{|l||}
\hline Number: 81 \\
\hline Event: Presentations - Suggested changes to internal system. \\
\hline Story: (Analyst \#34-8) \\
"I did presentations on the billing system and how certain projects or processes could \\
be modified to get a greater return and the amount expended on these projects was \\
not going to be all that great for the return. The return was like one year, return on \\
investment. I did about two presentations, two or three presentations, to the Steering \\
Committee. It was composed - comprised of a director and a cross-section of the \\
entire company. [...] [Following those presentations,] [t]hose projects were given \\
higher priority. Because of the constrained resources -- some of the resources were \\
allocated to - Partner Inc. resources were allocated to the reengineering process, so \\
there were very little resources concentrated on internal projects. And these \\
particular projects were given a higher priority. [...] So, I did see something come \\
out of it."
\end{tabular}

\begin{tabular}{l}
\hline Number: 82 \\
\hline Event: Change of procedure in the internal MIS group. \\
\hline Story: (Analyst \#34-8) \\
"Well, we've changed some procedures already since April, on how the user \\
requests, whether it's problems, enhancements. Before, the user picked up the phone \\
and called an individual in the MIS group. If it was something related to the xxx \\
system, they'd call me, and if something related to the xxxx system, they'd call my \\
co-worker. And now the Integration group set up a queue in the CEO, electronic \\
mail, where any request, whether it's problems, enhan -- anything. It goes through \\
that queue; it gets assigned a request number and gets assigned to one of the five \\
analysts, those five analysts that we have. So, there's more control in that respect. I \\
think that the user -- as a matter of fact, I had an internal project meeting -- it's a \\
monthly meeting with the managers -- and they have voiced that this seems to be \\
working better, than picking up the phone and just calling the user. There's more \\
control. There's, you know, formal reports being generated in one area versus \\
reports coming from me and reports coming from my co-worker. It's -- it's working \\
better. [...] It's an internal department change. No, it didn't come about \\
reengineering."
\end{tabular}




\begin{tabular}{|l||}
\hline Number: 83 \\
\hline Event: $\quad$ Mother Inc. and Second Inc. bankruptcies. \\
\hline Story: (Programmer \#11-4) \\
"It's because of my history, I think with, starting with Mother Inc. When I started \\
with Mother Inc., I started, like, a month after these cutbacks, because Mother Inc. \\
was teetering on the edge of bankruptcy about when I started. And it's been that \\
way just about ever since. Because Mother Inc., you know, went down and went \\
bankrupted, and then Second Inc. just came out of bankruptcy last year, so there's \\
constant - throughout my career has been constant rumors of disaster and things \\
like that, and so I've pretty much just learned to - So, I've learned pretty much just \\
to ignore all that and get on with my job. Because people get depressed and all \\
worried about what's going on in management and all this, you know, and really it \\
hasn't really affected me. I've seen people get laid off and people get wages cut back \\
and everything, and I've somehow managed to get through it all without having any \\
of those problems. And so I don't worry about what goes on at the upper level. I \\
mean, if it gets to be unpleasant - my job gets to be unpleasant due to all that, then \\
I'll find another job or something. I'm not going to worry about. It's not - I can't \\
control it, anyhow, so..."
\end{tabular}

\begin{tabular}{|l||}
\hline Number: 84 \\
\hline Event: $\quad$ Organization of the pilot projects. \\
\hline Story: (Analyst $\# 35-3 / 4$ ) \\
"There were supposed to be three [pilots]. There was -- excuse me. Software Corp. \\
Plus. [...] And there was Product for Windows. And [another product]. There were \\
supposed to be three of them. [The other product] then changed and is no longer \\
being managed as a pilot. And another one that's really kind of a cross between the \\
host and distributed, it's a new ticketing, PRojECT. It's a new ticketing requirement \\
by the industry. They have the magnetic... on the back of the ticket that you read. \\
Anyway, that's being managed by one of the new people from Mainframe Products \\
who's joined our staff. l...] It's a host and a distributed, and it's quite large in scope, \\
and they're manage - they trying to manage that one as a pilot, also, to see how the \\
concept goes. It's just starting."
\end{tabular}




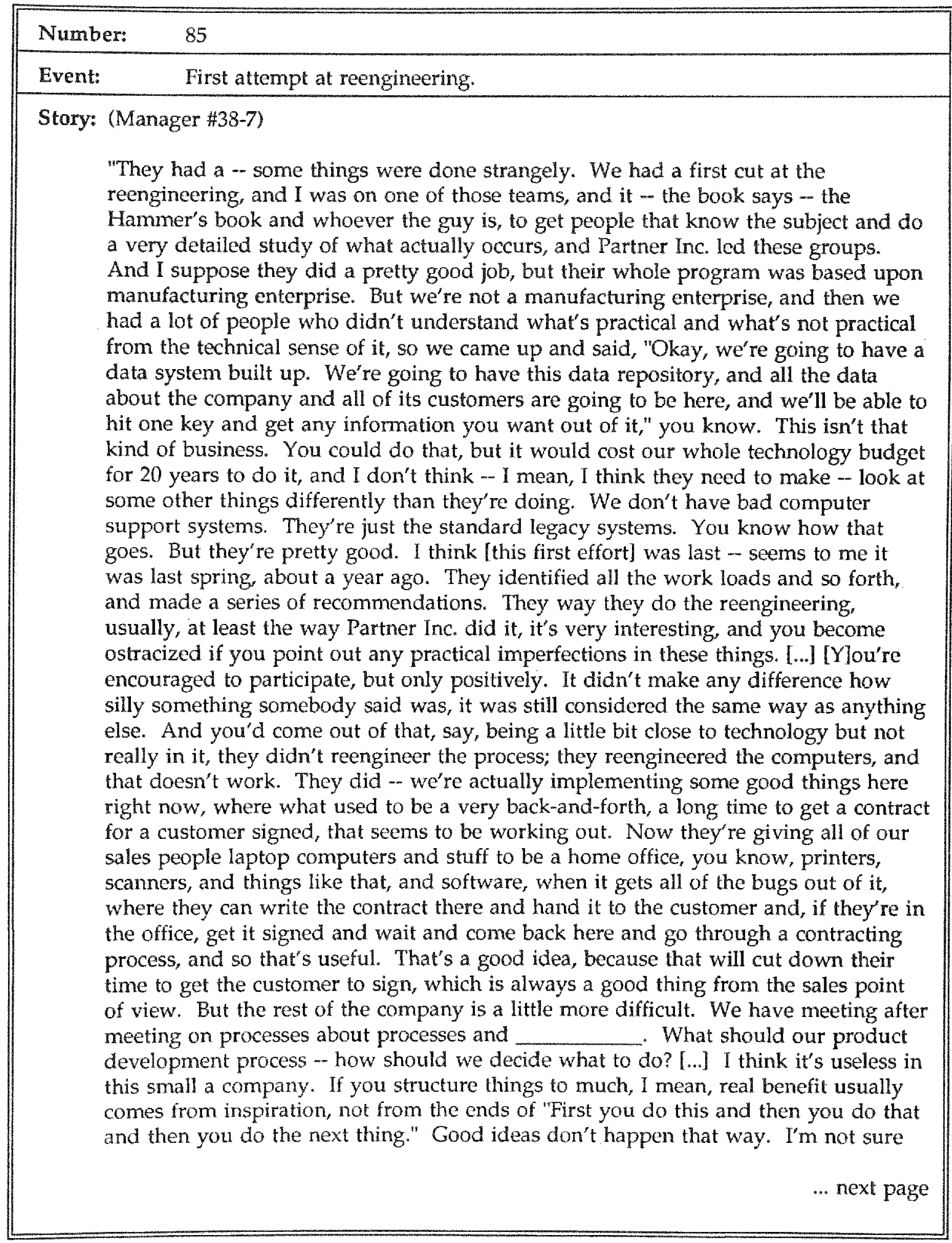




\begin{tabular}{|c|c|}
\hline Number & 85 (Cont'd) \\
\hline Event: & First attempt at reengineering. \\
\hline $\begin{array}{l}\text { Story: ( } \\
\text { in } \\
\mathrm{p} \\
\mathrm{w} \\
\mathrm{b} \\
\mathrm{a} \\
\mathrm{n} \\
\mathrm{or} \\
\mathrm{v} \\
\mathrm{ar} \\
\mathrm{r} \\
\mathrm{w} \\
\mathrm{d} \\
\mathrm{p} \\
\mathrm{st} \\
\mathrm{in} \\
\mathrm{d} \\
\mathrm{C} \\
\text { th } \\
\text { lo } \\
\text { th } \\
\mathrm{w} \\
\mathrm{sa} \\
\mathrm{p} \\
\mathrm{C} \\
\text { th } \\
\mathrm{d} \\
\mathrm{I}\end{array}$ & $\begin{array}{l}\text { (Manager \#38-7) } \\
\text { even that the big thing that our management is struggling with } \\
\text { involved, but all possible things you can do technologically including the Partner Inc, } \\
\text { people. And they've worked very long and hard to try to get a methodology, where } \\
\text { we work on the things that are most important. True? That's hard to do that. You } \\
\text { better think so. But it's very hard to do that, especially when things change as much } \\
\text { as they do in this industry. We get halfway through a project now, now this one's } \\
\text { not very important and that is important as that one, so you stop that, go to the next } \\
\text { one, go to the one that is most important, knowing that on the first one, that still has } \\
\text { value, and when you drop it and pick it up again, it's going to greatly increase the } \\
\text { amount of time, you know, all that stuff. That's an almost impossible thing to } \\
\text { regularize and you will have to use some judgement on those things. In other } \\
\text { words, they spent a lot of time on the process, not on the result, which personally I } \\
\text { don't like, but I can see that it's necessary. We have pretty good - I think we have a } \\
\text { pretty good management of the development process in terms of being very } \\
\text { structured with the requirements and have a change management, so you don't get } \\
\text { into those endless bugs, changing the changes, until you never get a product out the } \\
\text { door. They control that very well. [...] I think the reengineering - I think [Software } \\
\text { Corp.] could survive without it. I think the reengineering thing is a good thing and } \\
\text { his sales process is a good thing. That obviously is a good thing. I just think that a } \\
\text { lot of the expectations is that they're not really looking at changing the process; } \\
\text { hey're looking at changing the computer support for the process, and that's not } \\
\text { what reengineering's all about, so... But we had some } \\
\text { sales process is really - is a good thing, you know, for the company's competitive } \\
\text { position, but we can get into so many other things, like, how do you support } \\
\text { Lustomer Service with the computer? I mean, it's hard to describe, but people think } \\
\text { hat you can take all this information and all of the knowledge that's downstairs and } \\
\text { dump into a knowledge-base system, and that's going to solve all of their problems. } \\
\text { it doesn't work that way." }\end{array}$ \\
\hline
\end{tabular}




\begin{tabular}{|c|c|}
\hline Number & 86 \\
\hline Event: & Last organizational reorganization. \\
\hline $\begin{array}{c}\text { Story: ( } \\
\text { u } \\
\text { tr } \\
\text { th } \\
\text { te } \\
\mathrm{p} \\
\mathrm{w} \\
\mathrm{E} \\
\mathrm{d} \\
\mathrm{E} \\
\mathrm{kr} \\
\mathrm{th} \\
\mathrm{d} \\
\mathrm{w} \\
\mathrm{re} \\
\mathrm{er} \\
\mathrm{th} \\
\mathrm{su} \\
\mathrm{ca} \\
\text { in } \\
\text { ab } \\
\mathrm{al} \\
\mathrm{b} \\
\text { in } \\
\mathrm{re} \\
\mathrm{re} \\
\mathrm{p}\end{array}$ & $\begin{array}{l}\text { Manager \#38-7) } \\
\text { "There was a group that reports to Mr. F, who were the - and things had - Mr. F } \\
\text { used to work for me, let's see, before Partner Inc. or anything. We had - as this } \\
\text { travel agency business grew, it came to - I hadn't noticed it before, but I didn't work } \\
\text { this part of the company - we had some parallel organizations in marketing and } \\
\text { telecom. We had installations support in both of - a bunch of stuff that was } \\
\text { paralleled and [power plays] obviously. And then someone noticed and said, "Well, } \\
\text { we can't have but one of these." And part of the group in marketing, Mr. F and Mr. } \\
\text { E, and not any relationship, but youngsters, very bright youngsters, and since we } \\
\text { didn't have any formal technical support, the marketing people, they were it. } \\
\text { Everybody called Mr. F and Mr. E if they wanted something done or wanted to } \\
\text { know something or some customer wanted to do something } \\
\text { there was a whole organization built around the installation support in the marketing } \\
\text { department, and they were providing that -- not under technology supervision, they } \\
\text { were providing all the technical support that the field was getting, so then they } \\
\text { reorganized again and formed a group to provide some formal - but, at any rate, } \\
\text { eventually I was working for xxxx, reporting to xxxx, and I took this job, and one of } \\
\text { the guys that worked for me at the time in the job I had, which is product technical } \\
\text { support, and, I guess, I'm just trying to remember, because Tony was working -- he } \\
\text { came with me, he came with me. But he was doing -- coordinating the } \\
\text { mplementation of new distribu - you can't believe how many people have to know } \\
\text { about everything that we do. We've got the installation people and the vendors and } \\
\text { all the customer support people. We've got thousands and thousands things have to } \\
\text { be done, and so he had a group that ended up doing that, [honchoingl through and } \\
\text { mplementing, you know, coordinating the implementation of product. So, one of the } \\
\text { e-organizations, they decided, well, for the host products, xxxx' people have that } \\
\text { responsibility. So, that will them all - logically, we should put them all in that } \\
\text { olace. So, that's how this half of the page got away." }\end{array}$ \\
\hline
\end{tabular}




\begin{tabular}{|c|c|}
\hline Number: & 87 \\
\hline Event: & Contract writing process with Partner Inc. \\
\hline $\begin{array}{l}\text { Story: ( } \\
\text { th } \\
\text { C } \\
\text { w } \\
\text { en } \\
\text { it. } \\
\text { or } \\
\text { sig } \\
\text { re } \\
\text { In } \\
\text { ve } \\
\text { of } \\
\text { do } \\
\text { an } \\
\text { ha } \\
\text { Bu } \\
\text { is } \\
\text { se } \\
\text { lie } \\
\text { les }\end{array}$ & $\begin{array}{l}\text { Manager \#38-3) } \\
\text { "That was done by -- well, with } x x x x \text { and our financial people and some other } \\
\text { people, who did that, but none of us here - xxxxx, to a certain degree, the vice } \\
\text { president, was in on some of the negotiations, but for the most part we were handed } \\
\text { a contract and } \\
\text { going on and there were - there were other people, there were people in our Finance } \\
\text { Department, quite well aware of what was happening. And the way the services, } \\
\text { that part of that contract, was done, by going to the departments within Software } \\
\text { Corp. and asking them what they did, to write their services down, without knowing } \\
\text { why, as I understand that was done, so everybody wrote up all these. That's what } \\
\text { ended up in the services part of the contract. [...] It took them two years to negotiate } \\
\text { it. There were all kinds of people, a lot of them not knowing what they were doing } \\
\text { or why they were doing certain things. [...] It was really -- when the contract was } \\
\text { signed, it was really Mother Inc. and Second Inc. and Software Corp. The business } \\
\text { relationship with Partner Inc. went through many things, especially when Mother } \\
\text { Inc. was here, you know, in bankruptcy, it changed a lot of stuff. But they did a } \\
\text { very comprehensive job defining -- a lot of our people, most of them, the better part } \\
\text { of our people, went to Partner Inc., all the telecom people, all the people having to } \\
\text { do with host computers. And there was a lot of not knowing in the transition period } \\
\text { and so forth, what -- who was going to go end up where. My group might well } \\
\text { aave ended up there, but it didn't, so... Then the contract was pretty comprehensive. } \\
\text { But that's, as I understand, how they did it. And the basis of it, as far as the service } \\
\text { s concerned, was no matter what everybody wrote up - everybody talks about the } \\
\text { services - is what we were doing for ourselves, is in the transition day. So, if we } \\
\text { ied, they could find out about it. You know, they would be adjusted to whatever } \\
\text { evel of service we provided in our services." }\end{array}$ \\
\hline
\end{tabular}




\begin{tabular}{|l||}
\hline Number: 88 \\
\hline Event: History of Software Corp. \\
\hline Story: (Manager \#38-1) \\
"I went to work for Mother Inc. in 19XX. So I've been in effectively, never changed \\
jobs in all that time. [...] because originally Mother Inc. separated out the \\
communications and computer people. Well, first they separated out the travel \\
agency business into a subsidiary, and then they added to that subsidiary all the \\
computer and communications. First it was the marketing people, and then they put \\
all the computer communications people -- and I guess it was 1987? --when Second \\
Inc. bought Mother Inc. it already had a subsidiary - had a subsidiary that did their \\
computer work, and they merged the two companies, but the name Software Corp., \\
which is our name, survived. It's been through many other alterations of ownership, \\
but I've been in the computer business the better part of my adult life."
\end{tabular}




\begin{tabular}{|c|c|}
\hline Number: & 89 \\
\hline Event: & Difficulties with maintenance contractor. \\
\hline $\begin{array}{l}\text { Story: (I } \\
\text { "I } \\
\text { sh } \\
\text { th } \\
\text { A } \\
\text { ar } \\
\text { w } \\
\text { m } \\
\text { co } \\
\text { ai } \\
\text { al } \\
\text { [a } \\
\text { w } \\
\text { cu } \\
\text { th } \\
\text { fic } \\
\text { af } \\
\text { fir } \\
\text { bu } \\
\text { ca } \\
\text { th } \\
\text { vo } \\
\text { w } \\
\text { ne } \\
\text { th } \\
\text { re }\end{array}$ & $\begin{array}{l}\text { Manager \#38-3) } \\
\text { "That's a long story, that's right, it takes in } \\
\text { shortly after we got all this responsibility, I mean, this part of Software Corp. for, } \\
\text { things like the maintenance contract were administered by the Telecom Department. } \\
\text { At the point where those people were separated, we undertook -- well, we looked } \\
\text { and thought we were getting robbed on our maintenance costs, so -w and also that we } \\
\text { weren't getting good service from the vendors that were providing our domestic } \\
\text { maintenance at the time. So, as a cost-saving measure, we put it out for bid, and } \\
\text { contracted with la certain company], who was our - who we use their printers, their } \\
\text { airline printers, their specialized printers, to print tickets and things? And they were } \\
\text { already doing printer maintenance, and they came in with the most agreeable bid, } \\
\text { all around] save us a lot of money, so we went through that transition. And that } \\
\text { was - that wasn't too awful, because they knew - you know, they already knew our } \\
\text { customers, they were used to dealing with and understood our requirements, but } \\
\text { lhen [a certain company] sold their computer division, including their maintenance } \\
\text { tield people, to [another company]. So, we had another transition about six months } \\
\text { ffter the first one, and that was awful. Not because [this other company] isn't a real } \\
\text { first-class company, because they are, but simply because they didn't understand our } \\
\text { ousiness, and they were very decentralized. So, they assumed that whoever they } \\
\text { called on was their customer, so you went, "Well, that's my customer," but not, we're } \\
\text { heir customer. And it took a long while, but they finally came up -- they do very, } \\
\text { very good work. Just about three months of horror, of trying to convince them of } \\
\text { what we're doing. But our executives decided recently, last year sometime, that we } \\
\text { heeded another technology partner, so that was really the impetus to change from I } \\
\text { his company] to [another one], which effort is being hampered by their } \\
\text { teorganization." }\end{array}$ \\
\hline
\end{tabular}


APPENDIX 3

DATA ANALYSIS 


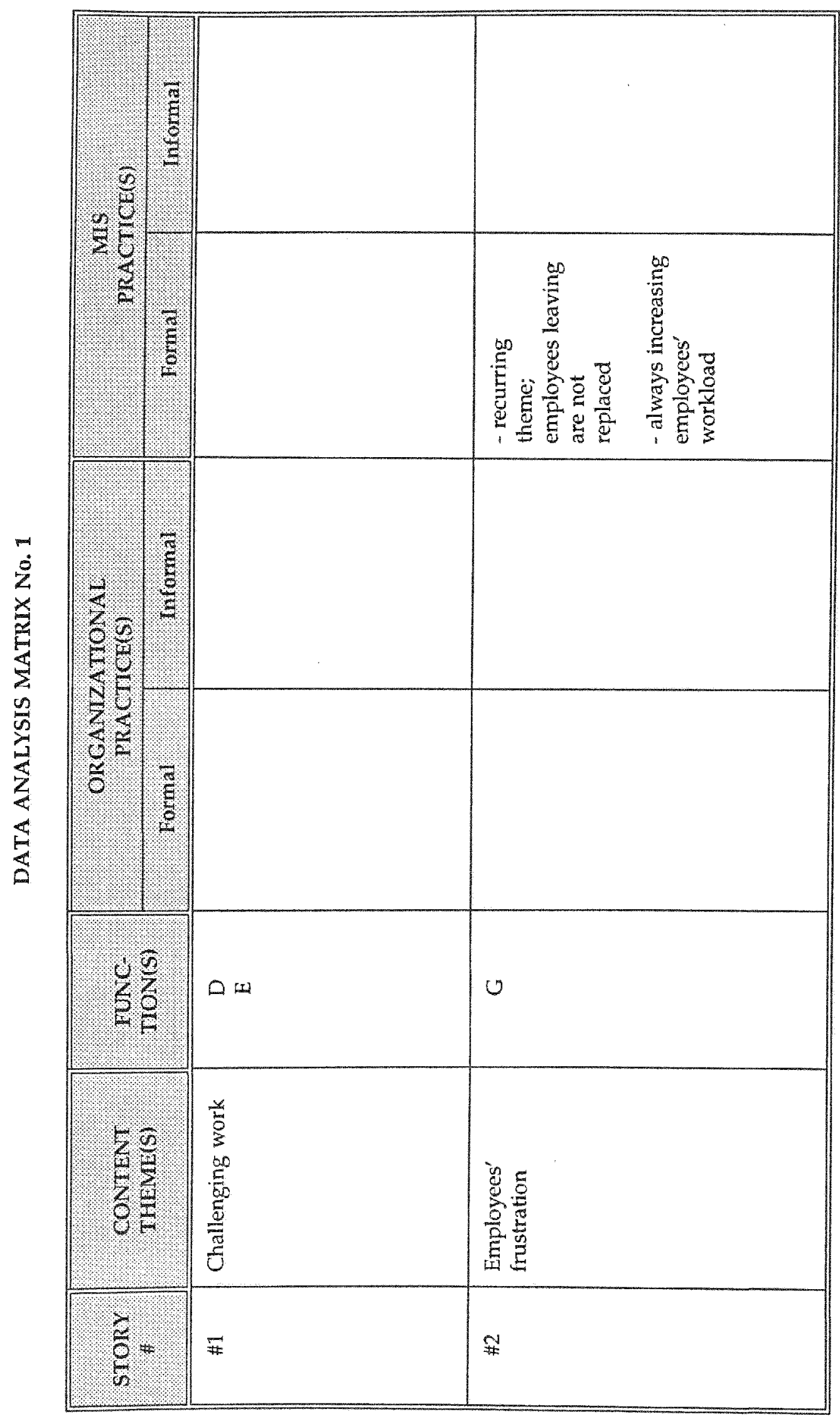

ฌั 


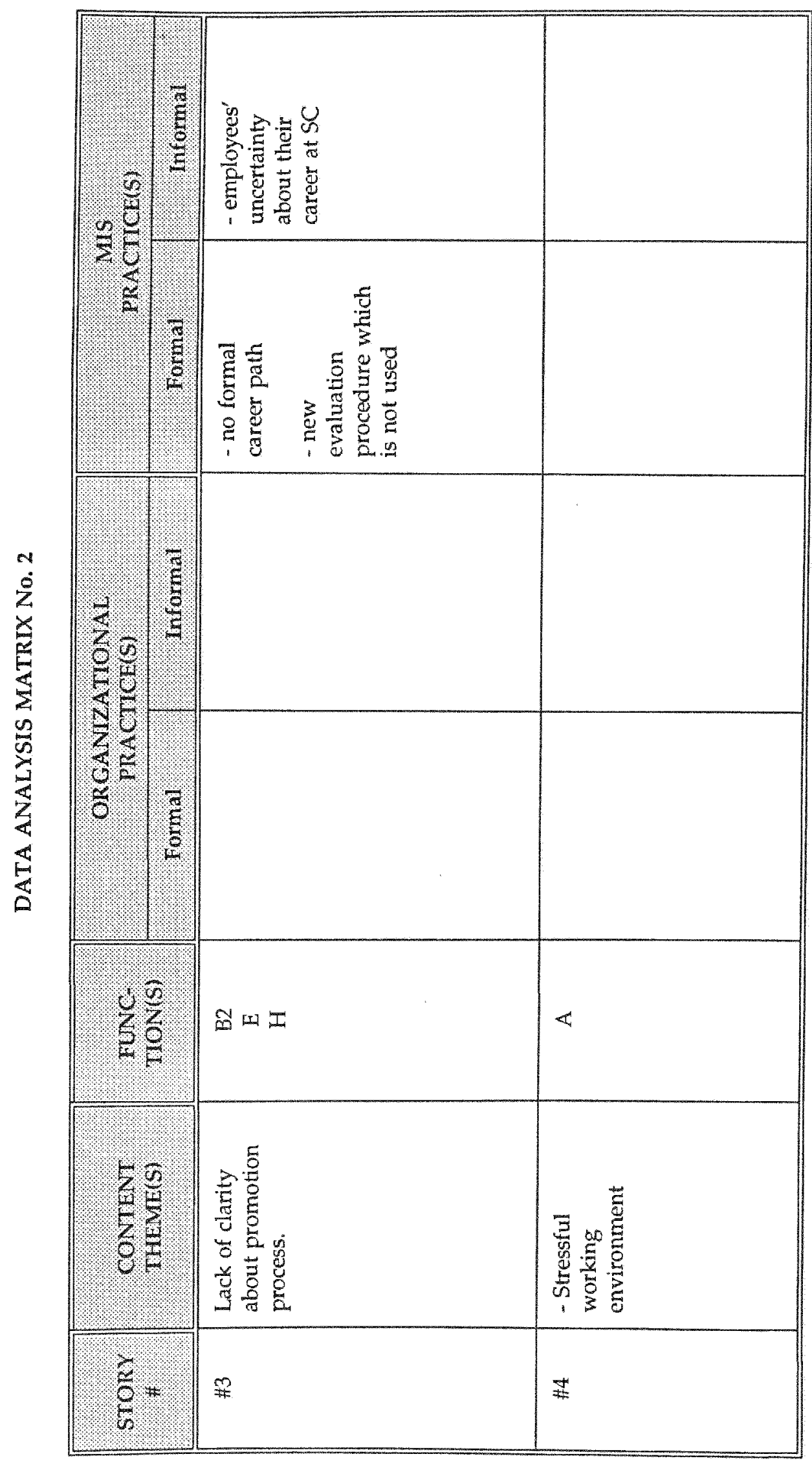

ลิ 


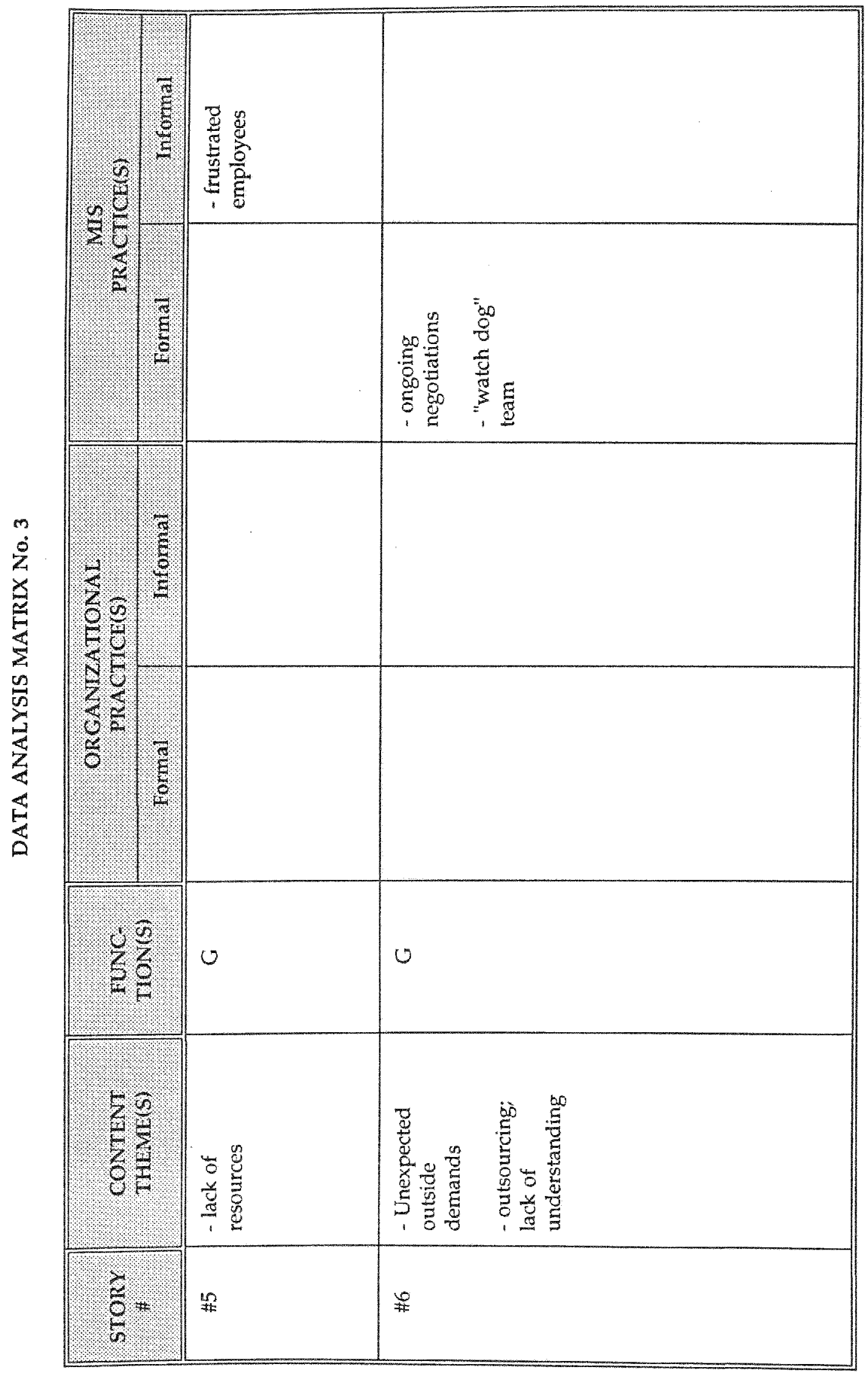

$\mathbb{N}$ 


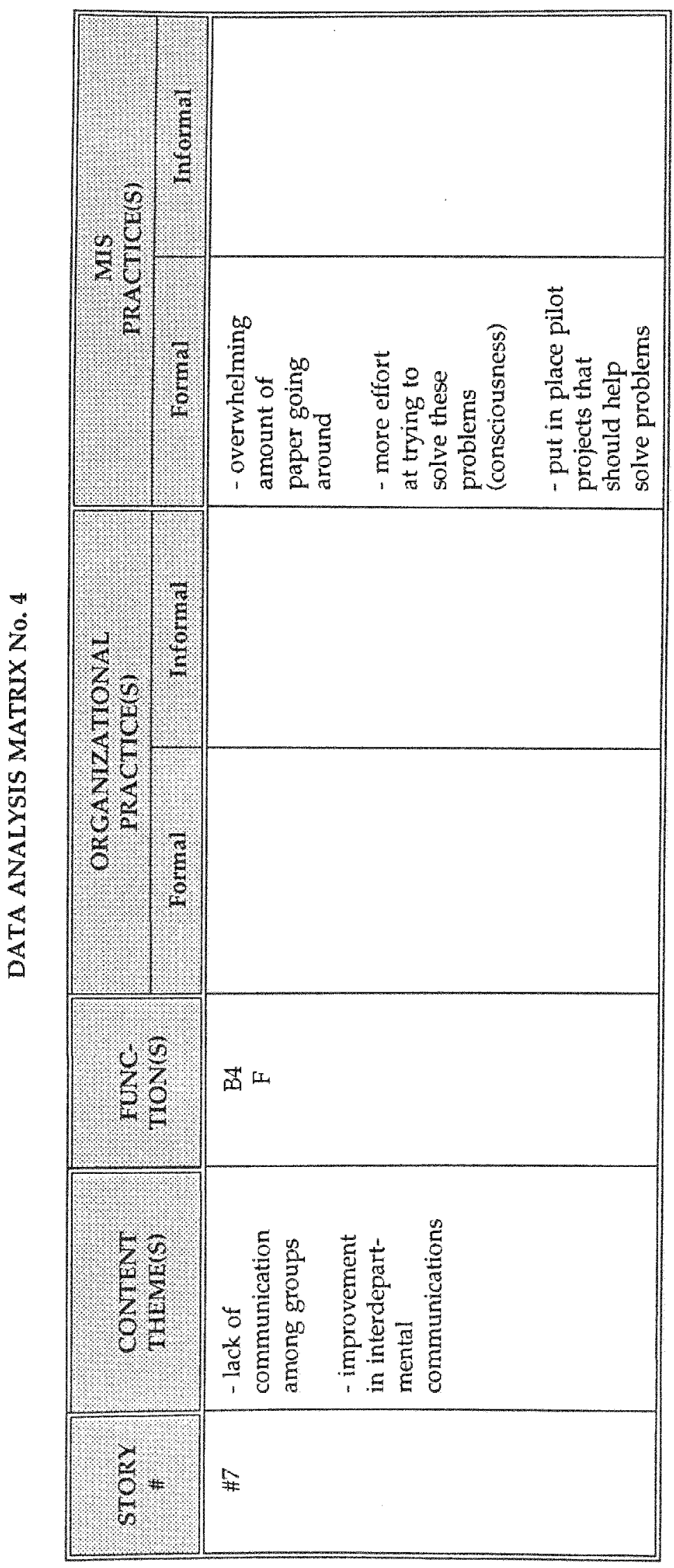

요 


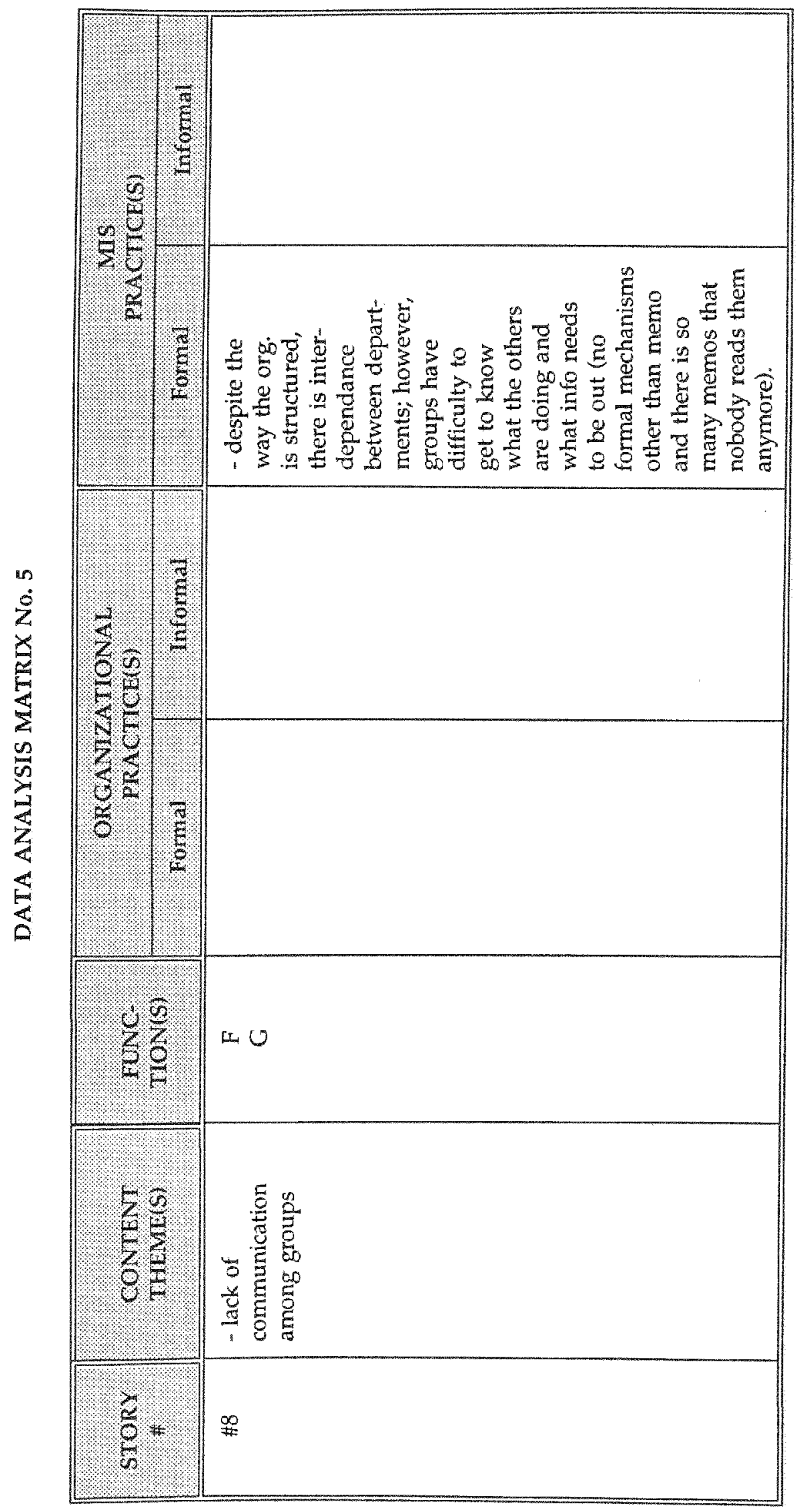

居 


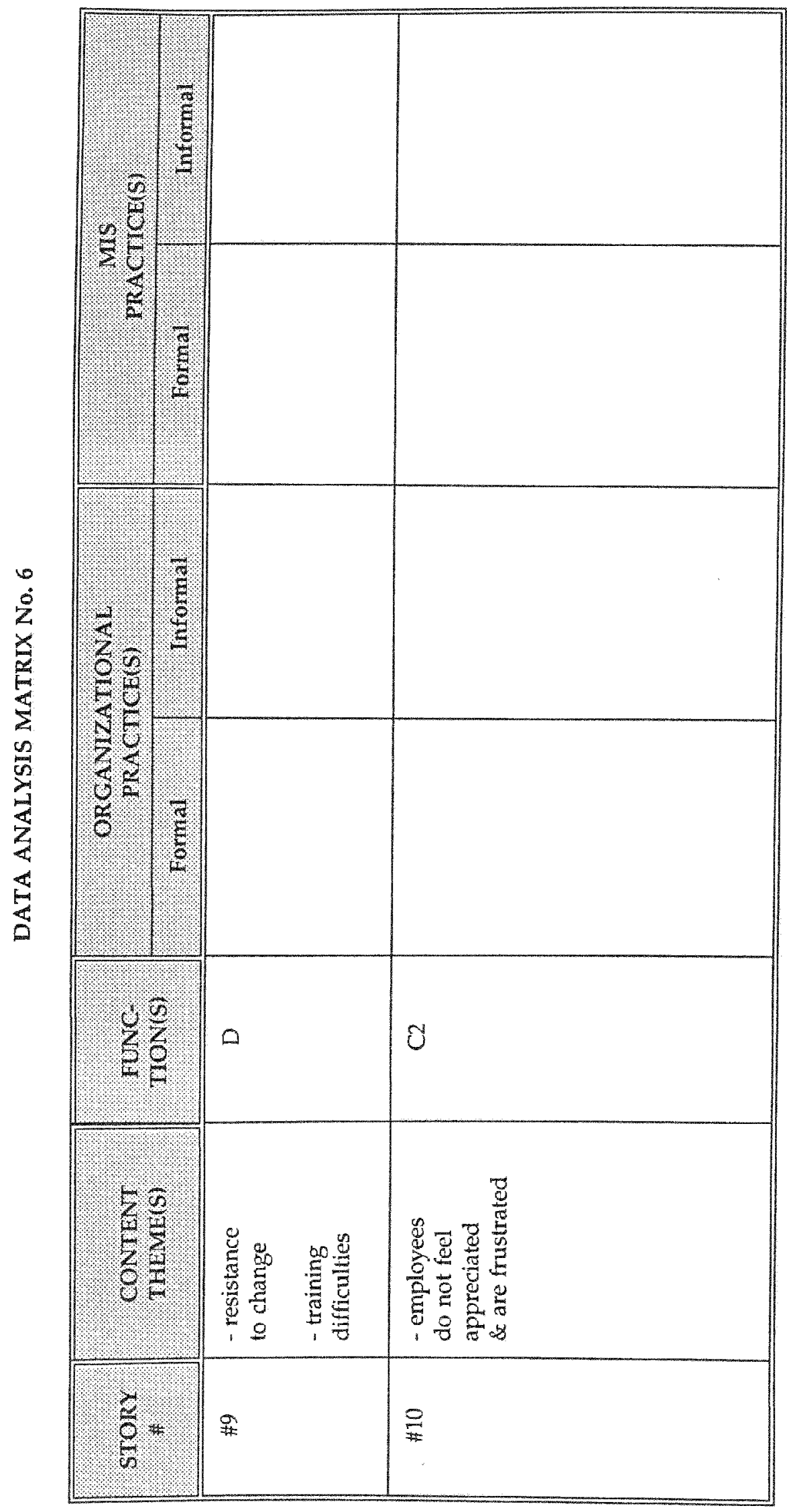

$\overrightarrow{\mathrm{s}}$ 


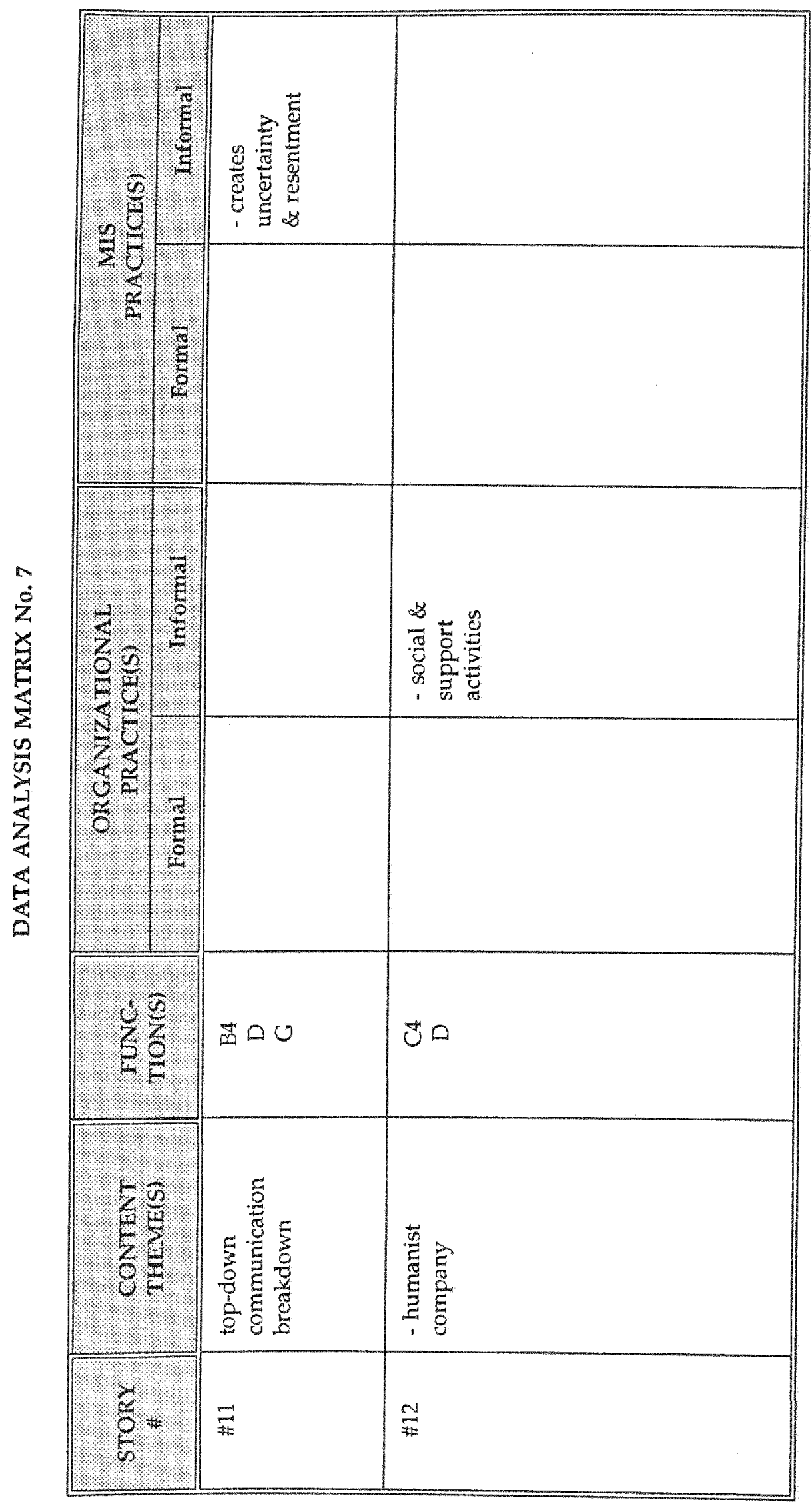

$\underset{\sim}{\infty}$ 


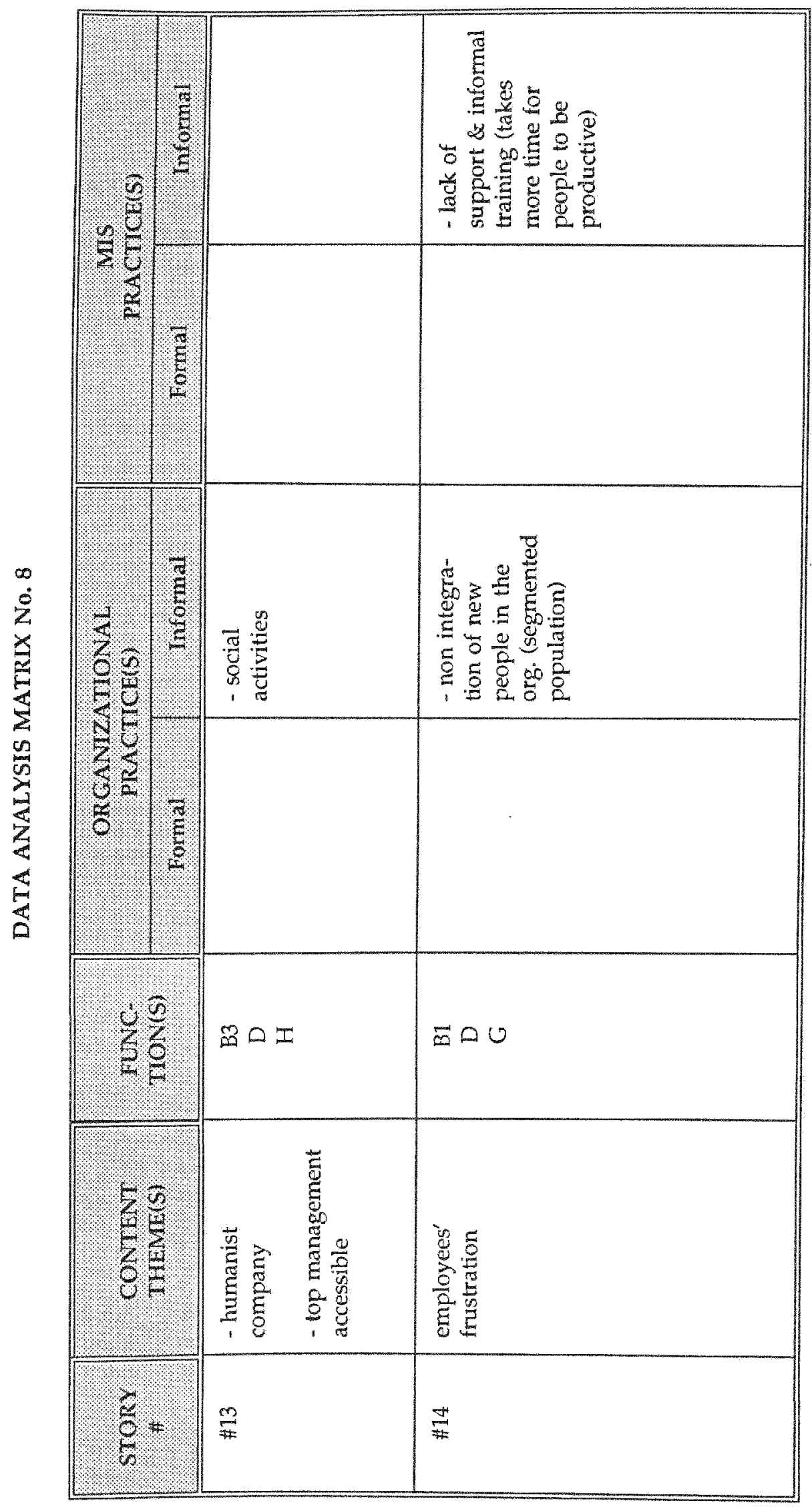




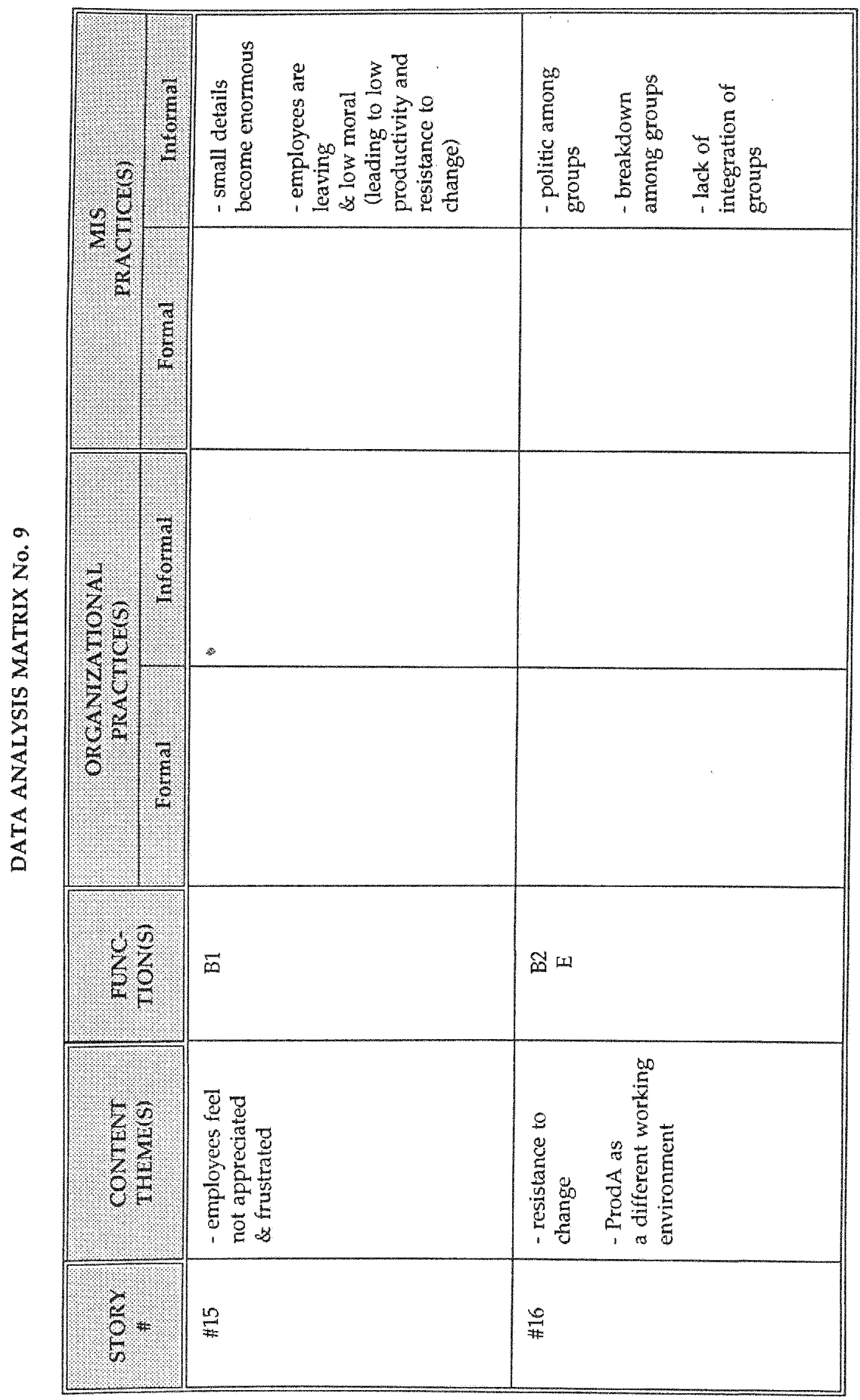

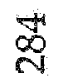




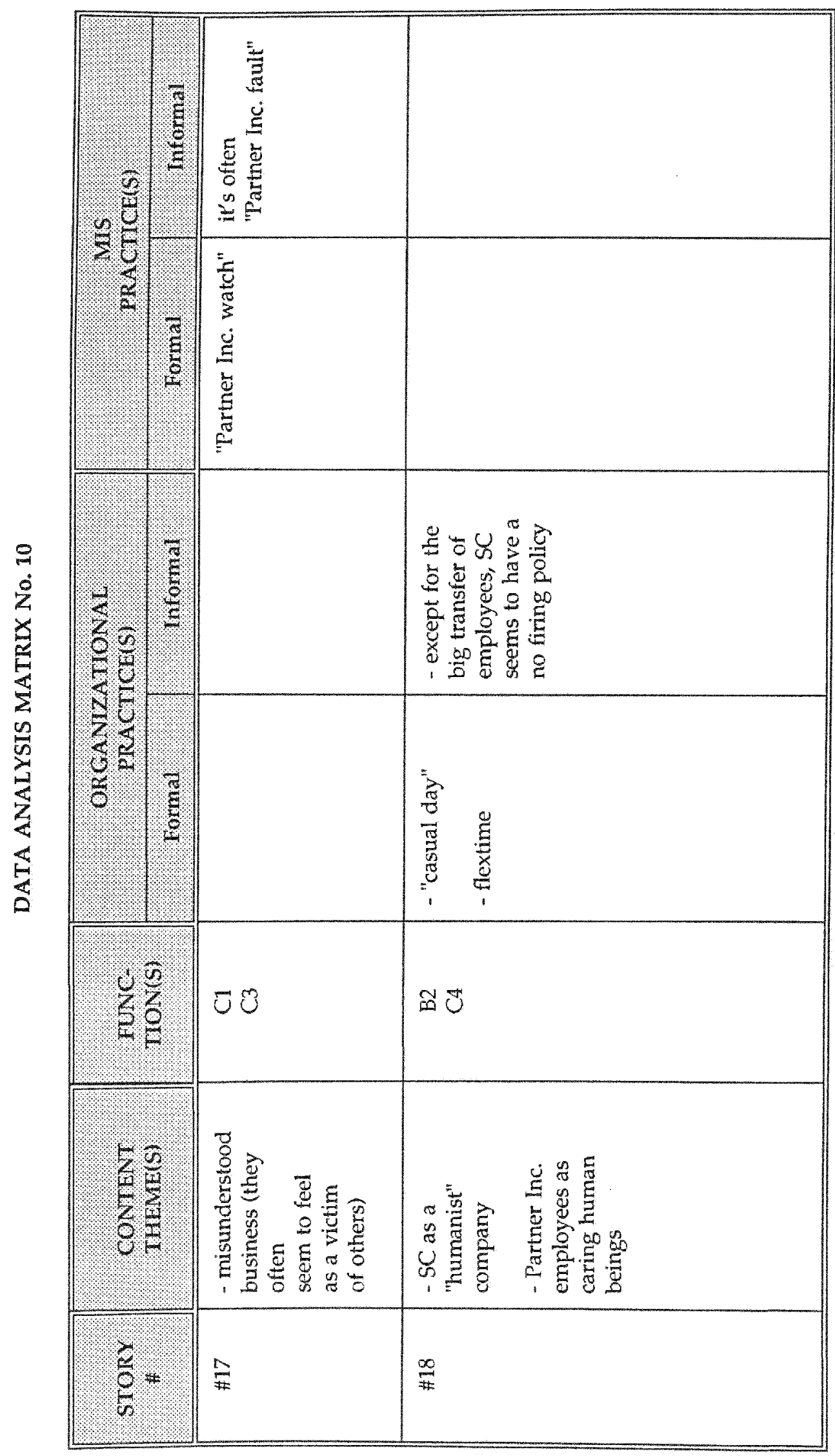

喿 


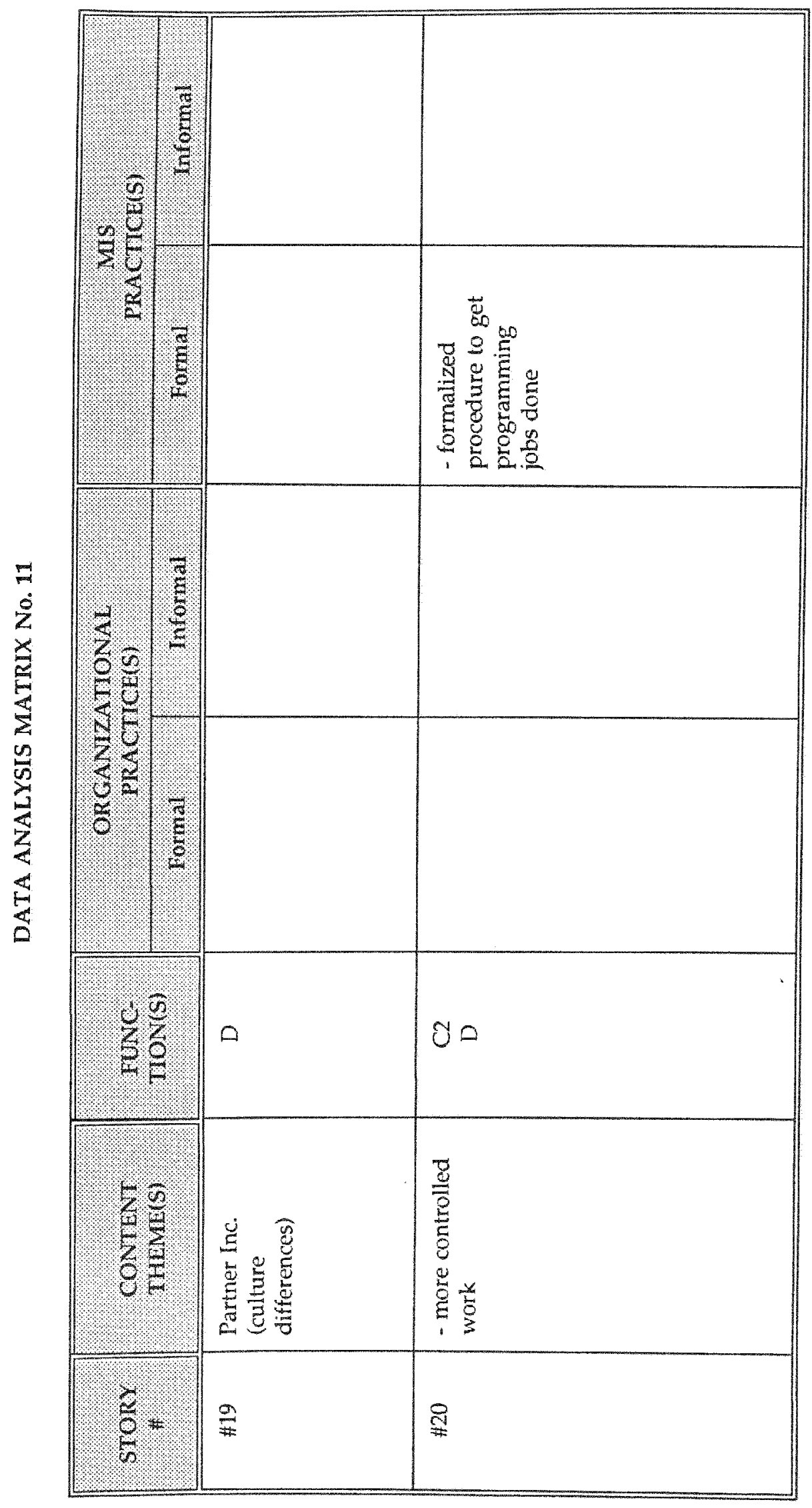

芯 


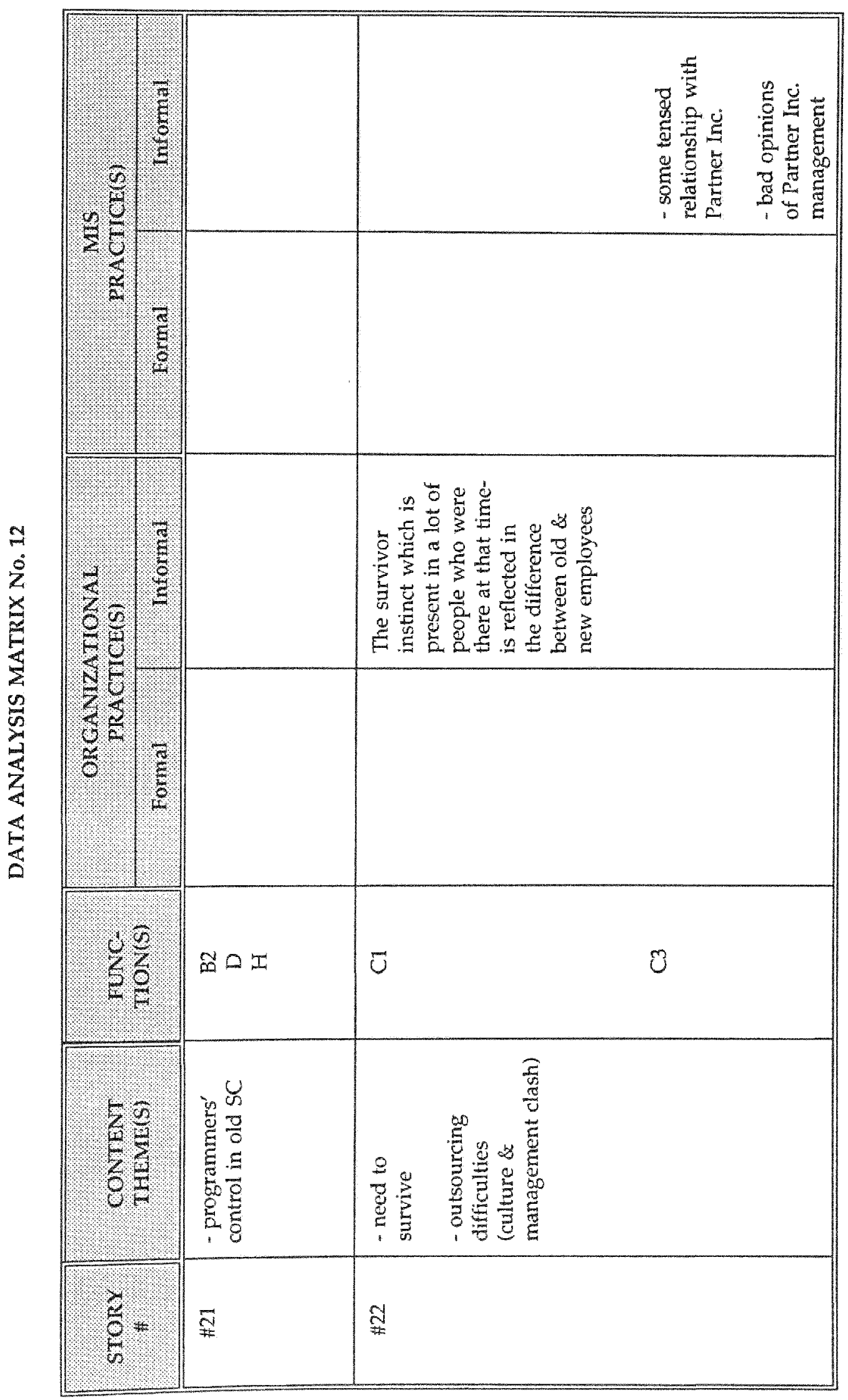

造 


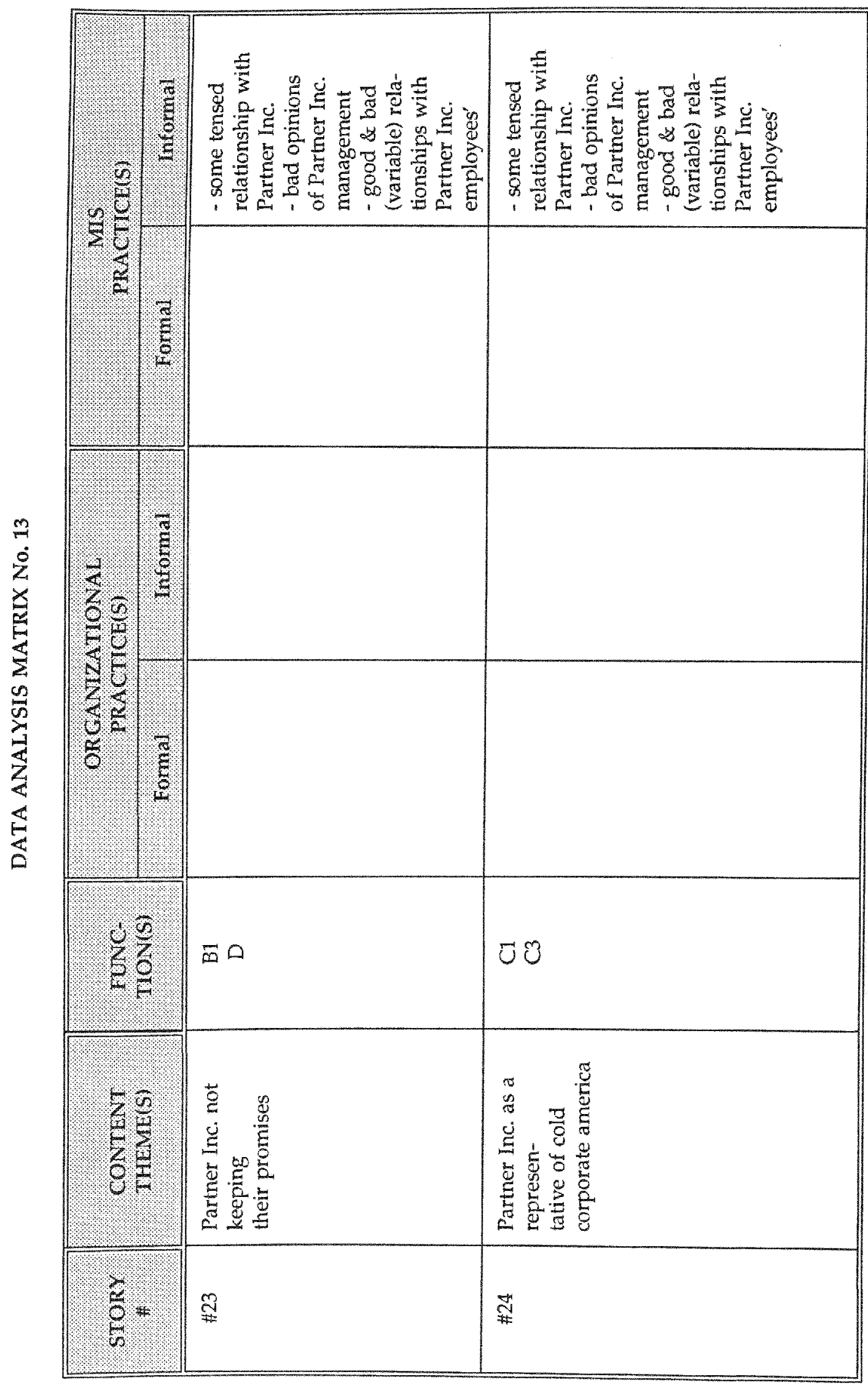

$\stackrel{\infty}{\sim}$ 


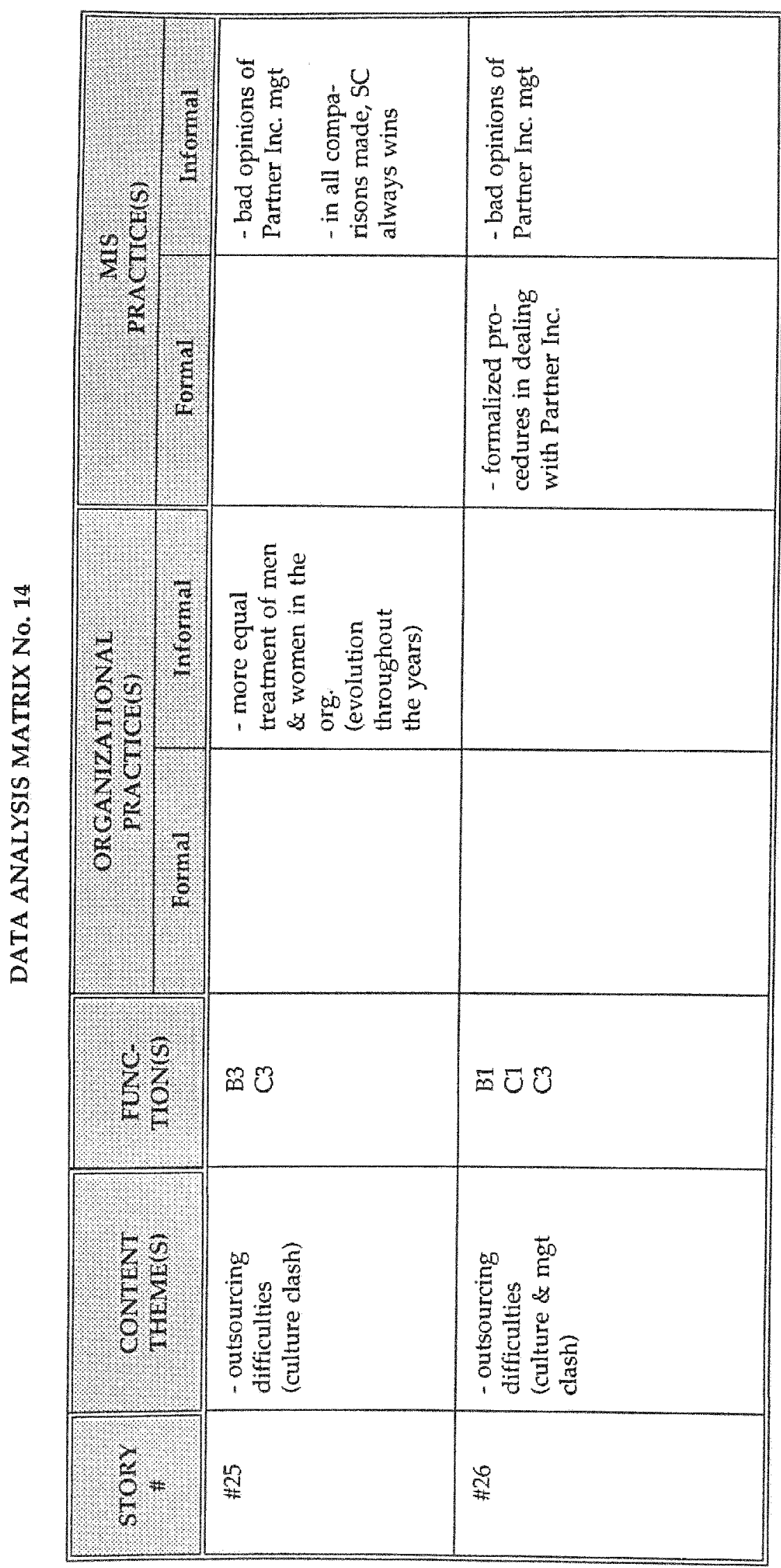

杽 


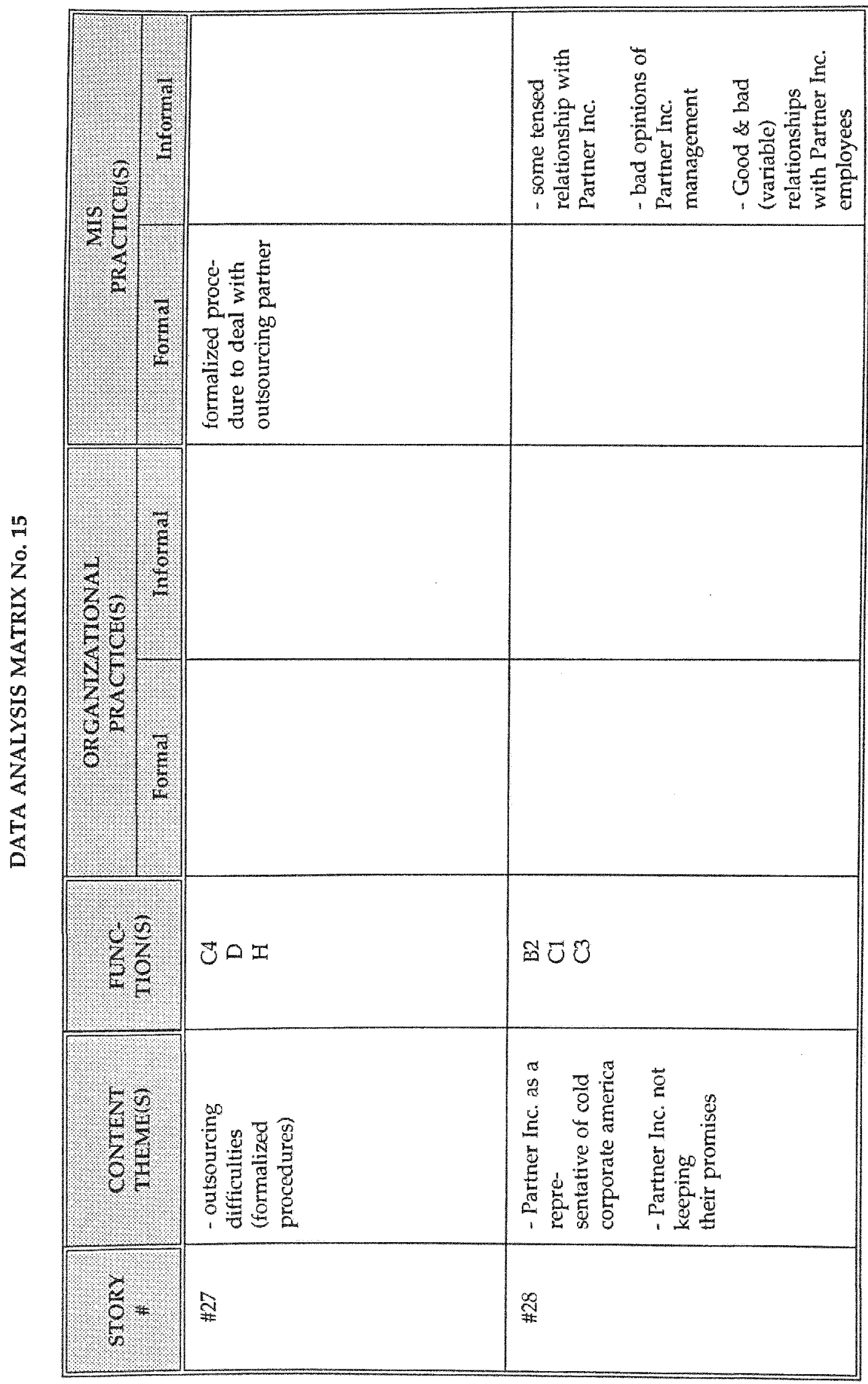

옹 


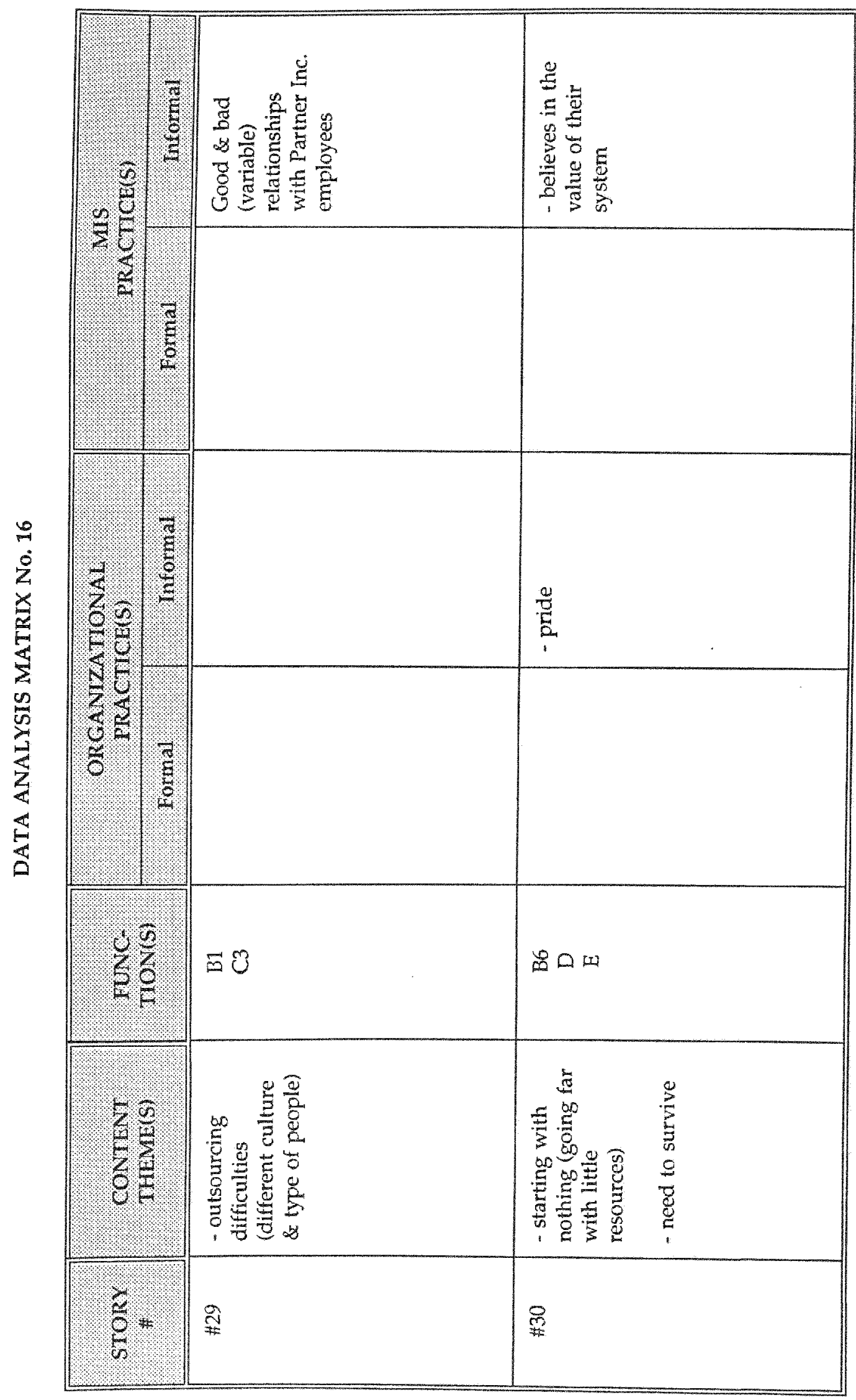

ลี 


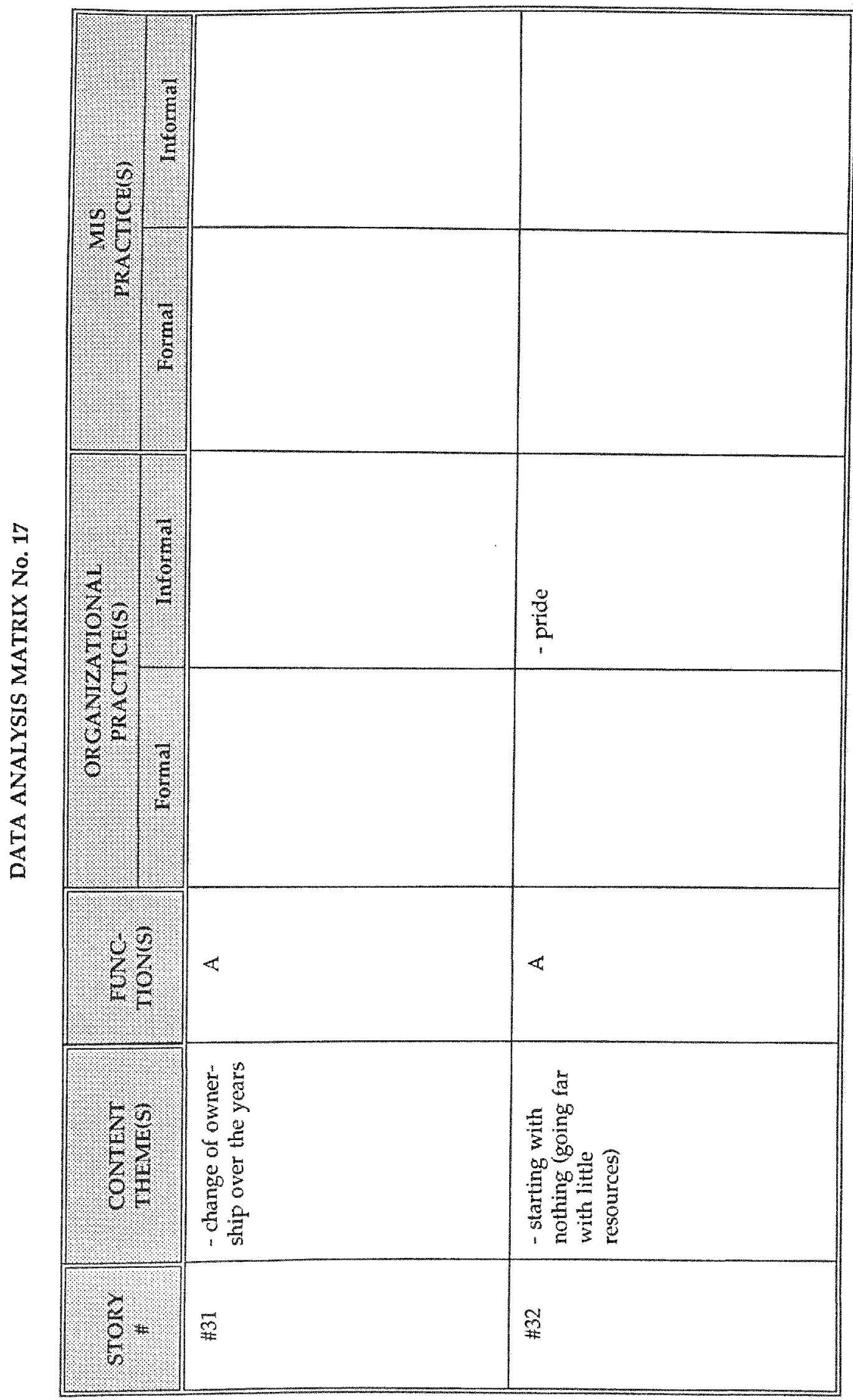

ब 


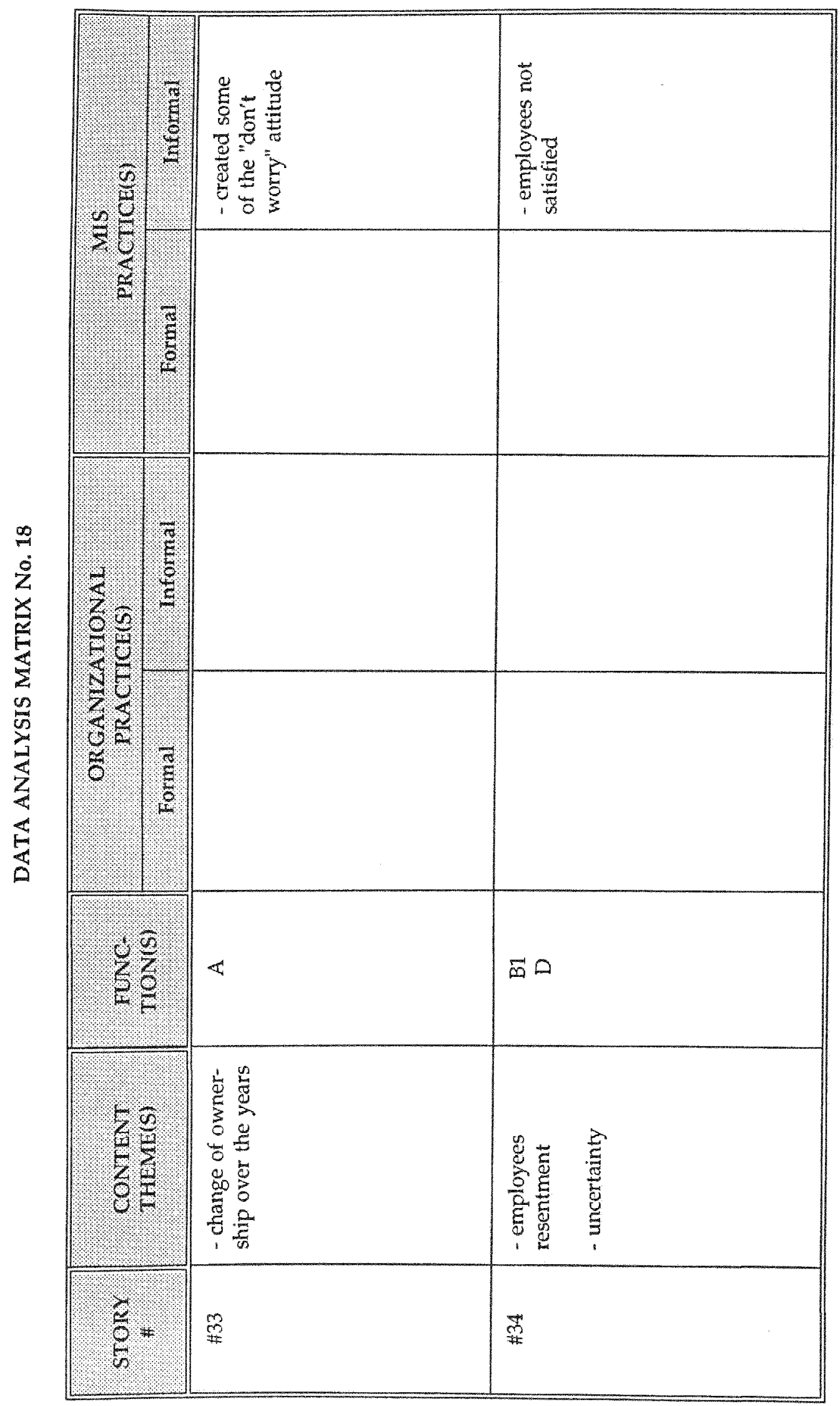

ฐึ 


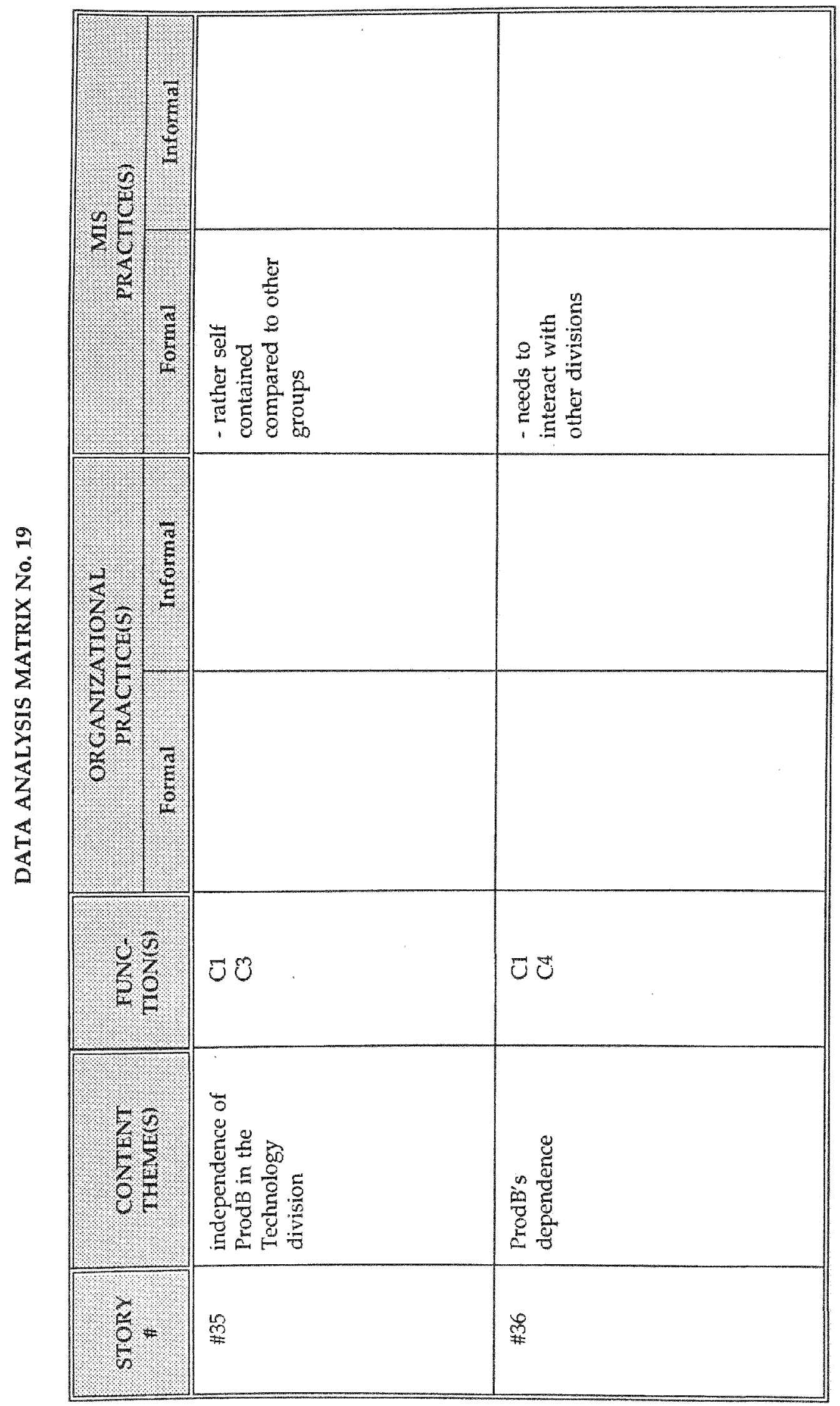

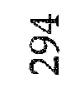




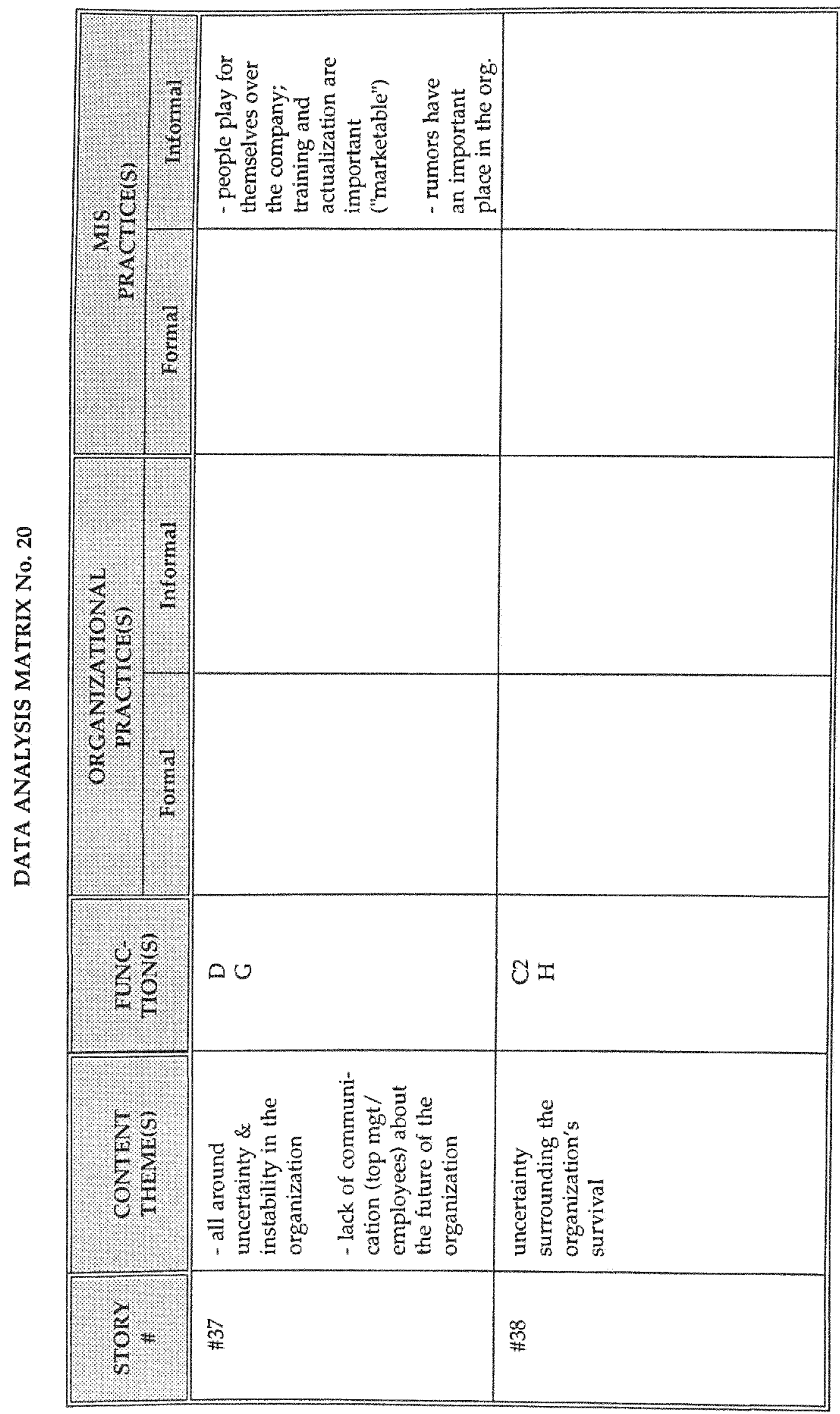

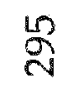




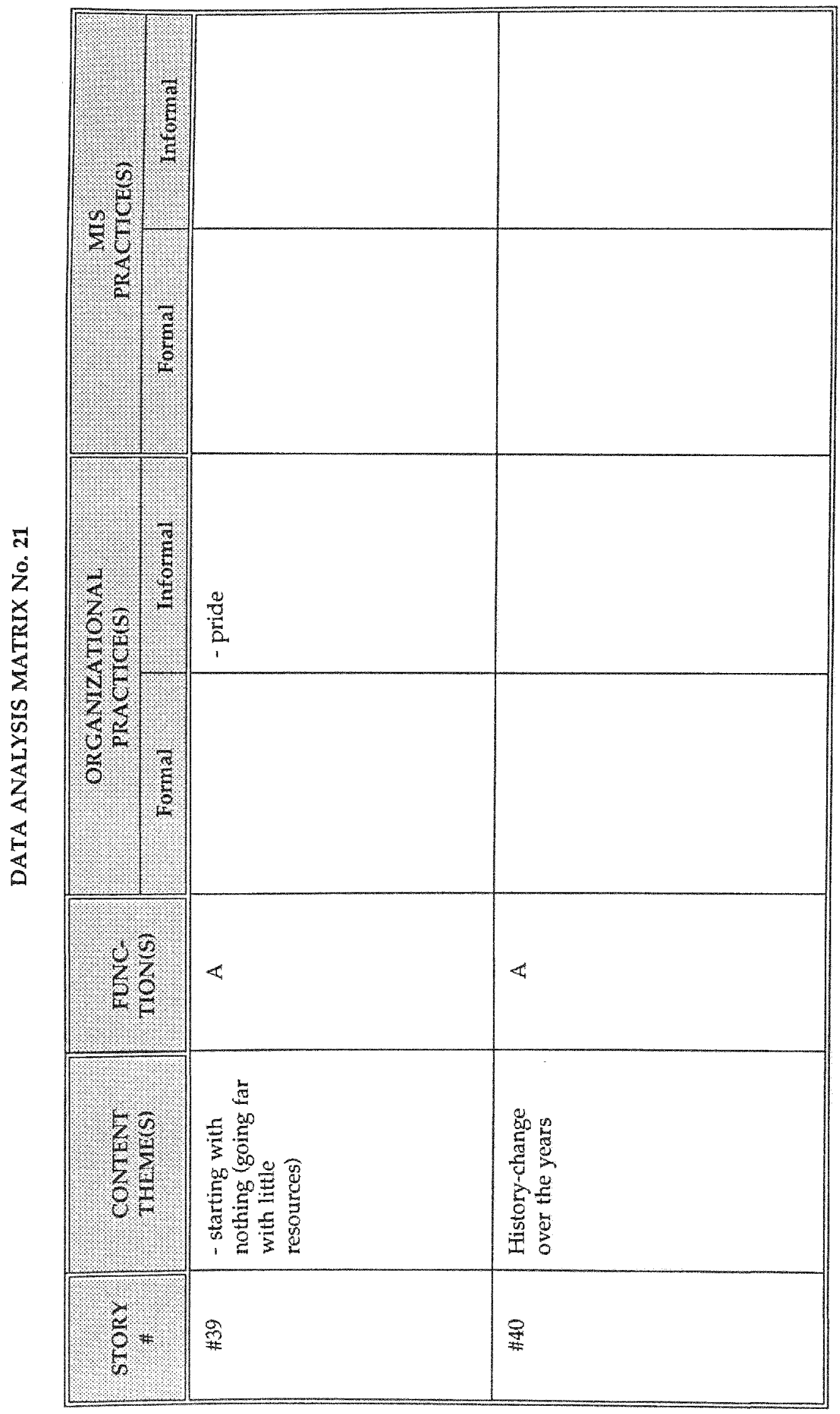

สั 


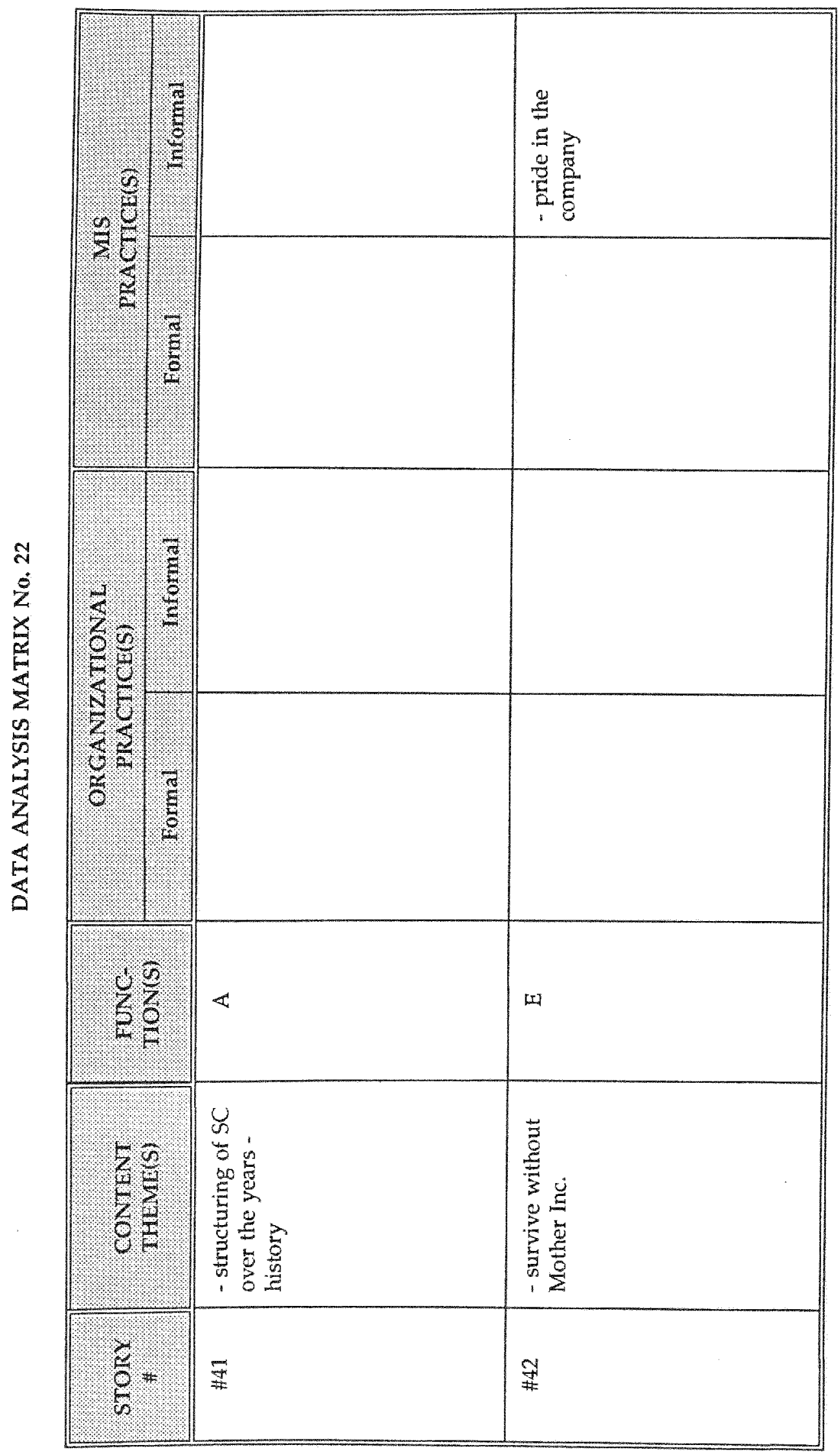

옥 


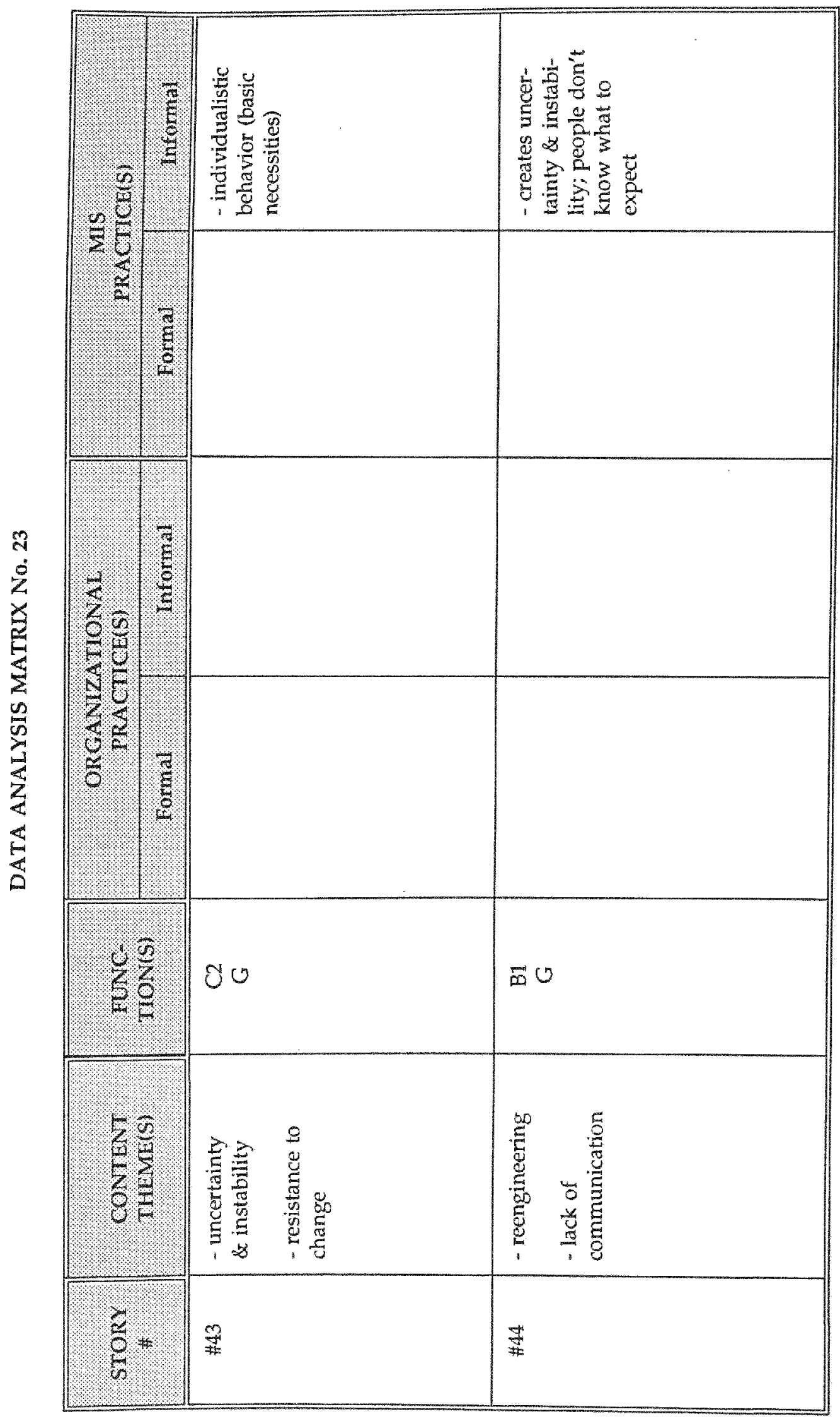

ㅇํำ 


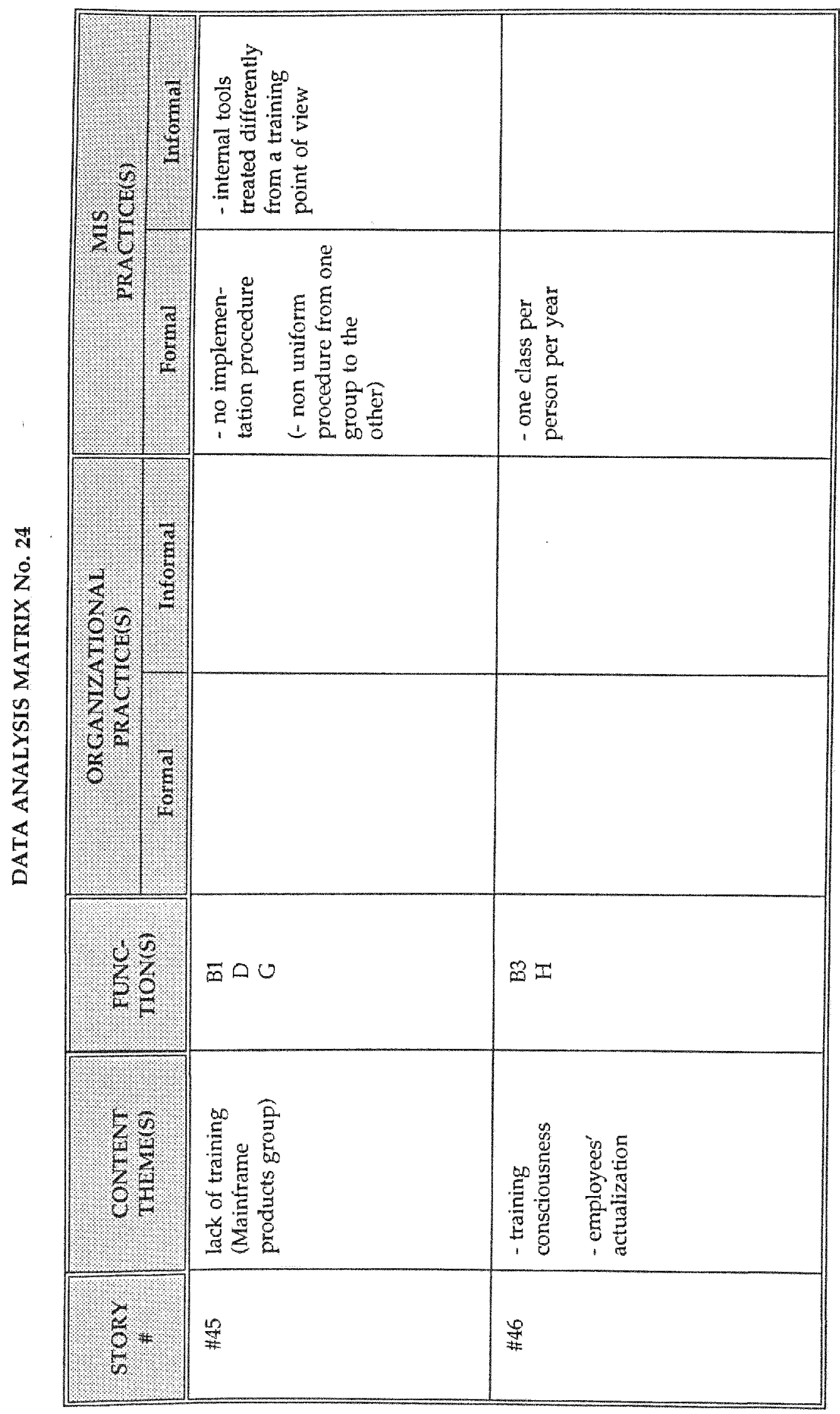

a 


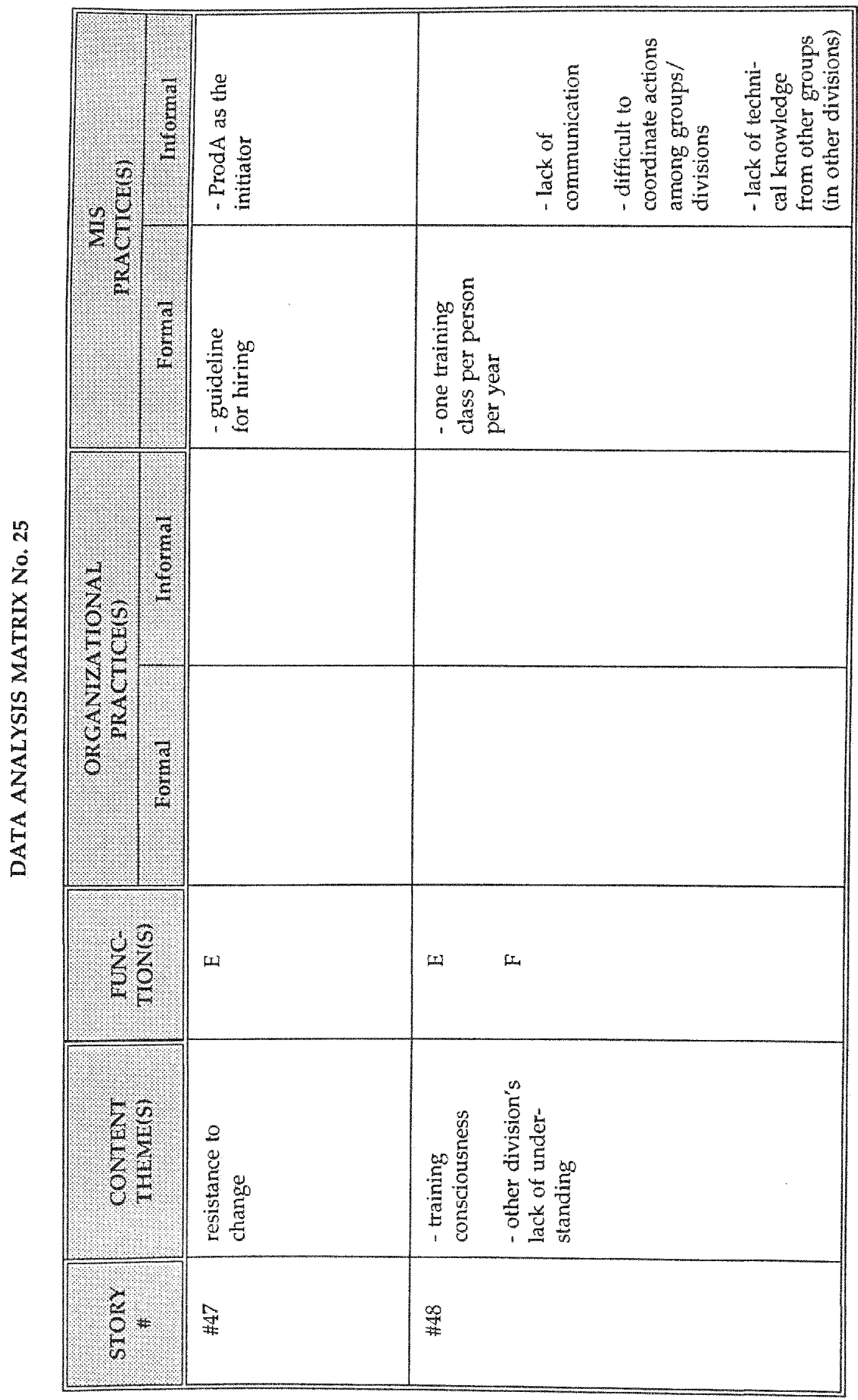

욤 


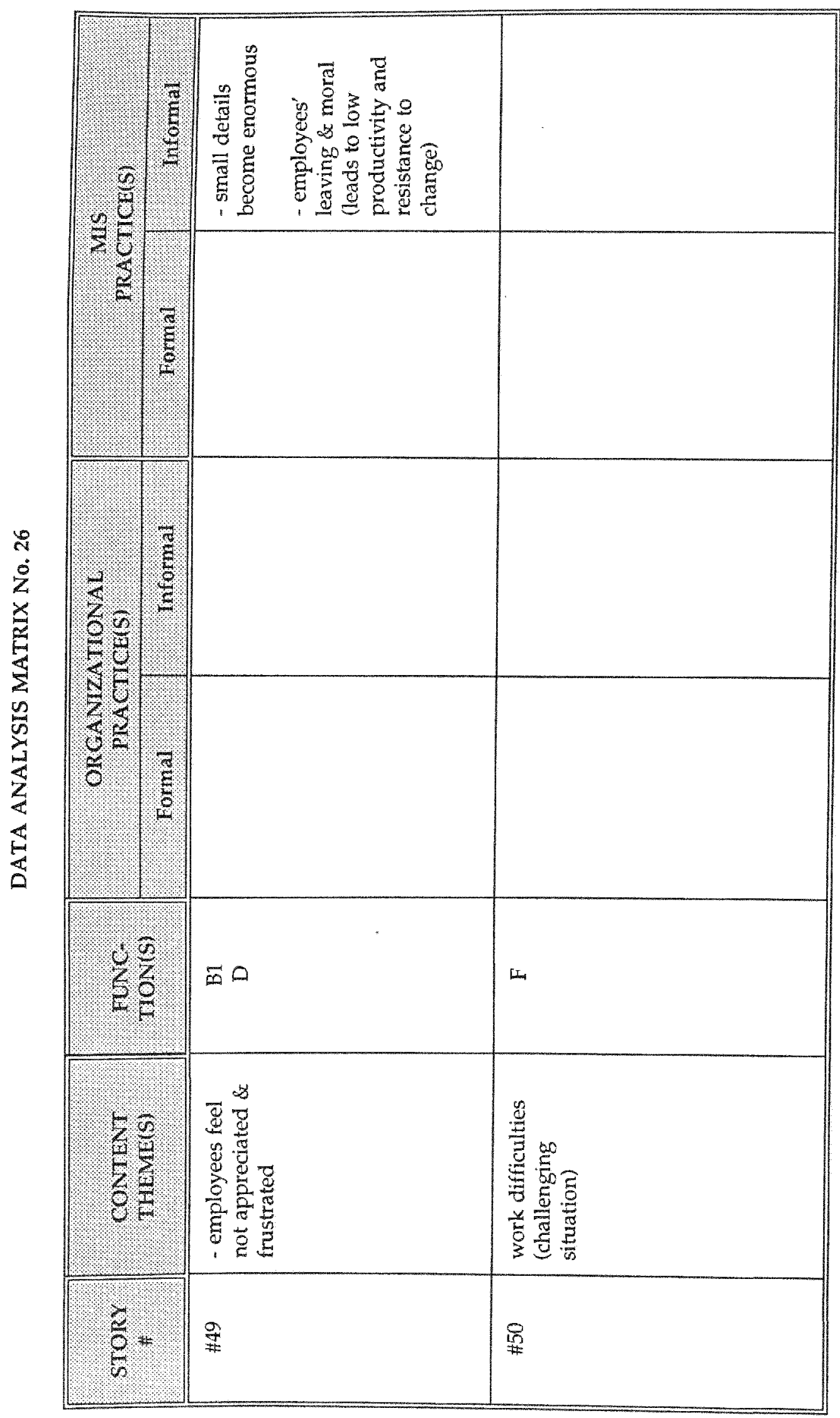

함 


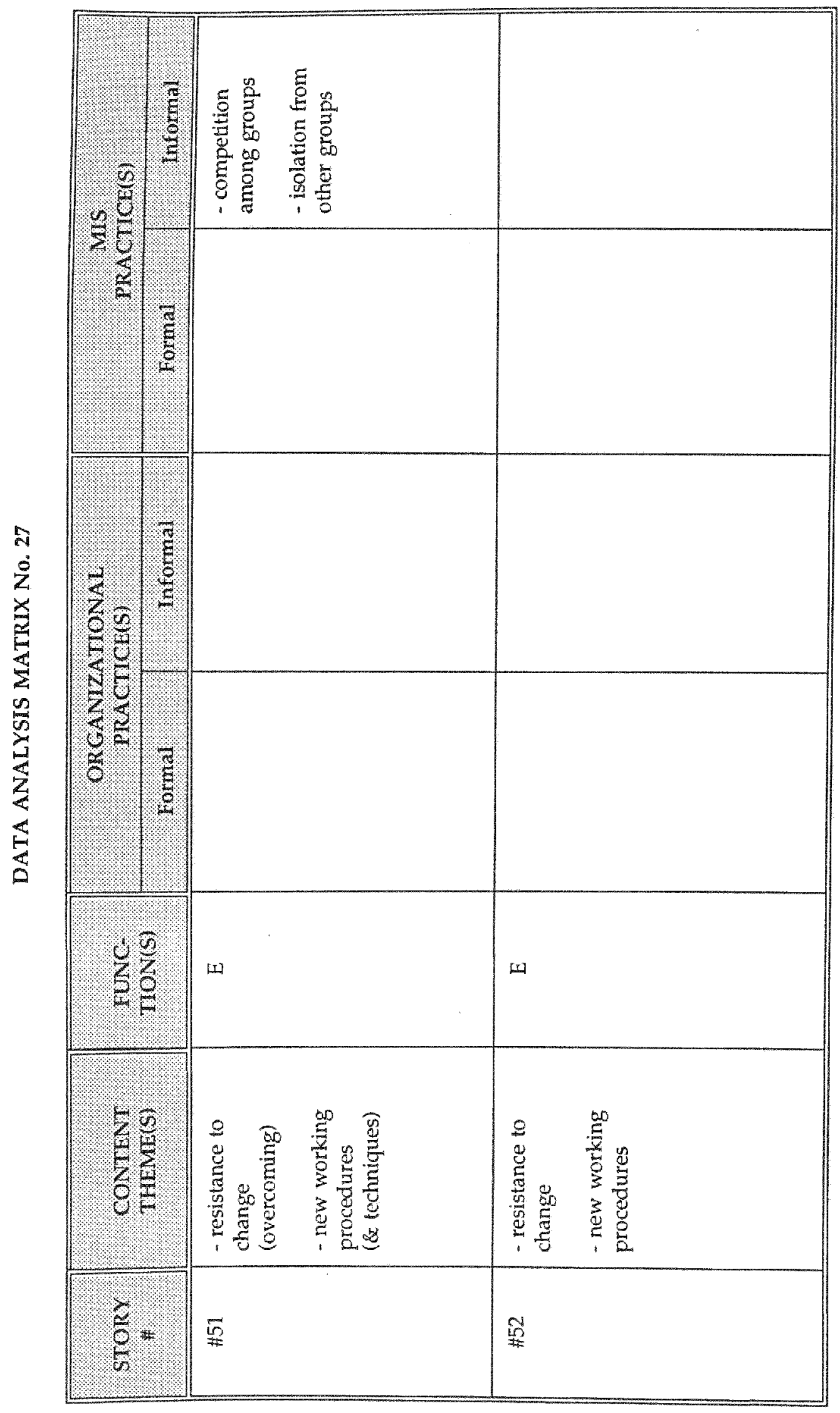

్ㅏㅁ 


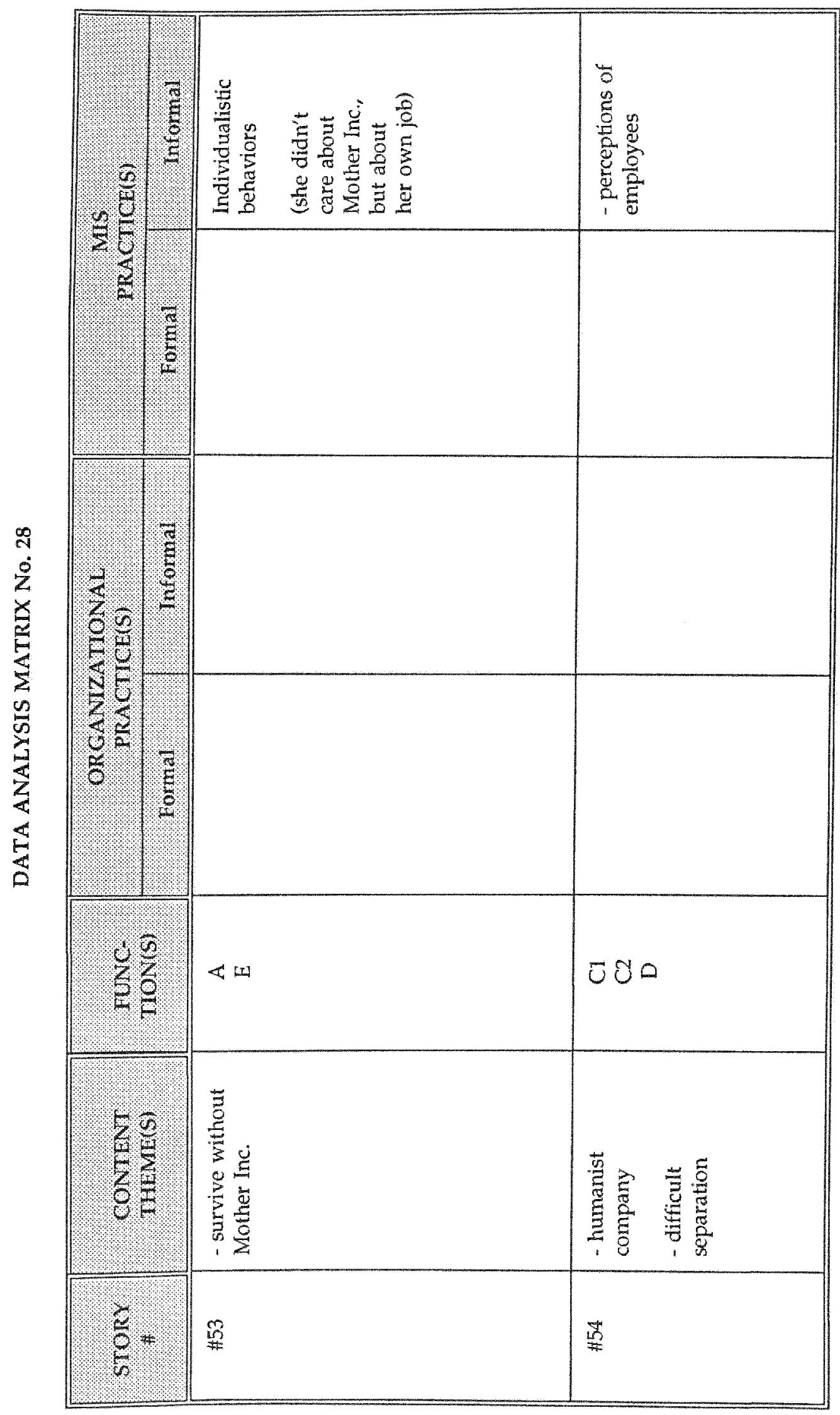

品 


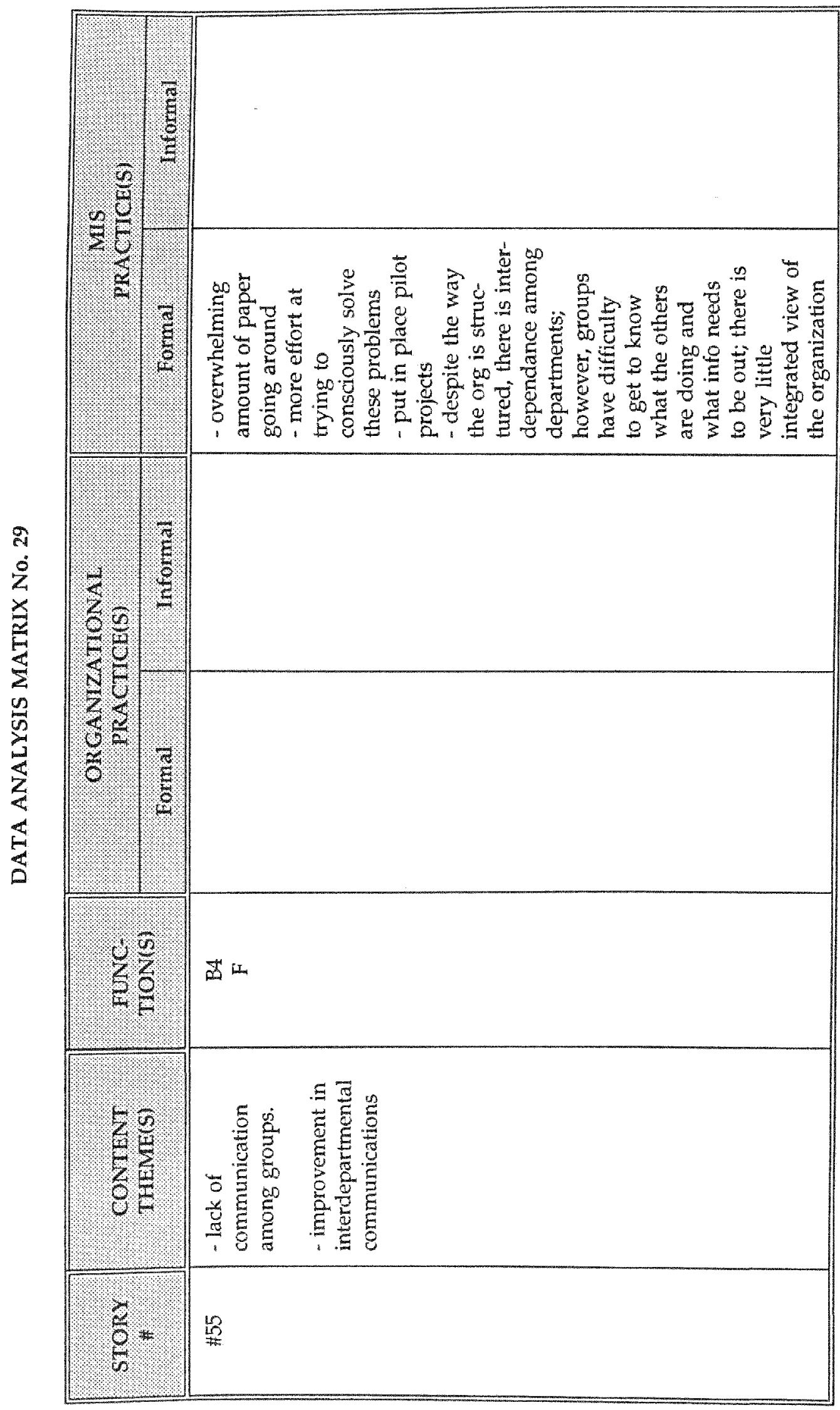

莒 


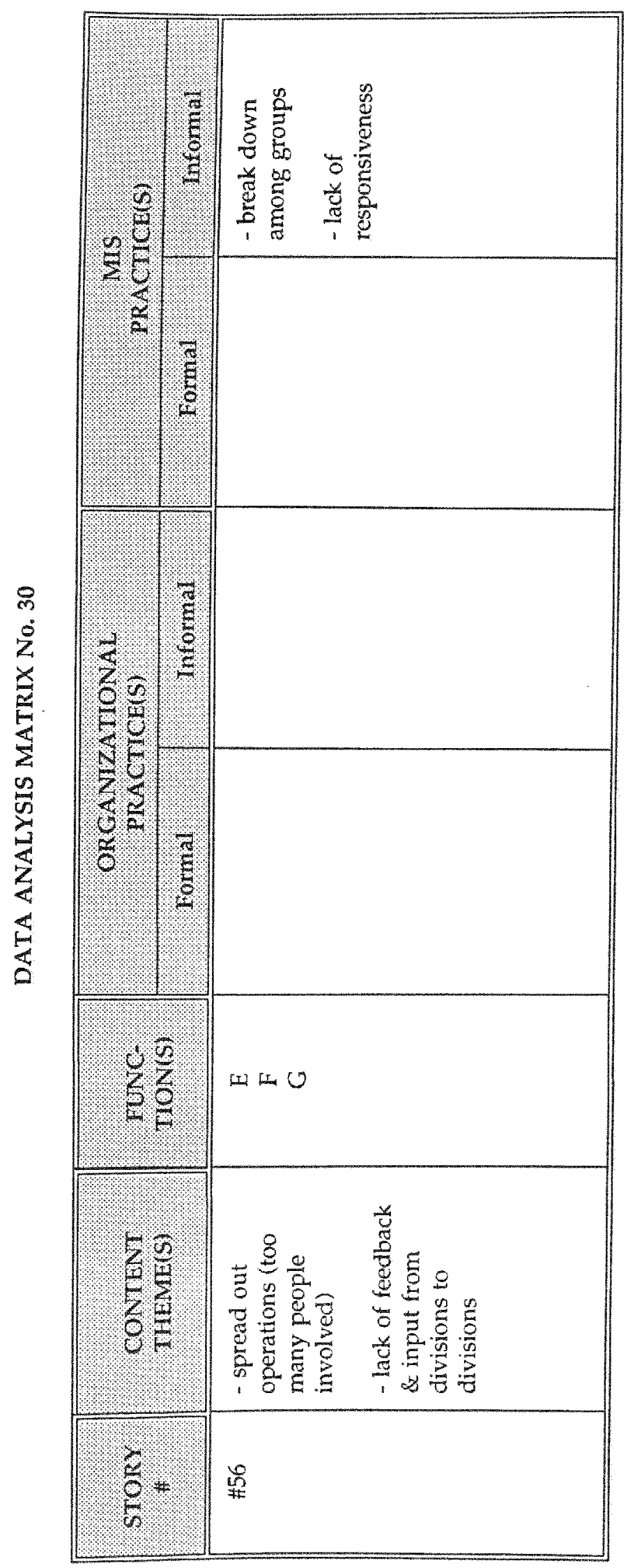

总 


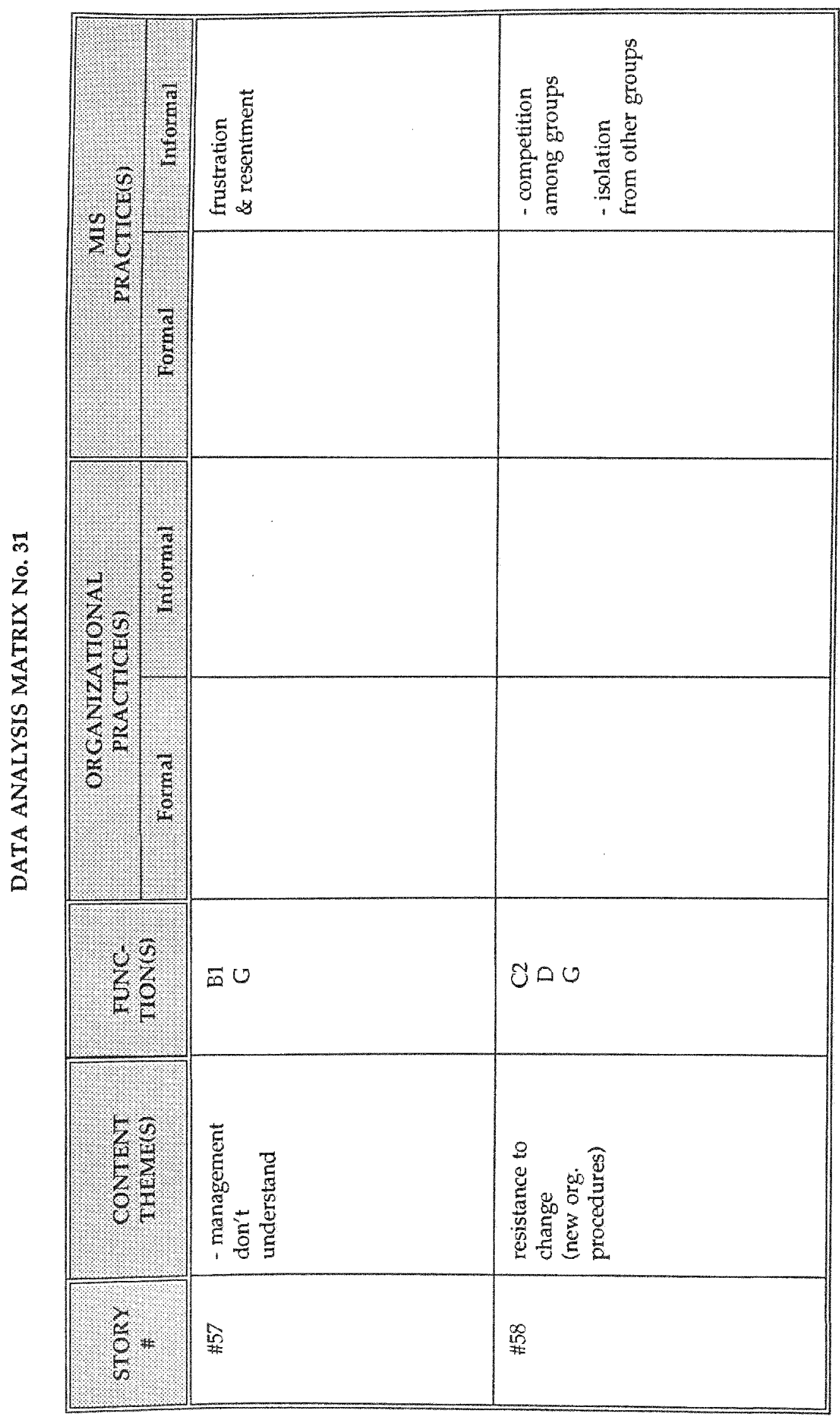

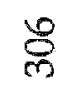




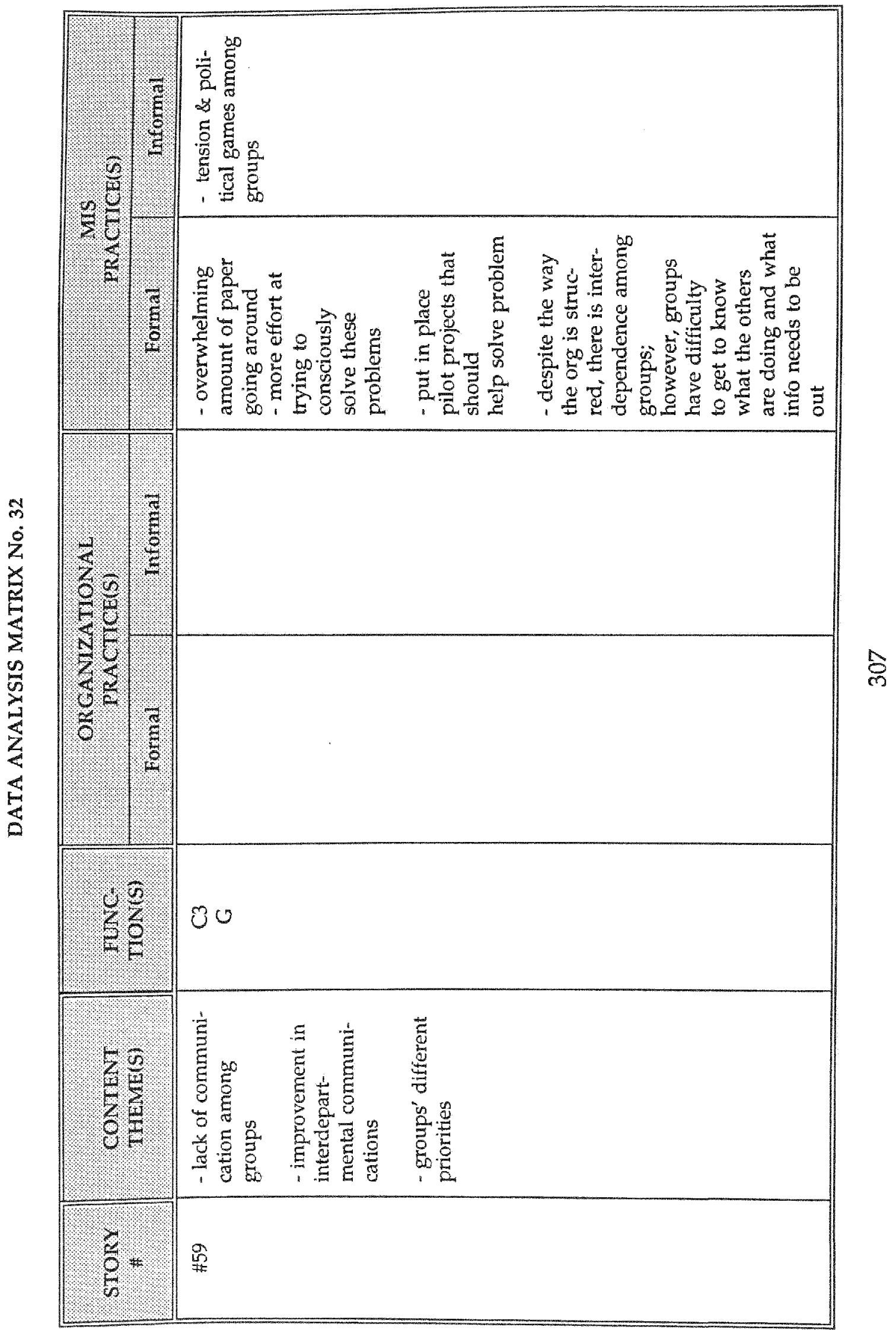




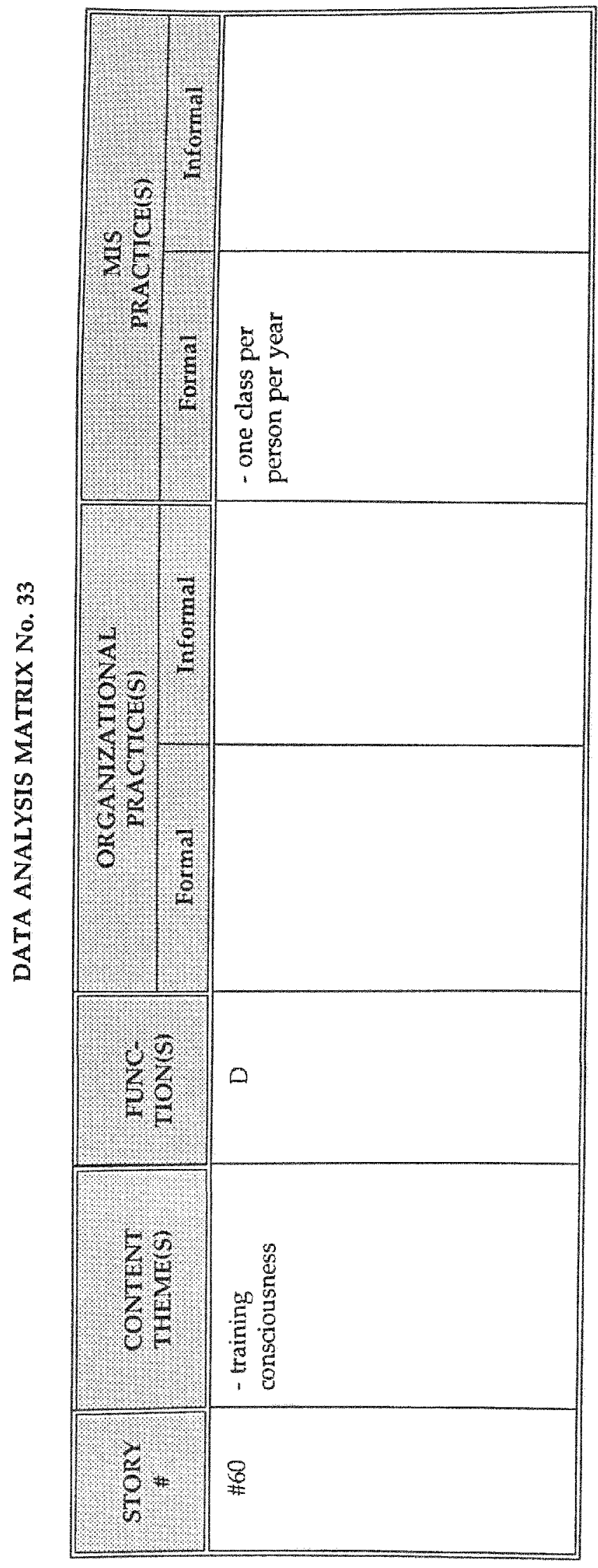

品 


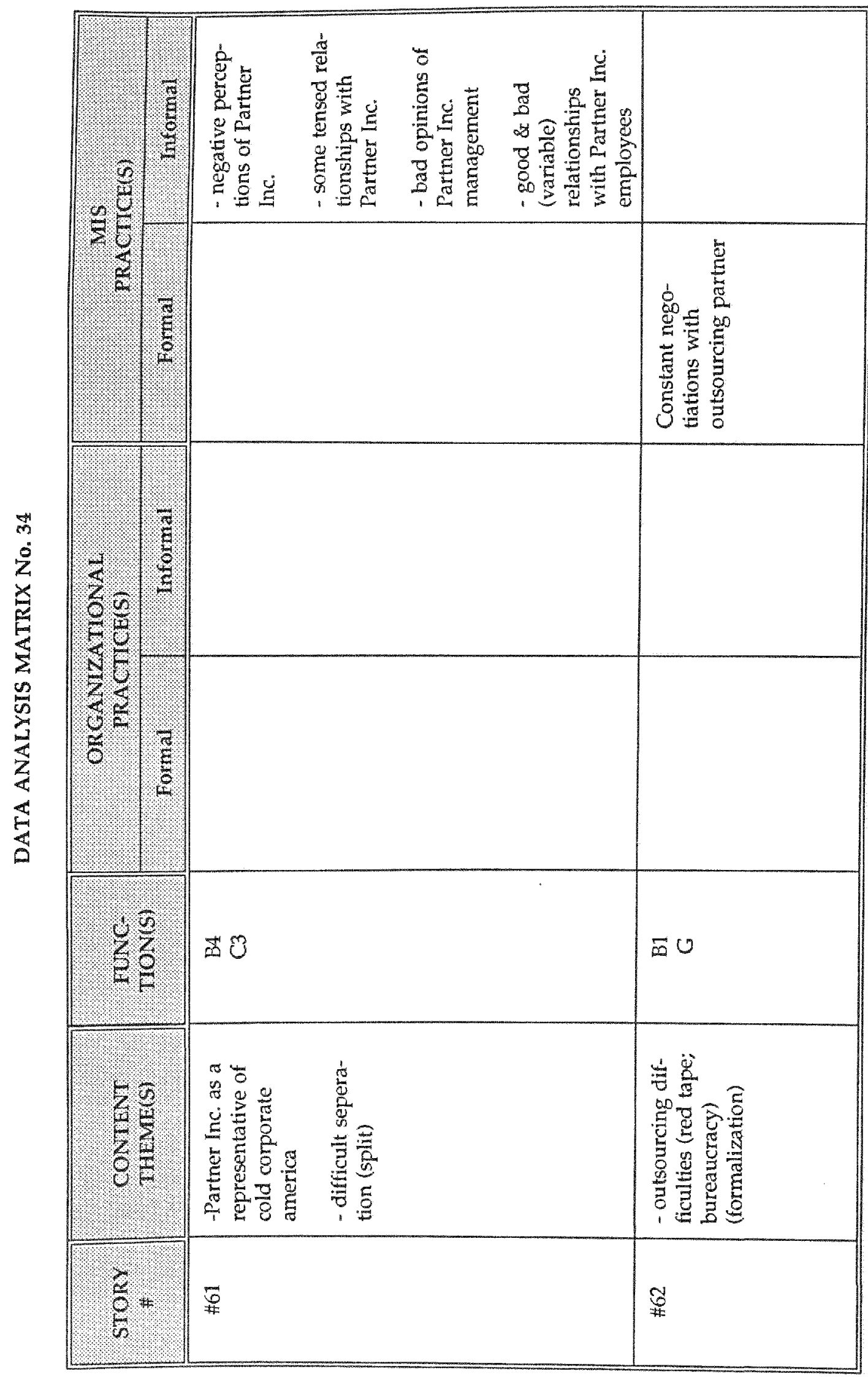

8 


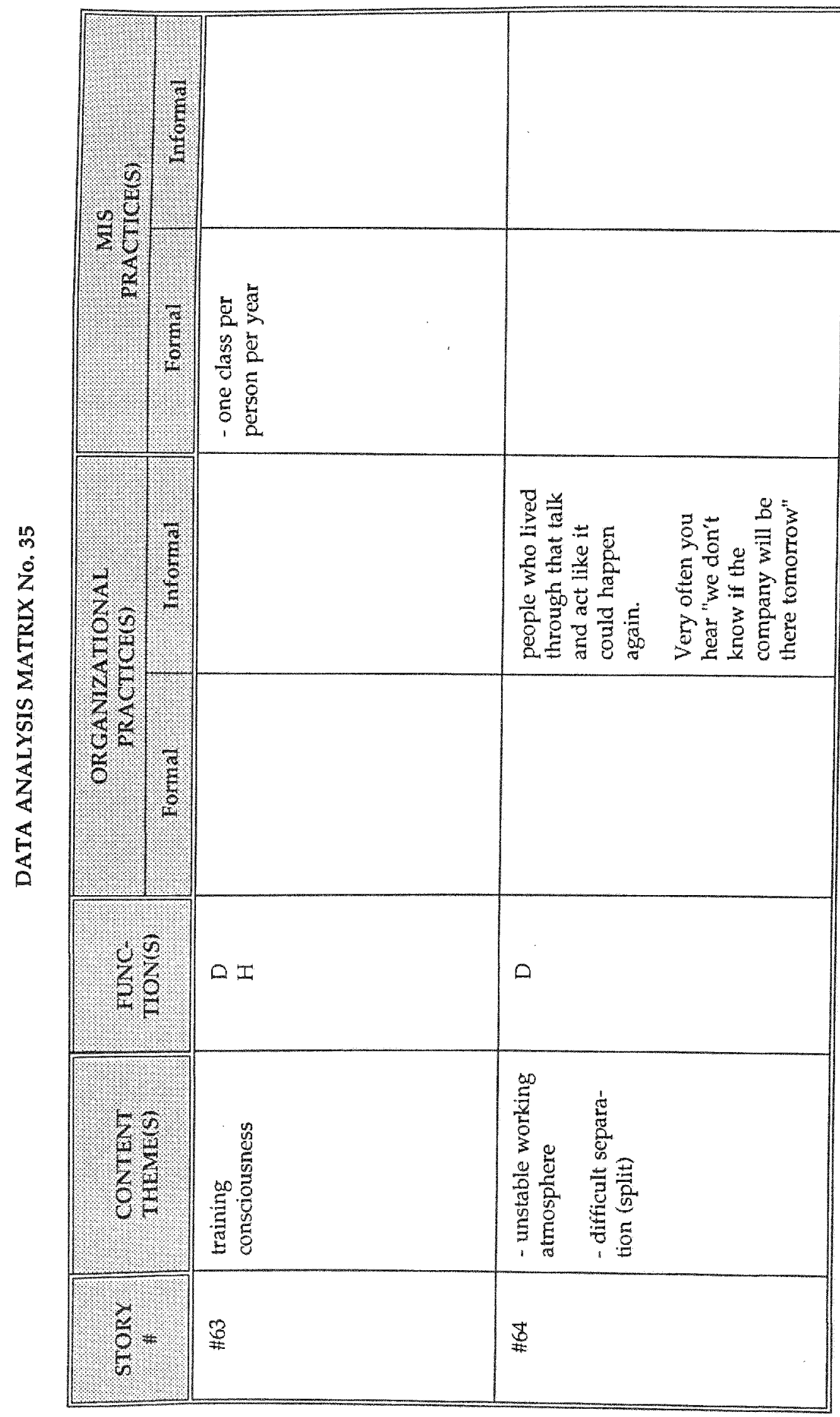

음 


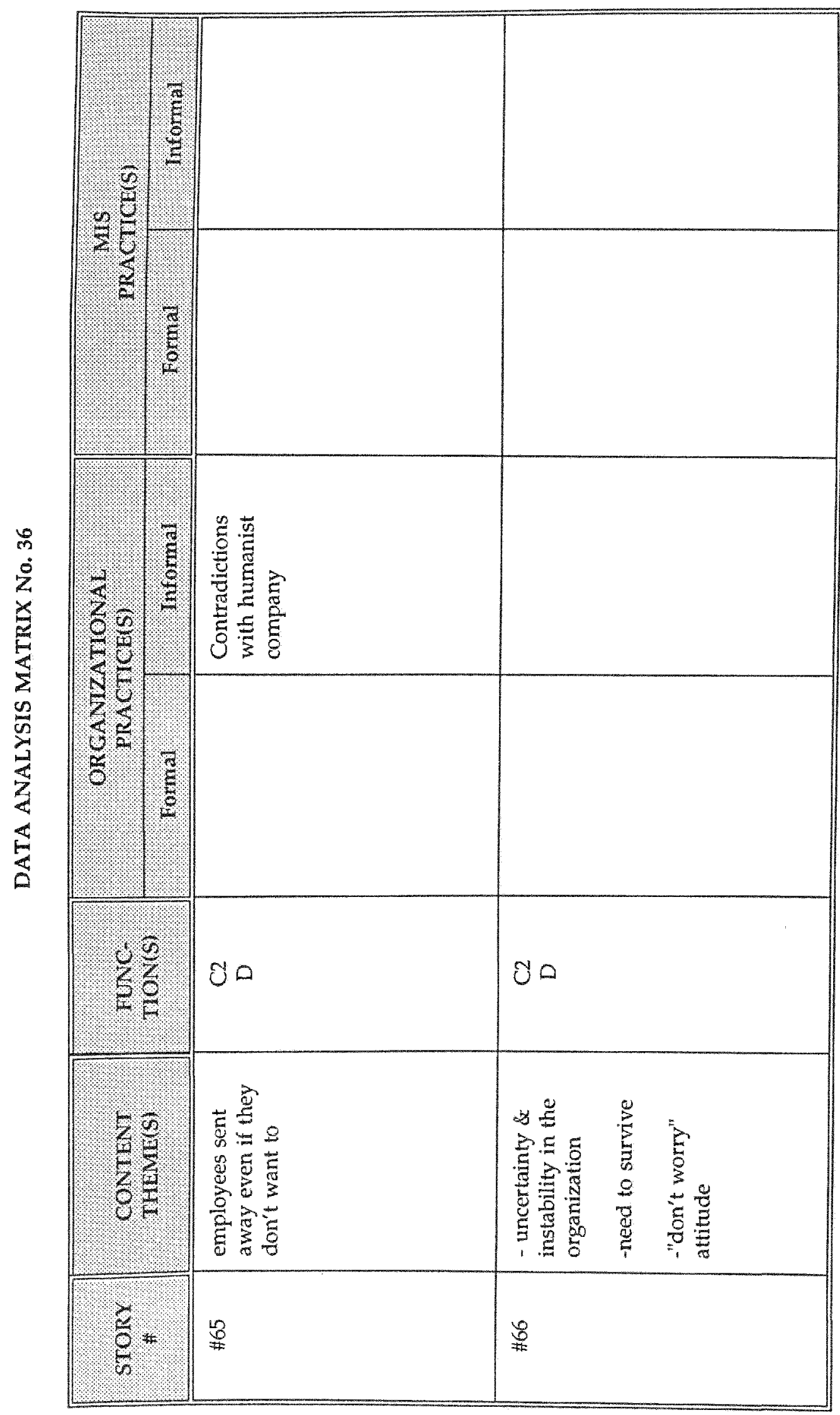

르 


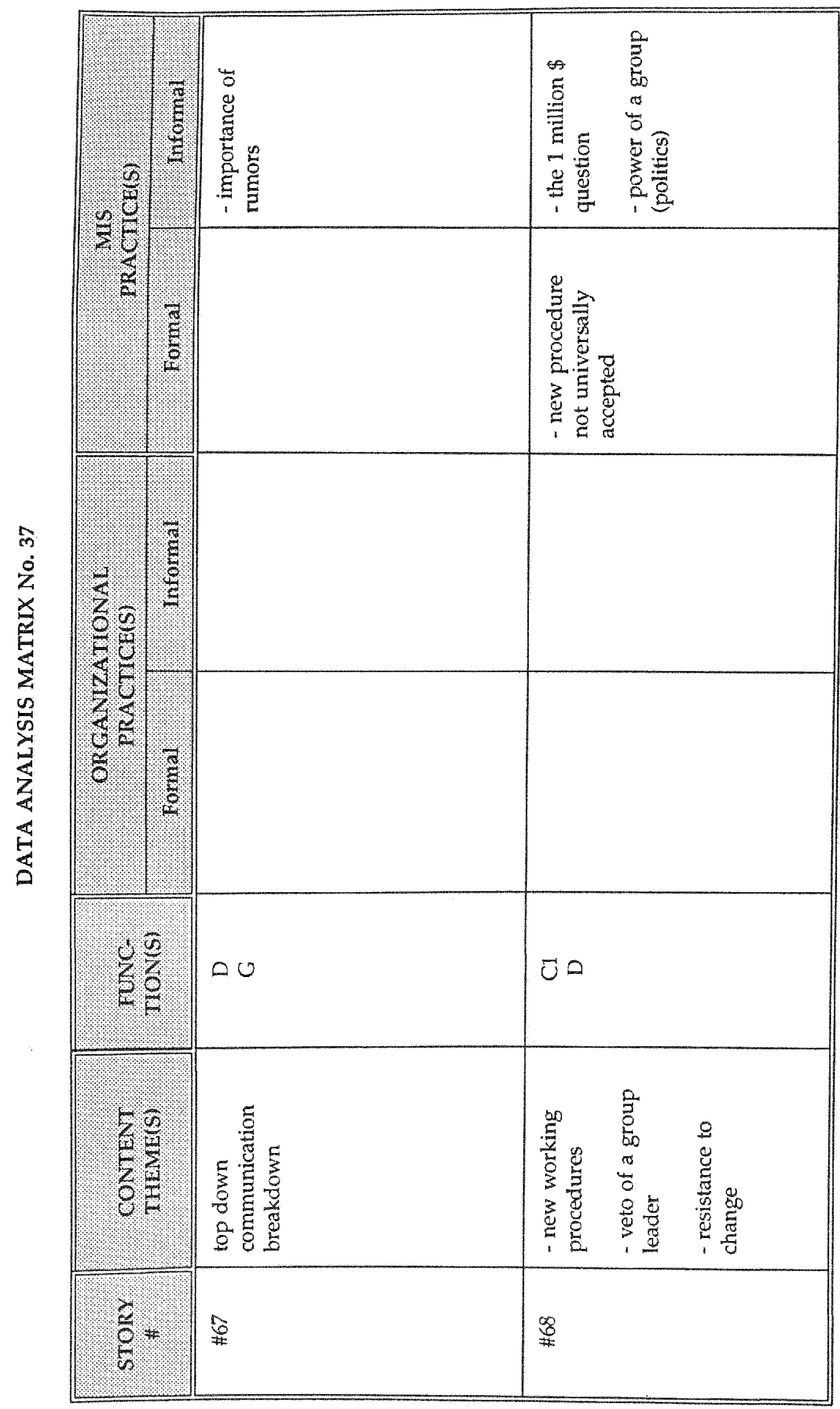

en 


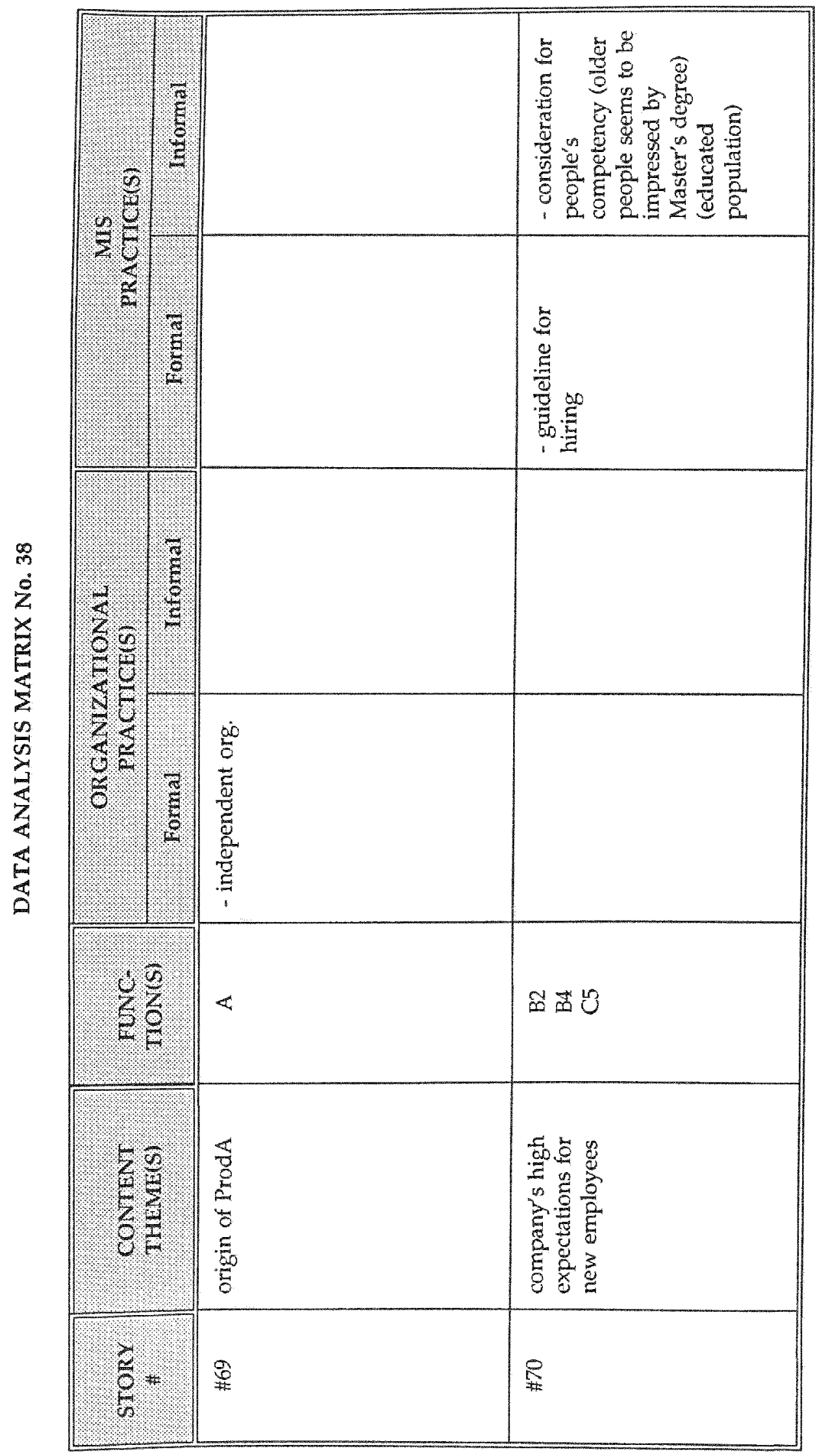

$m$ 


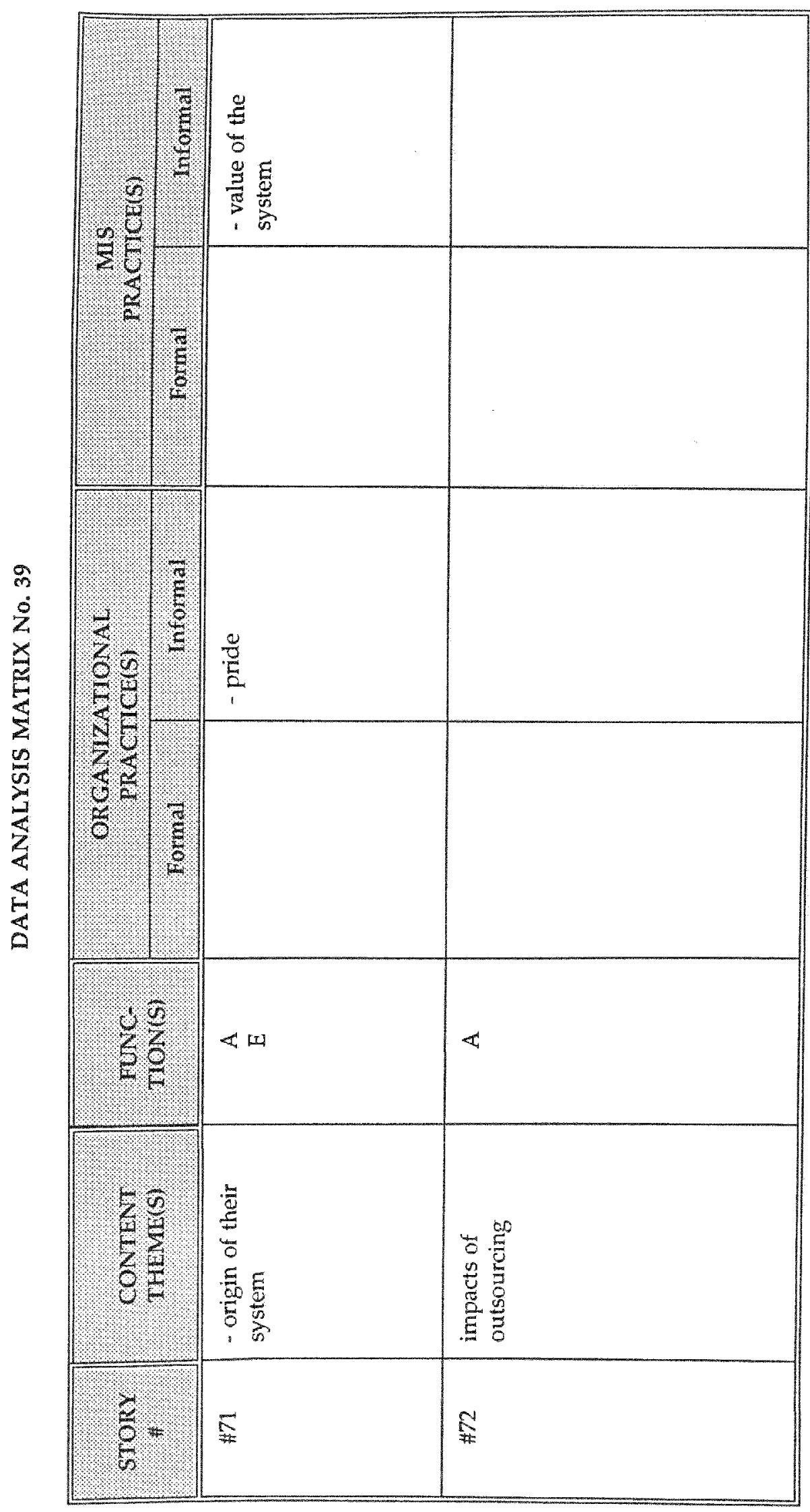

$\frac{1}{n}$ 


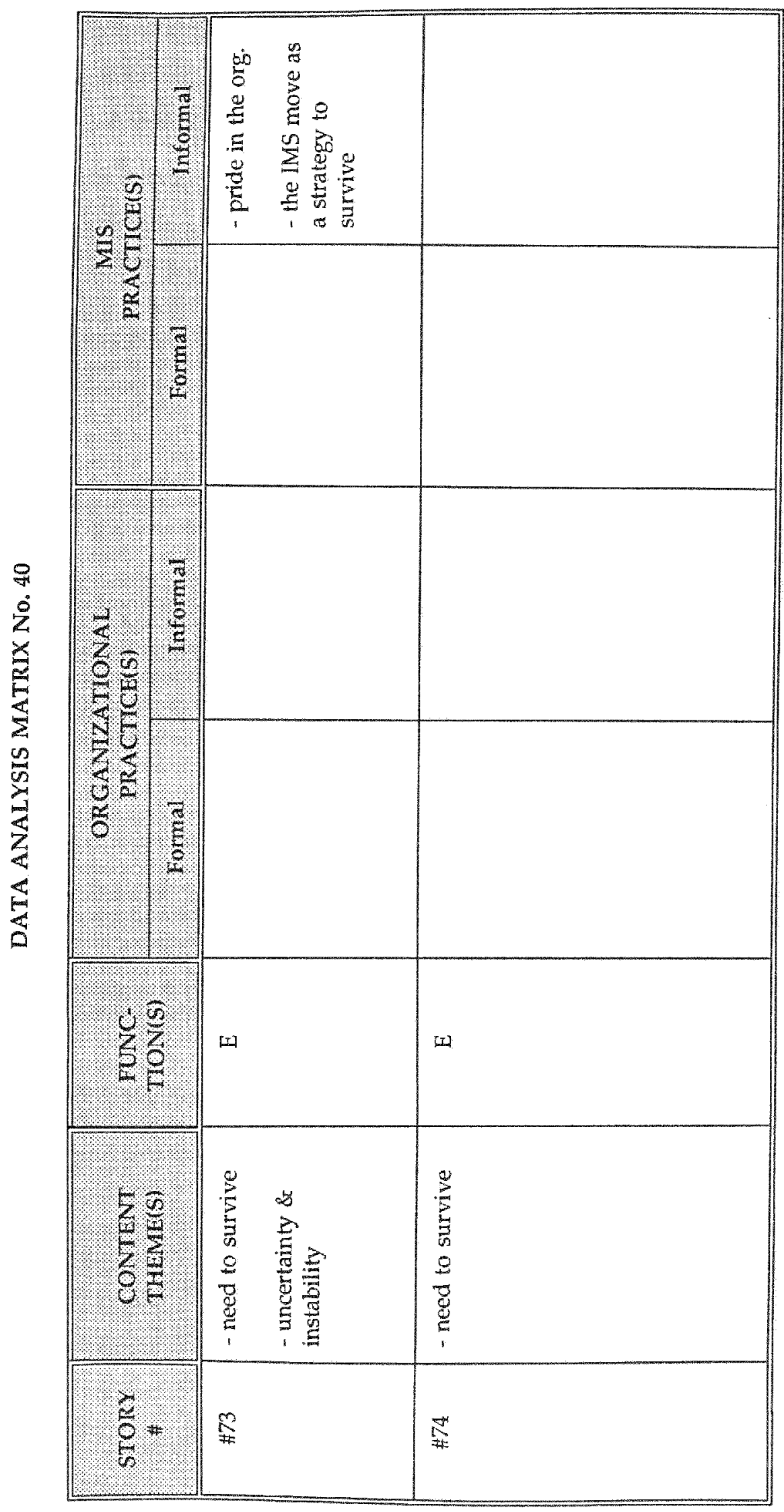

m 


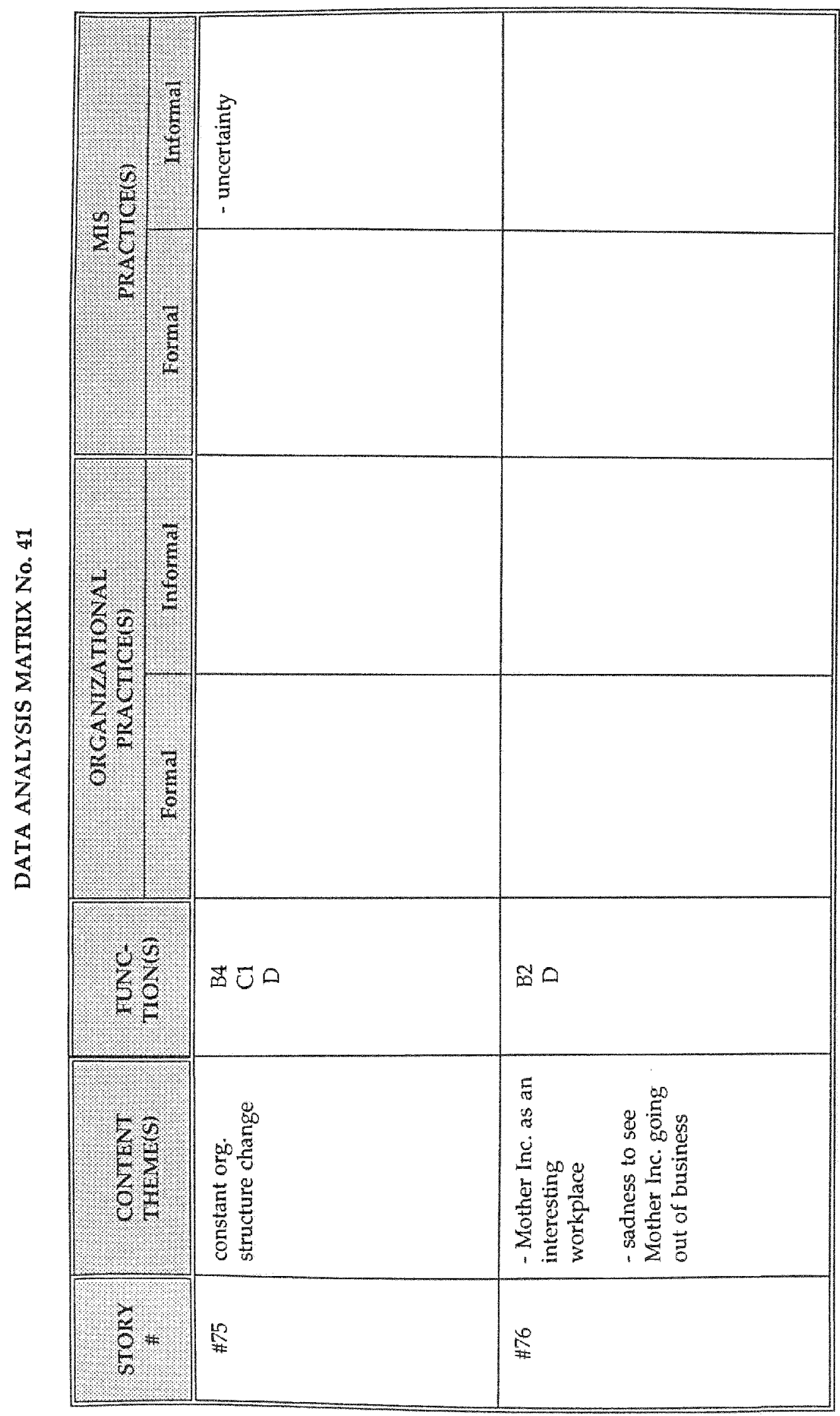

뭉 


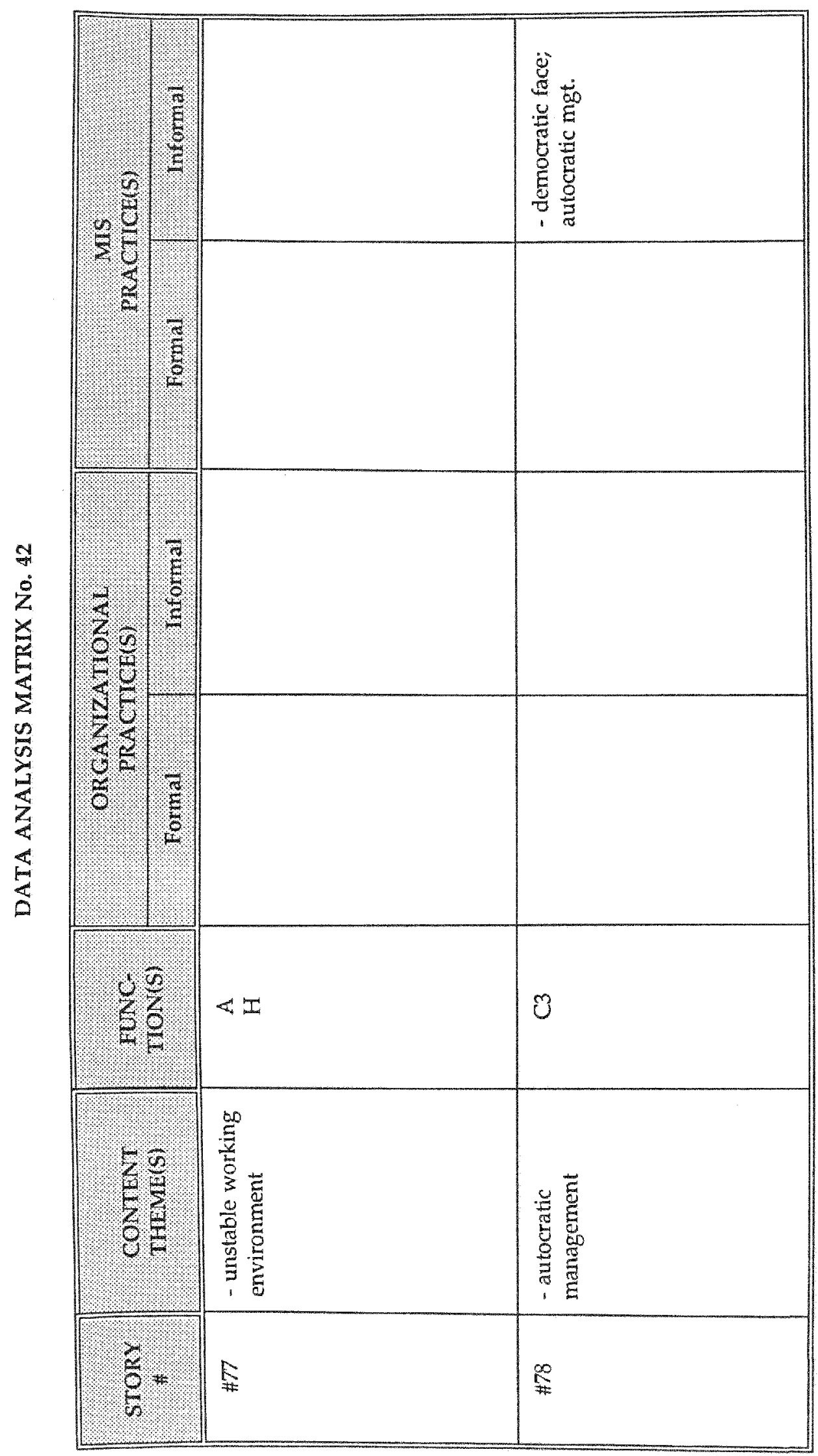

$\frac{n}{n}$ 


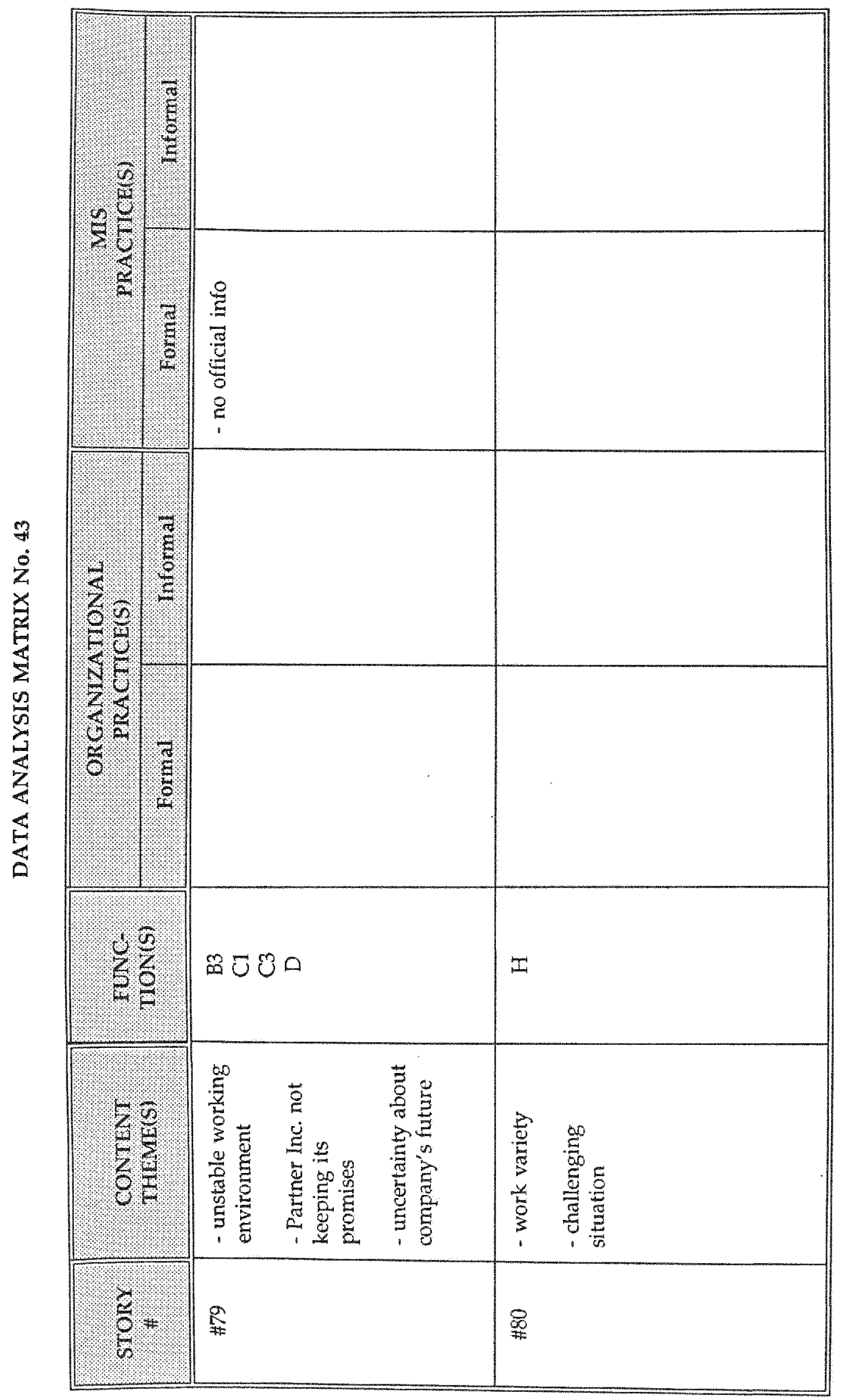

$\frac{\infty}{n}$ 


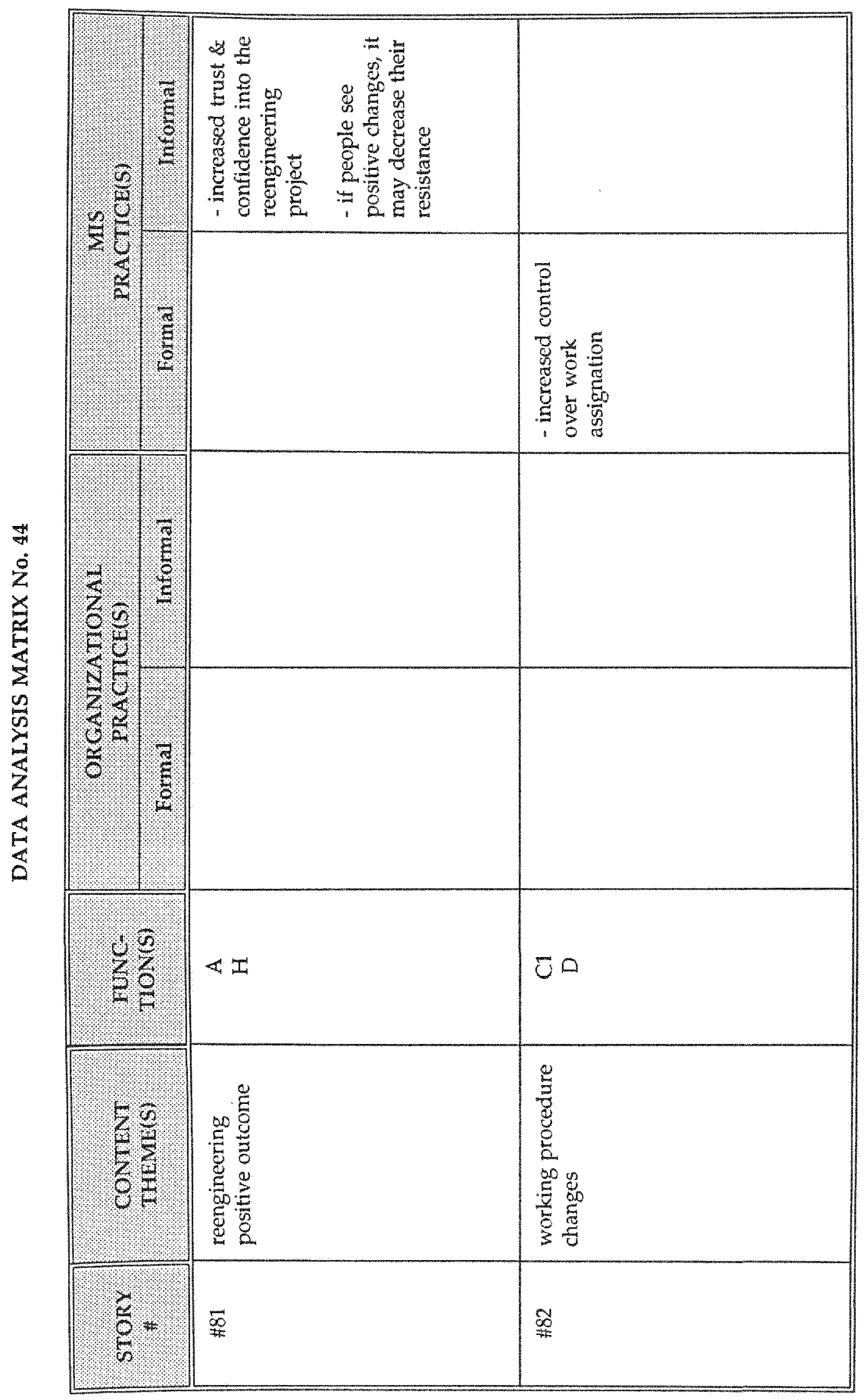

क) 


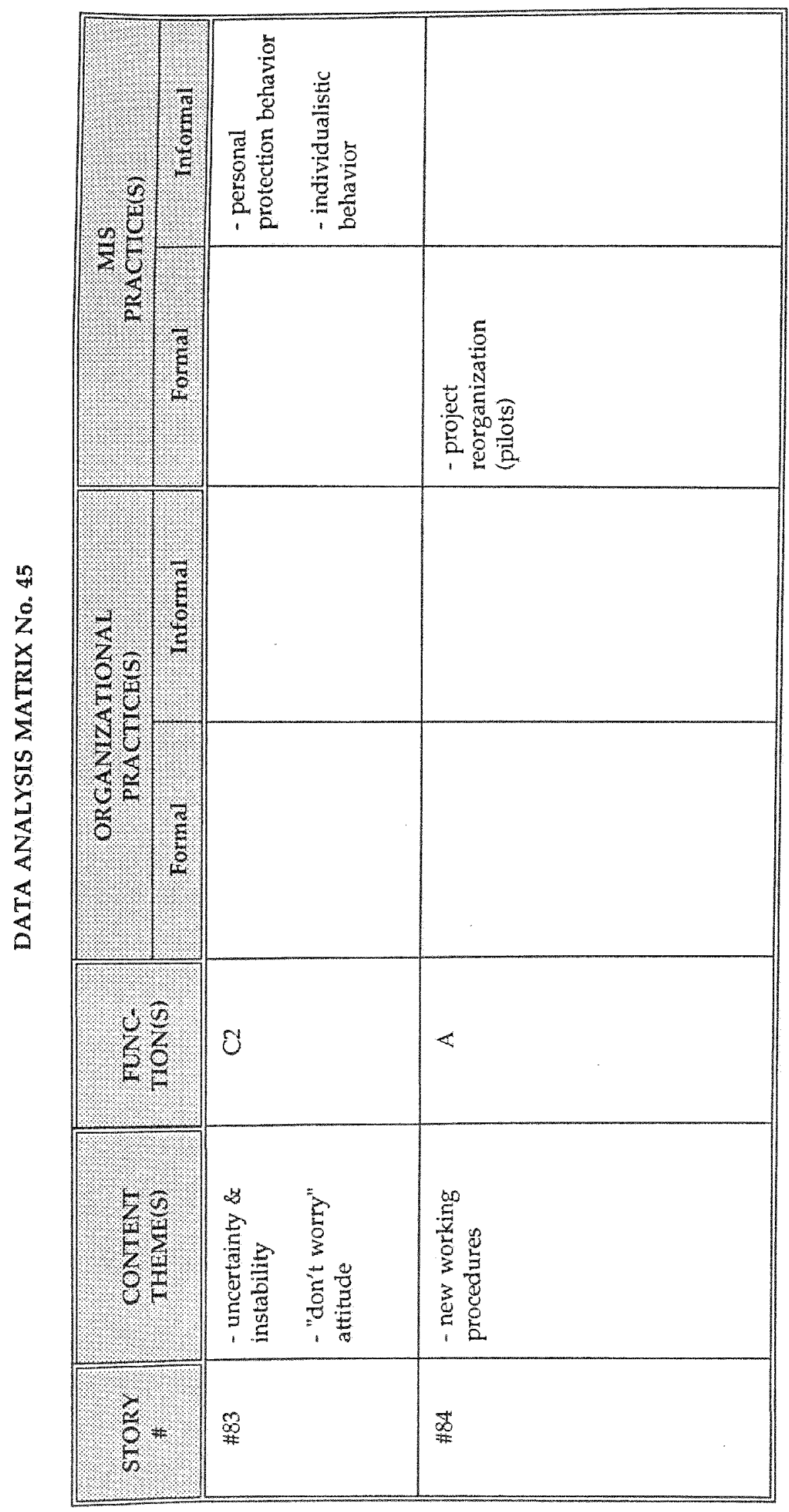

ซ్ 


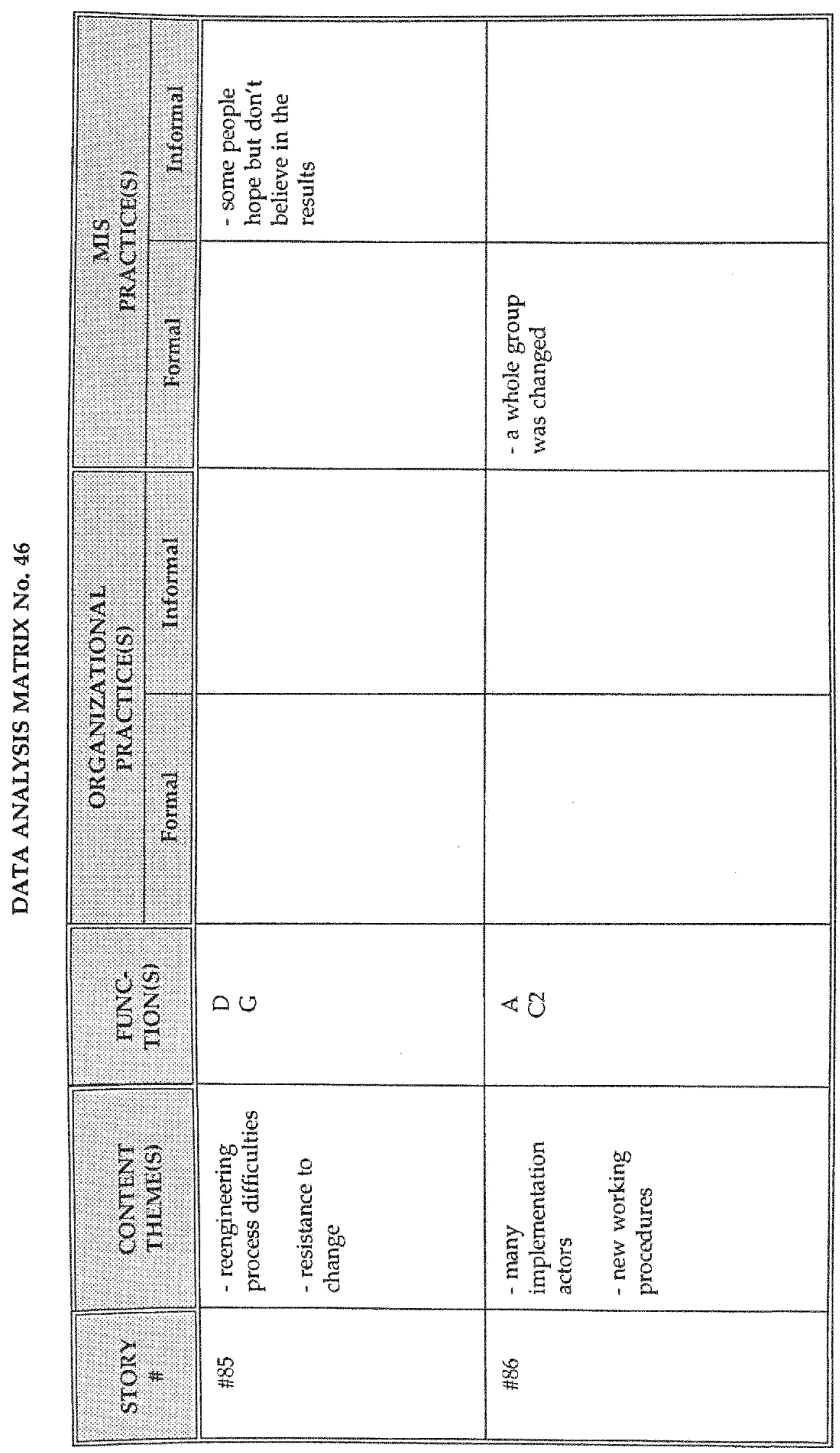

के 


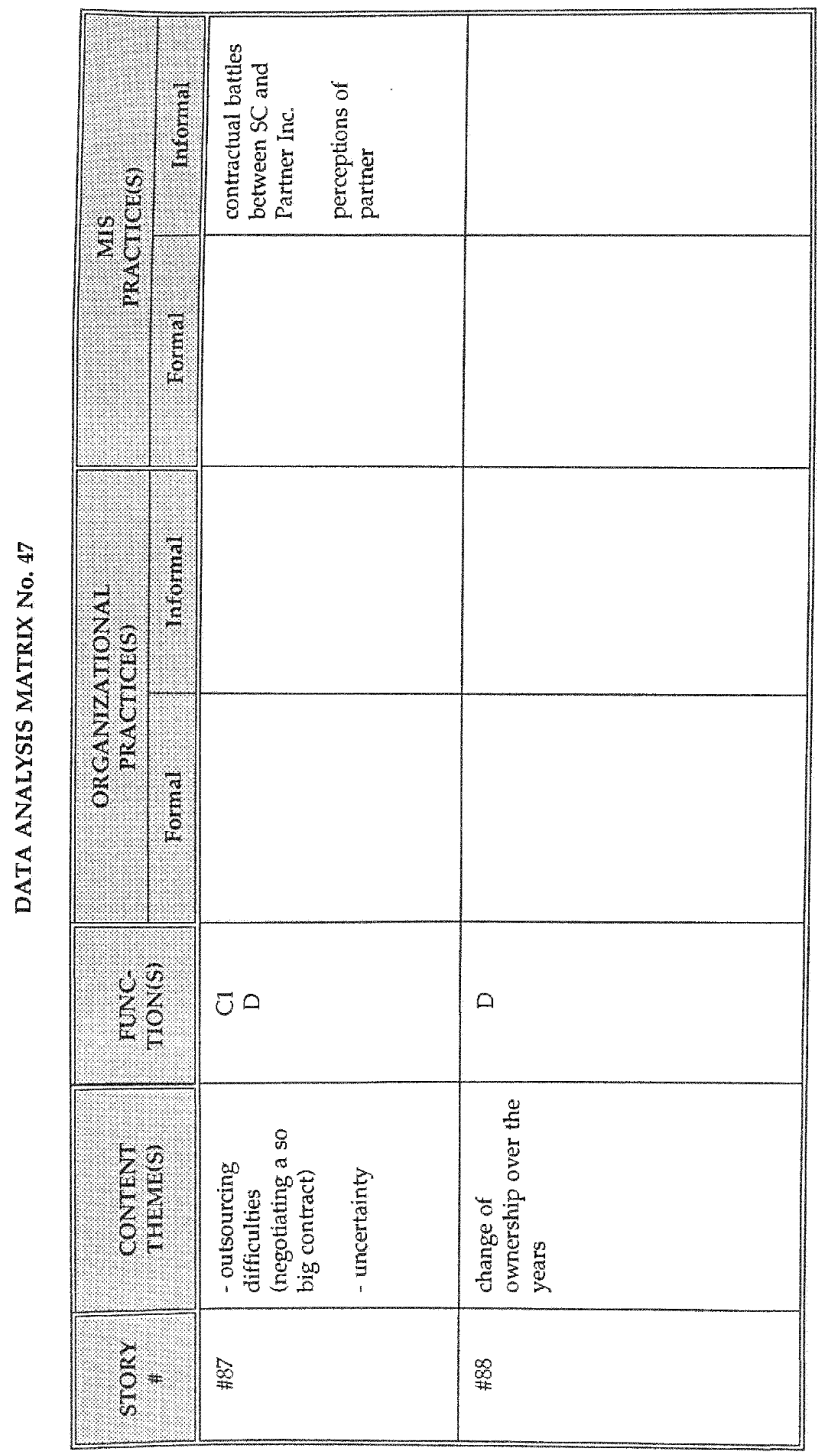

్ㅣ 


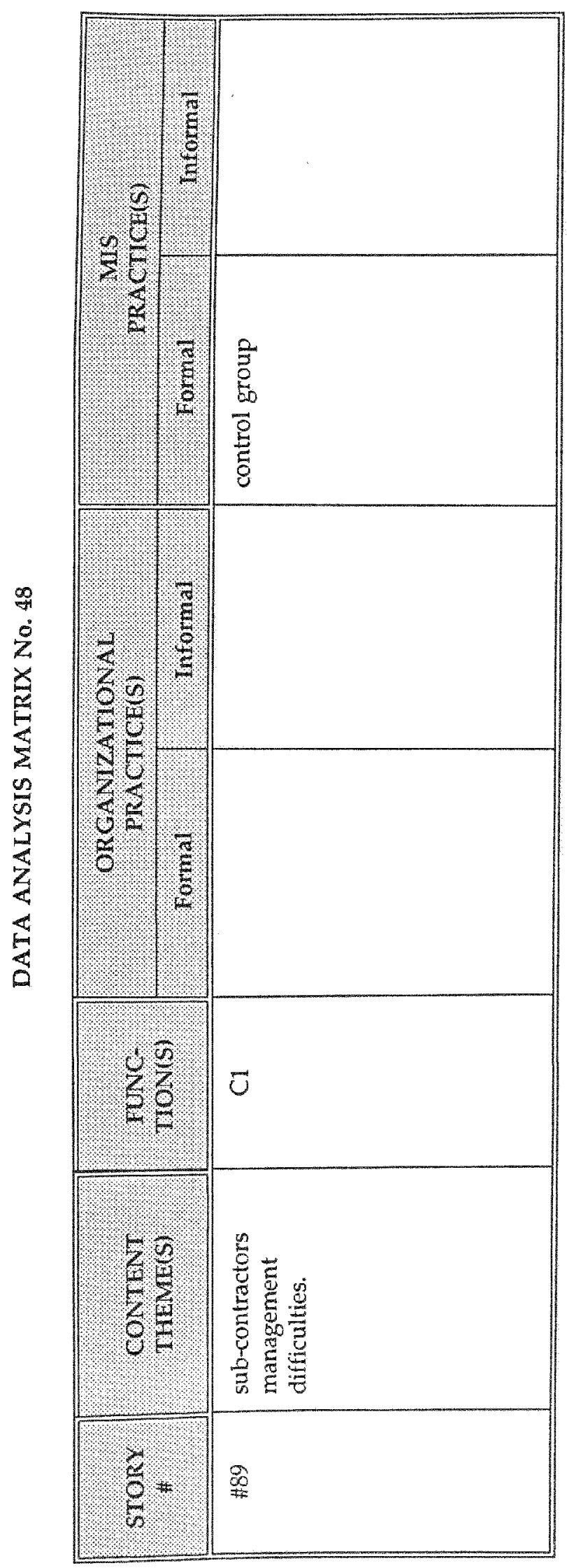

๓్ల 
August 21, 1965

1986

1987

1987-1989

1990-1991

1991

1991

1991

1991-1994

1994-
Born, Coaticook, Quebec, Canada

Information Systems Consultant Développement Informatique Intégral Inc.

Sherbrooke, Quebec

B.A.A, Business Administration

Université de Sherbrooke

Sherbrooke, Quebec

Information Systems Consultant

Andersen Consulting

Montreal, Quebec

FCAR Scholarship

Lecturer

Université du Québec à Montréal Montreal, Quebec

Lecturer

Collège de Rosemont

Montreal, Quebec

M.Sc., Project Management Université du Québec à Montréal Montreal, Quebec

CRSH Fellowship

Professor

Université du Québec à Montréal Montreal, Quebec

\section{PRESENTATIONS}

Dubé, L., Robey, D., Paré, G., \& Elam, J. J. (June, 1993). Exploring the Link Between Organizational Culture and the Use, Availability, and Attitudes Toward Microcomputers. Proceedings of the Annual Conference of the Administrative Sciences Association of Canada, Information Systems Division, Lake Louise, Alberta, Canada. 
Dubé, L., \& Muralidhar, K. (November, 1993). The Impact of Aggregation Methods on the Analytical Hierarchy Process. Proceedings of the Annual Meeting of the Decision Science Institute, Washington. 